\title{
Preserve the fire of life; uncoupling protein 3 in the defence against mitochondrial lipotoxity
}

Citation for published version (APA):

Hoeks, J. (2006). Preserve the fire of life; uncoupling protein 3 in the defence against mitochondrial lipotoxity. [Doctoral Thesis, Maastricht University]. https://doi.org/10.26481/dis.20060310jh

Document status and date:

Published: 01/01/2006

DOI:

10.26481/dis.20060310jh

Document Version:

Publisher's PDF, also known as Version of record

\section{Please check the document version of this publication:}

- A submitted manuscript is the version of the article upon submission and before peer-review. There can be important differences between the submitted version and the official published version of record. People interested in the research are advised to contact the author for the final version of the publication, or visit the DOI to the publisher's website.

- The final author version and the galley proof are versions of the publication after peer review.

- The final published version features the final layout of the paper including the volume, issue and page numbers.

Link to publication

\footnotetext{
General rights rights.

- You may freely distribute the URL identifying the publication in the public portal. please follow below link for the End User Agreement:

www.umlib.nl/taverne-license

Take down policy

If you believe that this document breaches copyright please contact us at:

repository@maastrichtuniversity.nl

providing details and we will investigate your claim.
}

Copyright and moral rights for the publications made accessible in the public portal are retained by the authors and/or other copyright owners and it is a condition of accessing publications that users recognise and abide by the legal requirements associated with these

- Users may download and print one copy of any publication from the public portal for the purpose of private study or research.

- You may not further distribute the material or use it for any profit-making activity or commercial gain

If the publication is distributed under the terms of Article $25 \mathrm{fa}$ of the Dutch Copyright Act, indicated by the "Taverne" license above, 


\section{Preserve the Fire of Life}

Uncoupling Protein 3 in the Defence against Mitochondrial Lipotoxicity 


\section{iutín}

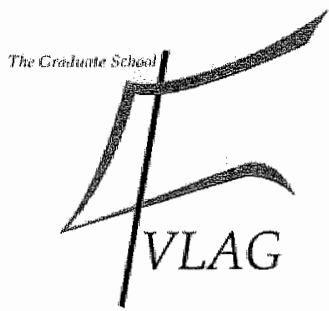

The study presented in this thesis was performed within the Nutrition and Toxicology Research Institute Maastricht (NUTRIM) which participates in the Graduate School VLAG (Food Technology, Agrobiotechnology, Nutrition and Health Sciences), accredited by the Royal Netherlands Academy of Arts and Sciences.

Cover design: Bart-Jan van Rooij, Joris Hoeks

Cover: Mouse skelctal muscle cells, stained for lipid droplets (red) and the basal membrane narker laminin (blue).

Layout: Joris Hoeks

Printed by: Datawyse / Universitaire Pers Maastricht

C Joris Hoeks, 2005

ISBN-10: 90-5278-515-5

ISBN-13: 978-90-5278-515-8 


\section{Preserve the Fire of Life}

\section{Uncoupling Protein 3 in the Defence against Mitochondrial Lipotoxicity}

\section{PROEFSCHRIFT}

ter verkrijging van de graad van doctor

aan de Universiteit Maastricht

op gezag van de Rector Magnificus,

Prof. mr. G.P.M.F. Mols

volgens het besluit van het College van Decanen,

in het openbaar te verdedigen

op wrijdag 10 maart 2006 om 14:00 uur

door

Joris Hoeks

geboren te Eindhoven op 29 december 1978

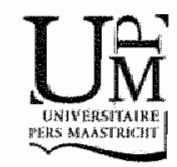




\section{Pronotor}

Prof. dr. ir. W.H.M. Saris

\section{Copromotoves}

Dr. P. Schrauwen

Dr. M.K.C. Hesselink

\section{Beoordalingscominissie}

Prof. dr. M.H. Hofker (voorzitter)

Prof. dr. A. Bast

Dr. M. Dianant (Vrije Universiteit, Amsterdam)

Dr. M-E. Harper (University of Ottawa, Canada)

Prof. dr. C.D.A. Stehouwer

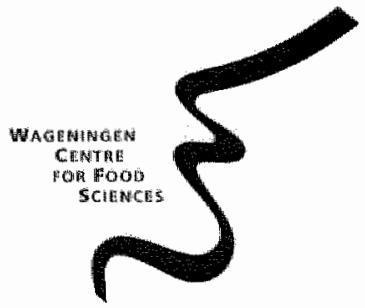

The research described in this thesis was supported by grants of the Netherlands Organisation for Scientific Research (ZonMW 904-62-217) and the Wageningen Centre for Food Sciences (WCFS).

Financial support by the Dutch Diabetes Research Foundation and the Netherlands Association for the Study of Obesity (NASO) for the publication of this thesis is gratefully acknowledged. 


\section{Contents}

\section{Chapter I}

The Fire of Life...

\section{Chapter 2}

Putative function and physiological relevance of the mitochondrial uncoupling protein 3: involvement in fatty acid metabolism?

\section{Chapter 3}

The effect of $\beta_{1}$ - and $\beta_{2}$-adrenergic stimulation on energy expenditure, substrate oxidation and UCP3 expression in human skeletal muscle

\section{Chapter 4}

Uncoupling protein 3 as a mitochondrial fatty acid anion exporter

\section{Chapter 5}

Differential response of UCP3 to medium versus long chain triacylglycerols; manifestation of a functional adaptation

\section{Chapter 6}

The effect of high-fat feeding on intramuscular lipid and lipid peroxidation levels in UCP3-ablated mice

\section{Chapter 7}

Down-regulation of PGC-1 $\alpha$ and PPAR $\alpha$ upon lipid-induced insulin resistance in human skeletal muscle depends on muscular fat accumulation

\section{Chapter 8}

General discussion

Summary - Samenvatting

Dankwoord

Curriculum vitae 
The Fire of Life... 


\section{The Fire of Life...}

The process of photosynthesis, which occurs in plants, is undoubtedly one of the most elementary chemical teactions in life, converting carbon dioxide and water to glucose and oxygen, fuelled by the energy of light. Just as essential to human and animal life is the chemistry of combustion, the reversed reaction that breaks down what photosynthesis creates. This process, providing energy for numerous cellular processes and finally leading to the release of heat, is what Max Kleiber called "the Fire of Life" (1). Approximately half a century ago, mitochondria, cellular organelles bounded by a highly folded inner and fairly smooth outer membrane, were recognised as the cellular fireplaces, harbouring the Fire of Life. The mechanism, that underlies the energy-generating capacity of mitochondria was described by Mitchell in 1961 (2) and awarded with the 1978 Nobel Prize in chemistry. Mitchell's chemiosmotic theory describes how the oxidation of nutritional substrates is coupled to the synthesis of adenosine triphosphate (ATP), the compound in which cellular energy is conserved. In mitochondria, NADH and $\mathrm{FADH}_{2}$, reducing equivalents derived from the degradation of nutritional substrates, undergo a series of oxidation-reduction reactions by a system of enzymes present in the inner mitochondrial membrane, collectively known as the electron transport chain. These reactions give rise to a flow of electrons from the substrates to oxygen, the final electron acceptor, and the energy released during this process is used to pump protons from the mitochondrial matrix to the intermembrane space. As a result, an electrochemical gradient (a difference in proton concentration, or $\mathrm{pH}$, and a difference in electric transmembrane potential) is created across the inner mitochondrial membrane that Mitchell refers to as "protonmotive force". The exported protons flow back into the mitochondrial matrix through $A T P$ synthase (also known as the Fo-F $F_{1}$ ATPase), a protein also present in the inner mitochondrial membrane that uses the energy derived from the proton flow to synthesise ATP from ADP and inorganic phosphate (Pi). In this way, the oxidation of substrates and the use of oxygen (respiration) maintains the electron flow, and are coupled to the synthesis of ATP (fig. 1.1). The efficiency of ATP synthesis driven by substrate oxidation is however not $100 \%$ since leakage of electrons and/or protons from the electron transport chain or mitochondrial inner membrane respectively, can diminish the proton gradient thereby releasing energy that is not coupled to the synthesis of ATP. This "uncoupling" is illustrated 
by the fact that incubation of isolated mitochondria, in the presence of stabstrate but with depleted ADP levels; still consume a certain anount of oxygen (state 4 respiration, fig. 1.2). In other words, the consumed oxygen (substrate oxidation) under these circumstances is used solely to compensate for the loss of proton gradient due to proton/electron leak, since ATP synthesis is excluded.

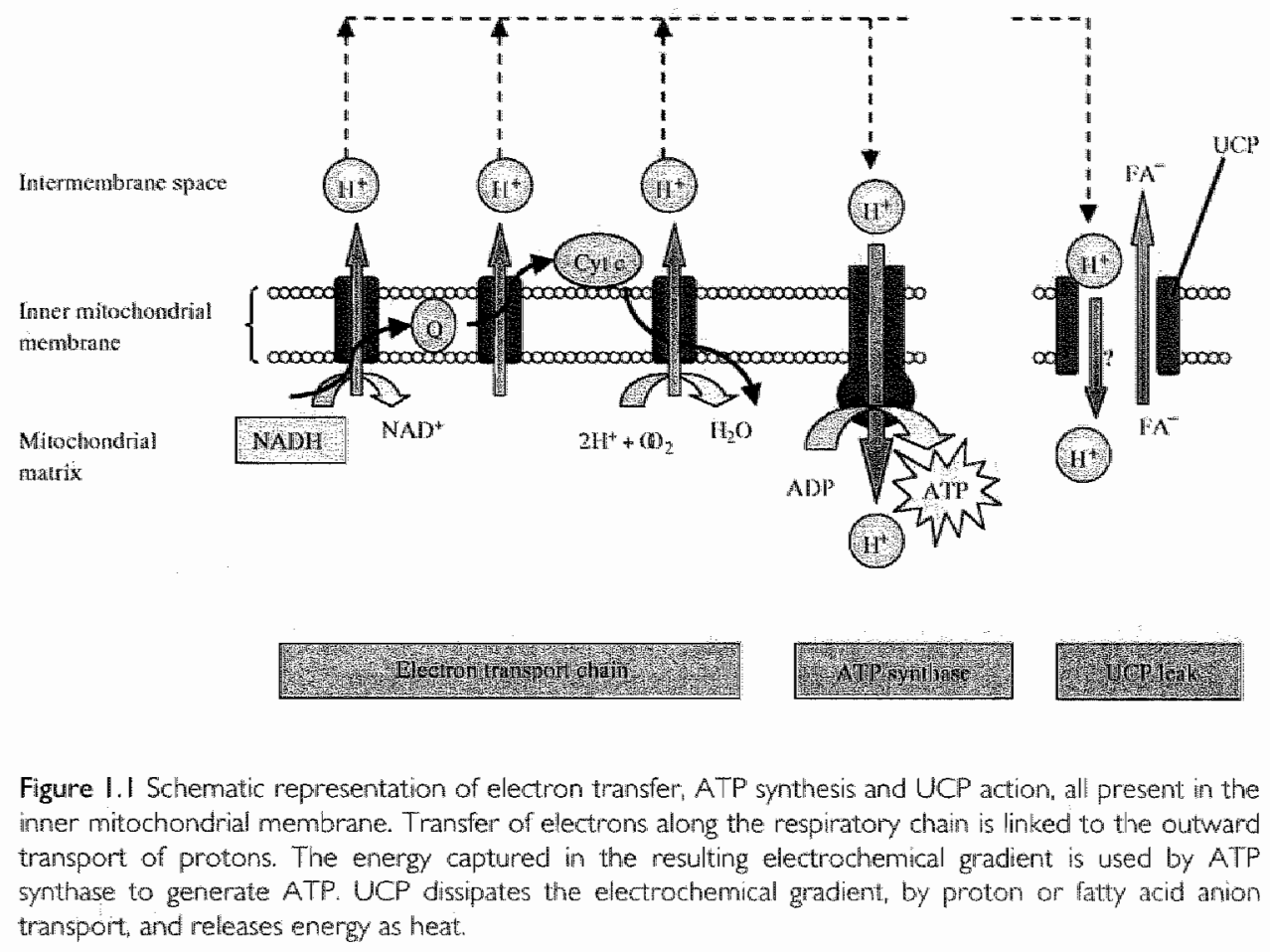

Although the exact causes for this phenomenon are not fully understood, uncoupling proteins are likely candidates in mediating mitochondrial uncoupling. These proteins are a family of mitochondrial transport proteins that might be involved in adaptive thermogenesis by regulating uncoupling of substrate oxidation from the production of ATP (fig. 1.1). In 1978 the first member of this family, uncoupling protein 1 (UCP1), was discovered in brown adipose tissue (3) that is present in rodents and some other mammals. It is now well established that UCP1, present in the inner mitochondrial membrane, is responsible for non-shivering thermogenesis in response to cold exposure, by catalysing a back-flux of protons not related to ATP synthesis, thereby regulating heat production. After the 
discovery of UCP1, several other UCP1 homologues were reported and referred to as UCP2 to UCP5 respectively, although differences in nomenclature exist $(4,5)$.

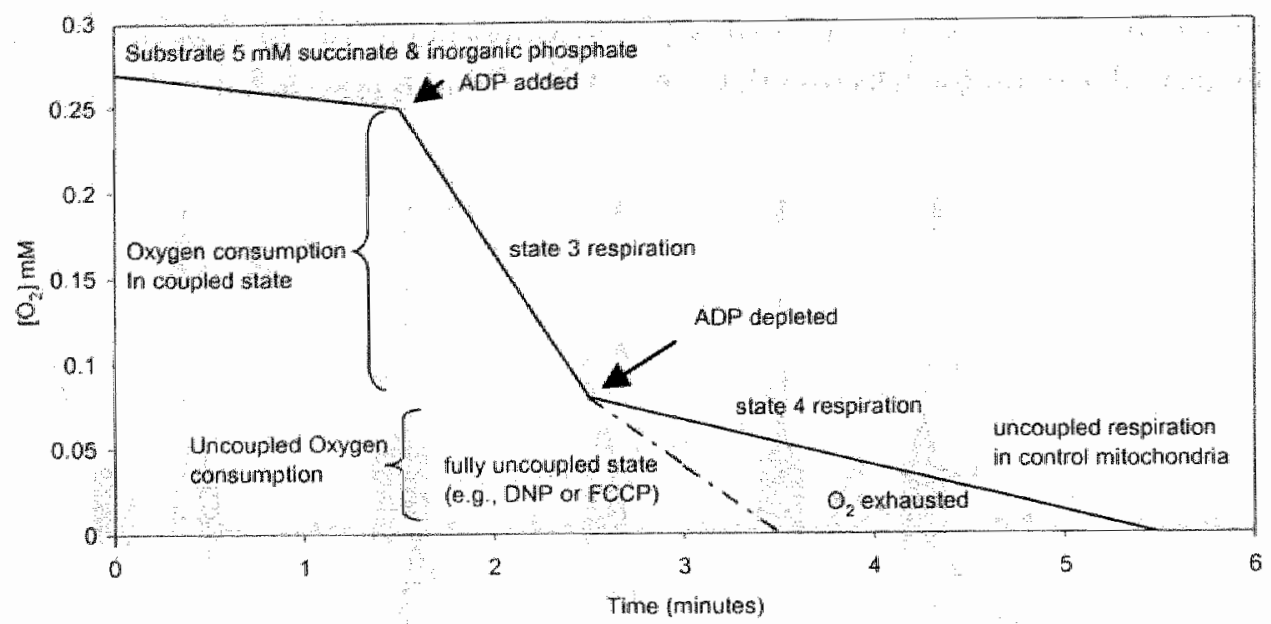

Figure 1.2 Oxygen comsumption in isolated mitochondria. In the presence of substrate and inorganic phosphate, mitochondria already consume oxygen. Upon addition of ADP, oxygen consumption increases and is coupled to the conversion of ADP into ATP (state 3 respiration). When the ADP levels are depleted, mitochondria continue consuming oxygen, but at a much slower rate. This respiration level is not couplled to ATP synthesis and thus referred to as uncoupled respiration (state 4 respiration). Mitochondria can be fully uncotipled (dotted line) by addition of chemical uncouplers such as dinitrophenal (DNP) or carbonyl cyanide-p-trifluoromethoxyphenyl-hydrazon (FCCP).

This thesis mainly focuses on the possible physiological role of uncoupling protein 3 (UCP3), that is almost exclusively found in skeletal muscle and, in analogy to UCP1, was hypothesised to be able to modulate energy expenditure by regulating mitochondrial uncoupling. Since humans in general lack brown adipose tissue (the site of UCP1 expression), the discovery of a potential uncoupling protein in an organ highly contributing to energy expenditure was regarded as a potential antiobesity target. However, the research initiated after the discovery of UCP3 in 1997 suggested that this protein might be involved in skeletal muscle fatty acid metabolism. Although the physiological function of UCP3 is thus so fat unknown, review of the available literature (presented in chapter 2) revealed that UCP3 is up-regulated or high when there is a mismatch between the fat supply to the muscle and its capacity to oxidise these fatty acids. Based on this observation we hypothesised (explained in chapter 2) that UCP3 might be involved in the export of non-merabolisable fatty acids, to protect mitochondria against the deleterious effects of intramitochondrial fat accumulation. 
In chapter 3, we studied the possible involvement of UCP3 in regulating energy expenditure in humans by exploring whether $\beta$-adrenergic stimulation, known to increase energy expenditure, is accompanied by changes in UCP3 gene expression. In addition we examined the effect of $\beta$-adrenergic stimulation on UCP3 mRNA expression independent of the concomitant increase plasma free fatty acids by simultaneously blocking lipolysis. Based on the results from chapter 3, further pointing towards a role for UCP3 in fatty acid metabolism, we used several animal models to interfere at distinct steps of fatty acid metabolism. In chapter 4 we used genetic and pharmacological interventions to elucidate the physiological function of UCP3 and support our hypothesis while chapter 5 focuses on the effect of specific high-fat diets on UCP3 protein levels in rats. In chapter 6 we studied the implications of the suggested UCP3 function by examining the consequences of the knockout of the UCP3 gene in mice fed a high-fat diet. Following these animal studies, chapter 7 describes a human study dealing with the effect of lipid-induced insulin resistance, via intravenous lipid infusion, on UCP3 gene expression, as well as the expression of other genes related to mitochondrial biogenesis and fatty acid oxidation. Finally, chapter 8 provides a general discussion that deals with the possible pitfalls of the conducted studies, the physiological relevance and implications of the suggested UCP3 function and addresses future directions for research and clinical applications.

\section{References}

1. Kublue M The Hine of Life. New York: John Wiley \& Sons Inc; 1961

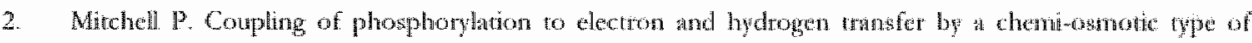
mechanism. Nature 1961;191:1448.

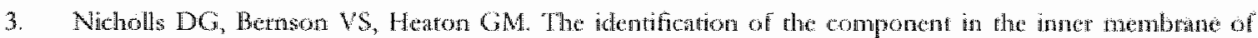
brown adipose tissue mirochondria responsible for segutang energy dissipation. Luperientia Suppl $1978,32,89.93$

4. Adams SH. Uncoupling protein homologs: emerging wiews of physiological funcron. I Num $2000 ; 130(4) \times 711-4$

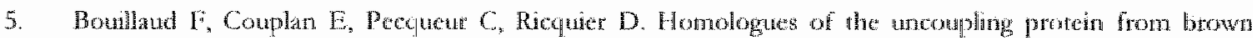
adipose rissue (UCP1): UCP2, UCP3, BMCP1 and UCP4, Biexhim Biophys Act 2001; 1504(1):107, 19.

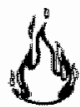





\section{Tin}

\section{Putative function and physiological relevance of the mitochondrial}

uncoupling protein 3: involvement in fatty acid metabolism?

Joris Hoeks, Matthijs K.C. Hesselink and Patrick Schrauwen

Departments of Human Biology and Movement Sciences, Nutrition and Toxicology Research Institute Maastricht (NUTRIM), Maasticht University: Maastricht, The Netherlands

Part of this review has been published in Progress in Lipid Research 


\section{Introduction}

Mitochondrial oxidative phosphorylation is the main metabolic process to meet the cellular energy demand and the energy generated during this process is captured in the high energy molecule ATP. Briefly, degradation of energy substrates ultimately leads to transfer of electrons along the enzymes of the electron transport chain, present in the inner mitochondrial membrane. Using the energy captured in this electron flow, protons ate pumped out of the mitochondrial matrix thereby establishing a proton gradient across the inner mitochondrial membrane. The reentry of these ptotons into the matrix through ATP-synthase results in the phosphorylation of ADP and regeneration of ATP. Although the oxidation of energy substrates, with concomitant respiration, and the regeneration of ATP are tightly coupled, this coupling is not $100 \%$ efficient which is illustrated by the fact that isolated mitochondria, in the presence of substrate, always use some oxygen, even in the absence of ADP or when ATP synthase is inhibited chemically. This suggests that the proton gradient can be lowered by other processes than ATP synthesis suggesting a leak of protons that does not result in the phosphorylation of $\mathrm{ADP}$.

In addition to the proton leak that is observed in mitochondria from a variety of tissues, brown adipose tissue (BAT) mitochondria contain a specialised protein (uncoupling protein 1, UCP1) that is capable of uncoupling mitochondrial respiration from ATP synthesis in a regulated manner. Although it is generally accepted that activated UCP1 generates heat by dissipating the proton gradient without ATP synthesis, the exact mechanism of action is still debated. In general, two mechanistic models are proposed by which UCP1 uncouples respiration from ATP synthesis. In the first model, UCP1 actually transports protons (1), while in the second model, UCP1 is involved in the outward translocation of fatty acid anions from the matrix (2-4). In the latter model, neutral fatty acids flip-flop over the inner mitochondrial membrane and donate a proton to the matrix. The resulting fatty acid anions, which are not able to flip-flop back, are transported by UCP1 to the intermembrane space where they pick up a proton, thereby lowering the proton gradient. Irrespective of the exact mechanism, the importance of this protein in rodent cold-induced thermogenesis is underscored by the observation that UCP1 knockout mice can't regulate normal body temperature in the cold (5). However, the amount of BAT in adult humans is negligible and, as mentioned above, proton leak is observed in mitochondria from several tissues while UCP1 is 
exclusively located in brown adipose tissue. Possible candidates being involved in this proton leak are the UCP1 homologues discovered in 1997 and named uncoupling protein 2 (UCP2) and -3 (UCP3), respectively. While UCP2 is generally believed to be ubiquitously expressed, UCP3 is mainly located in skeletal muscle, quantitatively the most important tissue in human energy expenditure. Based on these characteristics, UCP3 was considered a likely mediator in the regulation of energy expenditure.

Recent research on the function of UCP3 revealed however, that UCP3 is most likely involved in fatty acid metabolism rather than in energy expenditure. This review focuses on this shift of concept and will deal with the available literature on the role of UCP3 in metabolism. Furthermore, the characterisation of the UCP3 gene and the potential regulation of its transcription will be discussed, as well as some major hypotheses concerning the physiological function of UCP3.

\section{Characterisation of the UCP3 gene}

\section{UCP3 transcripts and protein}

In 1997, UCP3 was discovered through screening of a human skeletal muscle cDNA library for sequences homologous to UCP1. With this technique, Boss et al. (6) showed that wo RNA transcripts of UCP3 exist, which are predicted to encode long (UCP3L; 312 amino acids) and short (UCP3S; 275 amino acids) UCP3 proteins. UCP3L and UCP3S only differ by the presence or absence of 37 amino acid residues on the $\mathrm{C}$ terminus and both variants show a $57 \%$ and $73 \%$ similarity in amino acid sequence in comparison with UCP1 and UCP2, respectively (6).

The translated sequence from the coding CDNA for UCP3L predicts 6 transmembrane domains and a purine nucleotide binding domain, similarly to UCP1 and UCP2. The protein generated by the short UCP3 transcript would theoretically lack the last transmembrane domain and the purine nucleotide binding domain (6). Both UCP3 transcripts seem to be equally expressed in human skeletal muscle (7). Rodents however, seem to lack the short UCP3 mRNA isoform (8).

Northern blot analysis on the expression pattern of UCP3 in rars revealcd that UCP3 mRNA is expressed abundantly in skeletal muscle and BAT but was also present in heart and white adipose tissue (WAT), although at much lower levels (9). At the protein level, UCP3 was detected in skeletal muscle, BAT and cardiac muscle $(10,11)$. 


\section{Potential transcriptional regulatory sites of the UCP3 gene}

Most work on the charactetisation and the regulation of the UCP3 gene was cartied out by Solanes and co-workers. They showed that the human UCP3 gene contans at least 7 exons spread over $-8.5 \mathrm{~kb}$ and is located on chromosome 11 (11913), adjacent to the UCP2 gene (7). UCP3L and UCP3S ate derived from alternative splicing at the end of exon 6 and a polyadenylation signal present in intron $6(7)$.

Analysis of the 5 -flanking- and promoter region of the human UCP3 gene tevealed several potential sequences for regulatory transcription factors. The most abundant ones were recognition motifs for muscle-specific regulatory factors such as E-Box elements, a MEF2 site and CCAC-box motifs $(12,13)$. MEF2 and the CCAC-box motif are important for transcriptional regulation of muscle-specific genes (14). E-box is a binding site for the myogenic factor MyoD, a factor which is required for substantial promoter activity of the UCP3 gene (15).

Besides muscle-specific regulatory factors, which probably explain the selective expression pattern of UCP3, the promoter region was also shown to contain a tetinoic acid-responsive element (16). The element was located in the proximal promoter and consisted of a direct-repeat-like motif (DR-1), a 1-bp-separated alignment of direct repeats.

Furthermore, it was shown that putative peroxisome proliferator-activated receptor (PPAR)-responsive elements ate present in the promoter of the UCP3 gene $(12,13,15)$. The presence of these PPAR-responsive elements is in line with numerous physiological observations showing that high levels of plasma free fatty acids induce the expression of UCP3. Solanes et al. (15) reported from celltransfection studies that PPAR action occurred through the same direct repeatelement (DR-1) in the proximal promoter region as the one they had earlier characterised as the retinoic acid-responsive motif. The structure of this DR-1 motif, permissive for mulriple nuclear receptor-mediated responses, mediates retinoic acid-dependent effects, not only through activation of the retinoid $\mathrm{X}$ receptor moiety of the PPAR/retinoid X receptor heterodimer, but also through retinoic acid receptor $(15,16)$. Mutation of the DR-1 element resulted in unresponsiveness of the UCP3 gene to PPAR ligand and prevented fatty acidinduced gene expression. In these cell transfection studies, UCP3 gene transcription was initiated by PPAR $\alpha$ and PPAR 8 activation, but the responsiveness of the UCP3 promoter was not sensitive to PPARy (15). 
In addition to retinoic acid and PPAR-sensitive elements, the UCP3 gene was also shown to contain several motifs responsive to thyroid homone $(12,13,17)$. Recent work by Solanes et al. (17) revealed that the thyroid-responsive element (TRE) coincided with the reported site responsible for responsiveness to PPAR and retinoids, indicating that this DR-1 element acts as a multi-homonal responsive element.

Furthermore, the research by Solanes and co-workers showed that MyoD, which is required for a substantial UCP3 promoter activity, also functionally interacts with PPAR-dependent pathways in the regulation of UCP3 transcription (15). Although they act through separate sites in the promoter, MyoD and PPAR-dependent regulatoty pathways are functionally connected: only in the presence of $\mathrm{MyoD}$ does UCP3 become sensitive to PPAR ligand-dependent regulation (15). MyoD is also required for the initiation of UCP3 gene transcription induced by retinoids and thyroid hormone $(16,17)$.

Besides muscle-specific regulatory factors, retinoic acid-, PPAR-, and thyroid hormone-responsive elements, the UCP3 promoter region also contains a cAMP response-like element (12). Since cAMP acts as a second messenger in $\beta$-adrenergic stimulation, ligands for the skeletal or cardiac muscle-specific $\beta$-adrenoceptors may also activate UCP3 gene transcription.

Altogether, these findings indicate that the UCP3 gene is possibly regulated by changes in free fatty acids (endogenous ligands for PPAR), hyper- and/or hypothyroidism, changes in intracellular cAMP levels (i.e. during $\beta$-adrenergic stimulation) and retinoic acid and such regulation pattern suggests involvement in energy- or fat metabolism.

\section{UCP3 and energy metabolism}

Since the discovery of UCP3 in 1997 , many studies were conducted to establish the possible involvement of UCP3 in the regulation of energy metabolism. These studies varied from genetic linkage and association studies in which UCP3 expression was related to markers of obesity, to in vilwo experiments with transfected cells and transgenic mice tissue, to determine the ability of UCP3 to induce proton leak. Also physiological intervention studies were performed to elucidate the potential role of UCP3 in energy metabolism. 


\section{Genettic linkage and assocration studies of $\mathrm{UCP} 3$ in relation to energy metabolism}

Linkage and association studies can be used to determine whether variations in a gene of interest are associated with a certain phenotype. Shortly after the discovery of UCP3, a strong, significant linkage was reported between flanking markers at the UCP2/UCP3 gene locus and resting metabolic rate in a French-Canadian population (18).

In addition to this reported linkage, Walder et al. (19) showed that polymorphisms in the UCP2-UCP3 gene cluster were associated with sleeping metabolic rate and $24 \mathrm{~h}$ energy expenditure in Pima Indians, a population prone to obesity and diabetes. The same polymorphisms were also found to be associated with 24 h energy expenditure in a Danish population (20) as well as with metabolic efficiency during exercise (21). Halsall et all. (22) reported that age-adjusted body mass index (BMI) was significantly lower in carriers of a polymorphism in the promoter region of UCP3 $(-55 \mathrm{bp}, \mathrm{C} \rightarrow \mathrm{T}$ ) in a Caucasian population. However, Cassell et al. (23) showed that the same variant in the UCP3 promoter region was associated with an increased waist-to-hip ratio and influenced fat distribution, although this effect was restricted to females. In another study, this polymorphism was associated with an increased BMI in obese French Caucasians (24).

In contrast to these positive associations, several studies have also reported a lack of association between variations in the UCP3 gene and energy metabolism. We reported that the earlier mentioned $\mathrm{C} \rightarrow \mathrm{T}$ substitution in the UCP3 promoter was associated with increased UCP3 mRNA expression in male non-diabetic Pima Indians, but not with BMI (25). In a Danish population, this polymotphism was also not associated with increased BMI or percent body fat and did not seem to play a major role in the development of obesity (26). In addition, Urhammer et al. (27) investigated various variants in the coding region of the UCP3 gene but concluded that that none of the variants contributed to the pathogenesis of juvenile-onset obesity among Danish Caucasians.

In summary, the results of genetic linkage and association studies are equivocal with a substantial number of studies showing positive associations between UCP3 and body weight and an equal amount of studies showing no association. It should, however, be noted that the regulation of body weight is complex and that many factors, besides energy metabolism, can affect body weight. Therefore, physiological studies that directly measure UCP3 levels and human energy metabolism are better suited to investigate the relationship between these two paramerers. In that context, we measured human energy metabolism together with 
skeletal muscle UCP3 mRNA expression in Pima Indians and observed a positive correlation between sleeping metabolic rate and 24 h energy expenditure and the expression of UCP3 mRNA (28). $\beta$-adrenergic stimulation, thyroid homone treatment and exercise, all known to increase energy expenditure, are examples of other physiological factors that were investigated to clarify the relationship between UCP3 and energy metabolism.

\section{UCP3 and proton leak in transfected cell syistems}

Most studies investigating the activity of UCP3 as a bona fide uncouples reconstituted the UCP3 protein into liposomes or yeast cells and measured proton fluxes, oxygen consumption and/or membrane potential.

Jaburek et al. (29) expressed human UCP3 in E, coli and subsequently reconstituted the protein into liposomes. Their results implicated that UCP3 is capable of catalysing an electrophoretic proton flux (qualitatively) similar to UCP1, and that this UCP3-mediated proton flux is dependent on fatty acids (29). Putine nucleotides (like GDP), are recognised inhibitors of UCP1, but also inhibited proton transport mediated by UCP3 in this proteoliposome model, although the effect was modest in comparison with UCP1 (29). However, Hagen et al (30) showed from studies in a heterologous yeast expression system that UCP3L activity was not regulated by cellular free fatty acid levels. They also reported a poor or even absent inhibitory effect of purine nucleotides on proton transport activity of UCP3L, which is contradictory to the earlier findings by Jaburek et al. (29).

In another study (31), the long isoform of human uncoupling protein 3 (hUCP3I) was expressed in yeast cells and this transfection resulted in an increase in the overall tate of oxygen consumption. Although oxygen consumption increased, the portion of respiration actually coupled to the synthesis of ATP significantly decreased from $57 \%$ to $11 \%$ (31). The authors also reported a decreased mitochondrial membrane potential, a decreased cellular growth (an energy demanding process) and a significantly increased cellutar heat production (31). Zhang et al. (32) also used a hUCP3L-transfected yeast expression system and showed that state 4 respiration (i.e. respiration in absence of exogenous ADP), expressed as percentage of maximal respiratory capacity (FCCP-stimulated respitation), was significantly increased in hUCP3L cells. Addition of GDP to the incubation medium however, did not reverse the uncoupling activity of hUCP3L, possibly indicating distinct regulatory mechanisms for UCP1 and UCP3. The short 
isoform of UCP3 displayed qualitatively similat uncoupling characteristics when expressed in yeast $(33)$.

Taken together, these cell studies show that UCP3 is capable of increasing mitochondrial proton leak, indicated by changes in proton flux; incteased thermogenesis, increased state 4 respiration and decreases in mitochondrial membrane potential. However, it is unclear whether purine nucleotides and farty acids, generally accepted inhibitors and (re)activators of UCP1 respectively, are equally important in UCP3-induced proton leak. Although the possibility remains that UCP3 activity is regulated by other compounds in comparison with UCP1, these findings raised the question whether the interpretation of results obtained from yeast cells or liposomes transfected with UCP3 is correct. Furthermore, it was shown that the incorporation of UCP3 in yeast cells exists largely in a deranged and non-physiological state, thereby allowing an uncontrolled proton transport (34). Three portions of UCP3 can be clistinguished in transfected yeast cells: a small amount is functionally incorporated into mitochondria, competent for regulated uncoupling; another portion is inserted into the inner mitochondrial membrane but in a deranged conformation, causing uncontrolled proton leak and preventing further incorporation of expressed UCP3. As a result, the third and largest $(>90 \%)$ portion seems to aggregate outside the mitochondria (35). In addition, Harper et al. (36) revealed that the concentration of UCP3, at which yeast mitochondria clisplayed uncoupling activity, was 7-fold higher than physiological concentrations present in rodent skeletal muscle. When UCP3 was expressed at physiological concentrations in yeast mitochondria, only very little uncoupling activity was detected (36). Similar to the results obtained by Harper et al. (36) and Heidkaemper et al. (34), transfection of $\mathrm{hUCP}_{3}$ in $\mathrm{L6}$ rat skeletal muscle cells also resulted in uncoupling of tespiration, which was associated with an inhibition of maximal respiratory capacity and was unaffected by purine nucleotides and fatty acids (37). It was concluded that the (over)expression of UCP3 resulted in an uncontrolled uncoupling due to improper folcling of the protein, and did not represent a physiological phenomenon (37).

\section{Energy metabolism in UCP3 transgenic mice}

In addition to cell systems, UCP3 transgenic mice were generated to study the role of UCP3 in mitochondrial uncoupling and energy metabolism. The first paper on mice overexpressing human uncoupling protein 3 (supra-physiologically: $\sim 15$ to 20-fold on the protein level), reported that these mice were hyperphagic but lean, 


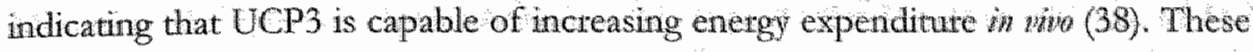
mice showed a reduced body weight gain upon high-far feeding and displayed significantly higher total oxygen consumption compared to wildtype littermates (39). Bezaire et al. (40) recently described mice overexpressing UCP3 in a more physiological range $(\sim 2.3$-fold) and revealed that these mice did not differ from wildtype mice with respect to body weight or 24 h oxygen consumption.

Oxygen consumption measurements in isolated mitochondria from mice overexpressing UCP3 at a supra-physiological level, revealed an increase in state 4 respiration and a decrease in state 3 respiration, resulting in a $\sim 29 \%$ decrease in respiratory control ratio (38). In addition, mitochondrial membrane potential decreased by $12 \%$, which, together with the decrease in state 4 respitation, is indicative of mitochondrial uncoupling (38). Although immunolocalisation of UCP3 at the electron microscopical level revealed that in mice overexpressing UCP3, the transgene is located almost exclusively in the mitochondria (41), it cannot be ruled out that supra-physiological overexpression of UCP3 leads to nonnative insertion of the protein into the inner mitochondrial membrane, resulting in an unregulated and artifactual uncoupling. This is underscored by the lack of effect of GDP on proton conductance in both UCP3 overexpressing and wildtype mice; as by the absence of a difference in fatty acid-induced uncoupling (42). These data led to the conclusion that the uncoupling effect measured in UCP3 transgenic mice is unregulated and an overexpressing artefact (42).

Besides transgenic mice overexpressing human uncoupling protein 3, the effect of UCP3 gene ablation on mitochondrial uncoupling and regulation of energy metabolism has also been studied. Isolated mitochondria from mice lacking UCP3 showed an increased respiratory control ratio as compared to their wildtype littermates (43). The effect was due to a significant decrease in state 4 respiration as state 3 respiration was unaffected (43). These results indicate that skeletal muscle mitochondria lacking UCP3 are more tightly coupled in comparison with wildtype mitochondria. Furthermore, Gong et al. (44) also showed that skeletal muscle mitochondria of UCP3-ablated mice display an increased protonmotive force.

In contrast, Cadenas et al. (42) reported that the basal proton conductance in skeletal muscle mitochondria of UCP3 $\%$ animals was similar to that of their wildtype littermates. Bezaire et al. (45) reported no change in state 4 respiration after UCP3 gene knockout; although they reported a significantly higher protonmotive force at state 4 respiration in UCP3-ablated mice. The latter study fits quite well with the data obtained by Gong et al. (44), who did not report differences in state 4 respiration. More physiological approaches showed that mice 
lacking UCP3 displayed no changes in testing oxygen consumption, were not obese and gained weight to a similar extent as wildtype mice when fed a high-fat dict (44). In accordance with these results; Vidal-Puig et al. (43) showed no effect of UCP3 knockout on body weight, total body lipid content and total oxygen consumption, neither after chow nor high fat feeding.

In summary, the results of mitochondrial respiration measurements in UCP3\% mice do not provide a uniform answer to the question if lack of UCP3 affects mitochondrial uncoupling. It is unclear what exactly caused the discrepancy in results between the studies. It is possible that the absence of serum albumin in the experimental media of the two studies showing an increased coupling in UCP3\% mice $(43,44)$ allowed variable endogenous fatty acid levels to influence the measurements. Since fatty acids are activators of UCP3 (as they are for UCP1) and because fatty acids in itself can induce mitochondrial uncoupling, through so far unknown mechanisms, different levels of contaminating fatty acids (i.e. in the absence of albumin) in mitochondrial preparations from knockout and wild type mice could have induced different levels of uncoupling, an argument also put: forward by Cadenas et al. (42). However, the discrepancy in results on mitochondrial coupling from UCP3 $\%$ mice remains relatively unexplained and therefore demands further validation.

\section{$U C P 3$ and $\beta$-adrenergic activity}

In rodents, the major site of thermogenesis is the brown adipose tissue, and UCP1 is the key player in this process. The activity of UCP1 is under control of the sympathetic nervous system acting through $\beta$-adrenoceptors (46). In humans, $\beta$ adrenergic stimulation also increases energy expendirure but, in contradiction to rodents, skeletal muscle is the major thermogenic tissue. It is not fully understood which mechanism is responsible for the increase in energy expenditure upon $\beta$ adrenergic stimulation but it can be hypothesised that the increase in energy expenditure upon $\beta$-adrenergic stimulation in skeletal muscle is mediated by UCP3. Thus, ligand-binding to $\beta$-adrenoceptors stimulates adenylate cyclase, producing CAMP which in turn activates protein kinase $A$. Subsequently, protein kinase $A$ phosphorylates cAMP-responsive element (CRE) binding protein (CABP), which can bind to the CRE reported in the promoter region of UCP3 (12). Through this mechanism, $\beta$-adrenergic stimulation has the potential to increase UCP3 transcription. 
Several stadies were performed to test the effect of $\beta$-adrenergic agonists on the expression of UCP3, both in witr and in vino. Nagase et al. (47) stridied the effect of several $\beta$-adrenergic agonists and antagonists on the expression of UCP3 in 166 myotubes. Administration of epinephrine increased UCP3 mRNA levels and these effects were mimicked by $\beta_{2}$-adrenergic agonists and abolished by $\beta_{2}$-adrenergic antagonists (47). Further analyses revealed that the $\beta_{2}$-adrenoceptor was the major adrenoceptor subtype present in these L6 myotubes, indicating that catecholamines

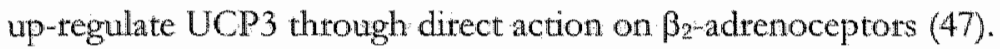

Most rodent studies on $\beta$-adrenergic stimulation and UCP3 expression focused on stimulation of $\beta_{3}$-adrenoceptors, with controversial results. Yoshitomi et al, (48) reported a down-regulation of UCP3 mRNA levels in femoral skeletal muscle of KK-Ay mice after 21 days of treatment with a $\beta_{3}$-adrenergic agonist. Savontaus et al. (49) found no effect of a $\beta_{3}$-adrenergic agonist on UCP3 expression in the soleus muscle of obese Zucker rats, while Nakamura et al. (50) described an increase in UCP3 mRNA in gastrocnemius muscle from both C57BL 6 and KK-Ay mice upon $\beta_{3}$-adrenergic stimulation. Although the in vitro results from Nagase et al. (47) show a direct effect of $\beta$-adrenergic stimulation on UCP3 mRNA expression in muscle cells, $\beta$-adrenergically-induced UCP3 regulation in muscle must be mediated by other factors in the in vivo rodent studies since skeletal muscle is believed to lack the $\beta_{3}$-adrenoceptor subtype. Furthermore, the treatment of cultured L6 myocytes with a $\beta_{3}$-adrenergic agonist did not affect UCP3 mRNA levels in this cell system (47).

The most likely mediator for the $\beta_{3}$-adrenergic induction of UCP3 are plasma free fatty acids levels. As will be discussed later, FFA are potent inducers of UCP3 (probably via activation of PPARs) and circulating FFA levels are increased in response to $\beta$-adrenergic stimulation. Indeed, the study by Nakamura et al. (50) showing an increase in UCP3 after $\beta_{3}$-adrenergic stimulation also reported an increase in plasma free fatty acid levels. Yoshitomi et al. (48), who found a downregulation of UCP3 also showed a significant decrease in circulating free fatty acids. Although a decrease in plasma FFA is surprising upon $\beta$-adrenetgic stimulation, it suggests a correlation with the reduction in UCP3 mRNA expression in skeletal muscle.

We studied the effect of $\beta_{1}$ - and $\beta_{2}$-adrenergic stimulation on UCP3 mRNA expression in healthy lean humans (51). $\beta_{2}$-adrenoceptors are abundant in skeletal muscle, but stimulation of these receptors also affects plasma FFA levels. Therefore, we introduced a third condition consisting of $\beta_{2}$-adrenergic stimulation with simultaneous blocking of lipolysis by acipimox. In short, $\beta_{1}$ and $\beta_{2}$-adrenergic 
stimulation did not affect skeletal muscle UCP3 mRNA levels (despite a small rise in plasma FFA), but infusion of a $\beta_{2}$-adrenergic agonist combined with decreased plasma tee faty acid levels due to acipimox treatment, resulted in a significant decrease in UCP3 mRNA expression (51). These data indicate that in humans, UCP3 is not direedy influenced by $\beta$ agonists. In addition, our data argued against a role for UCP3 in energy netabolism since we found that energy expenditure was equally increased in all three conditions.

In conclusion, $\beta$ zadrenengic stimulation was reported to directly up-regulate UCP3 expression in cultured muscle cells, but this effect could not be confirmed in humans in vivo. Most effects of $\beta$-adrenergic stimulation on skeletal muscle UCP3 mRNA levels can be attributed to changes in plasma free fatty acid levels. It should be noted, however, that none of these studies examined the effect of $\beta$-adrenergic stimulation on UCP3 activity directly, but only measured UCP3 at the MRNA level. It therefore temains possible that $\beta$-adrenergic stimulation does increase energy expenditure through an effect on (UCP3-meditated) mitochondrial uncoupling, possibly also via increased levels of fatty acids which have been shown to be able to activate UCPs.

\section{UCP3 and thyroid bormone treatwent}

As noted before, the UCP3 gene contains seweral potential motifs tesponsive to thyroid hormone $(12,13,17)$, and thyroid homone is a major regulator of energy expenditure in adult mammals $(52,53)$. Since the molecular mechanism by which thyroid hormone exerts its thermogenic effect is unknown, it can be hypothesised that thysoid hormone may promote mitochondrial uncoupling, possibly medtated by UCP3.

Numerous publications reported that thyroid hormone status or thyroid homone treatment is capable of up-regulating UCP3 mRNA $(9,47,54-58)$, and protein $(10$, $57-59$ ) levels. An interesting question remains whethet this up-regulation of UCP3 upon thyroid hormone is accompanied by changes in mitochondrial respiration rate and/or membrane potential. Lanni et al. (54) showed that a $\sim 5$-fold decrease in UCP3 mRNA levels in hypothyroid twts and a $\sim 5$-fold increase in UCP3 expression in hyperthyroid rats was accompanied by complimentary changes in state 3 and state 4 respiration, according to thyroid hormone status (i.e. hypothyroid < euthyroid < hyperthyroid). Furthermore, state 4 respiration correlated with UCP3 mRNA levels (54). In a study in rats, Jucker et al. (60) cstimated the decrease in energy coupling, assessed by a non-invasive, nuclear 
magnetic resonance (NMR) approach, to be approximately $60 \%$ upon 10 days of thyroid hormone treatment. In addition, UCP $3 \mathrm{mRNA}$ and protein levels appeared to correlate well with the changes in mitochondrial coupling after the thyroid hormone treatment (60). In a subsequent human trial, Lebon et al. (61) studied the effect of thyroid hormone on tnitochondrial energy coupling $i$ in wiz by the same NMR approach. Three days of treatment resulted in a $\sim 70 \%$ increase in muscle tricarboxylic acid (TCA) cycle flux, while the rate of ATP synthesis remained unchanged, indicating a less efficient ATP production, which again may indicate mitochondrial uncoupling (61). Whole-body energy expenditure (15\%) and oxygen consumption (17\%) also significantly increased upon treatment (61). This elegant approach indicates that thyroid hormone is capable of inducing mitochondrial uncoupling in humans. Whether or not this effect was mediated by UCP3 cannot be concluded since UCP3 levels or activity, were not assayed in this study.

In addition, de Lange et al. (57) showed that there was a high similarity in the time course of induction of skeletal muscle UCP3 expression (mRNA and protein), the decrease in mitochondrial respiratory efficiency and the increase in resting metabolic rate when hypothyroid rats were given a single injection of thyroid hormone. Maximal UCP3 expression (12-fold over basal) was reached at 65h after injection and this time-point, tresting metabolic rate was increased by $45 \%$, nonphosphorylating respiration rate (state 4) by $40 \%$ and membrane potential decreased by $8 \%$, data indicative of mitochondrial uncoupling (57).

Although the data above suggest a direct role for UCP3 in thyroid hormoneinduced thermogenesis, Jekabsons et al. (55) reported that 6 days of thyroid hormone treatment in mice increased both gastrocnemius UCP3 mRNA levels and resting metabolic tate but did not affect mitochondrial non-phosphorylating respiration rates (55). Surprisingly, resting metabolic rate did correlate wirh the UCP3 expression, possibly indicating differences in th wing and in vitro stimulation of proton leak by thyroid hormone (55).

In addition, Gong et al. (44) reported that UCP3 null mice showed the same increase in resting oxygen consumption as controls during 4 days of thyroid hormone treatment (i.e. 1.72 -fold stimulation in UCP3 $\%$ mice and 1.89 in wildrypes). These findings suggest that UCP3 is not a major determinant of metabolic rate upon thyroid hormone treatment.

Altogether, there is no doubt about the ability of thyroid hormone to induce UCP3 expression. Whether or not this induction is accompanied by an increase in UCP3. mediated proton leak and thus by increased energy expenditure is however less obvious. It should be noted that thyroid hormone can induce several metabolic 
changes such as increased mitochondrial fat oxidation, increased expression and activity of enzymes involved in lipid handling and increased mitochondrial superoxide production (62). Since UCP3 has been implicated in the metabolism of fatty acids and the protection against reactive oxygen species (as will be discussed later in this review), it is not unlikely that the metabolic changes induced by thyroid hormone are responsible for the increased UCP3 expression. Furthermore, the effects of thyroid hormone on UCP3 expression could also be indirectly mediated by plasma free fatty acids since thytoid hormone is well known to induce lipolysis (63).

\section{UCP3 and exercise}

Exercise is known to increase energy expenditure both during and for sevetal hours post-exercise and regular exercise training can improve mechanical enetgy efficiency. Therefore, the effect of acute and chronic exercise on UCP3 regulation. has been extensively studied. Cortright et al. (64) showed that $2 \mathrm{~h}$ of treadmill running up-regulated UCP3 mRNA levels in rats, with a more pronounced effect observed in white (glycolytic) gastrocnemius muscle, compared to the red (oxidative) portion of this muscle. In line with these results, Zhou et al. (65) showed that a single bout of exercise (both treadmill running and swimming) rapidly induced UCP3 mRNA and protein levels in rat skeletal muscle. In the latter study, the effect on UCP3 seemed to be highly specific since the expression of other mitochondrial genes remained unaffected (65).

In addition to rodent experiments, we also studied the effect of acute exercise on UCP3 expression in human individuals in the fasted state (66) and showed that $2 \mathrm{~h}$ of cycling exercise at $50 \%$ of maximal oxygen uptake, significantly increased UCP3 mRNA levels, confirming the results obtained in rodents. Interestingly however, this effect was completely abolished when glucose was ingested during exercise, thereby preventing the exercise-induced increase in plasma free fatty acids (66). This anding was recently confirmed by others (67). These observations led to the conclusion that the effect of acute exercise on UCP3 expression was mediated through the concomitant rise in plasma free fatty acids and/or increased fat oxidation rather than by changes in energy expenditure (66).

However, in mion studies showed that electrically induced contractions in m. extensor digitomm longw increased UCP3 mRNA 60 to 120 min after a single 10 min exercise bout and temained elevated for 4 hours after terminating exercise (68), which indicates that exercise is also capable of directly stimulating UCP3 expression, i.e. 
not depending on changes in homones or metabolites. AMCP-activated protein kinase (AMPK), activated during exercise, has been suggested to mediate this effect since actiontion of $A M P K$ by ATCAR was able to mimic the increase in UCP3 inNA (68).

In contrast to acute exercise, the effects of endurance training on UCP3 expression are ambiguous. Soon after the discovery of UCP3, it was shown that 8 weeks of endurance training on a treadmill reduced UCP3 mRNA in rat tibialis and soleus muscle by $76 \%$ and $59 \%$, respectively (69). However, Tsuboyama-Kasaoka et al. (70) showed that two weeks of swim training up-regulated UCP3 mRNA in w. gatronemius by $\sim 14$ to 18 -fold 3 hours after the last exencise bout, but this effect was completely abolished when samples were taken $22 \mathrm{~h}$ after the last exercise bout. Similar results were obtained for treadmill ruming training and acute treadmill exercise (70). This finding indicates that the up-regulation that was observed upon endurance training was merely an effect of the last exercise bout, rather than the endurance training itself. Similarly to the results obtained by Tsuboyama-Kasaoka et al. (70), Jones et al. (71), reported a large increase in UCP3 mRNA immediately and 3 h after a single bout of swimming exercise in rats. Upon consecutive endurance training, UCP3 protein levels progressively increased by 1.4-fold 18 hours after a single bout of exercise, 1.6-fold after 3 daily bouts and 1.8-fold after 10 daily bouts of exercise. These findings were not biased by a short tissue sampling interval since muscle samples were taken $\sim 18-20$ hours after the last exercise bout (71).

Besides todent experiments, several human studies have been performed to examine the effect of endurance training on the expression of UCP3. Our laboratory showed that trained subjects had significantly reduced UCP3 mRNA levels compared to untrained individuals, and UCP3 mRNA was negatively correlated with aerobic capacity (maximal oxygen consumption) and mechanical energy efficiency (72). Similat findings were obtained in another study (73). Russell et al. (74) found that similar to UCP3 mRNA levels, also UCP3 protein was decreased in endurance trained subjects, an effect observed in every muscle fibre type. In addition, longitudinal approaches in humans have also shown that endurance training lowers UCP3 protein content, when corrected for changes in mitochondrial density $(75,76)$.

In conclusion, acute exercise seems to induce gene expression of UCP3 while prolonged endurance training down-tegulates the protein, at least in humans. Studies conceming the effects of endurance training in rodents gained conflicted results. Differences in intensity and duration of the exercise and training protocols 
have been shown to differentially activate UCP3 transcription (7T) and may complicate a valid comparison between different studies. Also the time interval between the last exercise bout of the training protocol and the sampling of muscle may be involwed in the discrepancies in results observed upon endurance training in rodents. The exact mechanism behind the exercise-induced changes in UCP3 transcription remains to be elucidated but plasma free fatty acids (most likely through PPAR activation) and activation of AMPK have been suggested $(66,68)$. Although the up-regulation of UCP3 apon acute exercise, being abolished by glucose intake, point towards a role in fatty acid metabolism, the finding that UCP3 coincides with improved mechanical energy efficiency, suggest that UCP3 may affect energy metabolism as a secondary effect to its physiological function.

\section{The fasting paradox}

Besides physiological interventions, known to increase energy expenditure, several research groups studied the effect of fasting, a condition of energy conservation, on UCP3 expression and activity. It is obvious that inducing energy-wasting uncoupling processes during fasting would be non-beneficial in terms of energy conservation.

Remarkably, a $48 \mathrm{~h}$ fasting period up-regulated UCP3 expression in tat gastrocnemius muscle by $\sim 2.5$-fold, closely followed by an up-regulation at the protein level ( $\sim 2.6$-fold) (58) and similar effects were observed by Sivitz et al. (78). Jimenez et al. (79) found a marked 16.4-fold up-regulation of UCP3 mRNA already after $24 \mathrm{~h}$ of fasting in mouse gastrocnemius muscle which was accompanied by a 1.5-fold up-regulation of UCP3 protein in muscle from the same animals. In agreement with these results, Cadenas et al. (80) also found that $24 \mathrm{~h}$ of starvation increased UCP3 mRNA and protein, by $\sim 5$-fold and $\sim 2$-fold, respectively.

In humans, a 5 day hypocaloric diet increased skeletal muscle UCP3 mRNA levels by 2.5 -fold in both lean and obese subjects (81). Resting metabolic rate however, decreased significantly upon caloric restriction in both groups and was not correlated with the changes in UCP3 expression (81). Tunstall et al. (82) showed that skeletal muscle UCP 3 expression was induced by $\sim 5$-fold after $15 \mathrm{~h}$ and by $\sim 10$-fold after $40 \mathrm{~h}$ of fasting, while (PPAR-regulated) genes involved in lipid transport and oxidation remained unaltered. This is an important finding as the upregulation of UCP3 by fasting is sometimes regarded as a simple PPAR-mediated effect lacking physiological relevance. 
Taken together, there is ample evidence that fasting up-regulates UCP3 expression both in rodents and humans and the question that arises is whether these increases in UCP3 are accompanied by an increased mitochondrial proton leak. To this issue, Cadenas et al: (80) starved rats for 24 hours, resulting in a 2 -fold increase of UCP3 protein levels in skeletal muscle. Despite this up-regulation of UCP3 however, no differences were detected in proton leak kinetics of isolated mitochondria from fasted rats when compared to fed controls (80). Furthermore, Bezaire et al. (45) studied the effects of fasting on mitochondrial energetics in UCP3 knockout mice and wildtypes. In accordance with the results obtained by Cadenas et al. (80), they found increased levels of UCP3 m.RNA in wildtype mice, while mitochondrial proton leak remained unaffected in these animals (45). Despite differential levels of UCP3 in these mice, resting metabolic tate decreased to the same extent in both genotypes, further indicating that the fasting-induced UCP3 expression is not accompanied by increases in mitochondrial proton leak. Finally, Iossa et al. (83) studied subsarcolemmal and intermyofibrillar mitochondria of rat skeletal muscle and reported that the subsarcolemmal population indeed showed an increased proton leak upon 24 hours of fasting. However, UCP3 protein levels were equally increased in both mitochondrial populations indicating that UCP3 is not likely to be a major contributor to this increased proton leak (83). What could be the explanation for the seemingly paradoxical induction of UCP3 upon fasting? Mobilisation of fat stores, thereby releasing plasma free fatty acids (FFA), provides the major sulsstrate for skeletal muscle during fasting in order to spare glucose sources. Since the timeframe of the increase in plasma FFA and the maximal induction of UCP3 upon fasting display similarity, Weigle et al. (84) hypothesised that the increase in plasma FFA could be involved in the upregulation of UCP3. To test this hypothesis, Weigle et al. (84) interfered with circulating signals that occur during fasting such as leptin, glucocorticoids and free fatty acids. Administration of leptin or glucocorticoid to rats did not affect UCP3 expression, while increasing plasma FFA by lipid infusion caused significant increases in UCP3 expression, up to levels comparable to fasting (84). This result was confimed in humans by Khalfallah et al. (85) who showed that a 5 h infusion of lipids significantly increased UCP3 mRNA levels. In addition, the expression of UCP3 was positively correlated with plasma FFA levels (85). Sbraccia et al. (86) also reported a highly significant correlation between skeletal muscle UCP3 mRNA levels and plasma FFA in obese, but not lean, human subjects. Furthermore, a $24 \mathrm{~h}$ incubation of cultured human primary myotubes with FFA resulted in a 3 -fold 
increase in UCP3 mRNA, indicating a direct link between free fatty acids and UCP3 gene expression (86).

Based on the results discussed in this chapter: ie. the effect of acute exercise on UCP3, the paradoxical up-regulation of UCP3 upon fasting and the finding that free fatty acids are potent inducers of UCP3 gene expression led to the concept that UCP3 is involved in fat metabolism, rather than in regulation of energy expenditure.

\section{UCP3 in fat metabolism}

The finding that plasma free fatty acids, most likely through activation of PPARresponsive elements in the UCP3 promoter, are responsible for the induced expression of UCP3 during fasting, initiated numerous physiological studies interfering with fat metabolism. To elucidate its physiological role, UCP3 expression was measured during high-fat feeding, lipid infusion and in muscles with different fat oxidative capacity. In addition, UCP3 knockout and overexpressing mice were analysed for possible changes in metabolic parameters related to fatty acid handling.

\section{Lipid oversupply, PPAR action and UCP3}

Acute increases in plasma free fatty acid through the infusion of a lipid emulsion have been shown to induce UCP3 expression $(84,85)$. In addition, the effects of acute exercise, fasting and possibly thyroid hormone treatment on UCP3 may, as discussed earlier, be accounted for by increases in plasma free fatry acids. The most likely mechanism in mediating the increased UCP3 transcription upon high plasma FFA levels is activation of PPARs, since PPAR-responsive elements have been teported in the UCP3 gene promoter $(12,13,15)$. Furthermore, it is well tecognised that fatty acid acts as natural ligands for PPARs thereby activating gene transcription of numerous genes involved in (fat) metabolism. In this context, PPAR agonists are capable of up-regulating UCP3 mRNA levels, both in cultured muscle cells $(15,87,88)$ and in rodent models in wivo (89-91).

In addition, we and others showed that chronic increases in fat supply by way of high-fat feeding up-regulates UCP3 mRNA and protein levels, in both rodents (11, 92) and humans $(93,94)$. To study whether the high-fat diet-induced increase in UCP3 was accompanied by mitochondrial uncoupling we examined whether postexercise phosphocreatine (PCr) resynthesis in skeletal muscle was affected by the 
higher UCP3 levels. The rate of PCr resynthesis is entirely dependent on mitochondrial respiration, and if the primary role of UCP3 would be mitochondrial uncoupling, the PCr resynthesis tate would be diminished upon high UCP3 levels. However, no differences were observed in post-exercise $\mathrm{PC}$ resyntivesis rate, further stressing a primary role for UCP3 in fatty acid metabolism rather than being involved in the regulation of energy expenditure (94). In line with this finding, Chow et al. (92) also observed a 2-fold increase in UCP3 protein upon high-fat feeding in rats but this up-regullation did not contribute to mitochondrial ion permeability and $24 \mathrm{~h}$ energy expenditure.

\section{Differential UCP3 expression in muscle (fibre) types}

The expression pattern of UCP3, being up-regulated in situations of incteased supply of fatty acids to the muscle, led to the suggestion that UCP3 might have a role in fat metabolism by facilitating the oxidation of fatty acids. In support of this view, the increase in UCP3 expression upon high-fat feeding was shown to be mote pronounced in humans with high amounts of type 2 a muscle fibtes, which are characterised by a high capacity to switch from carbohydrate to fat oxidation (93). Muscle type-specific regulation was also observed by Samec et al. (95) who reported that a $48 \mathrm{~h}$ fasting period increased UCP3 more markedly in predominantly fast-twitch muscles (m. gastrocmemins and m. thalis anterior) in comparison to the predominantly slow twitch soleus muscle. In another study, Samec et al. (96) studied UCP3 expression in response to food deprivation and refeeding. Starvation led to a marked increase in UCP3 mRNA in rat $m$. garmomemins, a muscle with high capability to shift energy supply from carbohydrate to fat oxidation, but subsequent refeeding down-regulated UCP3 expression below control values (96). In the highly oxidative, lipid utilising soleus muscle, however, starvation induced a much less apparent increase in UCP3 mRNA and tefeeding resulted in a less pronounced down-regulation and more rapid restoration of basal UCP3 levels during continued refeeding (96). According to the hypothesis that UCP3 might facilitate the transition from glucose to fat oxidation, the highly oxidative soleus muscle has less capacty to increase lipid utilisation during starvation, compared to the mixed gastrocnemius muscle, thereby explaining the differental tesponse of UCP3 in these muscles (96). Along the same line, the more persistent down-regulation of UCP3 mRNA levels in the gastrocnemius vs, the soleus muscle during refeeding could be attributed to the higher glycolytic capacity of the latter (96). 
However, our laboratory studied the basal expression of UCP3 in a muscle (fibre) bype-specific manner, in both rodent and human models. In tats, basal UCP3 cxptession was extremely low in the highly oxidative cardiac muscle, while the oxidative skeletal muscle molus displayed $\sim 28$ fold higher basal UCP3 protein levels (11). However, the glycolytic white gastrocnemius muscle contained basal UCP3 proten levels that were -13 -fold higher in companison with cardiac muscle and $\sim 4.5$ fold when compared to the soleus muscle (11). In humans, we compared UCP3 protein levels in sepatate muscle fibre types of $m$. wanths lateralis by immunofluorescence. This analysis revealed that UCP3 is most abundant in type $2 \mathrm{~b}$, less abundant in type $2 \mathrm{a}$ and only moderately expressed in type 1 muscle fibres. (97), a result that was also obtained in a separate population using similar methodology (74). The abundant basal expression of UCP3 in type $2 \mathrm{~b}$ fibres does not easily match with a facilitative role for UCP3 in fatty acid oxidation, since these muscle fibres have the lowest capacity to utilise fat as a substrate. Another argument against a facilitarive role for UCP3 in fatty acid oxidation comes from experiments with etomoxir, an inhibitor of carnitine palmitopl transferase 1 (CPT1), the rate-limiting enzyme in mitochondrial fatty acid uptake. Both animall and human studies revealed that etomoxir treatment induced an up-regulation of UCP3 protein, rather than a down-regulation, as would be expected based on a putative facilitative role in fatty acid oxidation $(98,99)$.

\section{Fat metabolism in UCP3 transgenic mice}

In general, UCP3\% mice do not have an apparent phenotype. With respect to fat metabolisn, Gong et al. (44) did not detect changes in respiratory exchange ration (RER), but did report lower levels of plasma free fatty acids, although the latter result could not be reptoduced (44). Another study also reported similar RER values between UCP3-ablated mice and control mice, both in the fed and the fasted state (43) but, in contrast to Gong et al. (44), this study found a tendency to increased, rather than decreased, plasma FFA levels in older UCP3\% mice and this effect became statistically significant when these mice were challenged with a thighfat diet (43). Finally, physical performance, as well as their recovery capacity postexercise was unalteted in UCP3\% mice (43). In witro measurements of fatty acid and ghucose oxidation in muscle from sedentary and exercised mice revealed no difference berween UCP3 $\%$ and wildtype mice. In contradiction to these findings, Bezaire et al. (45) showed increased RER values in UCP3\% mice in a resting, ad Abitum-fed situation, indicating an impaired fat oxidation. This difference in RER 
between the two genotypes was, however, no longer statistically significant in the fasted state (45).

In contrast to UCP3\% mice, which lack an apparent phenotype, UCP3 overexpressing mice, having $\sim 15$ to 20 -fold increased levels of UCP3 protein, were shown to be hyperphagic but lean (38). In addition to these changes in energy metabolism these mice also displayed an increased palmitate oxidation in isolated soleus muscle, relative to wildrype mice (100). Bezaire et al. (40) recently reported that mice overexpressing UCP3 in a more physiological range ( 2.3 -fold) showed a significantly reduced $24 \mathrm{~h}$ RER, indicating an improved fatty acid oxidation. Next to an effect on RER, Bezaire et al. (40) also reported increases in several proteins involved in fatty acid oxidarion. The same set of markers of fatty acid oxidation were also applied to UCP3 $\%$ mice but revealed no differences compared to wildtype mice (40).

All in all, the data in UCP3 $\%$ mice are equivocal. Knockout of UCP3 does not lead to major changes in fat metabolism or body weight regulation. The effects on fat metabolism and body mass in UCP3 overexpressing mouse models, however, are more apparent. Although much work was conducted in mice with supraphysiological levels of UCP3, constitutive overexpression at physiological levels already seems to have beneficial effects on fat oxidative capacity.

\section{Suggested physiological functions of uncoupling protein 3}

Throughout the years, several functions have been ascribed to UCP3, based on the available data discussed in this review so far. In 2001, it was proposed that UCP3 acts as a mitochondrial fatty acid anion exporter and is involved in facilitating fatty acid oxidation (101). At the same time, we proposed a similar function of UCP3, although in our view, UCP3 exports fatty acid anions to protect mitochondria from the deleterious effects of intramitochondrial fat accumulation (102). In addition, UCP3 has been implicated in the defence against the production of reactive oxygen species (ROS) (103) or ROS-related compounds, such as lipid peroxides (104). This chapter will deal with the currently prevailing hypotheses concerning the putative physiological function of UCP3 in skeletal muscle metabolism. 


\section{UCP3 and ROS production}

During the final steps of substrate oxidation, electrons removed from reducing equivalents are transported along the electron transport chain, present in the inner mitochondrial membrane, and the released energy is captured in adenosine triphosphate (ATP). Reactive oxygen species (ROS), such as superoxide, are considered as an inevitable by-product of aerobic metabolism and originate from the direct reduction of oxygen by electrons that leak away from the electron transport chain. The resulting oxygen radical is highly reactive and can iniriate damage to phospholipids, proteins, DNA and RNA. The production of ROS is particularly sensitive to protonmotive force and only a small decrease in protonmotive force can already reduce the production of ROS tremendously (105, 106). Brand and colleagues proposed that UCP3 could be involved in lowering ROS production in skeletal muscle mitochondria through a mechanism of "mild" uncoupling, and conducted a series of experiments to explore this hypothesis. Echtay et al. (107) incubated rat skeletal muscle mitochondria in a superoxide- and hydrogen peroxide-generating system (by adding xanthine + xanthine oxidase) and found an increase in proton conductance, an effect that could be prevented by the addition of GDP or superoxide dismutase. Addition of external hydrogen peroxide did not affect GDP-sensitive uncoupling (107). Thus, it seemed that supetoxide was responsible for the observed decrease in proton conductance, which was sensitive to GDP, suggesting UCP3-mediated uncoupling. In line with this, skeletal muscle mitochondria from UCP3\% mice did not show superoxide-induced uncoupling that could be inlibited by GDP, in contrast to wildtype mice, which indicates that the uncoupling was indeed mediated by UCP3 (107). In subsequent work, Brand and colleagues extended this hypothesis by including hydroxynonenal (HNE) as a key player in their model.

Reacrive oxygen species (superoxide) can peroxidise polyunsaturated fatty acids present in the mitochondrial membranes, leading to formation of, among others, hyclroxynonenal. According to the (updated) Brand hypothesis, HNE will activate UCP3 thereby causing a regulated lowering of membrane potential and decreasing ROS production, providing a simple regulatory feedback loop.

Echtay et al. (108) revealed that hydroxynonenal was, like superoxide, able to increase proton conductance in isolated skeletal muscle mitochondria from rats, a process that was GDP-sensitive and thus indicative of UCP3-mediated uncoupling. This was further elucidated by the finding that the hydroxynonenal-induced increase in proton conductance was significantly less in mitochondria from 
UCP3- mice compared to wildtype mitochondra, and that GDP did not affect this increase in proton conductance.

In further support of the possible role for UCP3 in the protection against reactive oxygen species, it was shown that aconitase activity (an enzyme in the citric acid cycle), which inversely correlates with intracellular ROS production, was significantly decreased in UCP $3 \%$ mice, indicating an increased ROS production in wivo in these mice (43). Also mice underexpressing UCP3 in skeletal muscle were shown to display higher levels of oxidative damage to proteins and phospholipids than wildtype controls (109), compatible with a putative role for UCP3 in the protection against ROS production.

\section{UCP3 as a mitochondrial exporter of fath acids when faty acid oxidation predownates}

The numerous observations that UCP3 is up-regulated during conditions of high levels of fatry acid oxidation, such as fasting, exercise and lipid infusion, led to the suggestion that UCP3 might be involved in facilitating skeletal muscle fatry acid oxidation.

For their mitochondrial uptake and subsequent oxidation, fatty acids entering the cytoplasm of the muscle cell are first esterified into to fatty acyl-CoA by fatty acylCoA synthetase (ACS), an enzyme associated with the outer mitochondrial membrane. The fatry acyl-CoA crosses the outer mitochondrial membrane but needs to be converted to acyl-casnitine, a conversion catalysed by carnitine palmitoyl ransferase 1 (CPT1), before it can cross the inner mitochondrial membrane and access the mitochondrial matrix where $\beta$-oxidation takes place. Inside the matrix, reconversion of the fatty acyl-Cod from acyl-catnitine, catalysed by $C P T 2$, is necessary since only fatty-acyl $\mathrm{CoA}$ can enter the $\beta$-oxidation pathway. Besides being the location for $\beta$-oxidation, the mitochondrial matrix has also been shown to contain one or more acyl-CoA thioesterases, enzymes that can hydrolyse acyl CoA. (110). Thioesterase action removes a CoA from acyl $\mathrm{CoA}$, producing a fatty acid anion and it has been suggested that this occurs to replenish the CoA stores inside the mitochondrial matrix, essential to sustain other mitochondrial reactions involyed in fatty acid oxidation (i.c. TCA cycle and B-oxidation). $S_{0}, 1$ fatty acid oxidation is markedly acceletated, thioestetase action would liberate CoA to avoid deprivation of CoA that is required for other metabolic reactions and preventing impaiment of fatty acid oxidation due to lack of CoA. Although removal of CoA from fatty acyl-CoA will reduce the amount of fatty acids that can 
undergo oxidation, this will have a less dramatic effect on overall fat oxidation than a shortage of CoA in the TCA cycle and $\beta$-oxidation (101).

However, as stated above, hydrolysis of acyl-CoA by thioesterase activity also produces a fatty acid anion that cannot be further metabolised since the mitochondrial matrix does not contain the enzyme to activate fatty acids to their CoA-form (111), a necessary conversion for $\beta$-oxidation. According to the HimmsHagen and Harper hypothesis (101), UCP3 functions to export these fatty acid anions away from the mitochondrial matrix and providing a mechanism to both enhance fatty acid oxidation and to prevent intramitochondrial accumulation of potentially toxic fatty acid anions.

In support of this hypothesis it was shown that 1) mice overexpressing UCP3 were also characterised by increased levels of mitochondrial thioesterase (MTE-1) (112); 2) mice lacking the leptin receptor displayed up-regulated mRNA levels of both UCP3 and MTE-1, and both genes were concordantly down-regulated upon PPAR agonist treatment; and 3) both UCP3 and MTE-1 mRNA levels increased concordantly upon fasting and thyroid hormone treatment in rats (58), indicating that MTE-1 and UCP3 are likely involved in the same biochemical mechanism. However, it cannot be ruled out that UCP3 and MTE-1 are merely subject to the same regulatory pathway.

\section{UCP3 as a fathy acid anion exporter}

At the same time that Himms-Hagen and Harper published their hypothesis in 2001, we proposed a closely related function for UCP3 in skeletal muscle (102). This hypothesis was based on physiological findings that UCP3 is up-regulated or high when fatty acid supply to the mitochondria is likely to exceed the capacity to oxidise these fatty acids (high-fat feeding, fasting, acute exercise, lipid infusion, type 2 muscle fibres) and down-regulated or low when oxidative capacity is high or improved (weight reduction, endurance training, type 1 muscle fibres). As explained earlier, fatty acids enter the cytoplasm of the muscle cell and are subsequently esterified into fatty acyl-CoA by fatty acyl-CoA synthetase (ACS), an enzyme associated with the outer mitochondrial membrane. This farty acyl-CoA crosses both mitochondrial membranes through the carnitine shuttle system. Inside the matrix, the reconverted fatty acyl-CoA enters the $\beta$-oxidation pathway (fig. 2.1, right-hand side). When cytosolic levels of fatry acids increase inside muscle cells due to a mismatch between fat supply and oxidation capacity, the load of fatty acids on the mitochondria would drive neutral non-esterified fatty acids 
across the outer mitochondrial membrane, which is easily permeable to fatty acids. Although the inner mitochondrial membrane provides a barter for non-esterified fatty acids, neutral non-esterified fatty acids can partition into the phospholipid bilayer and access the mitochondrial matrix by flip-flop diffusion (113).

Once at the matrix side of the inner mitochondrial membrane, these neutral nonesterified fatty acids become deprotonated due to the proton gradient present across the inner mitochondrial membrane, leaving a proton and a fatty acid anion. Because the mitochondrial matrix lacks the enzyme to convert this fatty acid into fatty acyl-CoA and because of its anionic nature, the fatty acid can neither undergo $\beta$-oxidation nor flip-flop back to the intermembrane space (4).

Since the mitochondrial matrix is the major site of ROS production, oxygen radicals could attack the fatty acid anions, entering the mitochondrial matrix when the supply of fatty acids exceeds their oxidation. This would result in highly reactive lipid peroxide products, which can be, as mentioned before, detrimental to mitochondrial DNA, RNA and proteins.

Thus, we proposed that UCP3 is involved in the outward translocation of fatty acid anions that can enter the mitochondria during lipid oversupply, thereby preventing accumulation of non-metabolisable fatty acids inside the mitochondrial matrix or the inner side of the inner mitochondrial membrane (fig. 2.1, left-hand side). Once exported from the matrix, the fatty acid anion can pick up a proton from the intermembrane space and may either flip-flop back into the matrix, leading to mitochondrial uncoupling via fatty acid cycling as proposed by Skulachev et al. (3), or leave the mitochondrial innet membrane once the cytosolic fatty acid levels decrease. In support of this hypothesis, we showed that inhibition of mitochondrial fatty acid uptake and subsequent oxidation, through inhibition of CPT1 by etomoxir, resulted in significantly higher levels of UCP3 protein (98). In addition, we showed that a high-fat diet, based on medium chain triacylglycerols, does not alter muscular UCP3 protein levels, in contrast to a high-fat long chairi triacylglycerol diet, which caused a $\sim 2$ fold increase in UCP3 protein (11). Medium chain fatty acids (MCFA) ate characterised by shorter chain lengths and are taken up by the mitochondria in a CPT-independent manner $(114,115)$. Moreover, this type of fatty acids can be readily oxidised inside the marrix because of the presence of a matrix-associated enzyme, which allows the activation and subsequent $\beta$ oxidation of MCFA (116). Since these fatty acids would therefore not require UCP3 to expott fatty acids away from the mitochondrial matrix, the differential response of UCP3 to the two types of high-fat feeding (11) is in accordance with our hypothesis. Furthermore, we recently found that UCP3-ablated mice are 
characterised by increased levels of intramuscular lipid peroxides (chapter 6 of this thesis), as would be expected when the potential protective function of UCP3 is eliminated.

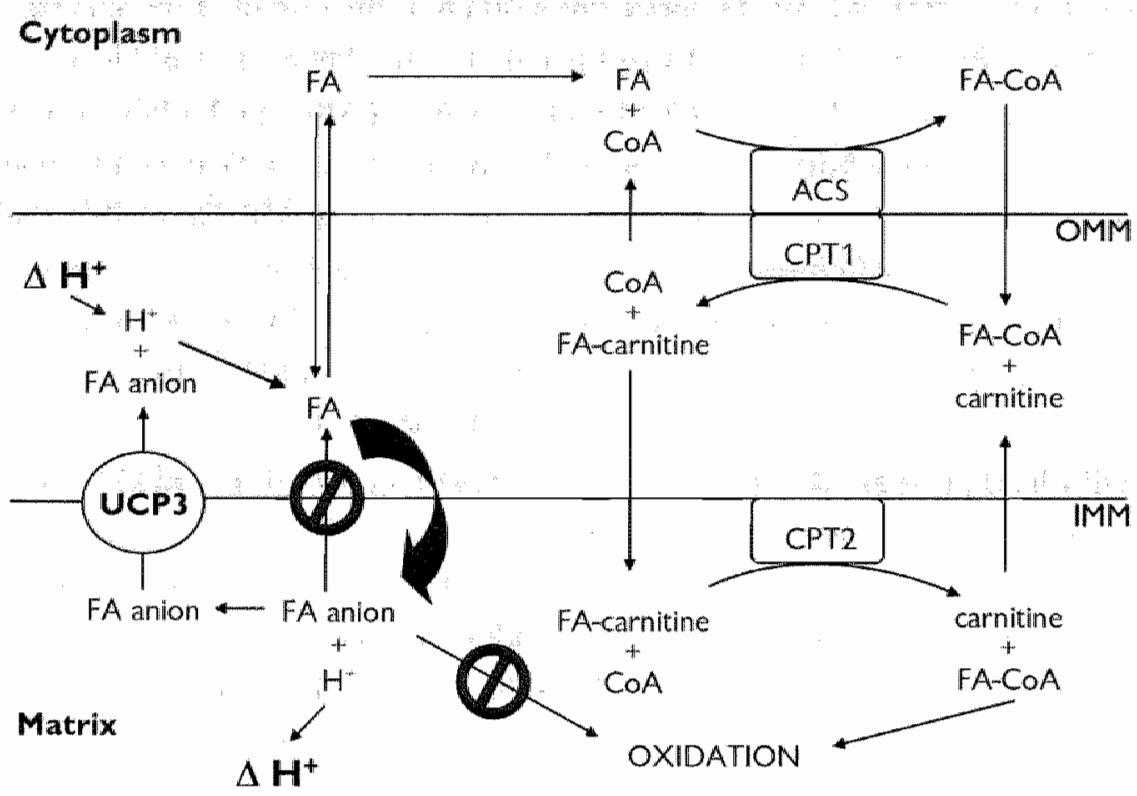

Figure 2.1 Schematic representation showing the inner (IMM) and outer (OMM) mitochondrial membrane. The right part of the figure displays the pathways involved in mitochondrial fatty acid uptake and oxidation. The left part of the figure depicts UCP3, located in the imner mitochondrial membrane, and putatively involved in the export of non-metabolisable fatty acid anions that become trapped in the mitochondrial matrix. FA, fatty acid; ACS, acyl-CoA synthetase; CPT, carritine palmitoyl transfierase.

Although these physiological studies support the proposed role for UCP3 as a fatty acid anion exporter, it cannot be regarded as definite proof for the suggested mechanism. As such, our physiological results are also supportive for another, closely related, putative role for UCP3, which is discussed in the next section.

\section{UCP3 transponts lipid peroxides}

In 2003, Goglia and Skulachey postulated the hypothesis that UCP3 operates as a carrier of fatty acid peroxide anions (104). Similar to our hypothesis of UCP3 being a fatty acid anion expotter, this hypothesis is in fact also an extension of the earlier farty acid cycling hypothesis by Skulachev (3) that aims to explain the mechanism 
of uncoupling action by UCPs. According to this latter hypothesis, UCP facilitates a fatty acid anion transport across the inner mitochondrial membrane. When these fatty acid anions reach the outer leaflet of this phospholipid bilayer, they pick up a proton from the intermembrane space and return to the inner leaflet of the inner mitochondrial membrane by a so-called flip-flop mechanism. In the inner leaflet; the fatty acids are deprotonated again, releasing a proton in the mitochondrial matrix and thereby lowering the proton gradient $(3,104)$.

As explained previously, reactive oxygen species, originating from oxidative metabolism in the mitochondrial matrix, can peroxidise fatty acids thereby initiating a chain reaction resulting in the formation of highly reactive lipid peroxides (117). The matrix is the most vital patt of mitochondria, containing mitochondrial DNA (mtDNA), RNA and numerous enzymes, catalysing essential metabolic reactions, some of which are highly sensitive to ROS (118-120). The hypothesis by Goglia and Skulachev (104) states that UCP3 functions to prevent potentially damaging accumulation of fatty acid peroxides in the inner leaflet of the inner mitochondrial membrane. It is assumed that UCP3 is capable of translocating fatty acid peroxides, like fatty acid anions, from the inner membrane leaflet to the outer membrane leaflet. The chemical nature of fatty acid peroxides (which are, in contrast to neutral fatty acids, unable to flip-flop) makes that the peroxides, transported to the outer leaflet by UCP3, will remain in this leaflet while the inner leaflet is purified from these compounds (104). In this way, potentially toxic fatty acid peroxides are removed from the matrix side of the membrane, thereby protecting mtDNA, RNA and critical metabolic enzyme systems. This hypothesis indeed is compatible with the numerous physiological observations that UCP3 is up-regulated under high free fatty acid conditions, since the probability of fatty acicl peroxidation must increase with fatty acid concentration. Although the fate of the exported fatty acid peroxides that would accumulate in the outer leaflet remains somewhat unclear, the intermembrane space is less vulnetable to oxidative damage since it does not contain nucleic acids or essential merabolic systems and limited amounts of enzymes (104). Most of these intermembrane space enzymes are much more resistant to ROS, while some of them even scavenge reactive oxygen species (i.e. cytochrome c) (121). 


\section{Conclusion}

The primary role for skeletal muscle UCP3 does not seem to be the regulation of chergy expenditure, as was initially predicted based on its homology to the known regulator of adaptive thermogenesis in btown adipose tissue. However, UCP3 has been shown to possess uncoupling activity and correlates with energy metabolism in certain situations. It was suggested that the protein could mediate a mechanism of mill uncoupling, thereby diminish the production of reaction oxygen species at the cost of a slight increase of energy expenditure. Such a function however, should be especially important in conditions of increased fat supply, given the numerous physiological conditions that point towards a role for UCP3 in fatty acid metabolism. Next to the direct decrease in ROS production, possibly mediated by UCP3, it is equally well possible that UCP3 exports farty acid anions and/or lipid peroxides to protect the mitochondria against these toxic compounds. Fixport of fatty acid anions would also lead to a decrease in protonmotive force, which could explain the correlations that were observed between UCP3 expression and energy expenditure.

Taken together, UCP3 seems to be involved in the protection of mitochondria against lipotoxicity, but establishing the exact mechanism of action requires more study.

\section{References}

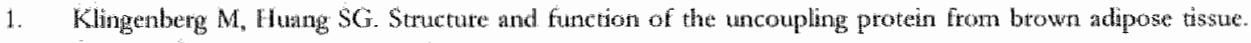
Buchion Biophys Actn 1999,1415(2):271-96.

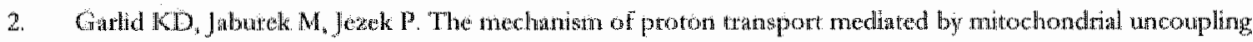
proteins. HEDS Leter 1998;438(1-2):10-4.

3. Skulathew VP. Faty acid cincuit as a physiological mechanism of uncoupling of oxidatiwe phosplyorylation. FHBS 1 ear $1991,294(3): 158-62$.

4. Jozek P, Otosz DE, Modtiansky $\mathrm{M}_{\mathrm{n}}$ Garlid KD. Transport of anions and protons by the mitochondrial thooupling protein and its regulation by nucleotdes and taty acids. A new look at old hypotheses. J Riol Chem $1994,260(42) 26184-90$.

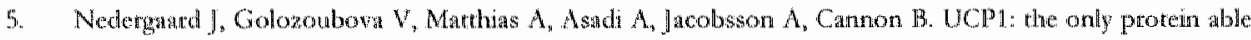
to mediate wdaptive non-shiwering themogenesis and metabolic inefficiency. Biochim Biophys Acta $2001 ; 1504(1): 82 \cdot 106$

6. Buss O, Sanee S, PaolonimGiacobino $A$, Rossior $C$, Dulloo A, Seydoux ], et all. Uncoupling protein-3: at new member of the mitochondral carrier family with tiscue-specific expression. FEBS Let 1997;408(1)39-42. 


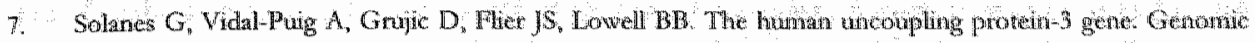

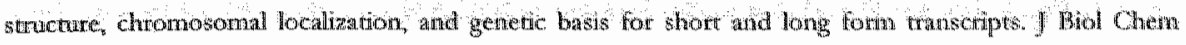
$1997272(41): 25433-6$.

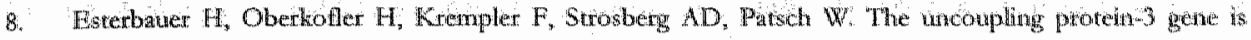
trancilbed from tisute-specific promoters an hamans but mot in rodents. J Biol Chem 2000,275(40):36394 9.

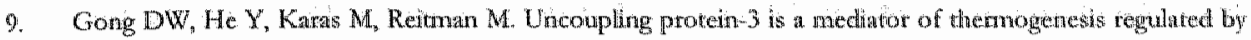
thymid hormone, beta3-adrenergic agonists, and leptin J Bobl Chem 1997,272(39):24129-32.

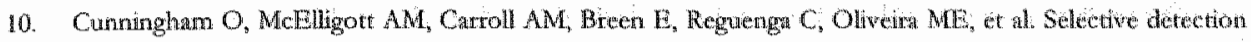
of UCP 3 expression in steletal muscle effect of thyrotd status and temperante acclimation. Biochun Biophys Acta 2003;1604(3):170)9.

11. Hoeks 1, Hesseliak MK, wan Bilsen M. Schart $G$, van der Vusse GJ, Saris WH, et al Difterential response of LCP3 to medium versus long chin triacylgycerols; mantestation of a functional adaptation. FEBS Letr $2003 ; 555(3): 6311 \% 7$

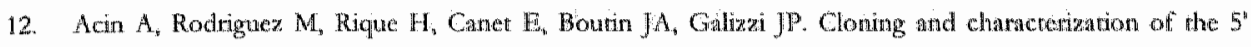
flanking region of the human uncoupling protein 3 (UCP3) gene. Biochem Biophys Res Commun $1999,258(2): 278-83$

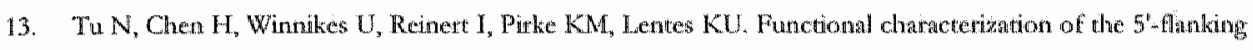
and the pronoter region of the human UCP3 (hUCP3) gene. Iife Sici $2000 ; 67(18): 2267-79$.

14. Olson EN, Perry M, Schulz RA. Regulation of muscle differentation by the MEP2 family of MADS box transcription factorts. Dev Biol 1995; 72 (1):2-14.

15. Solanes G, Pedraza N. Iglesias R, Giralt M, Villanoya F. Functional relationship between MyoD and peroxisome probletatot-activated receptor-dependent regulatong pathways in the control of the human uncoupling protein-3 gene transcription. Mol Endocrinol 2003;17(10):1944-58.

16. Solanes $\mathrm{G}$, Jedraza N, Iglesias R, Giralt M, Villarroya F, The human uncoupling protein-3 gene promoter: requires MyoD and is induced by retinoic acid in muscle cells. Faseb J 2000;14(14):2141-3.

17. Solanes $\mathrm{G}$, Pedrza $N$, Calvo V, Vidal-Pug $A$, Lowell BB, Villartoya T. Thyroid hormones directly activate the expression of the human and mouse uncoupling protein-3 genes through thyroid response element in the proximal promoter region. Biochem $\mathrm{J} 2004$.

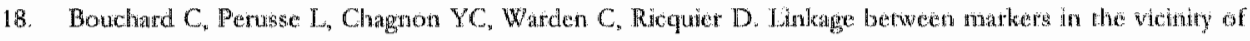

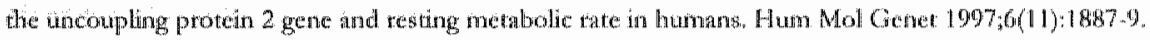

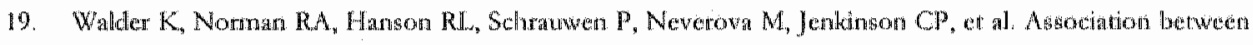

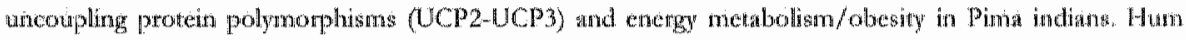
Mol Genet $1998 ; 7(9): 1431-3$.

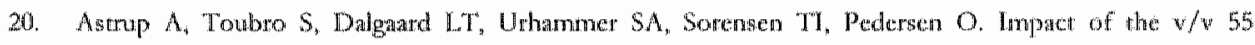
polymorphism of the uncoupling protein 2 gene on 24 henergy expenditure and substrefte oxidarion. Int I Obes Relat Merab Disord 1999,23(10):1030-4.

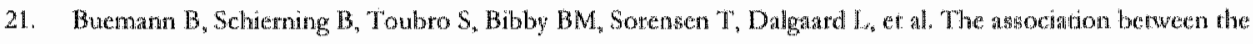

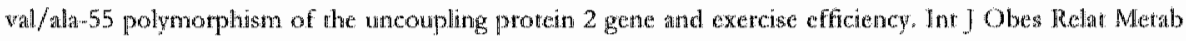
Disord $2001 ; 25(4): 467-71$.

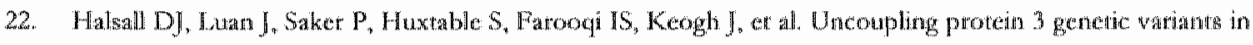
humban obesity: the c-55t promoter polymomphism is negatively corredsted with body mass index in a UK Catucasian population. Int J Obes Relat Metab Disord 2001,25(4):4727.

23. Cassell PG. Saker P]. Huxtable SJ, Kousta E, Jackson AE, Hatterstey AT, et al. Evidhence that single tuldeotide polymorphism in the uncoupling protein 3 (UCP3) gent infuences fat distribution in womeri of Exinopean and Asian origin. Diabetologia 2000;43(12)/1558-64. 


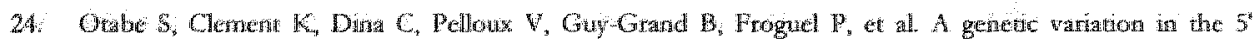
flanking region of the UCP3 gene is assichated wath body mass index in humans in interaction wath physical actionily. Dabetologia $2000,43(2): 245-9$

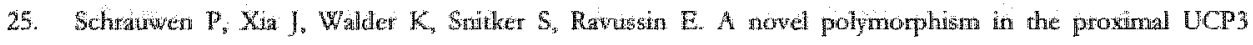

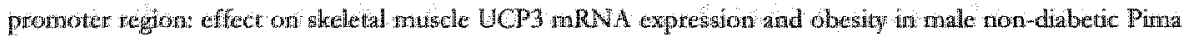

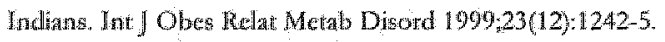

20. Dalgard $1 T$, sorenen T, Drwholm 1 , Borch-johnsen $K$, Andersen $T$, Hansen T, et al. A prevalent polymorphism in the purmoter of the UCP3 gene and its relationshis to body mass index and bong enn

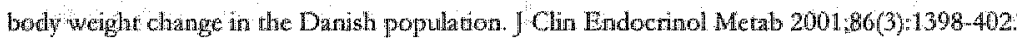

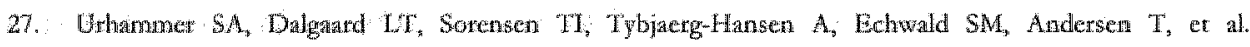
Otgandation of the coding exons and matational screcning of the uncoupling protein 3 gene in subjects whith furenilu-conget obesity. Diabetologia $1998,41(2), 241-4$.

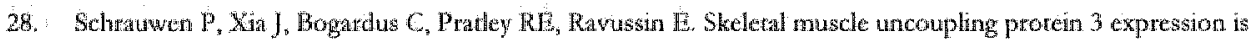

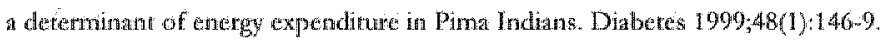

29. Jiburels M; Vareclla M, Gimeno RE, Dembsizi M, Jezek P, Zhang $M$, et all "Transpott function and regulation of mitochondrial nucoupling proteins 2 and 3 , J Bioll Chem 1995;274(37),26003-7.

30. Hagen $T$, Zhang $C Y$, Vianna $C R$, Lowell BB. Uncoupling proteins 1 and 3 are regulated differenty. Biocheristry 2000,39(19) 5845-51.

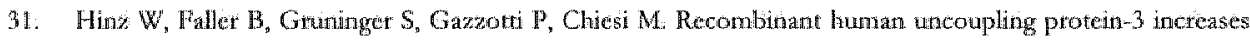
themogenesis in yeetst cella. HEBS Let 1999;448(1):57-61.

32. Zhang CX, Hagen T, Mootha WK, Sheter LJ, Lowell BB. Assessment of uncoupling activity of uncoupling protein 3 using a yeast theterologous expression system. FEBS Lett 1999;449(2-3):129-34.

33. Hagen T, Thang CX, Slicher LU, Chewg WK, Leibel RL, Lowell BB. Assessment of uncoupling actiwity of the human uncoupling procein 3 shork form and three muturs of the uncoupling protein gene using a yeast hetrerologous expression system, FIBS Let 1999;454(3),201-6.

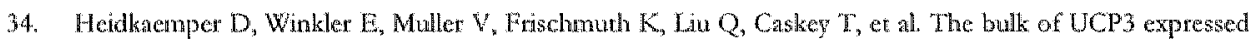
in yeast cells is incompetent for a nucleotide tegulated H+ cransport. [FEBS Letr 2000;480(2-3):265-70.

35. Wraker $\mathrm{E}$, Heidkaemper D, Klingenberg M, Lhu Q, Caskey T. UCP3 expressed in yeast is primarily locatized in extramirochondral pardeles. Biochem Biophys Res Commun 2001:282(1):334.40.

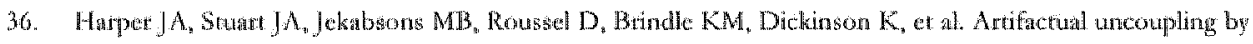
uncoupling protein 3 in yenst mitochondrat at the concentations found in mouse and rat shelctal-nuscle mitochondria. Biochem I $2002,361(\mathrm{Pt} 1) \cdot 49-56$.

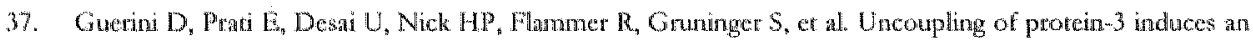
uncontrolled cancoupling of mitochondria after cxpression in muscle derived Lo cells. Eu J Biochem $2002 ; 209(5): 1373-81$.

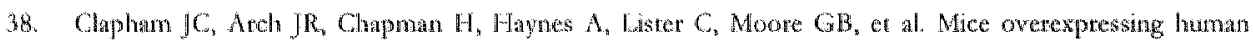
uncoupling protein 3 in sketernl muscle are hyperphagic and lean. Nature $2000,406(6794): 415-8$.

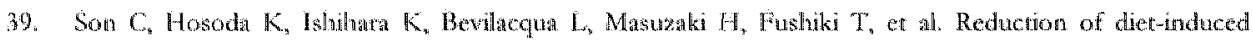
obtwity in mongenic mic oxerexptessing uncoupling proten 3 in skeletal muscle. Diabetologia $2004: 47(1): 4,7-54$

40. Bexaite V, Sptier LL, Gampbell S, Sabet N. Gotrits M, Bonen A, et al. Constitutive UCp3 owerexpression at phyziological levels increases mouse skeletal muscie capacity for faty acid tonspott and oxidacion. Faseb I $2005: 19(8 ;, 977,9$

4t. Scluruwen P. Hardie DG, Roorda B, Clapham JC, Abuin A, Thomason Flughes M, et al. Improved glucose homeostasis in mice overexpessing human UCP3; a role for AMP-kinase? Int I Obes Relat Metab Disord $2004286(6) 8248$ 


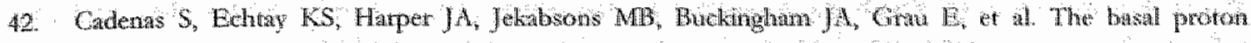

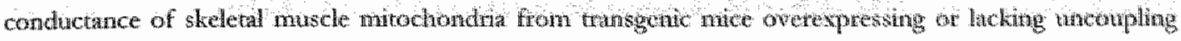
protein-3.] Biol Chem $2002,277(4) 2773-8$

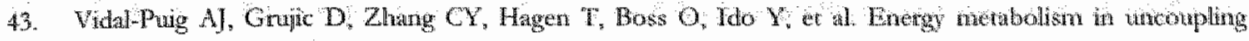
protein 3 gene knockout mice:] Brol Chem $2000,275(21), 1625866$.

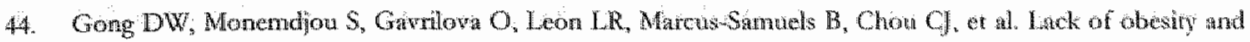

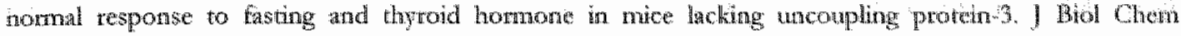
$2000 ; 275(2) 1) \times 16251-7$.

45. Bezare V, Hofmann W, Kamer IK, Kozak LP, Harpet ME. Effects of Esting on muscls mitochondral

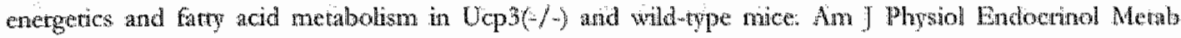
$2001,281(5):=975-82$.

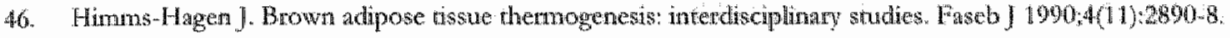

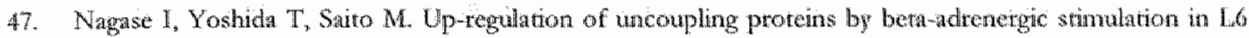
nyotubes. FEBS Let 2001;494(3):175-90.

48. Yoshitomi $\mathrm{H}$, Yamazaki $\mathrm{K}$, Abe $\mathrm{S}$, Thata I. Differential regulation of mouse ancoupling proteins anong brown adipose tissue, white adpose tissue, and skeletal muscle in chtonic bea 3 adrenerge receptor agonist treatment: Biochem Biophys Res Commun 1998;253(1):85-91.

49. Savontaus E, Rouru J, Boss O, Huupponen R, Koulu M. Differential tegulation of uncoupling proteins by chronic treatments wirh beta 3 -adrenergic agonist BRE 35135 and metormin in obese fa/fa Zucker rats. Biochem Biophys Res Commun 190,8;246(3):899-904.

50. Nakamera $\mathrm{X}$, Nagase 1, Asano A, Sasaki N, Yoshida T, Umekawa "T, at al. Beta 3-adrenergic agonist upregulates uncoupling proteins 2 and 3 in skethet nuscle of the mouse. I Ver Med Sci 2001;63(3):309-14.

51. Hoeks J, Van Baak MA, Hesselink MK, Hal GB, Vidal H, Siris WH, et all. The EFfect of (beta) 1. and (beta)2-Adrenergic Simulation on Energy Expenditure, Substrate Oxidation and UficP3 Fxpression in Human Skeletal Muscle. Am J Playsiol Endocrinol Metab 2003.

52. Freake HC, Oppenheimer IH. Themogenesis and thyroid function. Anau Rev Nutr 1995;15:263-94.

53. Goglia $\mathrm{F}$, Moreno M, Lanni A. Acton of thyroid homones at the cellulat lkwel: the mirochondrial target. FEBS Lett $1999,452(3): 115-20$.

54. Lanni $A$, Beneduce $L$, Lombardi $A$, Moreno M, Boss O, Muzzin P, er al Expression of uncoupling protein

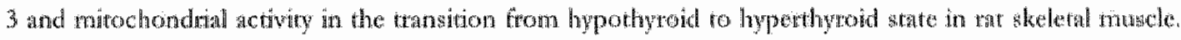
AEBs Letr $1999,444(2-3) \div 250-4$

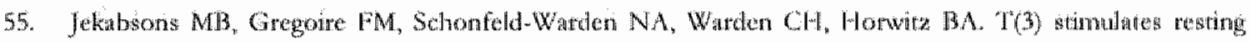

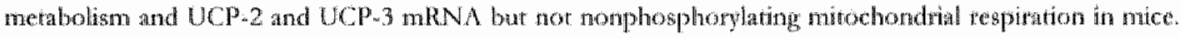
Am J Physiol 1999;277(2 Pat 1): 1 380-9

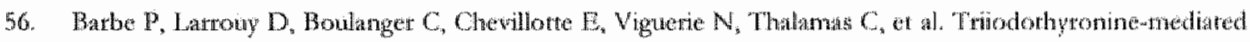

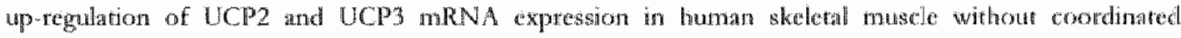
induction of mitochondral respiratory chan genes. Faseb J 2001;15(1):13-15.

57. de Lange P, Lanni A, Benedace L, Moreno M, Lombardi A, Silvestri $\mathrm{P}$, at al, Unconpling protan-3 is at molecular deteminant for the regulation of resting metalbolic rate by thytoth hormone. Endocrincology $2001 ; 142(8), 3414-20$.

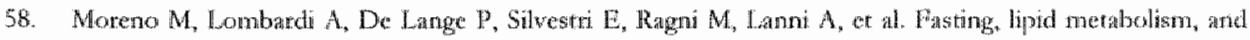
tribodothyronine in raf gastrocnemis muscle: interrelated roles of uncoupling protein 3 , mitorhondaial Whoesterase, and coenzyme Q, Haseb) $2003: 17(9): 111244$.

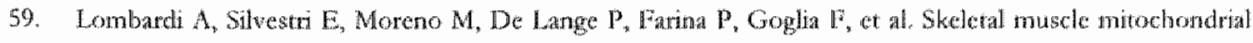

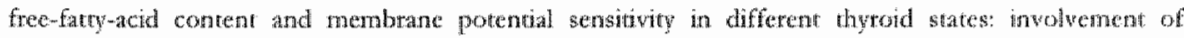
uncoupling protein-3 and adenine nucleotde translocase. FEBS Lett 2002,532(1-2):12-6x. 


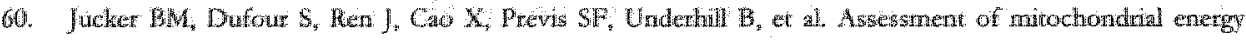

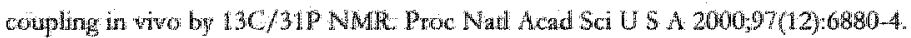

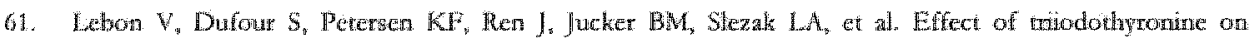

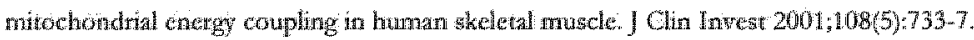

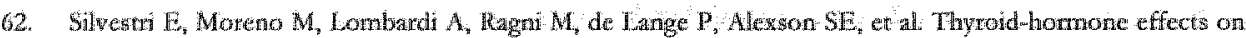

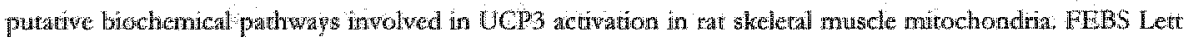
$2605,579(7)=63045$

63. Latrin A. Moreno M, Lomilatdi $A$, Goglia $F$. Thyroid homone and uncoupling protems. FEBS Latr. $2003,5,43(13), 5-10$.

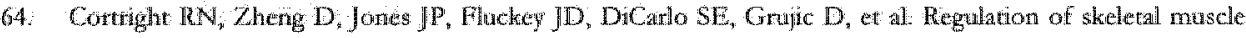
UCP-2 and UCP-3 gethe expression by exewcisc and denervation. Am J Physiol 1999;276(1 Pt 1):E217-21.

65. Zhou M, Lin BZ, Coughin 5, Vallega G, Pilch PF. UCP-3 expression in skeletal muscle; effects of exercise,

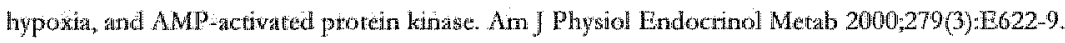

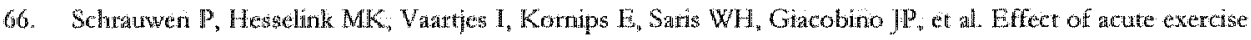
on uricoupling protein 3 ir a fat metbolism-nodiated effect Am J Physiol Endocrinol Merab 2002:282(1)

67. Chberton IJ. McGe SL, Murphy RM, Hargreaves M. Effect of carbohyduate ungeston on exerciseinchuced al texarions in metrbolic gene expression. J Appl Physiol 2005.

68. Pedersen SB, luind S. Buhl ES, Richelsen B. Insulin and contraction directly stintate UCP2 and UCP3 mRNA expression in at skeletal muscle in witro. Biodiem Biophys Res Commun 2001;283(1);19-25.

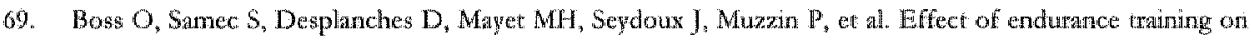
mRNA expression of uncoupling proteins 1,2 , and 3 in the rat. Faseb I 1998;12(3),335*9.

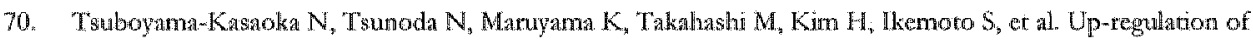
uncoupling protein 3 (UCP3) mRNA by exercise training and down-regulation of UCP3 by denervation in skeletal muscles. Biochem Biophys Res Conmmun 1998;247(2):498-503.

71. Jones " $\mathrm{TE}, \mathrm{Bar} \mathrm{K}$, Ojuka $\mathrm{E}$, Chen $\mathrm{M}$, Hollioszy JO. Exercise induces an increase in muscle UCP3 as a componeme of the increase in mitochondral biogenesis. An J Plysiol Endocrinol Metab 2003,284(1):E96101.

72. Solvinuen P. Troost FV, Xia J, Ravussin E, Saris WH. Skeletal muscle UCP2 and UCP3 expression in

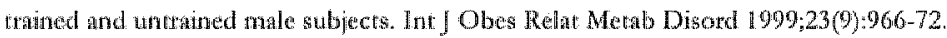

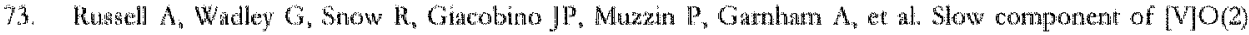

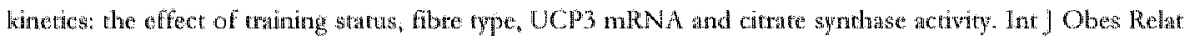
Mots Disord 2002:26(2):157-64.

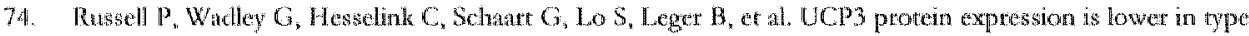

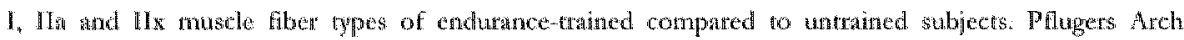
$2003 ; 445(5) \div 563 \% 9$

75. Sctwawwen P. Russell MP, Moonen-Fotnips E, Boon N, Hesselink MK Effect of 2 weeks of endurance tratining on uncoupling protein 3 content in untrained human subjects. Acta Physiol Scand 2005:183(3):27380.

76. Ternstom M, Tonkonogi $\mathrm{M}_{3}$ Salilin $\mathrm{K}$. Erffects of acute and chronic enclurance exercise on mirochondrial uncoupling in linman skelcinl musck. J Physiol 2004;554(pt 3):755-63.

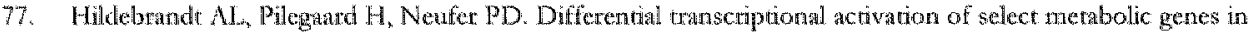
response to variations in exercise intensity and duraton. Am I Physiol Endocrinol Metab $2003,285(5) \mathrm{s} 1021-7$. 


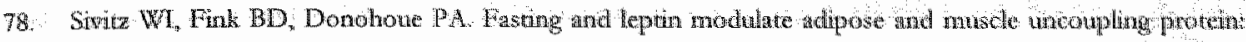

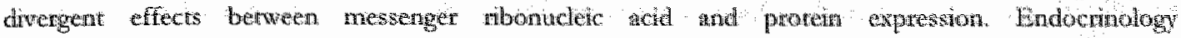
$1999 ; 140(4) \div 1511-9$

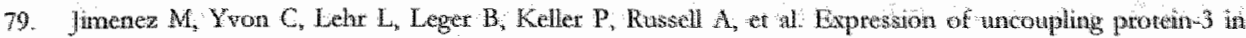

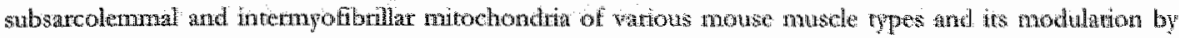
fasting: Eur ] Biochem 2002;269(12):2878-84.

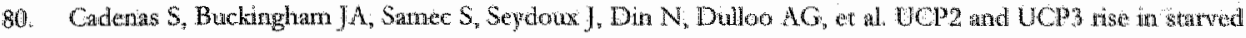

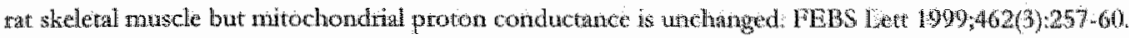

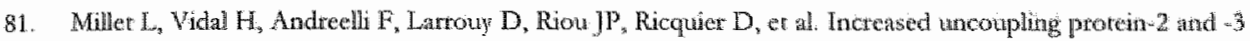

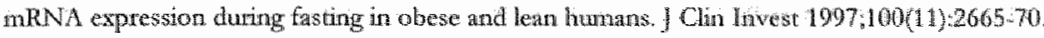

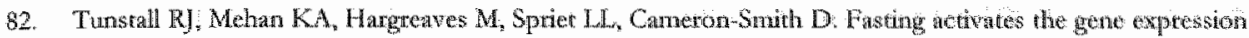

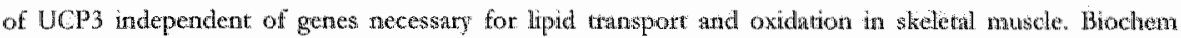
Bioplyys Res Commun 2002,294(2):301-8.

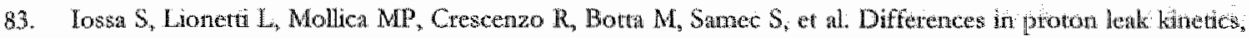

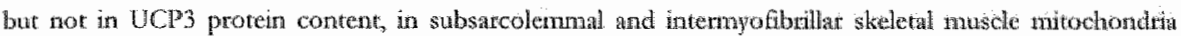
from fred and fasted rats. FEBS Lett $2001,505(1): 53-6$

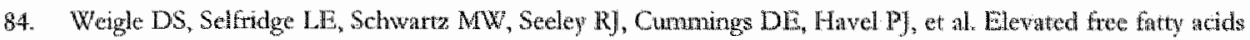
induce uncoupling protein 3 expression in muscle: a potental explanation for the effect of tasting. Diabustes $1998 ; 47(2): 298 ; 302$

85. Khalfallh $\mathrm{Y}$, Fages $\mathrm{S}$, Laville $\mathrm{M}$, Langin $\mathrm{D}$, Vidal H. Regulation of uncoupling prorein-2 and uncoupling protein-3 mRNA extession during lipid infusion in human skeletal mosele and subeutaneous rdipose tissue. Diabetce 2000;49(1):25-31.

86. Sbraccin P. D'Adamo M, Leoneti F, Buongiomo A, Silechia G, Basso MS, et al. Rehtionship between plasma free fatry acids and uncoupling protein-3 gene expression in skeletal muscle of obese stubjects: in vitro evidence of a causal link Clin Endocrinol $(\mathrm{Ox})$ 2002,57(2) 199-207.

87. Nagase 1, Yoshida S, Canas X, lite $\mathrm{Y}$, Kimura $\mathrm{K}$, Yoshida $\mathrm{T}$, et al. Up-regulation of uncoupling protein 3 by dhyroid homone, peroxisome proliferaror-activated receptor ligands and 9-cis retinoic acid in 16 myottobs. FEBS Let $1999,461(3): 319-22$

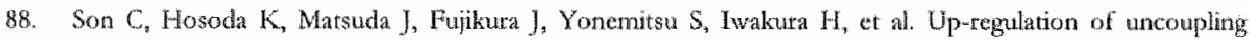
protein 3 gene expression by fatry acide and agonists for PPARs in do myonubes. Endocinology $2001 ; 142(109 ; 4189,94$.

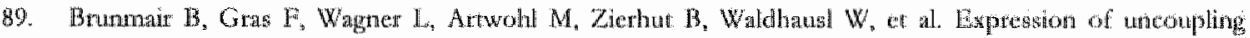

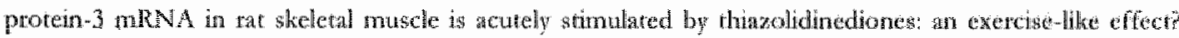
Dialberologia $2004: 47(9): 1611,4$.

90. Brun $S_{n}$ Gamona MC, Mampel T, Vhas $O$, Giralt M, Iglesias R, et al Activarors of penoxusone proliferator-activated receptor-alphat induce the expuession of the uncoupling protein-3 gene in skelestal mascle: a potental mechaism tor the lipid intake-dependent activanion of tucoupling proten-3 gene expuression at birtr. Diabetes 1999;486(6):1217-22.

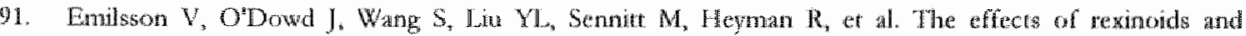

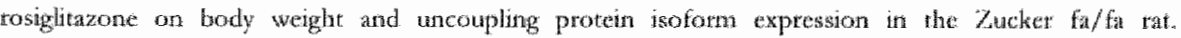
Metabolism $2000,49(12): 1610-5$.

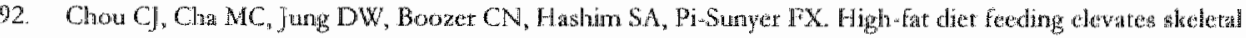
muscle uncoupling protein 3 levels but not its activity in rats. Obes Res 2001,965$): 313 \%$

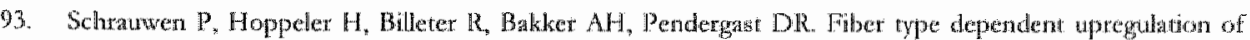
human skeletal musche UCP2 and UCP3 mRNA expression by high fat diet. Int I Obes Relat Metab Disord $2001,2544: 449-56$. 


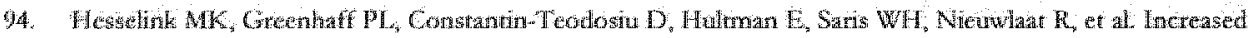
unesupling ptoten 3 content does nor affect mitochondrial function in human sketeral muscle in wro. I

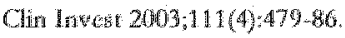

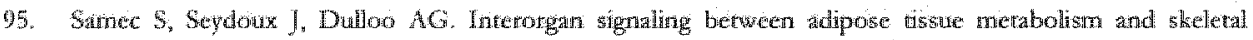

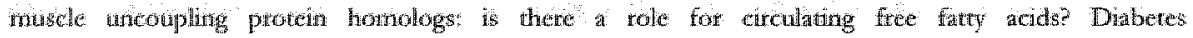
$1998,4711) \div 16938$.

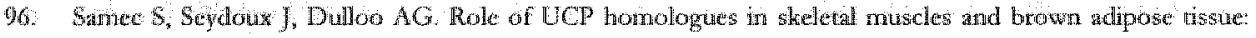

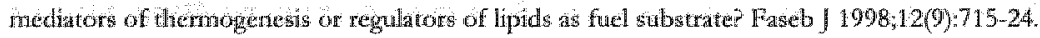

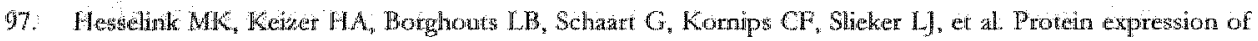

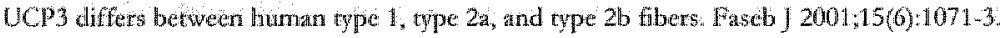

98. Schrawwen P. Hindering V, Hesselnk MK, Schart G, Komips E, Saris WH, et al Eromoxir-induced

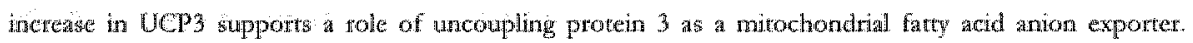
fusels $2002 \div 16(12) 1688,90$;

99. Schrawen P, Hoeks J. Scharar C, Kornips $\mathrm{E}$, Bthas B, Van De Vusse G], et al. Uncoupling protein 3 as a

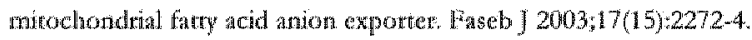

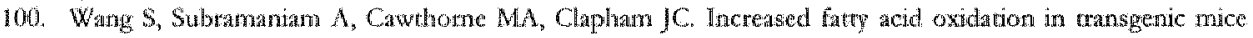

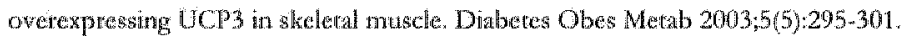

101. Mimms when Eutry acid oxidation predominates: an hypothesis. Exp Biol Med (Maywood) 2001;226(2):78-84.

102. Sthrawen P, Saris WH, Hesselink MK. An alternative functon for human ancoipling protein 3 : protection of mitochondriat agamst. aceumulation of nonesterified fatty acids inside the mitochondral matrix. Faseb J $20011: 15(13): 2497502$

103. Brath MD, Buckingham. JA, Esteves TC, Green K, Lambert A], Mwa S, et al Mitochondrial superoxide and aging: uncoupling-ptotein actiwiry and superoxide production. Biochem Soc Symp 2004(7):203-13.

104. Goglia F, Skulachew VP. A function for novel uncoupling proteins: antioxidant defense of mitochondral matrix by translocating fidty acid peroxides from the inner to the ourer nembrane leaflet. Faseb ) $2003 ; 17(12): 1585-94$

105. Korshurnow 55 , Skatachay VP, Stakow AA. High protonic potental actures a mechanism of production of reactive oxyger species in mitochondria. FEBSS Let 1997:416(1):15-8.

106. Stwhather VP. Role of uncoupled and nom-compled oxidations in maintenance of safely low levels of oxygen and its onic alectron teductints. Q Rev Biophys 1996,29(2):169-202

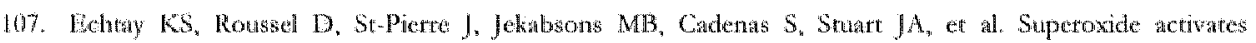

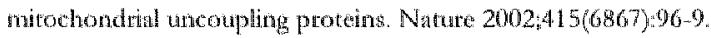

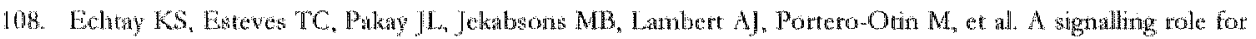
4-hydroxy-2-monenat in tegulation of mitomondrial uncoupling. Embo / 2003,22(16):4103-10.

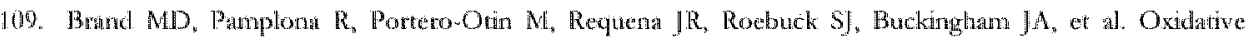
dariage atnd phosphotipad fatty acyl composition in skebtal muscle mitochondra from mice whderexpressing or ovetexpressing uncoupling protein 3 . Biochem J 2002,368(1) 2) 597-603.

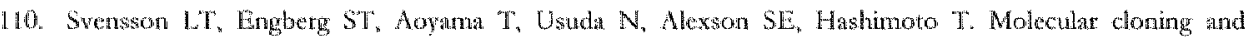
characterzation of a mitochondrat peroxisone prolifemtor-indaced acyl-CoA hioesterase from rat liver. Bioctlom I 1998; 320 ( $\operatorname{Pr} 3): 601-8$.

111. Tol VA. Aspects of long chain acyl-COA netabolism. Mol Cell Biochen 1975,7(1):19.31.

112. Moor GN, Himuns-Hagery J, Haper ME, Clapham JC. Overexpression of UCP-3 in skeleal muscle of une tesults in increased expression of mitochondral thioesterase mRNA. Biochem Biophys Res Commum $2001: 283(4): 78590$ 


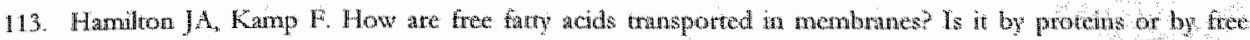
diffusion through the lipids? Diaberes $1999,48(12) 2255-69$.

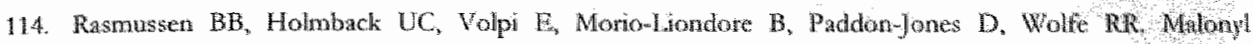

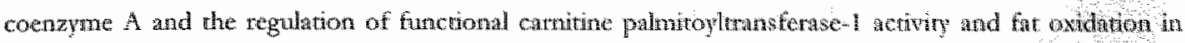
human skeletal muscle f Clin Inxest 2002-110(11):1687-93.

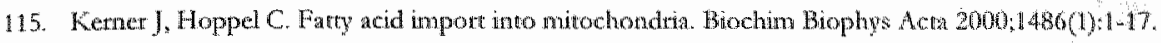

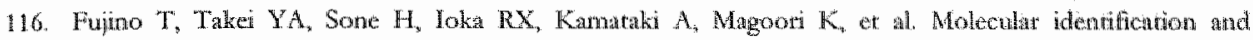

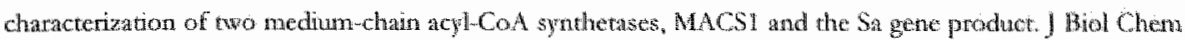
$2001,276(38): 35961-6$

117. Yagi $\mathbb{K}$. Lipid peroxides and hurman discases. Chem Phys Lipids 1987;45(2,4),377.51.

118. Gardner PR. Superoxide-driven aconitase FE-S center Cycling. Biosei Rep $1997 ; 17$ (1)33.42.

119. Gmancwicz MA, Day B], Copeland WC. The mitochondral DNA polymerase as a target of oxidative damage. Nuicleic Acids Res 2002;30(13):2817-24.

120. Skunchey VP. Menbrane-linked systenas preventing superoxide fomation. Biosci Rep 1997; $17,3,34,37-66$.

121. Shutachev WP. Cytochrome $c$ in the apoprotic and antioxidant cascates FEBS Letr 1998,423(3):275-80. 
s.

$\therefore$

$\ldots \ldots$ 


\section{$i_{i m}$}

The effect of $\beta_{1}$ - and $\beta_{2}$-adrenergic stimulation on energy expenditure, substrate oxidation and UCP3 expression in human skeletal muscle

Joris Hoeks, Marleen A. van Baak, Matthijs K.C. Hesselink, Gabby B. Hul, Hubert Vidal, Wim H.M. Saris and Patrick Schrauwen

Departments of Human Biology and Movement Sciences, Nutrition and Toxicology Research Institute Maastricht (NUTRIM), Maastricht University, Maastricht, The Netherlands

Inserm Unit 449. Faculty of Medicine RTH Laennec, Lyon Cedex 08. France

Am J Physiol Endocrinol Metab. 2003 Oct:285(4):E775-82 


\section{Abstract}

In humans, $\beta$-adrenergic stimulation increases energy and fat metabolism. In case of $\beta_{1}$-stimulation, this is fuelled by an increased lipolysis. We examined the effect of $\beta_{2}$-adrenergic stimulation, with and without a blocker of lipolysis, on thermogenesis and substrate oxidation. Furthermore, the effect of $\beta_{1}$ and $\beta_{2}$ adrenergic stimulation on UCP3 $\mathrm{mRNA}$ expression was studied.

Nine lean males received a 3 h-infusion with dobutamine $\left(D O B, \beta_{1}\right)$ or salbutamol $\left(\mathrm{SAL}, \beta_{2}\right)$. Also, we combined SAL with acipimox to block lipolysis $(\mathrm{SAL}+\mathrm{ACI})$. Energy and substrate metabolism was measured continuously, blood was sampled every 30 min and muscle biopsies were taken before and after infusion.

Energy expenditure significantly increased by $\sim 13 \%$ in all conditions. Fat oxidation increased by $47 \pm 7 \%$ in the DOB group and by $19 \pm 7 \%$ in the SAL group but remained unchanged in the $\mathrm{SAL}+\mathrm{ACI}$ condition. Glucose oxidation decreased by $40 \pm 9 \%$ upon $\mathrm{DOB}$, remained unchanged during $\mathrm{SAL}$ and increased by $27 \pm 11 \%$ upon SAL+ACI. Plasma FFA levels were increased by SAL $(57 \pm 11 \%)$ and DOB $(47 \pm 16 \%)$, whereas $S A L+A C I$ caused $\sim 4$-fold lower FFA lewels compared to basal levels.

No change in UCP3 was found after DOB or SAL, while SAL+ACI downregulated skeletal muscle UCP3 mRNA levels by $38 \pm 13 \%$.

In conclusion, $\beta_{2}$-adrenergic stimulation directly increased energy expenditure, independent from plasma FFA levels. Furthermore, this is the first study demonstrating a down-regulation of skeletal muscle UCP3 mRNA expression after lowering plasma FFA concentrations in humans, despite an increase in energy expenditure upon $\beta_{2}$-adrenergic stimulation. 


\section{Introduction}

In rodents, the major site of thermogenesis is the brown adipose tissue (BAT) and a key molecule in BAT thermogenesis is uncoupling protein 1 (UCP1). This protein dissipates the mitochondrial proton gradient by catalysing back-flux of protons into the mitochondrial matrix thereby generating heat (1). Sympathetic stimulation increases energy expenditure in rodents, amongst others by stimulating BAT thermogenesis (2). Brown adipose tissue contains all three $\beta$-adrenoceptor subtypes, each of which is coupled to a $G$-protein to stimulate adenylate cyclase and thereby the $\mathrm{AMP} / \mathrm{PKA}$ pathway (3).

In humans, both $\beta_{1}$ - and $\beta_{2}$-adrenergic stimullation also increase enetgy expenditure $(4,5)$. However, in contrast to rodents, $\beta$-adrenergic stimulated thermogenesis in humans is mainly located in skeletal muscle $(6,7)$, and the mechanism is still unknown. Besides increasing energy expenditure, $\beta_{1}$-and $\beta_{2}$-adrenergic stimulation also increase adipose tissue lipolysis $(4,5)$, and it has been shown that the increase in plasma free fatty acids resulting from the increased lipolysis is responsible for a great part of the increase in energy expenditure after $\beta_{1}$ stimulation (8). However, since $\beta_{2}$-adrenoceptors are mainly localised in skeletal muscle and not in adipocytes, it can be hypothesised that $\boldsymbol{\beta}_{2}$-adrenergic stimulation may exert a direct effect on energy expenditure. Therefore, the first aim of the present study was to examine the effect of $\beta_{z}$-adrenergic stimulation, with and without a blocker of lipolysis, on energy and substrate metabolism.

As mentioned above, the mechanism through which sympathetic stimulation might inctease energy expenditure in skeletal muscle is still unknown. UCP3, which shows approximately $55 \%$ amino acid homology with UCP1 and is predominantly expressed in skeletal muscle $(9,10)$, has been reported to have uncoupling activity $(11,12)$. With respect to the possible role of UCP3 in human themogenesis, we reported that UCP3 $\mathrm{mRNA}$ expression was positively correlated with sleeping metabolic tate in Pima Indians, suggesting that skeletal muscle UCP3 is a mediator in the regulation of energy metabolism (13). More recently, however, we reported that human UCP3 probably plays a role in fatty acid metabolism with uncoupling as a possible secondary effect $(14,15)$. Therefore, UCP3 could eirher directly or indirectly, be involved in the $\beta$-adrenoceptor-stimulated thermogenesis. In this respect, animal and cell culture studies have revealed controversial data regarding the effect of $\beta$-adrenergic stimulation on UCP3 expression. Nakamura et al. (16) 
reported that skeletal muscle UCP3 in mice was up-regulated after treatment with a

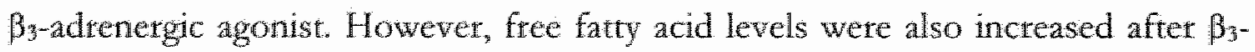
adrenergic stimulation, which could have caused the observed effect on UCP3 expression (17). In addition, Gomez-Abrosi et al. (18) were unable to detect any changes in skeletal muscle UCP3 expression upon short-term $\beta_{3}$-adrenergic stimulation in male Wistar rats. However, Nagase et al. (19) showed that stimulation of L6 myotubes with epinephrine increased UCP3 mRNA levels and that the regulatory effects of catecholamines were mediated through the $\beta_{2}$ adrenoceptor pathway. Regardless the controversial data in animal studies and cell culture systems, no data is currently available on the effect of $\beta$-adrenergic activity on UCP3 mRNA expression in human skeletal muscle.

Thesefore, the second aim of the present study was to examine the effect of $\beta$ adrenergic stimulation $\left(\beta_{1}\right.$ or $\left.\beta_{2}\right)$ in healthy lean human subjects on the expression of skeletal muscle UCP3 mRNA. Since high fatty acid levels are known to upregulate UCP3 $(17,20,21)$, we examined the effect of $\beta_{2}$-adrenergic stimulation on UCP3 mRNA expression independent of the effect of increased lipolysis.

\section{Methods}

\section{Subjects}

Nine healthy lean male volunteers participated in this study. Subject characteristics are displayed in table 3.1. All subjects were in good health as assessed by medical history and physical examination. All subjects engaged in sports activities no more than $2 \mathrm{~h}$ a week, and none had physically demanding jobs.

The study protocol was reviewed and approved by the Medical Ethical Committee of Masstricht University and all subjects gave written informed consent before participating in the study.

Table 3.1 Subject characterisucs

\begin{tabular}{lr}
\hline Parameter & Mean \pm SEM \\
\hline Body weight $(\mathrm{kg})$ & $71.5 \pm 3.2$ \\
Fat free mass $(\mathrm{kg})$ & $58.0 \pm 2.7$ \\
Height $(\mathrm{m})$ & $1.79 \pm 0.03$ \\
Body mas index $\left(\mathrm{kg}^{2} \mathrm{~m}^{2}\right)$ & $22.2 \pm 0.8$ \\
Age $(\mathrm{y})$ & $24.4 \pm 1.3$ \\
\hline
\end{tabular}




\section{Experimental design}

Subjects arrived at the laboratory at $8: 00$ am after an overniglt fast. Subjects were asked to avoid physical activity prior to the test. All subjects underwent three different conditions in a tandomised crossover design. Between conditions, a washout period of at least one week was maintained.

On arrival at the laboratory, a percutaneous muscle biopsy was taken from the vastus lateralis muscle. After local anaesthesia ( $0.2 \%$ xylocain without epinephrine), a 5 -mm diameter side-cutting needle was passed through a 7 -mm skin incision. The muscle biopsy was frozen immediately in liquid nitrogen and stored at $-80^{\circ} \mathrm{C}$ until assayed. Subsequently, two Teflon cannulas were inserted into an antecubital wein of each arm. One cannula was used for the infusion of $\beta$-adrenergic agonists and one cannula for sampling of blood. After taking the muscle biopsy and placing the cannulas, subjects rested on a bed for approximately 2 hours, to avoid induction of endogenous stress hormone levels. Next, oxygen consumption and carbon dioxide production was measured for 30 minutes using a custom-made ventilated hood system (Omnical, Maastricht. University, The Netherlands). After 30 minutes, a first blood sample was taken $(t=0)$. After this, a continuous infusion of either $4.6 \mu \mathrm{g} / \mathrm{kg}$ m.M.min dobutamine (DOB, a selective $\beta_{1}$-adrenoceptor agonist, Dobax, Zwanenburg, The Netherlands) or $77 \mathrm{ng} / \mathrm{kg}$ w min salbutamol (SAL, a selective $\beta_{2}$-adrenoceptor agonist, Ventolin, GlaxoSmithKline, Zeist, The Netherlands) was started and maintained for three hours. The third condition $(\mathrm{SAL}+\mathrm{ACI})$ consisted of salbutamol infusion combined with simultaneous blocking of lipolysis by acipimox. To that purpose, two doses of $250 \mathrm{mg}$ acipimox were given orally at $\mathrm{t}=-120$ and $\mathrm{t}=0$. Blood samples were taken every 30 minutes and ventilated hood measurements were continued throughout the experiment. After the 3 hours of infusion, a second muscle biopsy was taken.

\section{Body composition}

One week before the first test, body density was determined by hydrostatic weighing in the morning in the fasted state. Body weight was measured with a digital balance with an accuracy of $0.01 \mathrm{~kg}$ (Sauter, type E1200). Lung volume was measured simultaneously with the helium dilution technique using a spirometer (Volugraph 2000, Mijnhardt). Body composition was calculated according to the equation of Siri (22). Fat free mass (FFM) was calculated by subtracting fat mass from total body weight. 


\section{Indinet calorimetry}

Whole body energy expenditure and substrate oxidation were measured by indirect calorimetry, using a custom-made ventilated hood system (Omnical, Maastricht University, The Netherlands). The volume of air drawn through the hood was measured by a dry gas meter (Schlumberger, Dordrecht, The Netherlands) and the compostion of the in- and out-flowing air was analysed by a paramagnetic $\mathrm{O}_{2}$ analyser (Serwomex, Crowborough, UK) and an infrared $\mathrm{CO}_{2}$ analyser (Hartmann en Braun, Frankfurt, Germany). The airflow rate and the $\mathrm{O}_{2}$ and $\mathrm{CO}_{2}$ concentrations were used to compute $\mathrm{O}_{2}$ consumption and $\mathrm{CO}_{2}$ production online through an automatic acquisition system connected to a personal computer. Oxygen consumption and carbon dioxide production were averaged over the last 15 min of each 30 min time interval. Energy expenditure was calculated according to the Weit formula (23). Total carbohydrate and fat oxidation were calculated using stoichiometric equations (24).

\section{Blood analysis}

Blood for determination of plasma free fatty acids (FFA) was collected in tubes containing $30 \mu l 0.2 \mathrm{M}$ EDTA. Blood was immediately centrifuged at high speed and plasma was transferred to Eppendorf tubes. Plasma was rapidly frozen in liquid nitrogen and stored at $-20^{\circ} \mathrm{C}$ until further analysis. Plasma FFA concentrations were measured using the Wako NEFA $\mathrm{C}$ kit (Wako chemicals, Neuss, Germany).

\section{Quantiation of UCP3 $m \mathrm{RNA}$}

Total RNA was extracted from skeletal muscle biopsies using Trizol reagent (Invitrogen, Breda, The Netherlands). First-strand cDNAs were first synthesised from $1 \mu \mathrm{g}$ of total RNA in the presence of 100 units of Superscript Il (Invitrogen, Eragny, France) using both random hexamers and oligo (dT) primers (Promega, Charbonnières, France). Real-time PCR was performed using a LightCycler (Roche Diagnostics, Meylan, France) in a final volume of $20 \mu \mathrm{l}$ containing $5 \mu \mathrm{l}$ of a 100 fold dilution of the RT reaction and $15 \mu \mathrm{l}$ of reaction buffer from the FastStart DNA Master SYBR Green kit (Roche Diagnostics) with $3 \mathrm{mM}$ of $\mathrm{MgCl}_{2}$ and the specific forward (5'-ATGGACGCCTACAGAACCAT-3) and reverse $\left(5^{\circ}-\mathrm{CTGG}\right.$ GCCACCATCTTTATCA-3') UCP3 primers (Sigma-Genosys, Cambridgeshire, UK). After amplification, a melting curve analysis was performed to verify the 
specificity of the reaction. For quantification, a standard curve was systematically generated with if different amounts (150 to 30,000 molecules/tube) of human UCP3 cDNA cloned in the pGEM plasmid (Promega). To contect for possible variations in the efficiency of the reverse transcription, a reference gene (cyclophilin) was simultaneously measured using the specific forward (5'-GCCAT GGAGCGCTTTGG-3') and reverse (5'-CCACAGTCACGAATGGTGATC-3') cyclophilin primers. The levels of UCP3 mRNA were normalised to cyclophilin mRNA expression used as house-keeping marker and values were expressed as the ratio of UCP3 and cyclophilin. The analysis was performed using the LightCycler softwate (Roche Diagnostics).

\section{Statistical analysis}

All values are expressed as mean \pm SEM. Changes in energy expenditure, plasma free fatty acids, fat oxidation and glucose oxidation were calculated as total area under the curve (AUC) minus baseline values. Differences between conditions were evaluated by analysis of vatiance (One-way ANOVA). When significant differences wete found, a Bonferroni adjusted post hoc test was used to determine the exact location of the difference. Pre- and post-experimental differences within groups were analysed pair-wise by Student's t-tests. Outcomes were regarded as statistically significant if $p<0.05$.

\section{Results}

\section{Energy expenditure and substrate oxidation}

Baseline energy expenditure was similar in all three conditions $(5.51 \pm 0.30,5.24 \pm$ 0.35 and $4.97 \pm 0.28 \mathrm{~kJ} / \mathrm{min}$ in DOB, SAL and SAL $+\mathrm{ACI}$ respectively, NS). Upon $\beta$-adrenergic stimulation, energy expenditure increased and remained stable during the entire 3h-infusion period (fig. 3.1a). Dobutamine (DOB) infusion resulted in a $0.58 \pm 0.2 \mathrm{~kJ} / \mathrm{min}(p<0.05)$ increase in energy expenditure while the salbutamol (SAL) and salbutamol + acipimox (SAL $+\mathrm{ACI})$ condition showed a $0.72 \pm 0.12$ $(\phi<0.001)$ and $0.62 \pm 0.12(\beta<0.001) \mathrm{kJ} / \mathrm{min}$ increase respectively. No significant difference existed between conditions regarding the increase in energy expenditure (fig. 3.1b). 
Figure 3.22 displays the changes in respiratory exchange ratio during the $\beta$ adrenergic stimulation. From the respiratory exchange ratio, fat and glucose oxidation were calculated (fig. $3 \mathrm{~b}$ and c).

At baseline, fat oxidation was similar between conditions $(81.5 \pm 5.7,75.5 \pm 10.8$ and $63.7 \pm 9.2 \mathrm{mg} / \mathrm{min}$ in $\mathrm{DOB}, \mathrm{SAL}$ and $\mathrm{SAL}+\mathrm{ACI}$ respectively, NS). Administration of dobutamine or salbutamol significantly increased the oxidation of fatty acids by $38.0 \pm 5.9$ and $14.3 \pm 5.5 \mathrm{mg} / \mathrm{min}$ respectively $(\phi<0.05)$. The increase in fat oxidation after salbutamol administration was completely absent when acipimox was co-administered $(-1.0 \pm 6.8 \mathrm{mg} / \mathrm{min}$; NS). The increase in fat oxidation was significantly higher in the DOB condition compared to both SAL and $\mathrm{SAL}+\mathrm{ACI}(p<0.005)$.

Glucose oxidation did not show statistically significant differences between conditions at baseline $(147.9 \pm 12.7,146.2 \pm 23.7$ and $158.5 \pm 13.9 \mathrm{mg} / \mathrm{min}$ in $\mathrm{DOB}, \mathrm{SAL}$ and SAL+ACI respectively, NS). Glucose oxidation significantly decreased by $58.5 \pm 13.4 \mathrm{mg} / \mathrm{min}(p<0.005)$ upon dobutamine administration, while no change was detected during salbutamol infusion $(+10.3 \pm 11.8 \mathrm{mg} / \mathrm{min}$, NS). However, addition of acipimox to salbutamol significantly increased glucose oxidation by $42.5 \pm 17.5 \mathrm{mg} / \mathrm{min}(p<0.05)$.
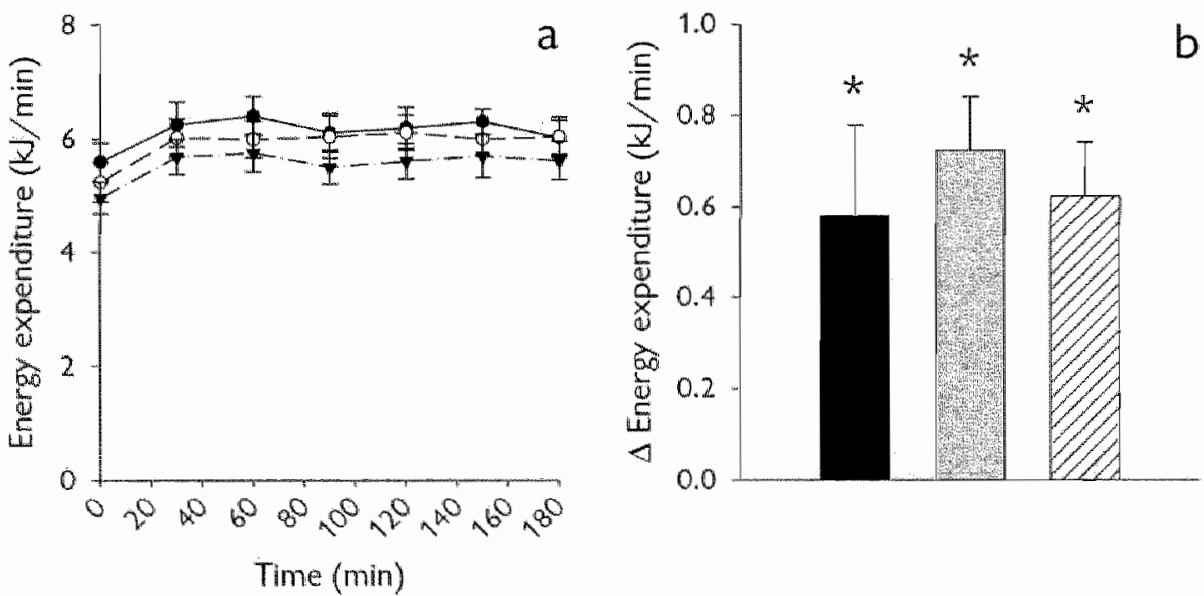

Figure 3.1 a) Energy expenditure during 3 hours of $\beta$-adrenergic stimulation. Closed circles, DOB; open circles, SAL: triangles SAL+ACI. b) Changes in energy expenditure calculated as total area under the curve of energy expenditure vs. time (panel a) minus baseline. Black bar, DOB; grey bar. SAL; hatched bar, $S A L+A C l$ Values are mean 1 SEM. * $p<0.05$ compared to baseline. 


\section{Bbod and muscle substrutes.}

Baseline plasma free fatty acid concentrations were significantly lower after administration of acipimox compared to both the dobutamine and salbutamol condition $(67.0 \pm 13.3$ vs. $443.7 \pm 72.2$ and $341.3 \pm 68.1 \mu \mathrm{mol} / \mathrm{L}$ in $S A L+A C I$ vs. $\mathrm{DOB}$ and $\mathrm{SAL}$ respectively, $p<0.001)$. Upon $\beta$-adrenergic stimulation, free fatty acid levels significantly rose in all conditions $(209 \pm 72,196 \pm 37$ and $57 \pm 19$ $\mu \mathrm{mol} / \mathrm{L}$ in $\mathrm{DOB}, \mathrm{SAL}$ and $\mathrm{SAL}+\mathrm{ACI}$ respectively, $p<0.05$ ), although the increase in plasma free fatty acids in the $\mathrm{SAL}+\mathrm{ACI}$ condition was approximately 4 -fold lower than during both dobutamine and salbutamol infusion (fig. 3.3a).
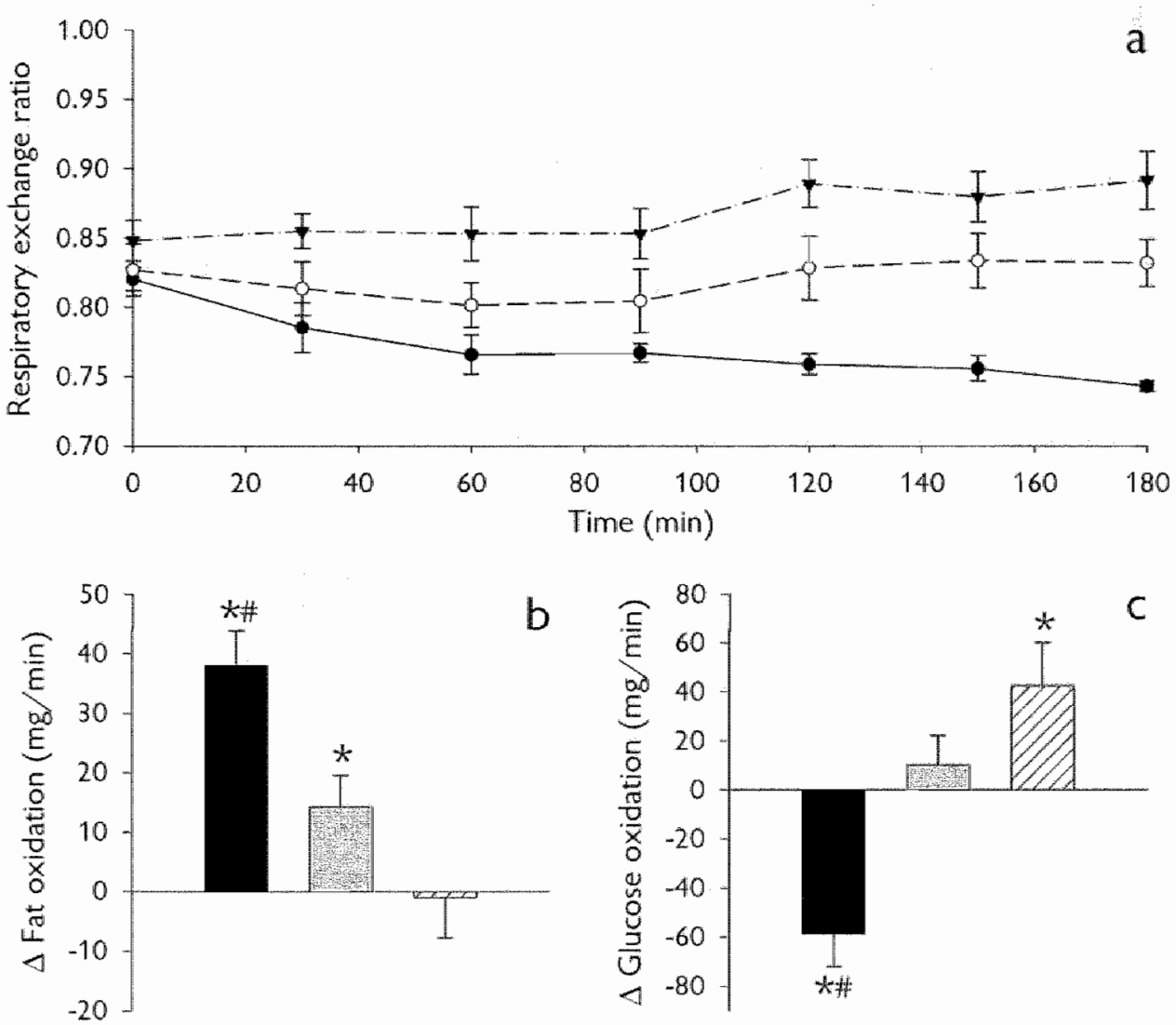

Figure 3.2 a) Respiratory exchange ratio during $\beta$-adrenergic stimulation. Closed circles, DOB; open circles, SAL; triangles SAL $+A C l$. Lower panels represent changes in substrate oxidation calculated as area under the curve of b) fat and c) glucose oxidation vs. time minus baseline. Black bars, DOB: grey bars, SAL; hatched bars, SAL+ACI. Values are mean \pm SEM. * $p<0.05$ compared to baseline: " $p<0.05$ compared to SAL and SAL-4ACI. 
Basal UCP3 mRNA lewels were not different between the three conditions (DOB: $43 \pm 12 ;$ SAL: $52 \pm 14, \mathrm{SAL}+\mathrm{ACI}: 79 \pm 12$ arbitrary units, NS). Simultaneous administration of salbutamol and acipimox significantly lowered UCP3 mRNA levels by $38 \pm 13 \% \quad(p<0,05)$. However, neither dobutamine nor salbutamol administration alone altered UCP3 expression significantly (fig. 3.3b).

\section{Discussion}

In rodents, uncoupling protein 1 (UCP1), located in the inner mitochondrial membranes of BAT, plays an important role in sympathetic stimulation-induced adaptive thermogenesis (25). In contrast, in humans, skeletal muscle is responsible for a major part of $\beta$-adrenergic-induced thermogenesis $(6,7)$. Uncoupling protein 3 (UCP3), primarily localised in skeletal muscle $(9,10)$, is a candidate to explain sympathetic stimulation-induced adaptive thermogenesis but possible regulation of UCP3 expression by the sympathetic nervous system has not yet been studied in

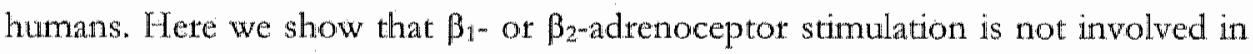
the regulation of UCP3 mRNA expression.

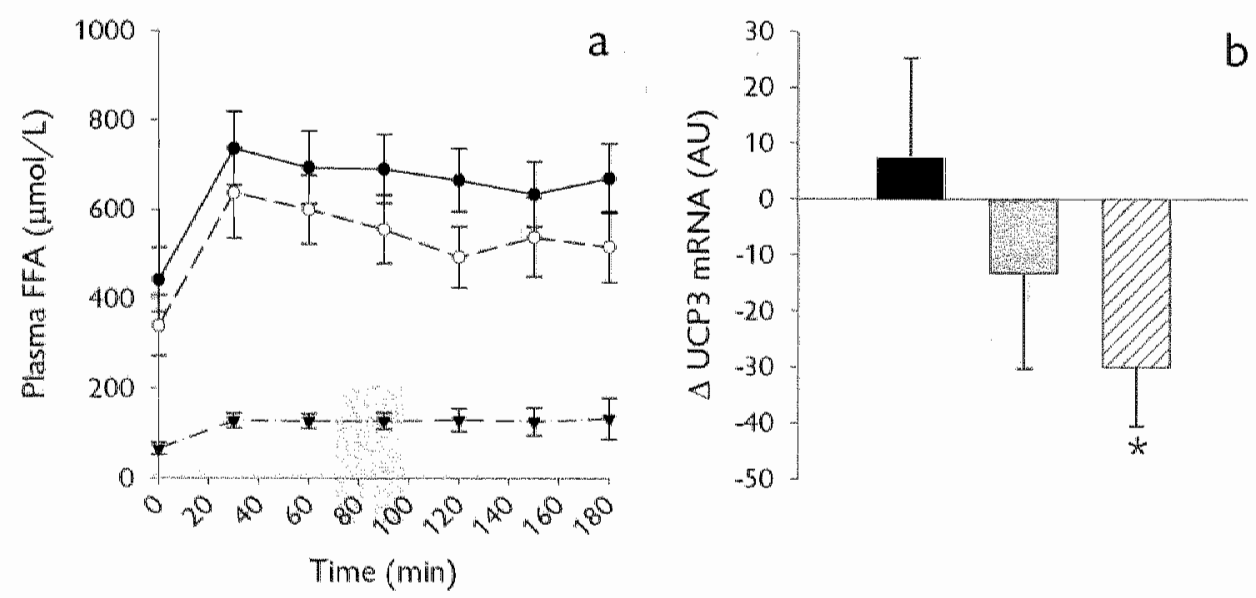

Figure 3.3 a) Plasma free fatty acid levels during 3 -adrenergic stimulation. Closed circles, DOB; open circles, SAL: triangles SAL $+A C l$ b) Changes in UCP3 mRNA levels after B-adrenergic stimulation calculated as post-experimental UCP3 mRNA minus pre-experimental levels. Black bars, DOB; grey bars, SAL; hatched Bars. SAL. ACI. Values are mean 4 SEM. * $p<0.05$ compared to baseline. 
In the present study, energy expenditure significantly increased upon both $\beta_{1^{-}}$ (dobutamine) and $\beta_{2}$-adrenergic stimulation (salbutamol). It was previously shown that the increase in energy expenditure upon $\beta_{1}$-adrenergic sumulation was an indirect effect, fuelled by plasma free fatty acids released from adipose tissue (8). However, in contrast to $\beta_{1}$-adrenoceptors, $\beta_{2}$-adrenoceptors are primatily located in skeletal muscle and therefore we hypothesised that the $\beta_{2}$-adrenergic-induced increase in energy expenditure would be directly fuelled by skeletal muscle. To this purpose, we examined the effect of $\beta_{2}$-adrenergic stimulation on energy expenditure with and without acipimox to suppress lipolysis. Acipimox indeed effectively suppressed lipolysis, but did not affect the $\beta_{2}$-adrenoceptor-mediated increase in energy expenditure. Thus, the $\beta_{2}$-adrenergic-induced increase in energy expenditure is directly fuelled by skeletal muscle energy sources and is not: mediated by increased plasma free fatty acid levels.

The increase in energy expenditure upon $\beta_{1}$-adrenoceptor stimulation has been shown to be covered by an increased fat oxidation and again this increase is reduced when lipolysis was inhibited during $\beta_{t}$-adrenergic stimulation with dobutamine (8). Also in the present study, dobutamine $\left(\beta_{1}\right)$ as well as salbutamol $\left(\beta_{2}\right)$ administration significantly increased fat oxidation compared to basal levels. However, the increase in fat oxidation was approximately 2.6 -fold higher upon $\beta_{1}$ adrenergic stimulation by dobutamine than upon $\beta_{2}$-adrenergic stimulation by salbutamol, while the rise in energy expenditure and plasma FFA were comparable between the two conditions, indicating that part of the increase in energy expenditure upon $\beta_{2}$-adrenergic stimulation was due to increased glucose oxidation. Schiffelers et al. (5) also studied the increase in fat oxidation after selective stimulation of $\beta_{i}$-adrenoceptor by dobutamine as well as after selective $\beta_{z^{-}}$ adrenoceptor stimulation by salbutamol. In contradiction to our results, this study revealed that when energy expenditure was equally increased with certain concentrations of dobutamine and salbutamol, the relative contribution of fatt oxidation to total energy expenditure was not different between $\beta_{1}$, and $\beta_{2-}$ adrenergic stimulation (5). However, in the study by Schiffelers et al. (5), subjects received consecutive infusions of increasing concentrations dobutamine and salbutamol, each dose for $30 \mathrm{~min}$, whereas in the present study, a fixed concentration was administered continuously for 3 hours. In the present study, administration of acipimox, to block lipolysis, completely abolished the $\beta_{2}$-induced increase in fat oxidation, without affecting energy expenditure, again indicating that $\beta_{z}$-adrenergic stimulation directly influences glucose oxidation. This suggestion is underscored by the observation that the increase in fat oxidation was less 
pronounced during $\beta_{2}$-adrenergic stimulation compared to $\beta_{1}$-adrenergic stimulation; despite a similar increase in plasma FFA and thermogenesis. Moreover, when plasma free fatty acids were reduced by inhibiting lipolysis with acipimox during $\beta_{2}$-adrenergic stimulation, glucose oxidation significantly increased by $\sim 27 \%$, completely covering the increase in energy expenditure. Taken together, these data indicate that next to a small increase in fat oxidation driven by increased lipolysis, $\beta_{2}$-adrenergic stimulation also directly increases glucose oxidation. Previous studies have shown that non-selective blockade of all $\beta$-adrenoceptors impeded enhancement of exercise-induced glycogenolysis in human skeletal muscle $(26,27)$. Chruscinski et al. (28) selectively disrupted the $\beta_{2}$-adrenoceptor gene in mice and observed a lower respiratory exchange ratio (RER) duting exercise in the knockout mice, suggesting that they may use a greater ratio of fat to carbohydrate than wildtype mice. Since during exercise, glycogen provides a major part of the energy required, this observation is consistent with a tole for the $\beta_{2-}$ adrenoceptor in the mobilisation of glycogen (28). Specific $\beta_{1}$-adrenergic effects on glycogenolysis in skeletal muscle are unknown but seem unlikely since skeletal muscle lacks $\beta_{1}$-adrenoceptors (29).

Independent of the substrate being oxidised, the mechanism for the increased thermogenesis in skeletal muscle upon $\beta$-adrenergic stimulation is unknown. Since UCP3 is capable of uncoupling $(11,12)$ and is primarily localised in skeletal muscle $(9,10)$, this protein is a potential mediator in this process. In the present study, we examined whether UCP3 mRNA expression is under regulation of the sympathetic nervous system. We found that administration of dobutamine or salbutamol did not up-regulate UCP3 mRNA expression in the current study. Therefore, a stimulatory effect of $\beta_{1}$ - or $\beta_{2}$-adrenergic activity on skeletal muscle UCP3 mRNA expression cannot be concluded from the present study. Even more, UCP3 mRNA levels were significantly decreased when acipimox was co-administered with salbutamol, further indicating that $\beta$-adrenergic stimulation in humans does not up-regulate UCP3 expression. However, low FFA levels seem to be responsible for the observed down-regulation of UCP3 mRNA upon simultaneous administration of salbutamol and acipimox, further providing evidence for an important role of FA in the regulation of UCP3. It has already been shown that high levels of plasma free fatty acids are able to up-regulate skeletal muscle UCP3 $(17,20,21)$. Khalfallah et al. (20) increased plasma FFA concentrations in humans up to a final concentration of $989 \mu \mathrm{mol} / \mathrm{L}$ during triacylglycerol infusion and found a significant increase in UCP3 mRNA. Furthermore, we showed that acute exercise, a condition of increased energy expenditure, fat oxidation and plasma free 
fatty acid levels, up-regulated skeletal muscle UCP3 mRNA (30). In addition, glucose ingestion during and after exercise, abolished the commonly observed increase in plasma FFA levels and/or faty acid oxidation, and prevented the up regulation of UCP3 after acute exercise indicating that the observed increase in UCP3 mRNA levels appeared to be an effect of elevated plasma FFA levels and/or increased fatty acid oxidation tather than an effect of increased energy expenditure (30). The lack of increase in UCP3 mRNA levels upon $\beta_{1}$ - and $\beta_{2}-$ adrenergic stimulation in the current study, despite increased levels of plasma free fatty acids, might be explained by the fact that plasma FFA Levels only reached $50 \%$ of the values obtained by Khalfallah et al. (20) and our own lab (30). The present study is the first to show a significant down-regulation of skeletal muscle UCP3 mRNA levels upon low plasma FFA concentrations in humans, despite an increase in energy expenditure. This finding further favours a role for fatty acids in the regulation of UCP3 mRNA expression, and suggests that the physiological function of UCP3 more likely is related to fatty acid metabolism rather than to the regulation of energy expenditure. From the present study however, we cannot exclude the possibility that UCP3 protein content or UCP3 activity is altered upon $\beta$-adrenergic stimulation.

We recently suggested that UCP3 might act as a mitochondrial fatty acid anion exporter, to prevent accumulation of non-metabolisable and potentially toxic fatty acid anions inside the mitochondrial matrix (14), and the acipimox-induced downregulation of UCP3 is compatible with this hypothesis.

In conclusion, 3-hour infusion of both dobutamine $\left(\beta_{1}\right)$ and salbutamol $\left(\beta_{2}\right)$ increased energy expenditure, fat oxidation and plasma free fatry acid levels. In

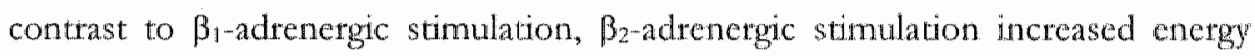
expenditure independent from plasma FFA levels. Furthermore, $\beta_{2}$-adrenergic activity stimulated ghcose oxidation, most likely due to increased glycogenolysis.

No evidence was found for a regulatory role for $\beta_{1-}$ or $\beta_{2}$ adrencrgic activity on skeletal muscle UCP3 expression in this study, since neither salbutamol nor dobutamine affected UCP3 expression. However, significant down-regulation of skeletal muscle UCP3 mRNA levels was observed upon low plasma FFA concentrations in humans, despite an increase in energy expenditure. Therefore changes in UCP3 mRNA expression seem to be related to fatty acid metabolism, rather than to energy metabolism. However, future studies are needed to reveal whether mitochondrial uncoupling, for example by increasing UCP3 activity, is involved in $\beta$-adrenergic-induced adaptive thermogenesis. 


\section{Acknowledgements}

Dr. P. Schrawwen and M. Sc. J. Hoeks were supported by grants from the Netherlands Organisation for Scientific Research (NWO).

\section{References}

1. Heaton GM, Wagenvoord IRI, Kemp A, Jr. Nicholls DG. Brown-adiposemsisue miochondria: photontrinity labelling of the regulatoty site of energy disipation. Wur J Biochen $1978,82(2), 515-21$.

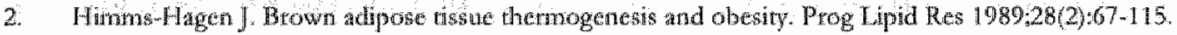

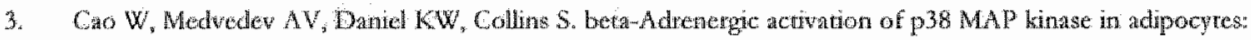
cAMP inducton of the uncoupling protein 1 (UCP1) gene requires $\mathrm{p} 38$ MAl kinase $J$ Biol Chem $2001 ; 276(29) \div 27077-82$

4. Schiffeles SI, wan Harmeten V], de Graw HA, Saris WH, van Bab MA. Dobutanine as selectre beta(1) adrenoceptor agonist in in wo studies on human themogenesis and lipid utilization. I Appl Physiol $1999,87(3): 977-81$

5. Schiffelers SI, Saris WH, Boomsma F, van Bask MA. beta(1)- and beta(2)-Adrenodeptor-mediated themogenesis and lipid utilizaton in obese and lean men. I Clin Endocrinol Metab 2001,86(5)2\$91-9.

6. Simonsen L, Stallknecht B, Bulon ]. Contribution of skeletal musche and adprose visgue to adrenalineinduced thermogenesis in man. Itr J Obes Relat Metab Disond 1093\%17 Suppl 3.S47.51: discussion S68.

7. Simonsen $\mathrm{L}$, Bullow $\mathrm{J}$, Madsen J, Christensen NJ. Themogenic response to epinephrine in the foream and abdominal subcutaneous adipose tissue. Am J Physiol 1992,263(5 Pr 1):E850-5.

8. Sehiffels SI, Butwer EM, Saris WH, wan Bak MA Inhibition of lipolysis reduces beta -adrenoceptor mediared themogenesis in man. Metabolism 1998;47(12):1462-7.

9. Boss O, Samec S, Paoloni-Gincobino A, Rossiem C, Dulloo A, Seydoux J, et al. Uncoupling protein-3: a new

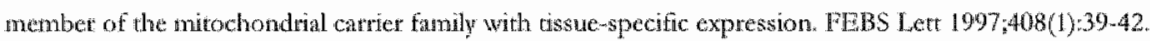

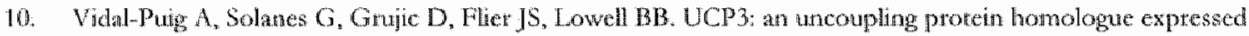
preferentially and aldudandly in skeletal muscle and brown adpose tissue. Biochem Biophys lRes Commun $199,235(1), 79-82$

11. Goug DW, He Y, Katas M, Reiman M. Uncoupling proten-3 is a mediatot of themogeness regulated by dhyroid howmone, beia 3-adrenegic agonists, and lepin. J Biol Chem 1997,272(39):24120-32.

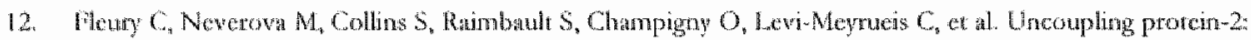
a nowel gene linked ro obesiry and hyperinalinemia Nat Gener 1997;15(3):269-72

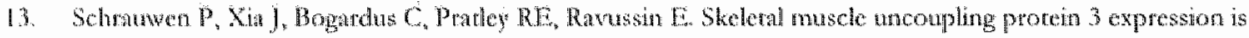

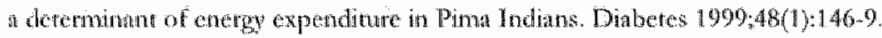

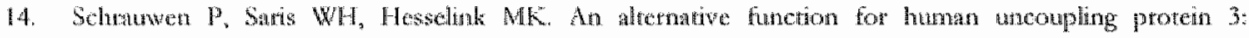

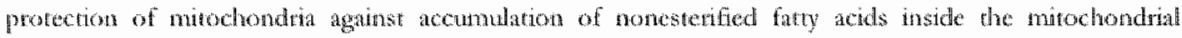
matrix. Fasclo ) $2001 ; 15(13): 2497-502$

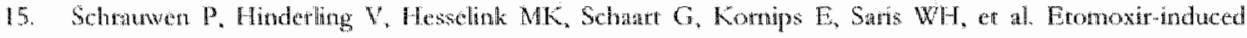
increase in UCPS supports a role of uncoupling proten 3 as a mitochondrial fatty acid anion exporter [uscob $2002: 16(12): 1688-90$.

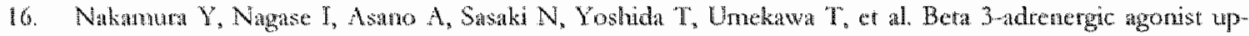
regulates ancoupling proteins 2 and 3 in skeletal muscle of the mouse. I Vet Med So $2001,63(3) ; 309-14$ 


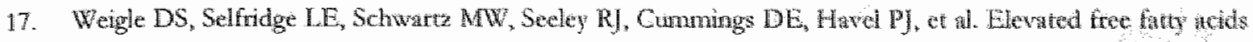

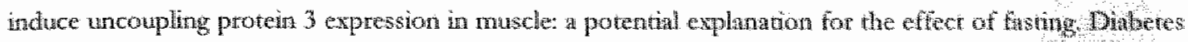
$1998 ; 47(2) \div 298-302$

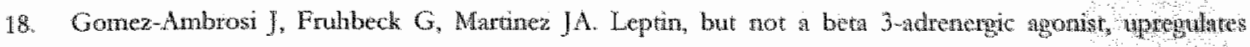

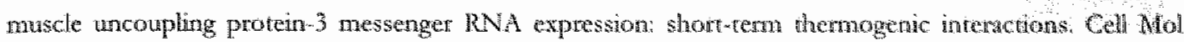
Lifte Sci 1909 ; $55(6-7), 992-7$.

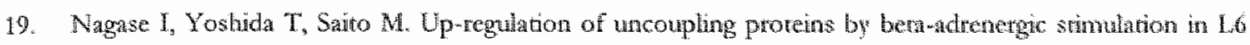
nyyoubes. FEBS Lett 2001; $494(3) 175-80$.

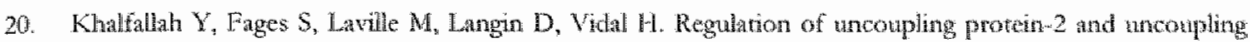
protein-3 mRNA expression during lipad infasion in human skeletal muscle nad subcuiraneous adipose rissue Diabetes $2000,49(1): 25-31$.

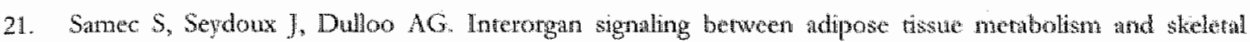

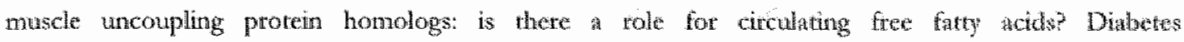
$1998 ; 47(11): 1693-8$.

22. Siri W. The gross composition of the body. Adw Biol Med Physiol 1956 4:239-80.

23. Weit. New methods for calculating metabolic rate with spectat reference to protein metwolism $j$ Plysiol $1049,109: 1 \%$.

24. Peronnet F, Massicotte D. Table of nopprotein tespiratory quotient: an update. Car I Spont Sci $199,16,16) \div 23-9$

25. Himms-Hagen ]. Brown adipose tissue themogenesis: interdisciplinary studies, laseb y 1900,4(1):2890-8.

26. Clenoux J, Leenen FH. Effects of beta-blockade on muscle metabolistu during prolonged excreise. $A$ shot review. Am ] Hypertens $1988 ; 1(3 \mathrm{D}$. 3):2005-2945.

27. Opie LI. Effect of beta-adrenergic blockade on biochemical and metabolic response to exercise. An J Catrcliol $1985555(10) ; 95 \mathrm{D}-100 \mathrm{D}$.

28. Chruscinsti AJ, Rolarer DK, Schauble E, Desa KKH, Bernstein D, Kobilka BK. Margeted distuption of the beta2 allenergic receptor gene. I Biol Chem 1999,274(24):16694-700.

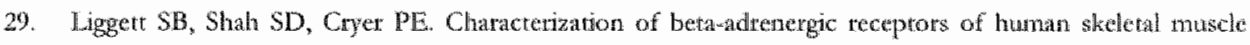

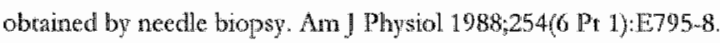

30. Schrawera P. Hesselink MK, Vaaties I, Konnps E, Saris WH, Giacobino JP, et al. Elhect of acute excreise on uncoupling protein 3 is a far roctabolismanediated effect. Am ] Physiol Endoctinol Merab $2002 ; 282(1): 1: 11-7$. 



\section{Ain}

\section{Uncoupling protein 3 as a mitochondrial fatty acid anion exporter}

Patrick Schrauwen, Joris Hoeks, Gert Schaart, Esther Kornips, Bert Binas, Ger J. van der Vusse, Marc van Bilsen, Joost J.F.P. Luiken, Susan L.M. Coort, Jan F.C. Glatz, Wim H.M. Saris and Matthijs K.C. Hesselink

Departments of Human Biology and Movement Sciences, Nutrition and Toxicology Research Institute Maastricht (NUTRIM), Maastricht University, Maastricht. The Netherlands.

Department of Physiology, Cardiovascular Research Institute Maastricht (CARIM), Maastricht University, Maastricht, The Netherlands

Department of Hypertension Research, Max Delbruck Center for Molecular Medicine Berlin-Buch, Germany

FASEB J. 2003 Dec: $17(15): 22724$ 


\section{Abstract}

In contrast to UCP1, the primary function of UCP3 is not the dissipation of energy. Rather, several lines of evidence suggest that UCP3 is related to cellular long chain fatty acid homeostasis. If long chain fatty acids enter the mitochondrial matrix in their non-esterified form, they cannot be metabolised and may exert deleterious effects. To test the feasibility that UCP3 exports fatty acid anions, we systematically interfered at distinct steps in the fatty acid metabolism pathway, thereby creating conditions in which the entry of (non-esterified) fatty acids into the mitochondrial matrix is enhanced. First, reducing the cellular fatty acid binding capacity, known to increase cytosolic concentrations of non-esterified fatty acids, up-regulated UCP3 5.3-fold. Second, inhibition of mitochondrial entry of esterified long chain fatty acids up-regulated UCP3 by 1.9 -fold. Thirdly, high-fat diets, to increase mitochondrial supply of non-esterified long chain fatty acids exceeding oxidative capacity; up-regulated UCP3 2-fold. However, feeding a similar amount of medium chain fatty acids, which can be oxidised inside the mitochondrial matrix and therefore do not need to be exported from the matrix, did not affect UCP3 protein levels. These data are compatible with a physiological function of UCP3 in facilitating outward transport of long chain fatty acid anions, which cannot be oxidised, from the mitochondrial matrix. 


\section{Introduction}

In contrast to the brown adipose tissue-specific UCP1, there is ample evidence that the physiological function of UCP3 is not in energy dissipation. For example, fasting, an energy preserving condition, rapidly up-regulates UCP3 (1). We have recently demonstrated in humans that a diet-induced up-regulation of UCP3 did not affect mitochondrial coupling, suggesting that the primary function of UCP3 is not mitochondrial uncoupling (2). Rather, several lines of evidence suggest that UCP3 is related to cellular fatty acid metabolism. Thus, aberrations in whole-body fat oxidation were observed in humans with an exon 6 splice donor mutation in UCP3 (3), as well as in UCP3 knockout mice (4). Furthermore, in skeletal muscle UCP3 is rapidly up-regulated during fasting (1), acute exercise $(5,6)$ and high dietary fat intake $(7,8)$, all situations in which fat metabolism is affected. In addition, UCP3 protein content declines in situations in which fat oxidative capacity is improved, like after endurance training $(9,10)$, and after weight reduction $(11,12)$, and UCP3 has lowest expression in type 1 muscle fibres, which are characterised by a high fat oxidative capacity $(13,14)$.

This pattern of regulation of UCP3 can consistently be explained by considering the balance between fatty acid delivery to mitochondria and the capacity to oxidise fatty acids. In situations chatacterised by a positive balance (i.e. fatty acid delivery exceeds oxidative capacity), such as fasting, high fat intake, acute exercise and in type $2 \mathrm{~b}$ fibres, UCP3 levels are high and/or up-regulated. On the other hand, in situations characterised by a high fat oxidative capacity leading to a negative or zero balance (i.e. fatty acid delivery is lower than of ballances oxidative capacity), such as training, weight reduction and type $\mathbb{1}$ muscle fibres, UCP3 levels arc low and/or down-regulated. Based on these findings, we have postulated the hypothesis that UCP3 might be involved in the export of non-esterified fatty acids from the mitochondrial matrix (15). Thus, when fatty acid delivery exceeds the muscle's oxidative capacity, fatty acids will accumulate inside the myocyte. To be diverted to $\beta$-oxidation, the majority of the long chain fatty acids in the cytoplasm are activated by conversion to their fatty acyl-COA esters by the enzyme long chain acyl-CoA synthetase (ACS). Subsequently, these long chain fatty acyl-CoA esters are transported into the mitochondria via the carnitine shutte system (CPT1 and CPT2). Only as CoA esters, fatty acids are able to undergo $\beta$-oxidation, and the esterification of fatry acids and subsequent transport across the inner membrane is 
rate-limiting in the oxidation of long chain fatty acids. The surplus of long chain farty acids that accumulate inside the myocyte may enter the mitochondria by a socalled flip-flop mechanism (16). Due to the higher pH inside the mitochondrial matrix, part of these long chain fatty acids will be deprotonated at the matrix side, and in this way, fatty acid anions can reach the mitochondrial matrix side. It is important to note that, once at the matrix side, these long chain fatty acid anions can neither be diverted to $\beta$-oxidation (due to lack of ACS inside the matrix) nor cross the inner mitochondrial membrane (17), and are thus trapped inside the mitochondria. Here, they can have deleterious effects on mitochondrial function, for example due to their amphiphilic nature and proneness to peroxidation. Here, UCP3 could become involved in facilitating outwatd transport of these fatty acid anions, since it has been shown that UCP3 is able to transport fatty acid anions $(17,18)$.

To test the feasibility that UCP3 functions to export fatty acid anions away from the matrix, we systematically interfered at distinct steps in the pathway of fatty acid metabolism, theteby creating conditions in which the entry of (non-esterified) fatty acids into the mitochondrial matrix is enhanced, and examined UCP3 protein content in these situations.

\section{Methods}

\section{Animals}

All studies were approved by the Instirurional Animal Care and Use Committee of the Maastricht University and complied with the principles of laboratory animal care. Animals were housed individually on a 12:12h light-dark cycle (light from 7:00 am to $7: 00 \mathrm{pm})$, at $21-22^{\circ} \mathrm{C}$ and allowed unlimited access to standard chow dict.

To examine the effect of the absence of H-FABP on UCP3 protein content (experiment 1), adult (10-12 weeks of age) mice lacking H-FABP $(n=5)$ and their wildtype littermates ( $\mathrm{n}=7$ ) were used, as previously described (19). Under general anaesthesia (1.5-2.0\% halothane in $\mathrm{O}_{2}$ and $\mathrm{N}_{2} \mathrm{O}\left(3: 1,4.01 \mathrm{~min}^{-1}\right)$, medial gastrocnemius muscles were rapidly excised unilaterally and freeze-clamped within 7 seconds after cutting the nerve and blood vessels.

The effect of etomoxir administration on UCP3 protein content was studied in 12 male Jewis rats, weighing $210-220 \mathrm{~g}$ (experiment 2). Rats were randomly divided into etomoxir and control group. The former group was treated with etomoxir 
dissolved in $0.9 \% \mathrm{NaCl}(20 \mathrm{mg} / \mathrm{kg}$ body mass) intraperitoneally for 8 days. The final injection was given $24 \mathrm{~h}$ before the experiment. Animals were anesthetised with an intraperitoneal injection of nembutal and left hindlimb muscle was removed.

The effect of high-fat diets on UCP3 protein content was studied in thirty male, ten week-old Wistar rats (experiment 3). Rats were randomly divided into three different groups $(\mathrm{n}=10)$, receiving either low-fat control (low-fat), high-fat medium chain triacylglycerol (high-fat MCT) or high-fat long chain tracylglycerol (high-fat LCD ) diets. Rats were fed ad libitum and had free access to tap water during the experimental period. Food intakes were recorded daily at $8: 30$ am and body weight was measured twice a day at $8: 30$ am and $5: 30$ pm. After a two week diet intervention period, blood was sampled and medial gastrocnemius muscle was rapidly excised unilaterally and freeze-clamped within 7 seconds after curting the nerve and blood vessels under general anaesthesia. Rats were deprived from food approximately 6 hours prior to tissue sampling.

\section{Diets}

The H-FABP mice and the rats in the etomoxir experiment had ad libitum access to standard lab chow (Hope Farms, Woerden, The Netherlands).

In experiment 3, rats were given the following diets: low-fat (LF) diets consisted of $7 \mathrm{EN} \%$ fat (of which approx. $79 \% \mathrm{C} 16: 0,6 \% \mathrm{C} 18: 0$ and $12 \% \mathrm{C} 18: 1$ ) and $74 \mathrm{EN} \%$ carbohydrate. High-fat (HF) LCT diets consisted of $46 \mathrm{EN} \%$ fat (of which approx. $79 \% \mathrm{C} 16: 0,6 \% \mathrm{C} 18: 0$ and $12 \% \mathrm{C} 18: 1)$ and $35 \mathrm{EN} \%$ carbohydrates. High-fat MCT diets consisted of $46 \mathrm{EN} \%$ fat (of which approx. $60 \% \mathrm{C} 80$ and $40 \% \mathrm{C} 10.0$ ) and $35 \mathrm{EN} \%$ carbohydrates. Protein content was constant in all diets (19 EN\%). All diets were purchased from Hope Farms (Woerden, The Netherlands).

\section{CPT7 activity}

Muscle $(50 \mathrm{mg}$ ) was homogenised in $1 \mathrm{ml}$ of "TES-buffer supplemented with PMSF-DMSO, and homogenised with an Ultra 'Turrax homogeniser. The resulting muscle homogenate was further disintegrated in 4 cycles ( $5 \mathrm{sec}$ on and $15 \mathrm{sec}$ off) with an amplitude of $10-12$ using an ultrasonic disintegrator. CPT1 activity was assayed by the CPT-forward measurement (20). It measures the palmitoylcarnitine formation from palmitoyl-CoA and an ATP regenerating system. The reaction mixture contained $10 \mu \mathrm{M}$ palmitoyl-CoA, $250 \mu \mathrm{M} \mathrm{L} / 3 \mathrm{H}]$ carnitine, $80 \mathrm{mM}$ 'TrisHCl, $2 \mathrm{mM}$ ATP, $2.5 \mathrm{mM} \mathrm{MgCl}, 0.25 \mathrm{mM}$ Na-palmitate, $36 \mu \mathrm{M}$ BSA, $0.5 \mathrm{mM}$ 
DTA, $1 \mathrm{mM} \mathrm{KCN}, 0.5 \mathrm{mM}$ dithotheitol, $5 \mathrm{mM}$ phosphoenolpytuvate, $2.5 \mathrm{Hg}$ pyruvate hirase, 1 Hg adenylate kinase and 10 ful homogenate. Incubation was carried out at $\mathrm{pH} 7.4$, in a total volume of $0.25 \mathrm{ml}$ for $10 \mathrm{~min}$ at $37^{\circ} \mathrm{C}$. The reaction was started with carnitine and terminated with $1 \mathrm{ml} \mathrm{M} \mathrm{HCl}$. The product palmitoy -13 H canitine was extracted with 1 ml butanol. After 30 seconds of mixing and centrifugation $(3,000 * \mathrm{~g})$ for $5 \mathrm{~min}$, the upper butanol phase was washed with: $2 \mathrm{ml}$ H2O saturated with butanol. After $30 \mathrm{sec}$ mixing and centrifugation $(3,000 \times \mathrm{g})$, tadioactivity was measured in $0.4 \mathrm{ml}$ of the butanol with $10 \mathrm{mll}$ instagel in a liquid sintllation counter.

\section{UCPS protent measurentent}

Muscle samples for UCP3 protein content were homogenised in ice-cold phosphate buffered saline (PBS), containing $1 \mathrm{mM}$ EDTA and $0.4 \mathrm{mM}$ PMSF and subsequently sonicated for $3 \times 10$ s. After sonication, two volumes of each skeletal muscle homogenate and one volume of SDS-sample buffer (21), were boiled for 4 minutes. Thereafter, samples were centrifuged for $5 \mathrm{~min}$ at $10,000 \times \mathrm{g}$. Total protein content of each sample was measured spectrophotometrically (Protein assay, Bio-Rad Laboratories, Hercules, CA, USA) to make sure equal amounts of protein were loaded. Samples were loaded on $13 \%$ polyacrylamide slab gels containing $0.1 \%$ SDS, and electrophoresis was performed using a Mini-Protean 3 Electrophoresis Cell (Bio-Rad Iabotatories), followed by Western blotring using a Mini Trans-Blot Electrophoretic Transfer Cell (Bio-Rad Laboratories). The separated polypeptides were transferted to a nitrocellulose membrane by blotting for 1 h at $100 \mathrm{~V}$ in a cold buffer, containing $25 \mathrm{mM}$ Tris, $192 \mathrm{mM}$ glycine and $20 \%$ methanol.

After protein transfer, nitrocellalose shects were blocked with blocking buffer, containing $5 \%$ non fat dry milk and $0.05 \%$ Tween 20 in PBS, for ar least 20 min. Thereafter, antibody incubation was performed by gentle shaking overnight at room temperature at a dilution of $1: 5,000$ in blocking buffer. We used an affinity purificd rabbit polyclonal antibody against UCP3 (code 1338, kindly provided by IJ Slieker, Elli Lilly). After washing with $0.05 \%$ Tween 20 in PBS, blots were incubated with horseradish peroxidase-conjugated swine anti-rabbit Ig (SWARPO, DAKO, Glostrup, Denmark) fot 60 min at room temperature, diluted 1:10,000 in blocking buffer. Blots were subsequently washed for $90 \mathrm{~min}$ with $0.05 \%$ Tween 20 in PBS, and 10 min in PBS. Chemiluminescence was performed by using a Super Signal West Dura Extended kit (Pierce, Rockford, Ill, USA). Finally, the reaction 
product of each blot was analysed by denstomery using Imagamaster (Phamacia Biotech, Roosendaal, The Netherlands).

\section{Plasna FFA}

Frozen plasma samples were analysed for total free fatty acids (FFA) using the Wako NEFA C test kit (Wako chemicals, Neuss, Germany).

\section{Statistical analysis}

Results are presented as mean \pm SEM. Differences between groups were evaluated by analysis of variance (One-way ANOVA test). When significant differences were found, a Bonfertoni adjusted post hoc test was used to determine the exact lacation of the difference. Outcomes were regarded statistically significant if $p<0.05$.

\section{Results}

\section{Expeniment 1}

UCP3 protein levels in skeletal muscle of $\mathrm{H}-\mathrm{FABP} /$ mice were increased 5.3 -fold compared to their wildtype littermates $(529 \pm 99$ vs. $100 \pm 38$ arbittary units in $\mathrm{H}$ FABP- $-(n=5)$ and wildtype littermates $(n=7)$ respectively, $p<0.05$, fig. 4.1a).

\section{Experiment 2}

Etomoxir significantly decreased CPT1 activity by $58 \%$ in the etomoxir group, indicating effective blockade of mitochondrial uptake of long chain fatty acyl-CoA esters $(8.8 \pm 2.1$ ws. $3.3 \pm 2.2 \mathrm{mU} / \mathrm{g}$ wet mass in control and etomoxir, respectively, $\mathrm{n}=6, p<0.05$ ). In accordance with our hypothesis, we found that UCP3 protein levels were increased 1.9 -fold after etomoxir administration $(100 \pm$ 35 ws. $189 \pm 59$ arbitrary units in control and etomoxir, respectively, $n=6, p<0.05$, fig. 4.1b). 

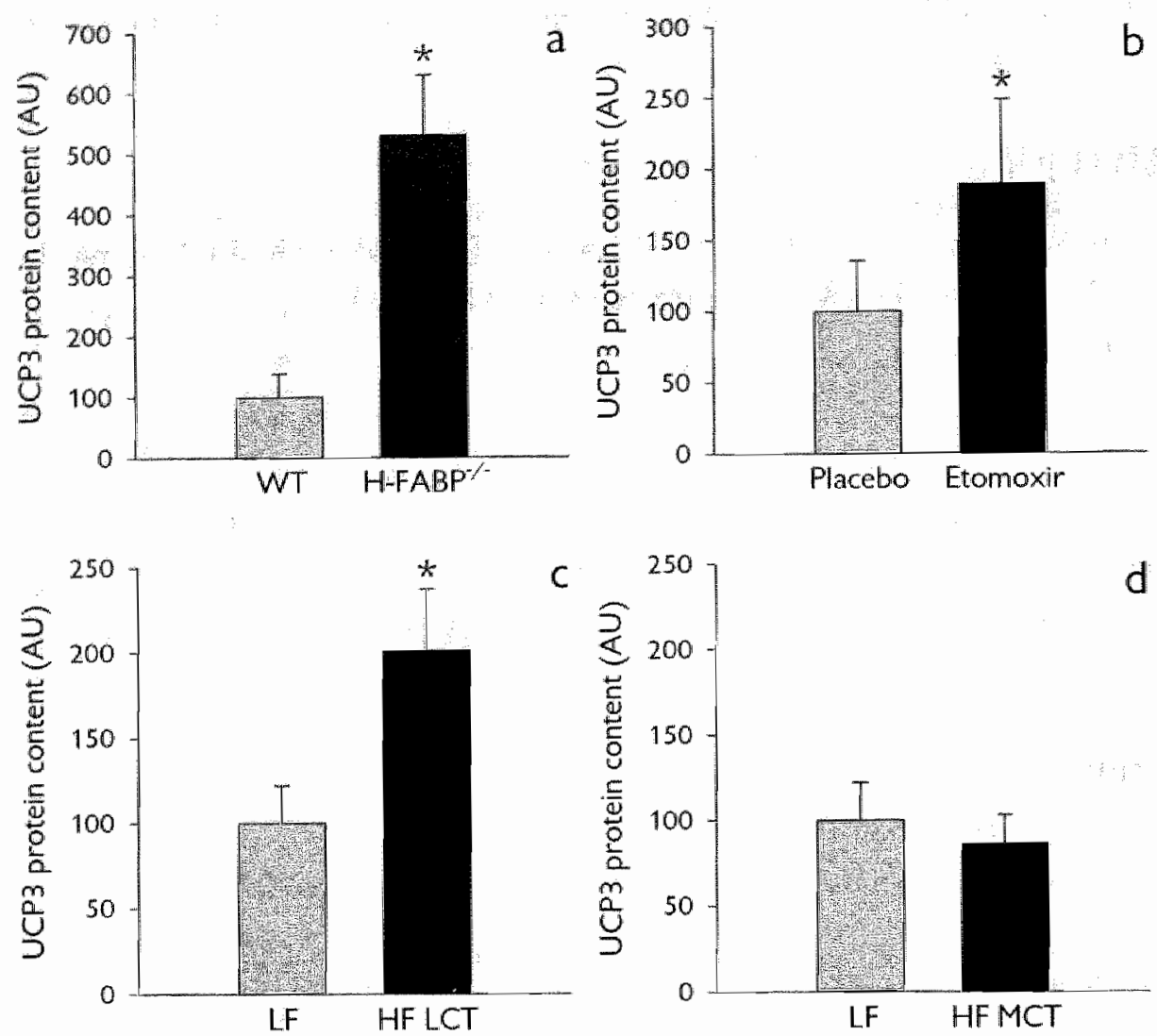

Figure 4.1 The effect of a) ablation of H-FABP b) administration of etomoxir c) feeding of a high-fat (HF) diet rich in long chain triacylglycerols (LCT) and d) feeding of a high-fat diet rich in medium chain triacylglycerols on UCP3 protein content. Control values are nomalised to 100 arbitrary units (AU). Values are mean \pm SEM. $* 0.05$ compared to control. UCP3 is systematically up-regulated when the entry of long chain fatty acids into the mitochondrial matrix is enhanced.

\section{Experiment 3}

Food intake was similar in the three groups $(4.23 \pm 0.08,3.96 \pm 0.12$ and $4.21 \pm$ $0.09 \mathrm{MJ} /$ two weeks in low-fat, high-fat MCT and high-fat LCT respectively, NS). However, body weight increased more pronounced in the high-fat LCT compared to the high-fat MCT and low-fat groups $(53.0 \pm 1.5 \mathrm{vs} .44 .6 \pm 2.9$ and $45.3 \pm 1.0$ $\mathrm{g} /$ two weeks in high-fat LCT vs. high-fat MCT and low-fat respectively, $p<0.05$ ). In accordance with our hypothesis, the high-fat LCT diet resulted in an upregulation of UCP 3 protein content by 2 -fold (201 \pm 36 vs. $100 \pm 22$ arbitrary units in high-fat LCT vs, low-fat, respectively, $\mathrm{n}=10, p<0.05$, fig. $4.1 \mathrm{c}$ ). The up- 
regulation of UCP3 as observed on a high-fat long chan fatty acid diet, was completely absent when the high-fat diet was provided in the form of nedum chain fatty acids (86 \pm 17 vs. $100 \pm 22$ arbitrary units in high-fat MCT vs. low-fat, respectively, $\mathrm{n}=10, p>0.05$, fig. $4.1 \mathrm{~d}$ ). The lack of up-regulation of UCP3 in the medium chain group versus the long chain group could not be explained by differences in plasma free fatty acid concentrations $(201 \pm 20,249 \pm 34$ and $274 \pm$ $26 \mu \mathrm{mol} / \mathrm{L}$ in low-fat, high-fat MCT and high-fat LCT, respectively, $\mathrm{n}=10$, $p>0.05)$.

\section{Discussion}

Soon after the discovery of human UCP3 several observations pointed out that the primary physiological role of UCP3 is not the regulation of energy turnover (2), as would be predicted from its homology to UCP1. Thus, mice lacking UCP3 have a normal metabolic rate and body weight $(22,23)$, and fasting, an energy preserving condition, rapidly up-regulates the exptession of UCP3 (1). Rather, several groups suggested a role for UCP3 in fatty acid handling $(1,3,7,13)$. Here we provide evidence for a new phystological function of UCP3 (15) as an outward transporter of long chain fatty acid anions from the mitochondrial matrix into the cytoplasm (fig. 4.2). By doing so, UCP3 prevents accumulation of non-esterified fatty acids that entered the mitochondrial matrix by so-called fip-flop across the mitochondrial inner membrane, especially in conditions in which the entry of nonesterified fatty acids into the mitochondrial matrix is enhanced.

After being taken up into the muscle cell, the majority of fatry acids inside the soluble cytoplasm are bound to heart-type fatty-acid binding protein (H.-FABP of FABPc). The water solubility of fatty acids $(4-6 \mu \mathrm{M})(16)$ exceeds the affinity of $\mathrm{H}$ FABP for fatty acids (4-14 nM) (24) by far, indicating an important role for $H$ FABP in controlling the intracellular unbound fatty acid concentration, in order to maintain a fatty acid gradient between plasma/interstitium and cytoplasm to facilitate fatty acid uptake (24-26). Lack of H-FABP would thus lead to an intracellular increase of unbound fatty acids, particular because plasma fatry acid levels are elevated in these mice too (27). In addition, the presence of H-FABP was shown to be crucial for proper mitochondral oxictation of fatty acids (19), as $\mathrm{H}$ FABP is suggested to be essential for activation (esterification) of fatry acids by interacting with long chain acyl-CoA synthetase (ACS) (28). Therefore, in mice lacking H-FABP the fraction unbound fatty acids in the cytoplasm will be 
increased while esterification of fatty acids by $\mathrm{ASC}$ will be diminished. Here, we have used mice lacking H FABP to increase the intracellular concentration of unbound (ron-esterified) fatty acids. Especially in the unbound form these fatty acids rapidly incorporate into (mitochondtial) membranes, and could reach the mitochondrial martix. The pronounced up regulation of UCP3 protein in these mice therefore fits our hypothesis that $\mathrm{LCP} 3$ is needed to facilitate outward transport of fatty acid anions.

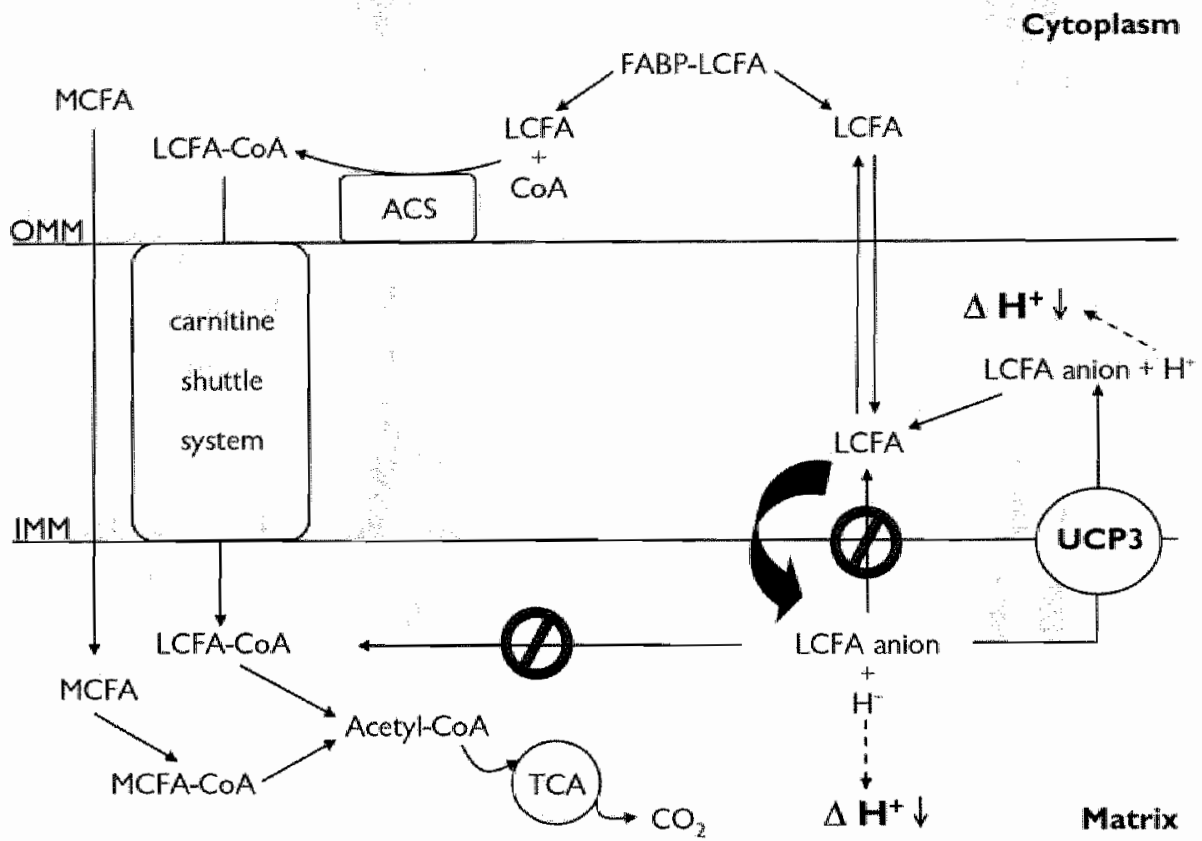

Figure 4.2 schematic model of the putative function of UCP3. UCP3 protein content is increased in concitions in which the enty of long chain fatty acids into the mitochondrial matrix is enhanced: I) in 1 w. FABP mice, which are chatacterised by enthanced unbound cytoptasmic faty act concentrations and decreased capacty to activate fitty acids via acy Coa synthetase (ACS) 2) atter inibibition of the cambitine shuthe system using etomoxir, and 3) on a high-fat diet, associated with increased supply of fatty acids to the mitochondria. Note that a high-fat diet rich in nedium chain fatty acids does not worease WCP3 protein content. Mediunt chain fatty acids can enter the mitochonorial matrix in their non-esterified form. but can still be oxidised due to the presence of a medium chain acy-Co.A synthetase inside the matrix. in the latter situation. UCP3 would not be needed for expont of faty acids. OMM. outer mitochondrial nembrane; IMM, inner mito dnondnal membrane; LCFA, long chain fatty acid; MCFA. medium chain fatty acid: FABP, fatty acid bunding protein" TCA tricarboxyllic acid cycle.

To provide further evidence for a physiological function of UCP3 in fatty acid anion export, we interfered more distally in the fatty acid oxidation pathway. The rate-limiting step in the mitochondrial uptake and oxidation of fatty acids is their 
esterification into fatty acyl-CoA and subsequent transport across the inner mitochondrial membrane after conversion into acylocamitine through the catalysing action of camitine palmitoyl transferase 1 (CPTI). Therefore, blocking the main route for mitochondrial transport of long chain fatty acyl-CoA esters will lead to accumulation of cellular non-esterified fatty acids, which could then enter the mitochondrial matrix. The observed up-regulation of UCP3 upon inhibition of CPT1 activity again is in accordance with a tole of UCP3 in fatty acid anion cxport. Clearly, blocking mitochondrial entry of long chain fatty acids decreases mitochondrial substrate availability. If the primary role of UCP3 were to tegulate energy dissipation, it would be anricipated that during decteased substrate availability, UCP3 would be down regulated rather than markedly increased, as was observed in the present study. Thus, increased expression of UCP3 after blocking CPT1 is inconsistent with a primary role of UCP3 in energy dissipation. In addition, increased UCP3 following blockade of CPT1 does not match with a role for UCP3 in the oxidation of fatty acids, indicating that the physiological function. of UCP3 is in a different step in the pathway of fatry acid metabolism.

In a more physiological approach to increase the entry of non-esterified fatry acids into the mitochondrial matrix, while not interfering with mitochondrial oxidative capacity, we used high-fat diets to oversupply fatty acids to mitochondria. With high-fat feeding, the continuous delivery of fatry acids exceeds the oxidative capacity and not all fatty acids can be oxidised, resulting in a transient accumulation of fatty acids inside the muscle cell (29). Under such conditions, the entry of non-esterified fatty acids into the mitochondrial matrix will increase and the observed high fat-induced up-regulation of UCP3 may serve to facilitate outward transport of these fatty acids from the matrix. In contrast to long chain fatty acids, medium chain fatty acids do not need to be esterified to CoA esters in the cytoplasm. Medium chain fatty acids bypass the control of mitochondrial transport by CPT1 and, in contrast to long chain fatty acids, medium chain fatry acids can be esterified to their nespective CoA esters inside the mitochondrial matrix and can therefore still be diverted to $\beta$-oxidation $(30,31)$. On a high-fat diet consisting of medium chain fatty acids, there would be no need to up-regulate UCP3, as the majority of fatry acids that enter the matrix will be of medium chain length and thus can still be diverted to $\beta$-oxidation once inside the matrix. The lack of up-regulation of UCP3 upon the medium chain high-fat diet versus the long chain high-fat diet, despite similar plasma non-esterified fatry acid levels, therefore suppotts the hypothesis that UCP3 is specifically involved in the rxport of nonesterified long chain fatty acid anions from the mitochondrial matrix into soluble 
cytoplasm. Moreover, upon entering the $\beta$-oxidation, the metabolism of fatty acids is independent of chain length, suggesting that the physiological function of UCP3 is not telated to fatty acid metabolism distal from $\beta$-oxidation.

A role for UCP3 as an exporter of fatty acid anions has also been proposed by Himms-Hagen et al. (32). They hypothesise that once inside the mitochondrial matrix in their esterified form, not all fatty acyl-CoA esters are diverted towards $\beta$ oxidation but that some may be hydrolysed by a mitochondrial thioesterase (MTE1), resulting in non-esterified fatty acids and CoA. Again, due to the lack of long chain acyl-CoA synthetase (ACS) within the mitochondrial matrix, outward transport of non-esterified fatty acid is preferred and UCP3 is the protein hypothesised to be responsible. Although the pronounced up-regulation of UCP3 upon etomoxir administration is not compatible with the hypothesis of HimmsHagen; we cannot exclude that UCP3 also serves to export of fatty acid anions derived from fatty acyl-CoA hydrolysis. Regardless the origin of the fatty acid anion within the matrix (either flip-flop across the inner mitochondrial membrane or by hydrolyses of fatty acyl-CoA by a mitochondrial thioesterase), both hypotheses propose that the primary tole of UCP3 is the outward translocation of fatty acids away from the mitochondrial matrix.

Export of non-esterified fatty acids from the mitochondrial matrix might be of physiological importance to prevent mitochondrial damage, as non-esterified fatty acids are prone to lipid peroxidation. In this context, it is important to note that it was recently found that mice lacking UCP3 indeed have increased lipid peroxidation (33). Furthermore, UCP3 protein content is decreased in type 2 diabetic subjects (34), who were found to be more susceptible to mitachondrial DNA damage in skeletal muscle (35). Moreover, the decreased UCP3 protein content in diabetic patients together with the generally observed accumulation of lipids inside the myocytes of type 2 diabetics, might be an explanation for the impaired mitochondrial functioning in type 2 diabetes (36), that could lead to the development of skeletal muscle insulin resistance, although further studies are needed to test this concept. In addition, accumulation of fatty acids inside the mitochondrial matrix might lead to disturbances in fatty acid oxidation, explaining the reported aberrations in fat oxidation in humans with the exon 6 splice donor mutation (3) and in UCP3 \% mice (4).

In summary, we have provided evidence that the physiological function of UCP3 is the outward transport of fatty acid anions. Interference in successive steps in fatty acid handling, transport and oxidation revealed that UCP3 is not directly involved. in fatty acid oxidation. Rather, we showed that UCP3 protein increases if the 
supply of fatty acids to the mitochondria exceeds fat oxidarive capacity, making it feasible that the physiological function of UCP3 indeed is in fatty acid anion export. Although we realise that none of the experiments presented provide divect and defunitive proof for our hypothesis, we interpret these data as compelling circumstantial evidence that UCP3 indeed facilitates outward translocation of farty acids from the mitochondrial matrix. Definitive proof for the hypothesis awaits the development of methodology to measure mitochondrial fatty acid anion accumulation and/or transport.

\section{Acknowledgements}

The research of Dr. Schrauwen has been made possible by a fellowship of the Royal Netherlands Academy of Arts and Sciences. M. Sc. J. Hoeks was supported by a grant from the Netherlands Organisation for Scientific Research (NWO) and Dr. Luiken by a VIDI-Innovational Research grant from the Netherlands Organisation for Scientific Research. S. Coort was supported by the Netherlands Heart Foundation (grant 2000.156). We thank Lawrence J. Slieker from Eli Lilly and Company for providing us with the UCP3 antibody, Dr. H.P.O. Wolf, Allensbach, Germany for providing etomoxir, and H.E.C. Niessen for help with the etomoxir studies.

\section{References}

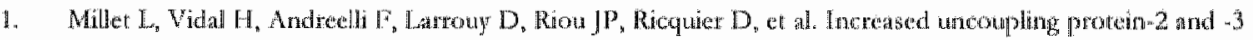

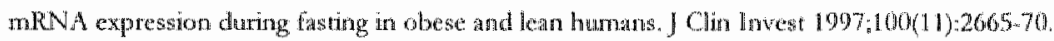

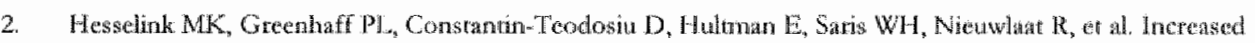

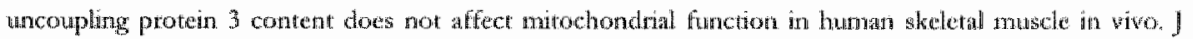
Cin Invert $2003 ; 1114(4) 479-86 \%$

3. Angroponlos $\mathrm{G}$, Brown $\mathrm{AM}$, Willi $\mathrm{SM}$, Zhu J, He $\mathrm{Y}$, Reiman M, ar al. Erfects of mutations in the bumath uncoupling protein 3 gene on the respiratory guotent and fat oxidation in severe obesity and type 2 diabetes J Chin Invest 1908; 10207):1345-51.

4. Dezatie V. Hotmann W. Kramer JK, Kozak LP, Harper ME. Effects of tasting on muscle mitochondrial

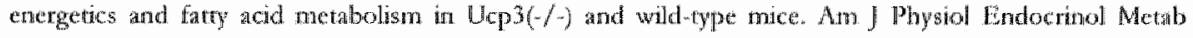
$2001 ; 281(5): E 975-82$

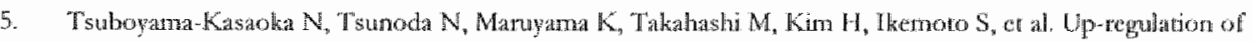
uncoupling provern 3 (UCP3) mRNA by exercise taining and down-tegulation of UCP3 by denerwation in skeletal muscles. Biochem Biophys Res Commun 1998;2472),498-503. 


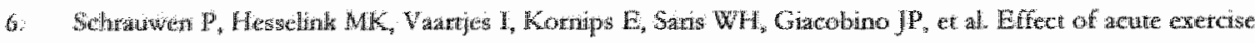

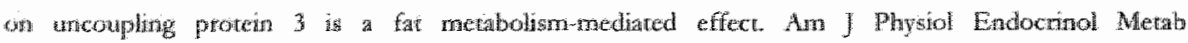
$2002,282(1 ; 1) 11-7$

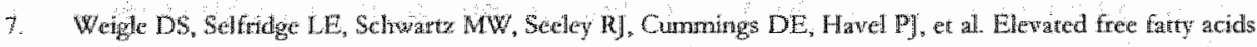

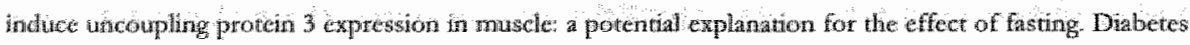

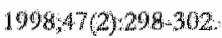

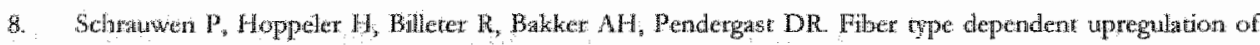

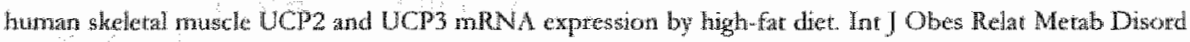
$2001,25(4) \times 449-56$

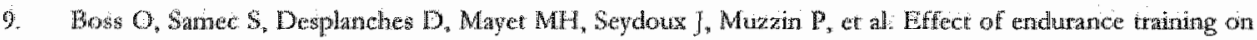

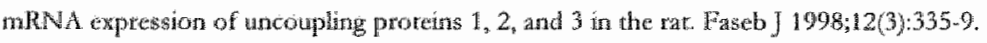

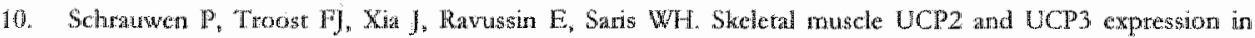
trained atd therained male subjects. Int / Obes Relat Metab Disord 1999,23(9):966-72.

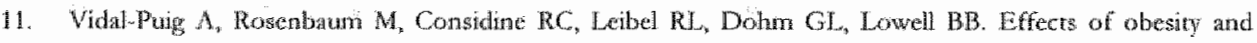
whble weight reduction on UC $\mathrm{I}^{2}$ and UCP3 gene expression in humans. Obes Res 1999;7(2):133-40.

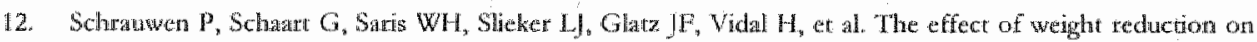
skeletal musche UCP2 and UCP3 mRNA expression ard UCP3 protein content in Type II diabetic subjects. Diaberologin $2000,43(1): 1408-16$.

13. Samer $\$$, saydow ), Dulloo $\mathrm{AG}$. Role of UOP homologues in skeletw muscles and brown adipose tissue:

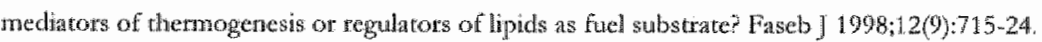

14. Hesselink MK, Keizer HA, Borghonts I. S, Shart $G$, Kormps CF, Slieker LJ, et al. Protein expression of UCP3 differs between human type 1, type 2a, and type $2 \mathrm{~b}$ fbers. Faseb ) 2001;15(6):1071-3.

15. Schrduwen $P$, Sitis WH, Hesselenk MK. An alternative function for human bincoupling protein 3 : provecion of mitochondra agangt accumulation of nonesterificd farty acids inside the mirochondrial matrix. Faseb ] $2001 ; 15(13) \div 2497-502$.

16. Hamilon IA, Kamp F. How ate free fatty acids transported in membranes? is it by proteins or by hece diffusion through the lipids? Diaberes 1999;48(12):2255-69.

17. Jezek P, Orosz DE, Modriarsky M, Garlid KD. Thansport of anions and protons by the mitochondrial uncompling protein and irs regulation by nucloorides and tarty acids. A new look at old hypotheses. J Biol Chen: $1904: 269(42): 26184-90$.

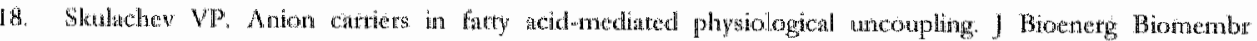
$1900,31(5) \cdot 431-45$

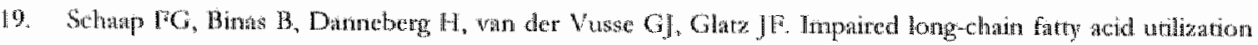
by cathac myocytes isolated from mice lacking the heartype faty acid binding proteingene. Cire Res $1909: 85(4), 329-37$

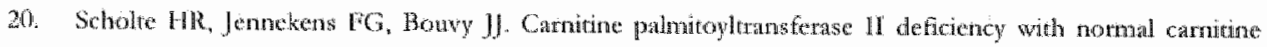

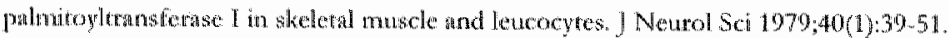

21. Lacmuli $U K$ Cleavage of structural proteins daring the assembly of the head of bacteroplage T4. Nature $1970 ; 227(5259): 680 \div 5$

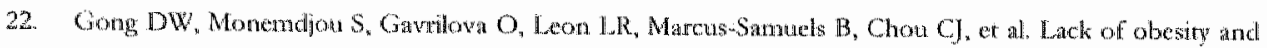
nomal ropponse to fasting and dyytoid homone in mice lacking uncoupling protein-3. I Biol Chem $2000 ; 275(21): 162517$.

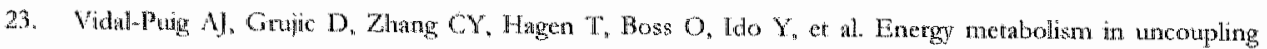
protein 3 gene knockont mice.] Biol Chem 2000275 (21):16258-66.

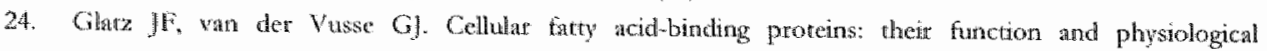
significonoce. Prog Ijpid Res 1996;35(3):243-82 


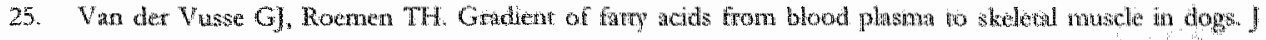
Appul Physiol 1995, $78(5): 1839-43$

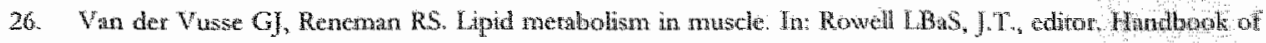

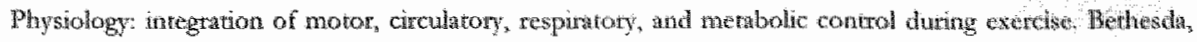
MD: Am Physiol Soc; 1996. p. 952.994

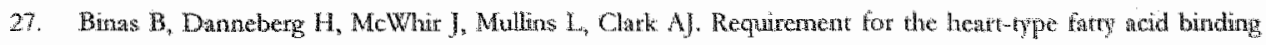
protein in cardiac fatty actd wilizarion. Faseb $1999 ; 138 ; 805-12$.

28. Veerkamp 1H, van Moctkerk HT. Farry acidinding protein and its relation to fatry acid oxidation. Mol Cell Biochem $1993,123(1-2): 101-6$.

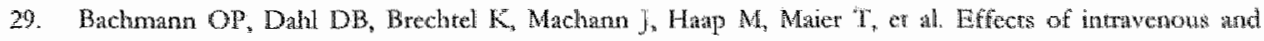

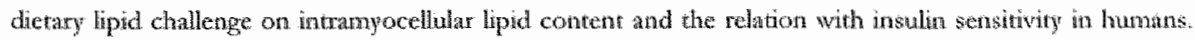
Diabetes $2001 ; 50(1): 2579-84$

30. Greenbetger N]. Skillman TG. Medium-chain triglycerides. N Engl J Med 1969,280(19):1045145.

31. MeGary JD, Foster DW. Regulation of hepatic faty acid oxidation and ketone body production. Arinu Rev Birochem $1980,49: 395-420$.

32. Winms-Hagen J Harper ME. Physiological role of UCP3 may be export of taty acids trom mirochondrat when fatry acid oxidation predominates an hpothesis. Exp Biol Med (Maywood) 200) 2206(2):78-84

33. Brand MD, Pamplona R, Portero-Otin M, Requena JR, Roebuck. SJ, Buckinglam JA, er al. Oxidauve damage and phospholipid fatty acyt composicion in skeletal nuscle mitochondra from mice underexpressing or overexplessing uncoupling protein 3. Biochem I 2002;68; Pt 2):597-603.

34. Schranwen P, Hesselink MK, Blaak EE, Borghouts LB, Schaar G, Saris WF, et al. Uncoupling protain 3 content is decreased in skeletal muscle of patients writh type 2 diabetes. Diabetes $2001 ; 50(12), 2870-3$.

35. Liang $P$, Hughes V. Fukagawa NK. Increased prexalence of mitochondnal DNA deletions in slketatal muscle of older individuals with impaited gheose tolennce possible trather of glycentic stress. Diaberes $1997,46(5): 920-3$

36. Kelley DE, He ], Menshikowa EV, Ritov VT. Dysfunction of mitochondria th human skeletal musclo in type 2 diabetes. Diaberes 2002,51(10):2944-50 


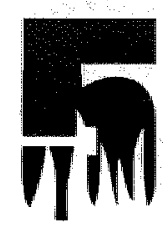

\section{Differential response of UCP3 to} medium versus long chain triacylglycerols; manifestation of a functional adaptation

Joris Hoeks, Matthijs K.C. Hesselink, Marc van Bilsen, Gert Schaart, Ger J. van der Vusse, Wim H.M. Saris and Patrick Schrauwen

Departments of Human Biology and Movement Sciences. Nutrition and Toxicology Research Institute Maastricht (NUTRIM), Maastricht University, Maastricht, The Netherlands:

Department of Physiology, Cardiovascular Research Institute Maastricht (CARIM), Maastricht University, Malastricht, The Netherlands

FEBS Lett. 2003 Dec 18;555(3):631-7 


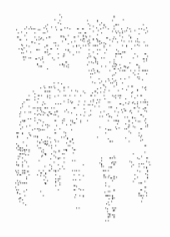

\section{Abstract}

We compared UCP3 protein in tat carcliac, glycolytic and oxidative skeletal muscle and examined the effect of high-fat medium chain vs. long chain triacylglycerol feeding on UCP3 content in these tissues.

Cardiac muscle displays the lowest basal levels of UCP3 protein. Increasing long chain - but not medium chain - fatty acid supply up-regulates UCP3 in all muscles. Since plasma non-esterified fatty acids and the expression of two PPAR-responsive genes, were not different between groups, we conclude that the differential upregulation of UCP3 is not merely PPAR-mediated. This study supports a role of UCP3 in export of non-metabolisable fatty acids. 


\section{Introduction}

The function of UCP3 is still under debate but there is increasing evidence that the primary physiological tole of UCP3 is in fatty acid metabolism. Evaluation of the available data on UCP3 expression shows that skeletal muscle UCP3 is upregulated in situations where fatty acid suppiy exceeds fat oxidative capacity such as acute fasting (1), high-fat diet (2-4) and acute exercise (5). On the other hand UCP3 is down-regulated in situations where fat oxidation capacity is improved like endurance training $(6,7)$ or during weight reduction $(8,9)$. In conditions where fatty acid supply exceeds fat oxidation capacity, non-esterified fatty acids will. accumulate in the cytosol and might enter the mitochondrial matrix through flipflop $(6,10-12)$. Based on these findings, we and others hypothesised that the physiological function of $\mathrm{UCP} 3$ is to protect mitochondria against accumulation of non-esterified fatty acids inside the mitochondrial matrix, especially in situations where fatty acid delivery exceeds oxidation capacity $(6,12,13)$.

In accordance with this hypothesis it was found that skeletal muscle with the lowest fat oxidative capacity (glycolytic, type $2 \mathrm{~b}$ muscle fibres) display the highest UCP3 mRNA and protein levels while oxidative muscles (type 1 muscle fibres) only moderately express UCP3 $(14,15)$. In this context, it is interesting to note that cardiac muscle, which mainly depends on fatty acids for its energy supply, also expresses UCP3 mRNA $(16,17)$ and protein $(16)$, while the level of UCP3 protein relative to skeletal muscle is unknown. As cardiac muscle has a very high capacity to oxidise fatty acids, we hypothesise that it contains UCP3 at levels even lower than in type 1 muscle fibres. Therefore, the first aim of the present study was to determine UCP3 protein levels in rat cardiac muscle and to compare these levels with UCP3 levels in the white gastrocnemius (mainly glycolytic) and soleus (mainly oxidative) muscle.

Additional support for a role for UCP3 in fat metabolism comes from the finding that prolonged consumption of a high-fat diet up-regulates skeletal muscle UCP3 mRNA and protein levels, both in humans $(2,4)$ and rodents $(3,18)$. During highfat feeding, fatty acid supply exceeds the oxidative capacity and fatty acids are likely: to accumulate in the cytosol. As a result, the entry of non-esterified fatty acids into the mitochondrial matrix most likely increases and the observed up-regulation of UCP3 may facilitate outward transport of these non-metabolisable fatry acids. 
Therefore, it is of relevance to study the effect of high-fat feeding on UCP3, at the protein level, in muscles with different fat oxidative capacities.

We recently showed that the up-regulation of UCP3 in white gastrocnemius muscle upon high-fat feeding in rats is specific for long chain triacylglycerols (LCT) and completely absent when equal amounts of medium chain triacylglycerols (MCT) are provided (19). Because of their chain-length, medium chain fatty acids (MCFA), in contrast to long chain fatty acids (LCFA), do not rely on the carnitine shuttle system for their transport across the mitochondrial membranes. In addition, they can be readily oxidised inside the matrix because of the presence of a matrix-associated enzyme which allows the activation and subsequent 3 roxidation of MCFA (20). Therefore, up-regulation of UCP3 upon high-fat MCT feeding would be redundant since non-esterified MCFA that enter the mitochondrial matrix can still be oxidised. Here, we extend our previous finding (19) and examine the effect of high-fat, medium chain vs. long chain triacylglycerol feeding on UCP3 protein content in the three earlier mentioned muscles with different oxidative capacity. In addition, we examined whether the lack of effect of MCT on UCP3 could be due to differential PPAR-induced UCP3 gene regulation. The promoter of UCP3 contains a peroxisome proliferatoractivated-receptor (PPAR)-responsive element (21), and LCFA are identified activators of PPARs while MCFA activate PPARs to a much lesser extent $(22,23)$. Hence, it could be argued that the lack of up-regulation of UCP3 on a diet comprised of mainly MCTs merely reflects the lack of PPAR responsiveness to MCTs rather than a functional adaptation of UCP3 to the increased mitochondrial long chain fatty acid supply.

Therefore, the final aim was to study the gene expression of UCP3 as well as two other, well-established, PPAR-responsive genes, acyl-CoA synthetase (ACS) and long chain acyl-CoA dehydrogenase (LCAD), upon high-fat MCT of LCT feeding.

\section{Methods}

\section{Animals}

Thirty male, ten-week old Wistar rats (Charles River) were housed individually on a 12:12h light-dark cycle (light from 7:00 am to 7:00 pm), at $21-22^{\circ} \mathrm{C}$ and subjected to a two-week dietary intervention. During the experiments, tats had free access to tap water. All experiments were approved by the Institutional Animal Care and 
Use Committee of the Maastricht University and complied with the principles of laboratory animal care.

\section{Diets}

Rats were randomly divided into three different groups $(n=10)$. Group 1 (LF LCT) received the low-fat control diet ( 7 EN\% from fat) for the duration of two weeks. Group 2 (HF MCT) was maintained on a high-fat MCT diet while group 3 ( $\mathrm{HF}$ LCT) received a high-fat LCT diet (both $46 \mathrm{EN} \%$ from fat). Diet specifications are displayed in table 5.1. All diets were purchased from Hope Farms (Woerden, The Netherlands) and provided ad hoifum. Food intake and body mass were recorded daily.

To check net energy intake in the high-fat groups, diet and faecal samples were analysed for gross energy content using adiabatic bomb calorimetry.

Table 5.1 Major components and fatty acid composition of triacylglycerols in the experimental diets.

\begin{tabular}{lccc}
\hline Diet & Low-fat control & High-fat MCT & High-fat LCT \\
\hline Protein (EN\%) & 19 & 19 & 19 \\
Carbohydrates (EN\%) & 74 & 35 & 35 \\
Fat (EN\%) & 7 & 46 & 46 \\
\hline Fatty acid profile & $\%$ of total fat & $\%$ of total fat & $\%$ of total fat \\
\hline C8:0 & & 60.0 & \\
C10:0 & 0.5 & 40.0 & 0.5 \\
C14:0 & 1.0 & & 1.0 \\
C16:0 & 79.0 & & 790 \\
C18:0 & 6.0 & & 6.0 \\
C18:1 & 12.0 & & 120 \\
C18:2 & 110 & & 1.0 \\
\hline
\end{tabular}

Minerals and vittamins were added in order to provide $100 \%$ Alv requirements for rats.

Basal differences in UCP3 protein concentrations between white gastrocnemius muscle (WGM), soleus muscle (SM) and cardiac muscle (CM) were compared in 4 tats of the low-fat control group.

\section{Tissue sampling}

After the two week dietary intervention period, tissue dissection was performed under ketamin (Nimatek $1.0 \mathrm{ml} \cdot \mathrm{kg}^{-1}$ ) and xylazin (Sedamun $0.5 \mathrm{ml} \cdot \mathrm{kg}^{-1}$ ) 
anaesthesia upon shorterm (less than 20s) $\mathrm{CO}_{2}$ sedation. Both anaesthetics were injected subcutaneously. Rats wete deprived from food approximately 6 hours prior to tissue sampling. Cardiac muscle and the mid-belly regions of the white gastrocnemius and soleus muscles were dissected and immediately frozen in liquid nitrogen. Futhermore, a blood sample was collected in EDTA-containing Eppendorf tubes and plasma was prepared by centrifugation at $10,000 \times \mathrm{g}$ for 2 minutes. Plasma samples were also frozen in liquid nitrogen. All samples were stored at $-80^{\circ} \mathrm{C}$ until analysis.

\section{Now-esierified fatty acids}

Plasma samples were analysed for total non esterified fatty acids using the Wako NEFA C test kit (Wako chemicals, Neuss, Germany).

\section{Analysis of mRNA expression}

Northern blot analysis of mRNA was performed as described elsewhere (24). Specifically, filters were probed with a $0.7 \mathrm{~kb}$ fragment of rat UCP3 generated via reverse transcriptase PCR using forward (5'-GGCCATCCTCCGGAACCATGG3) and reversed (5'-GCGGCCTGCTTGCCTTGTTCA-3') primers, a 520 bp EcoRV-HindIII fragment of ACS (gift from Dr. T. Yamamoto, Tohoku University, Sendai, Japan), and a 1390 bp EcoRI fragment of rat LCAD (a gift. from Dr. K. Tanaka, Yale University, USA).

\section{UCP3 protein content}

Western blot analysis of UCP3 protein was performed as described elsewhere (19). The affinity purified polyclonal antiserum against rUCP3 (code 1338, kindly provided by LJ Slieker, Eli Lilly) was raised in a rabbit against a 20 amino acid peptide that comprised amino acids 147-166 of rat UCP3 (rUCP3). The purified antiserum was tested extensively for specificity in immunoblotting assays using positive and negative controls (i.e. brown adipose tissue, skeletal muscle and UCP3 - mice). Since the rUCP3 antiserum shows cross-reactivity with human tissues, the reactivity and specificity of this antiserum was compared with the hUCP3 polyclonal antiserum (15), both resulting in a UCP3 product of $33 \mathrm{kDa}$ in human skeletal muscle. After pre-incubation of the antibody with the peptide, the specific $33 \mathrm{kDa} U \mathrm{CP} 3$ protein band was absent. 


\section{Statistical analysis}

Results are presented as mean \pm SEM. UCP3 levels upon control feeding were set at 100 arbitrary units. Differences between groups were evaluated by analysis of variance (One-way ANOVA). When significant differences were found, a Bonferroni adjusted post hoc test was used to determine the exact location of the difference. Outcomes were regarded as statistically significant if $p<0.05$.

\section{Results}

\section{Gain of body mass and energy intake}

By the end of the two-week dietary intervention period, the gain of body mass in the HF LCT group was $53.0 \pm 1.5 \mathrm{~g} / 2$ weeks, which was significantly higher than in the LF LCT $(45.3 \pm 1.0 \mathrm{~g} / 2$ weeks; $p=0.034)$ and HF MCT $(44.6 \pm 2.9 \mathrm{~g} / 2$ weeks; $p=0.018$ ) groups (table 5.2). Gross energy intake over the two-week period was also significantly higher in the HF LCT group $(5727 \pm 116 \mathrm{~kJ} / 2$ weeks) compared to the LF LCT (4824 $\pm 88 \mathrm{~kJ} / 2$ weeks; $p<0.001$ ) and HF MCT (4434 \pm $124 \mathrm{~kJ} / 2$ weeks; $p<0.001$ ) groups (table 5.2 ). There was a trend $(p=0.06)$ towards a higher gross energy intake in the LF LCT group in comparison with the HF MCT group. However, adiabatic bomb calorimetry of the faecal samples of both high-fat groups revealed that the amount of energy lost in the faeces was significantly higher in the HF LCT group compared to the HF MCT group (1514 \pm 45 vs. 477 $\pm 23 \mathrm{~kJ} / 2$ weeks; $p<0.001)$ As a result, net energy intake in the HF LCT group was not different from the HF MCT group over the two-week intervention period (4214 \pm 87 vs. $3956 \pm 116 \mathrm{~kJ}$; NS). Therefore, the net energy intake per gram gain of body mass was significantly higher in the HF MCT group $(90.8 \pm 4.1 \mathrm{~kJ} / \mathrm{g}$ ) than in the HF LCT group $(79.9 \pm 1.6 \mathrm{~kJ} / \mathrm{g} ; p=0.024$, table 5.2$)$, indicating that energy expenditure was increased on the HF MCT diet.

\section{Plasma free fatty acids}

After two weeks of dietary intervention, plasma non-esterified fatty acid levels averaged $201 \pm 20 \mu \mathrm{mol} / \mathrm{L}$ in the LF LCT group, while the HF MCT and HF LCT plasma non-esterified fatty acid levels averaged $249 \pm 34$ and $274 \pm 26 \mu \mathrm{mol} / \mathbb{L}$. respectively. These differences did not reach staristical significance. 
Table 5.2 Gain of body mass and energy intake over 2 weeks of dietary intervention

\begin{tabular}{|c|c|c|c|}
\hline Parameters & Low-fat control & Highti-fat MCT & High-fat LCT \\
\hline Gain of body mass (g) & $4.5 .3 \pm 1.0$ & $446 \pm 29$ & $53.0 \pm 1.5^{*}$ \\
\hline Gross energy intake (k)) & $4824 \pm 88$ & $4434 \pm 124$ & $5727 \pm 116^{2 *}$ \\
\hline Net energy intake $(\mathrm{k})$ & - & $3956 \pm 116$ & $4214 \pm 87$ \\
\hline $\begin{array}{l}\text { Energy intake per gram gain of } \\
\text { body mass (k/g) }\end{array}$ & - & $91 \pm 4$ & $80 \pm 2^{\prime \prime}$ \\
\hline
\end{tabular}

Values are mean 4 5EM. * $p<0.05$, ** $p<0.001$ compared to low fat control. " $p<0.05$, ${ }^{\text {at }} p<0.001$ compared to high-fat MCT.

\section{UCP3 protein content}

Basal UCP3 protein levels in white gastrocnemius muscle were approximately 4.5fold higher than the soleus muscle and $\sim 13$-foll higher compared to cardiac muscle (550 \pm 102 vs. $118 \pm 42$ and $42 \pm 17$ arbitrary units, in gastrocnemius vs. soleus and cardiac muscle respectively, $p<0.005$ ). Thus, cardiac muscle displayed the lowest UCP3 protein levels, which were 2.8-fold lower than soleus muscle UCP3 protein levels (118 \pm 42 vs. $42 \pm 17$ arbitrary units), although the latter difference failed to reach statistical significance (fig. 5.1).

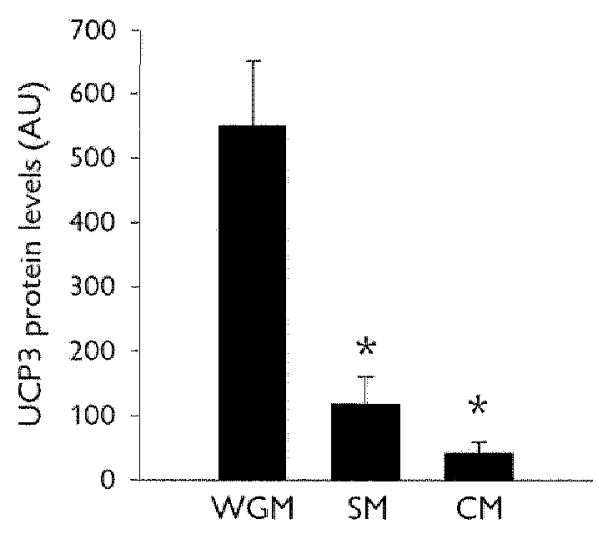

Figure 5.I Basal UCP3 protein levels among different muscles. WGM, white gastrocnemius muscle: SM, soleus muscle: CM, cardiac muscle. Values are mean \pm SEM. * $p<0.05$. 

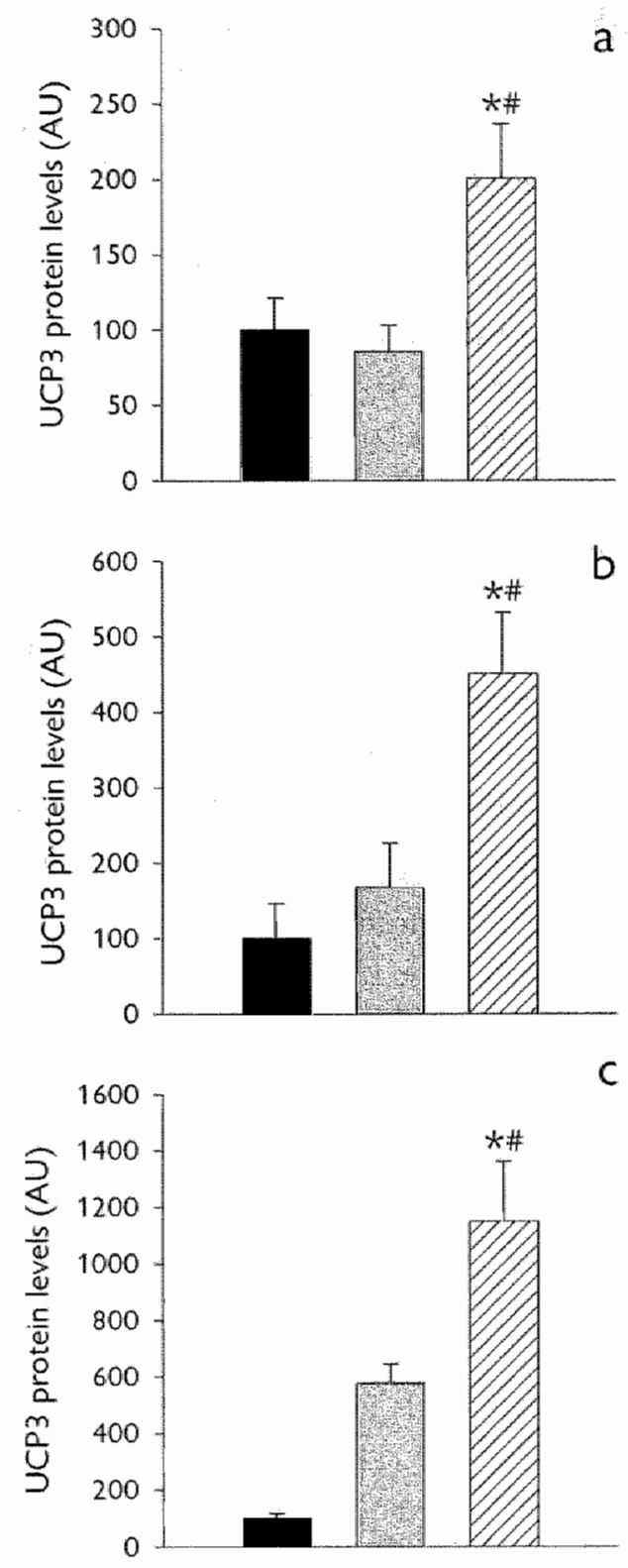

Figure 5.2 Protein levels of UCP3 after dietary intervention in a) white gastrocmemius muscle b) soleus muscle and c) cardiac muscle. Solid bars, low-fat control, grey bars, high-fat MCT; hatched bars, high-fat LCT. Values are mean \pm SEM. * p<0.05 compared to low-fat control. "p 00.05 compared to high fat MCT. 
High-fat LCT feeding significantly increased UCP3 protein content in white gastrocnemius muscle by 2 -fold in comparison with the low-fat diet $201 \pm 36 \mathrm{vs}$. $100 \pm 22$ arbitrary units, $p<0.05$ ), while MCT feeding did not affect UCP3 protein levels ( $86 \pm 17$ vs. $100 \pm 21$ arbitrary units, NS; fig. 5.2a).

UCP3 protein content in soleus muscle (fig. $5.2 \mathrm{~b}$ ) increased 4.5 -fold upon HF LCT feeding compared to the control diet ( $451 \pm 81$ vs. $100 \pm 46$ arbitrary units, $p<0.005)$.

Again, there was no difference in UCP3 protein levels in soleus muscle between $\mathrm{HF} \mathrm{MCT}$ feeding and the low-fat control diet (168 \pm 58 vs. $100 \pm 46$, NS).

Cardiac muscle UCP3 protein content (fig. 5.2c) showed an 11.5-fold increase after the HF LCT diet intervention ( $1150 \pm 211$ vs, $100 \pm 17$ arbitrary units, $p<0.001$ ). HF MCT showed a tendency towards an increase in UCP3 protein levels in cardiac muscle but, due to high variation, this increase was not statistically significant (578 \pm 67 vs. $100 \pm 17$, NS).

Although the high fat-induced increase in UCP3 is most ptonounced in cardiac muscle, it should be kept in mind that the baseline levels were 13-fold lower in cardiac compared to gastrocnemius muscle. If the basal differences were taken into account, absolute UCP3 values after two weeks of HF LCT feeding would still be highest in white gastrocnemius muscle compared to soleus and cardiac muscle.

\section{$m R N A$ analysis}

After two weeks of dietary intervention UCP3 mRNA levels mimicked the change in protein levels in cardiac and white gastrocnemius muscle. Thus, UCP3 mRNA levels in the white gastrocnemius muscle increased by $\sim 75 \%$ upon HF LCT feeding compared to the control diet although this difference did not reach statistically significance (176 440 vs. $100 \pm 18$ arbittary units, NS). UCP3 mRNA levels after HF MCT feeding were comparable to control values (131 \pm 35 vs. 100 \pm 18 arbitrary units; fig. $5.3 \mathrm{a}$ ).

In cardiac muscle, UCP3 mRNA levels increased 11-fold upon HF LCT feeding compared to the low-fat control diet $(1121 \pm 378$ vs. $100 \pm 18$ arbitrary units, $p<0.001$ ) whereas after HF MCT feeding UCP3 mRNA expression in rat heart were not significantly different from control values $(333 \pm 137$ vs. $100 \pm 18$ arbitrary units, NS; fig. 5.3b).

In contrast, gene expression of the well-established PPAR-responsive genes, ACS and LCAD, did not respond to either the high-fat LCT or MCT feeding, neither in cardiac muscle nor in skeletal muscle (fig. 5.3a and b). 

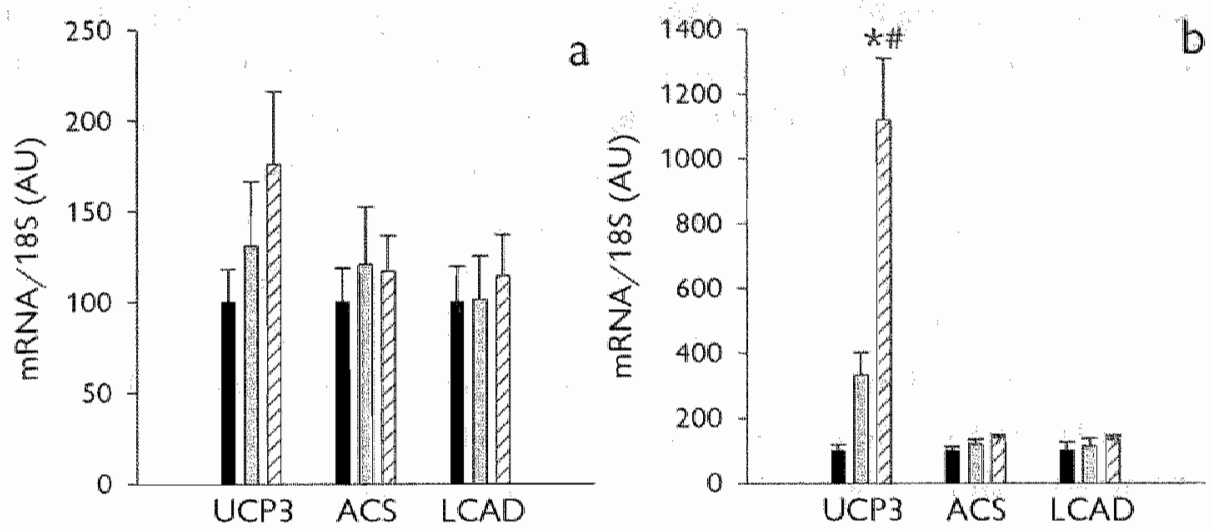

Figure 5.3 Expression of UCP3, acyl-CoA synthetase (ACS) and long thain acyl-CoA dehydrogenase (LCAD) after dietary intervention in a) white gastrocnemius muscle and b) cardiac muscle. Solid bars, low-fat control; grey bars, high-fat MCT; hatched bars high-fat LCT. Values are mean \pm SEM. * $p<0,05$ compared to low-fat control." p<0.05 compared to high-fat MCT.

\section{Discussion}

We previously hypothesised that UCP3 acts as a fatty acid anion exporter, hence preventing accumulation of non-metabolisable fatty acid anions inside the mitochondrial matrix (6). Such a function of UCP3 is of importance, as fatty acid anions are prone to lipid peroxidation and could potentially damage mitochondrial DNA and ptoteins. According to this hypothesis, UCP3 is especially needed in muscle with low fat oxidative capacity. Here, we show that cardiac muscle, which is characterised by a very high capacity to oxidise fatty acids, displayed the lowest basal levels of UCP3 by Far. Basal UCP3 levels in cardiac muscle were approximately 13 fold lower in comparison with the mainly glycolytic white gastrocnemius muscle, whereas UCP3 in the latter was approximately 4.5 -fold higher when compared to the oxidative soleus musclle.

Recently, Russell et al. (7) quantitatively compared UCP3 protein levels in type 1, type $2 \mathrm{a}$ and type $2 \mathrm{~b}$ muscle fibres in human m. kastus lateralis using immunofluorescence. In the present study, we confirm these results and earlier qualitative results from our group (15) and others (14), showing that oxidative muscles express the lowest levels of UCP3 protein compared to glycolytic muscle types that express high levels of UCP3. These data support our hypothesis that UCP3 facilitates export of non-metabolisable fatty acids. 
As reported previously (2-4), we confirm at the protein level that high-fat feeding up-regulates UCP3, compared to low-fat feeding. This up-regulation was most pronounced in cardiac muscle (11.5-fold) and only 2-fold in glycolytic muscle. According to our hypothesis, the balance between fatty acid delivery to the muscle cell and the oxidarive capacity of this cell drives UCP3 expression. On the one hand, it could thus be teasoned that upon high-fat feeding, the greatest changes in UCP3 protein would be expected in muscles with a low fatty acid oxidlation capacity, like white gastrocnemius muscle. On the other hand, it should be noted that basal UCP3 levels in cardiac and solcus muscle are very low. If basal UCP3 levels are taken into account, UCP3 protein levels upon HF feeding are still 2.1fold higher in white gastrocnemius muscle compared to soleus muscle and 2.3-fold higher than cardiac muscle.

Up-regulation of UCP3 upon high-fat feeding is consistent with the proposed physiological function of UCP3, since in this condition non-metabolisable fatty acids are more likely to reach the matrix. However, in contrast to long chain fatty acids, which need to be activated to long chain fatty acyl-CoA by the acyl-CoA synthetase (ACS) in the cytosol, all medium chain fatty acids that enter the mitochondrial matrix can be oxidised. Therefore, accumulation of fatty acid anions inside the mitochondrial matrix is unlikely to occur upon HF MCT feeding and the need for UCP 3 is thus diminished compared to HF LCT feeding. Here we confirm the absence of an up-regulation of UCP3 upon the HF MCT diet (19) in skeletal and cardiac muscles with different fat oxidative capacity, further supporting our hypothesis that UCP3 acts as an exporter of non-metabolisable fatty acid anions.

Very recently, it was suggested that UCP3 does not export fatty acid anions but rather fatty acid peroxide anions (25). Based on our metabolic data we cannot conclude whether UCP3 transports fatty acid anions or fatty acid peroxide anions, but both hypotheses state that UCP3 has an important role in protecting mitochondria against fatty acid-induced mitochondrial damage.

An alternative explanation for the present results could be differential effects of MCT vs. LCT on peroxisome proliferator-activated receptor (PPAR) activation, as the promoter of the UCP3 gene contains a PPAR-responsive element (21). Although plasma non-esterified fatty acids were similat on MCT. and LCT cliets, it is also known that especially long chain fatty acids are potent PPAR ligands while fatty acids of medium chain length are poor PPAR activators $(22,23)$. Therefore, the observed up-regulation of UCP3 upon HF LCT but not on HF MCT feeding could be general PPAR-mediated effects. 
However, we show that UCP3 mRNA levels in cardiac muscle and skeletal inuscle displayed the same expression pattem observed on the protein level, following the different dietary interventions. In contrast, neither ACS nor LCAD showed differences in mRNA levels in reaction to the dietary interventions, in any of the muscle types studied (fig. 5.3). These results indicate that HF LCT and HF MCT feeding did not induce different PPAR responses. Collectively, these findings suggest that the up-regulation of UCP3 upon high-fat LCT feeding is very specific, and suggest that the observed upmegulation is of physiological and functional importance.

An early-proposed physiological function of UCP3 was the regulation of energy expenditure. In this context, it is important to note that high-fat LCT feeding induced a more prominent increase in body mass compared to MCT feeding, even though net energy intake (gross energy intake minus energy lost in faeces) was similar. This observation indicates a possible thermogenic effect of MCI consumption, although we cannot exclude the possibility that activity-induced energy expenditure (AEE) was different among the groups. Earlier animal studies revealed lower weight gain and smaller adipose tissue depots upon medium chain triacylglycerol feeding compared to a long chain triacylglycenol diet, suggesting a lower storage efficiency of MCT's (26-29). Recently, St-Onge et al. (30) also reported decreased adipose tissue storage upon a diet rich in MCTs in overweight human males. Several animal (31-33) and human (30, 34-37) studies also reported a thermogenic effect of MCT ingestion. In addition, MCT's are rapidly absorbed in the intestine and preferentially oxidised. The increased intestinal uptake was confirmed by our results since MCT fed animals showed a significantly lower faecal energy loss than LCT fed animals. Together these data suggest a lower storage efficiency and themogenic effect of medium chain triacylglycerols. Importantly, this MCT-induced thermogenesis occurs while a significant upregulation of UCP3 is lacking. If the primary role of UCP3 were to regulate enengy expenditure by increasing thermogenesis one would expect a substantial increase in the (thermogenic) HF MCT condition rather than in the HF LCT condition. Again this finding underscores our notion that the primary role of UCP3 is not in the thermogenic response. Accordingly, the mechanism behind the thermogenic effect of MCTs does not seem to be mediated by UCP3.

In summary, we found that UCP3 levels in cardiac muscle are, as expected, very low when compared to glycolytic skeletal muscle. In addition, UCP3 protein levels were up-regulated in white gastrocnemius muscle, soleus muscle and cardiac muscle after two weeks of high-fat, long chain triacylglycerol feeding. High-fat, 
medium chain triacylglycerol feeding did not affect UCP3 protein levels in any of these muscles. Since plasma non-esterified fatty acids and the expression of $\mathrm{ASC}$ an LCAD, two PPAR-responsive genes, were similat after HF LCT and HF MCT feeding, the effects on UCP3 levels seems to be very specific. Taken together, these dat support our hypothesis that UCP3 acts as a fatty acid anion exporter to prevent mitochondrial accumulation of non-metabolisable fatty acids.

\section{Acknowledgements}

The research of Dr. P. Schrawwen has been made possible by a fellowship of the Royal Netherlands Academy of Arts and Sciences. M. Sc. J. Hoeks was supported by a grant from the Netherlands Organisation for Scientific Research (NWO), and Dr. M. wan Bilsen is an Established Investigator of the Netherlands Heart Foundation (grant 1998T015).

\section{References:}

1. Millet $\mathrm{L}_{\mathrm{z}}$ Vidal $\mathrm{H}_{\mathrm{*}}$ Andreelj $\mathrm{F}$, Lartouy $\mathrm{D}$, Rinu JP, Ricouter D, et al. Increased uncoupling protein-2 and -3 miNA expressiton during fasting in obese and lean lumans. J Clin Invest 1997;100(11):2665-70.

2. Hesselink MK, Greenhaff PL, Constantin Teodosiu D, Hulman E, Saris WI, Nieuwlat R, et al Increased uncoupling proten 3 content does not affect mitochondrial function in human skeletal muscle in vivo. I Clin Invest $2003 ; 111(4): 479 \times 86$.

3. Matsuda J, Hosoda $\mathrm{K}$, Troh $\mathrm{H}$, Son $\mathrm{C}$, Doi $\mathrm{K}$, lataka $\mathrm{T}$, et al, Cloning of rat uncoupling protein-3 and uncoupling proten-2 CDNAs: thein gene expression in ars fed high-fat diet. FEBS Lett 1997:418(1-2):200 蚴,

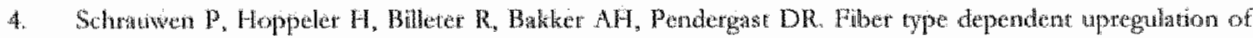
human selent musele UCP2 and UCP3 mRNA expression by lugh fat diet. Thit J Obes Relat Metab Disord $2001,25(4) \times 449-50$

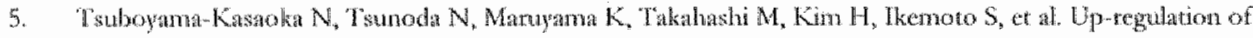
uncouphing protein 3 (UCP3) mRWA by exercise traning and down-regulation of UCP3 by denerwation in

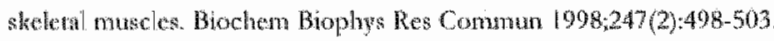

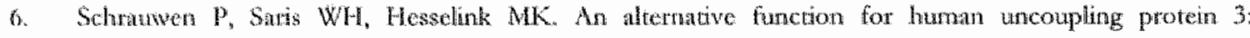

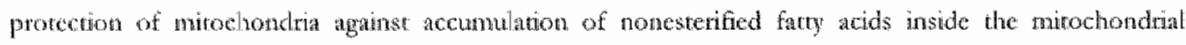

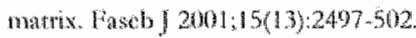

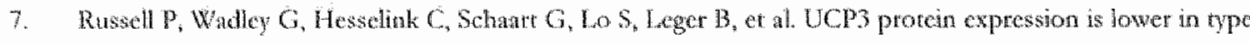

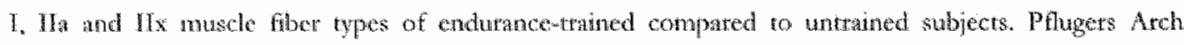
$2003,445,5): 563-9$

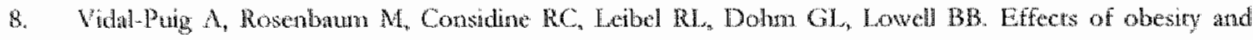
stable weight reduction on UCP2 and UCP3 gene expression in humanas. Obes Res $1999,7(2) 133-40$. 


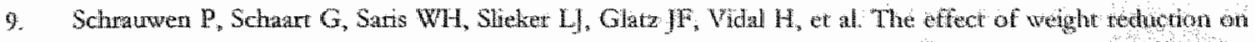

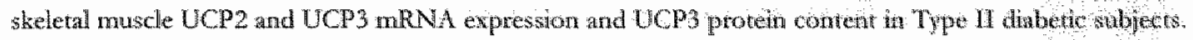
Diabe tologiga $2000,43(11): 1408-16$.

10. Jezek P, Orosz DE, Modransky M, Garlid KD. Tansport of anions and protons by the natochonklowal

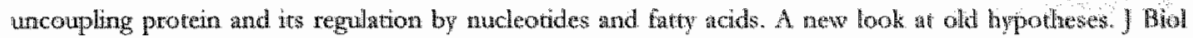
Chem $1994269(42): 2618490$.

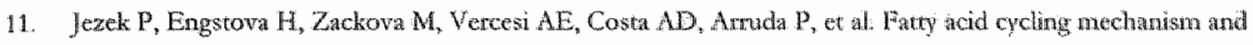
mitochondrial uncoupling proteins. Biochim Buophys Acta 1998; $1365(1-2): 319-2 \%$

12. Skulachev VP. Anion cartiers in fatry acidmediated physiological uncouphing J Biomerge Hionnembr $1999,31(5): 431-45$

13. Himms Hagen ], Harper MEE. Physiological tole of UCP3 may be export of fithy acids from mitochondna when farry acid oxdation predominates: an hypothesis. Exp Biol Med (Maywood) 2001,226(2):78-84.

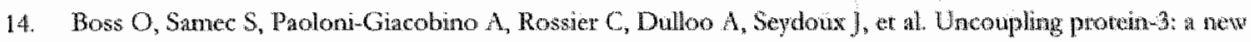
nember of the mitochondrial chrrier family with tissue-specific expression. 1EBS Lett 1997,408(1)39-42.

15. Hesselenk MK, Keizer HA, Borghours LB, Schart $G$, Kormips $C F$, Sleker M, et al. Protein expression of UCP3 differs berween human type 1, type 2a, atad gype 2b Gibers. Haseb ) 2001;15(6):1071 3.

16. Skarka L, Bardowa K, Brauner P, Flachs P, Jarkowska D, Kopecky J, et al. Expressom of miromondrial uncoupling protein 3 and adenine nucleotide translocase 1 genes in developing that heart putative involwement in control of mitochondrial membrane potential. I Mol Cell Cardiol $2003,35(3): 321-30$.

17. Vetor $R_{*}$ Fabris $\mathbb{R}$, Serm $R$, Lombardi $A M$, Tonello $C$, Granzoto $M$, et al. Changes in 1 AT/CD36, UCP2, UCP3 and GLUT4 gene expression during lipid infusion in mat sketetn and heart muscte. Int Obes Relat Metab Disord $2002,26(6), 838-47$.

18. Chrou Cl, Cha MC, Jung DW, Boozer CN, Hashim SA, Pi-Sunyer FX. High-fat diet feeding elewtites skeletal muscle uncoupling protein 3 levels but not its activity in rats. Obes Res 2001,9(5):313-9.

19. Schwowen D, Hocks J, Schaart G, Kornips E, Binas B, Van De Vusse GJ, et al. Uncoupling protein 3 as a mitochondrial farty acid anion exporter. Faseb ] 2003; 17 (1.5).

20. Jackson $\mathrm{S}$, Schater J, Middleton $\mathrm{B}$, Turnbull DM. Characterisation of a novel enzyme of hunnan faty acid beta-oxdlation: a matrix associnted, mitodhondribl 2 renoyl-CoA hydratase. Biochem Hiophys Res Comman $1995,214(1): 247-53$

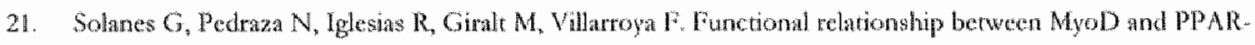
dependent regulatory pathwas in the control of the bunan uncoupling protedn-3 gene transcription Mol Findacinol 2003 ; in press.

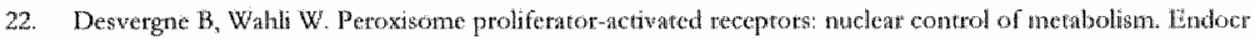
$R e \times 1.9992015) \cdot 649-88$

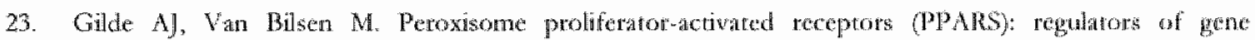
crpression in heart and skeletal muscle. Acta Physiol Scand 2003; $178(4) 425-34$.

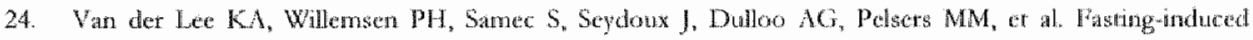

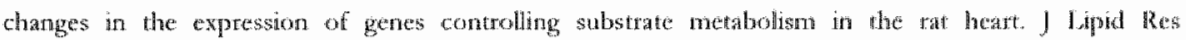
$200: 42(1) 1752-8$.

25. Goglin F, Skulachev YP. A fanction for nove] uncoupling proteins: antiowidan defense of mitchondtal matrix by manslocating fatty acid peroxides from the inner to the outer membiare leaflet. Paseb ] $2003,1712 \% 1585-91$

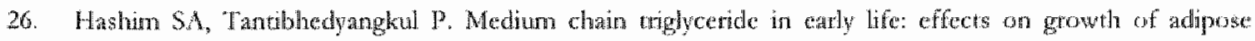
tissue. $\|$ ipids $1987,22(6): 429-34$.

27. Han J, Hamitor JA, Kirkland JL, Corkey BE, G to W. Medim-Chan Od Reduces Fut Mase and Downregulates Expression of Adpogenic Genes in Rats. Obes Res 2003;11(6);734,44. 


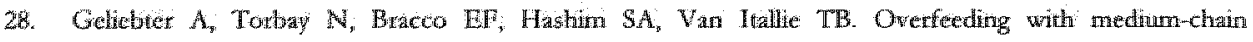
triglyceride diet tesuts in diminished depositom of fat Am ] Clin Nutr 1983,37(1):1-4.

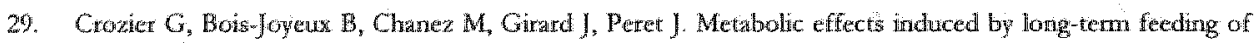
ricdum-chan mglycerides in the rat. Metholism 1987;36(8),807-14.

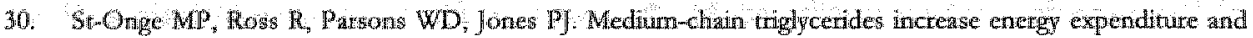
decrease adiposity in coverwe ght men. Obes Res $2003 ; 11(3) 395-402$.

31. Lotwwel NJ. Stock M]. Stimulaton of thermogenesis and browa fat activing in rats fed medium chain triglycende. Metabolism 1987,36(2):128-30.

32. Baba $\mathbb{N}$, $\mathbb{B}$ racco $\mathrm{EF}$, Hashim SA. Enhanced thermogenesis and dimirished deposition of far in response to overteding with diet containing medium chain triglyceride. Am J Cin Nutr 1982;35;4);678-82.

33. Lasekan JB, Rvera J, Hirvonen MD, Kewsey RE, Ney DM. Energy expendinare in rate maintained with intwavenous or intragastric infoision of total parenteral nutrition solutions containing medium- or long-chain triglyceride embisions. ] Nutt 1992;122(7),1483-92.

34. Dullow $A G$, Fathi $M_{3}$ Mensi $N$, Giradier $L$. Twenty-fouthour energy expenditure and wrinary catecholaminces of humans consuming low- owmoderate amounts of medium-dhain triglycerides: a doseresponse study in a human respiratory chamber, Eur / Clin Nutr 1996,50(3):152-8.

35. Scalf $\mathrm{L}$, Coltort $A$, Contaldo $\mathrm{F}$. Postprandial themogenesis in lean and obese subjects after meals supplemented with nedium-chain and long-chain triglycerides. Am I Clin Nutr 1991;53(5):1130m.

36. St-Onge MIP, Bourque $\mathrm{C}$, Jones PJ, Ross R, Parsons WE. Medium-versus long chatir tinglycerides for 27 days increases fat oxidation and energy expenditure without resuling in changes in body composition in overweight women. Int J Obes Relat Metab Disord 2003;27(1):95-102.

37. Seaton TB, Welle SL, Warenko MK, Campbell RG. Themic effect of medium-chain and long-chain triglycerides in man. Am ] Clin Nutr 1986;44(5):630-4.

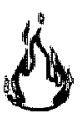




\section{The effect of high-fat feeding on} intramuscular lipid and lipid peroxidation levels in UCP3-ablated mice

Joris Hoeks, Matthijs K.C. Hesselink, Wim Sluiter, Gert Schaart, Jodil Willems, Alastair Morrisson, John C. Clapham, Wim H.M. Saris and Patrick Schrauwen

Departments of Human Biology and Movement Sciences, Nutrition and Toxicology Research Institute Maastricht (NUTRIM), Maastricht University, Maastricht. The Netherlands

Department of Biochemistry, Erasmus MC. Rotterdam. The Netherlands

Departments of Comparative Genomics and Vascular Biology, GlaxoSmithKline, Harlow, Essex United Kingdiom

FEBS Lett. 2006 (in press) 


\section{Abstract}

Uncoupling protein 3 (UCP3) has been suggested to protect against lipid-induced oxidative damage. Therefore, we studied intramuscular lipid peroxide levels and high-fat diet-induced alterations in muscle lipid metabolism of UCP3-ablated mice. UCP $3 \%$ mice showed $\sim 3$-fold higher levels of intramuscular lipid peroxides upon standard chow feeding, compared to wildtype littermates. Remarkably, this difference was no longer apparent on the high-fat diet. However, upon high-fat feeding, intramuscular triacylglycerol levels were $\sim 50 \%$ lower in UCP $3 \%$ mice, in comparison to UCP3 $3^{* /+}$ animals. Succinate dehydrogenase activity, and total protein content of the muscle fatty acid transporter FAT/CD36 were however similar between UCP3 $\%$ and UCP3 $3^{+/+}$mice. 


\section{Introduction}

Since the discovery of uncoupling protein 3 (UCP3) in 1997, many studies were devoted to the function of this UCP1 homologue, which is primarily expressed in skeletal muscle. However, its physiological role remains to be established. The most supported hypotheses concerning the physiological function of UCP3 state that this protein is either involved in the protection against reactive oxygen species (ROS) or has a role in fat metabolism. UCP3 is suggested to limit the production of ROS by mediating a mechanism of mild uncoupling resulting in a decrease in protonmotive force, thereby diminishing superoxide production (1).

Although there is support for a role of UCP3 in ROS defence (1-4), studies have also consistently observed that UCP3 content is increased when the supply of lipids to the muscle exceeds the capacity to oxidise these lipids (5-9), and is decreased when fatty acid oxidation is improved $(10,11)$ or lipid supply to the mitochondria is lowered (12). Together, these data suggest that UCP3 may specifically have a function in the defence against excessive ROS production under conditions of high-fatty acid supply to the mitochondria. In that context, we previously hypothesised that UCP3 is involved in the outward translocation of non-metabolisable fatty acid anions, to protect mitochondtia from the deleterious effects of intramitochondrial fatty acid accumulation (13). When the fatty acid supply to the mitochondria exceeds the oxidative capacity, and the load of fatty acids on the mitochondrial membrane increases, neutral fatty acids can enter the inner mitochondrial membrane and reach the matrix side through flip-flop (14), where they will be deprotonated due to the proton gradient across the inner mitochondrial membrane. Because the mitochondrial membrane is impermeable to the resulting fatty acid anions (15), and because the fatty acids cannot be oxidised due to the lack of activation by acyl-CoA synthase, they are trapped at the matrix side of the inner mitochondrial membrane. Since the mitochondrial matrix is also the sire where ROS are produced, these fatty acid anions are highly susceptible to peroxidation by the oxygen radicals. The resulting lipid peroxides are potentially hazardous to the mitochondrial proteins and DNA and could induce mitochondrial damage and dysfunction. By facilitating the export of these fatty acid anions, UCP3 could be involved in the protection of the mitochondria against: lipid-induced oxidative damage. In a variant of this hypothesis, Goglia and Skulachev (16) suggested that UCP3 exports lipid peroxicies, with the same 
protective function. Together with the anti-ROS hypothesis of the group of Brand $(1,17)$, these three hypothesis all predict that a lack of UCP 3 would eesults in lipidinduced oxidarive damage.

In this context, insulin resistant subjects and type 2 diabetics are characterised by high plasma free fatty acid levels and low oxidative capacity, theoretically demanding a high UCP3 protein content to protect mitochondria against lipidinduced oxidative damage. Interestingly, however, type 2 diaberic patients are characterised by a $50 \%$ reduction in UCP3 protein content (18), increased levels of lipid peroxides (19) and mitochondrial damage and dysfunction (20-24). It is therefore tempting to suggest that a low level of UCP3 fails to protect fatty acids against ROS-induced peroxidation, ultimately leading to lipid-induced mitochondrial damage in type 2 diabetic patients (25)

Therefore, we anticipated that lack of UCP3 would lead to increased levels of musculat lipid peroxides uncler diabetogenic conditions, such as on a high-fat diet and investigated the effect of UCP3 ablation on intramuscular lipid peroxide levels and high-fat diet-induced alterations in muscle lipid metabolism.

\section{Methods}

\section{Animals}

Sixteen UCP3-ablated (aged: $12.2 \pm 1.3$ weeks) and twelve wildtype littermates (aged: $12.8 \pm 1.2$ weeks), original breeding pairs a gift from GlaxoSmithKline (Iatlow, UK), were used in the present study (26). The mice were housed individually on a 12:12 h light-dark cycle (light from 7:00 am to 7:00 pm), at 21$22^{\circ} \mathrm{C}$ and subjected to a four week-week dietary intervention. During the experiments, mice had free access to tap water. All experiments were approved by the Institutional Animal Care and Use Committee of the Maastricht University and complied with the principles of laboratory animal care.

\section{Diets}

UCP3-ablated mice (UCP3 $\%$ ) and their wildtype littermates (UCP3 ${ }^{+/}$) were randomly divided into a total of four groups. Eight UCP $3 \%$ and six UCP3 $\% /+$ mice had unlimited access to standard chow diet (ssniffe $\mathrm{t} / \mathrm{m}-\mathrm{h} 10 \mathrm{~mm}$, Bio Services, Uden, The Netherlands, $16.3 \mathrm{MJ} / \mathrm{kg}, 7.5 \mathbb{E N} \%$ from fat) for the duration of four weeks. Another eight UCP3 $\%$ and six $\mathrm{UCP}^{+/+}$mice wese maintained on a high-fat 
diet (4031.10, Hope Farms, Woerden, The Netherlands, $19.8 \mathrm{MI} / \mathrm{kg}, 45 \mathrm{EN} \%$ from Eat,), which was also provided ad likitum. In the high-fat diet, the fat component was comprised of $\mathrm{C} 16: 0(\sim 25 \%), \mathrm{C} 18: 0(\sim 34 \%), \mathrm{C} 18: 1(\sim 33 \%), \mathrm{C} 18: 2$ $(\sim 3 \%)$ and $\mathrm{C} 24: 0(\sim 5 \%)$. Food intake and body mass were recorded.

\section{Tissue sampling}

After the four-week dietary intervention period, tissue dissection was performed under general anaesthesia (1.5-2.0\% halothane in $\mathrm{O}_{2}$ and $\mathrm{N}_{2} \mathrm{O}$ [3:1, 4.0 $\left./ \mathrm{min}\right]$ ). Mice were deprived from food approximately 8 hours prior to tissue sampling. For histological analysis, the mid-belly region of the left tibialis anterior muscle was dissected and freed from any visible fat and blood, embedded in Tissue-Tek (Sakura Finetek, Zoeterwoude, The Netherlands) and rapidly frozen in liquid nitrogen-cooled isopentane (2-methyl-butane, Fluka, Zwijndrecht, The Netherlands). The tibialis anteriot muscle of the contralateral leg was dissected and immediately frozen in liquid nitrogen for the determination of lipid hydroperoxide (LPO) levels. All samples were stored at $-80^{\circ} \mathrm{C}$ until further analysis.

\section{Determination of intramuscular lipid bydroperoxides}

Snap-frozen tissues in liquid nitrogen were pulverised during three min at 1800 rpm in a Braun Mikro-dismembrator homogeniser type $U$ (Braun Biotech Int, Melsungen, Germany) using a PTFE-coated steel bead of $10 \mathrm{~mm}$ in diameter, next suspended 1:3 (wt/wol) in phosphate-buffered saline, $\mathrm{pH}$ 7.4, supplemented with 4 $\mathrm{mM}$ butylated hydroxytoluene and further homogenised at $44^{\circ} \mathrm{C}$ using a Teflon hand-held pestle in an Eppendorf vial. The concentration of lipid hydroperoxides (LPO) of the homogenate was determined after incubation with $35 \mathrm{U} / \mathrm{mil}$ catalase for two min at room temperature to inactivate any hydrogen peroxide, by the ferric iron-dependent increase in absorbance of xylenol-orange at $560 \mathrm{~nm}$ (lipid hydroperoxide apparent $\varepsilon=0.08904 \mu \mathrm{M}^{-1} \mathrm{~cm}^{-1}$, experimentally assessed using freshly-made reagents only and standard curves of $t$-butyl peroxide and cumene peroxide) essentially as described by Nourooz-Zadeh et al. (27) using the sample treated by $0.9 \mathrm{mM}$ tris(2-carboxyethyl)phosphine to reduce the LPO to their respective alcohols as the reference. 


\section{Histological analysis}

Cryosections $(5 \mu \mathrm{m})$ were thaw-mounted on uncoated pre-cleaned $(96 \%$ ethanol) glass slides. Immediately after mounting, air-dried, fresh cryosections were stained for intramuscular tracylglycerols (IMTG) by Oil Red $O$ staining (ORO) (28) combined with immunolabelling of the basal membrane marker laminin, to allow quantification of IMTG. Serial sections were stained for activity of succinate dehydrogenase (SDH), also known as complex II in the electron transport chain, to determine the oxidative capacity of skeletal muscle, largely according to (29).

\section{IMTG analysis}

Briefly, cryosections were fixed in $3.7 \%$ formaldehyde for $1 \mathrm{~h}$. Then the sections were treated with $0.5 \%$ Triton X-100 in PBS for 5 min, and washed three times with PBS. Thereafter, sections were incubated for $30 \mathrm{~min}$ with a polyclonal rabbit antibody against the basement membrane protein laminin (Sigma-Aldrich, St. Louis, MO, USA, 1:50 dilution in PBS) to visualise individual cell membranes followed by a $30 \mathrm{~min}$ incubation with a Alexa350-conjugated goat anti-rabbit (Invitrogen Molecular Probes, Leiden, The Netherlands; 1:80 dilution in PBS). After washing with PBS, glass slides were immersed in the ORO working solution for $30 \mathrm{~min}$ for the detection of lipid droplets (17) and rinsed three times with deionised water for 30 s followed by 10 min of washing with running tap water. Stained sections were embedded in Mowiol.

\section{SDH activity analysis}

Cryosections were incubated in a $0.2 \mathrm{M}$ sodium phosphate buffer containing $0.1 \mathrm{M}$ succinic acid (Sigma-Aldrich, St. Louis, MO, USA) and $1.2 \mathrm{mM}$ nitro-blue tetrazolium (Sigma-Aldrich, St. Louis, MO, USA). Incubation was performed at a strictly controlled temperature of $37^{\circ} \mathrm{C}$ for the duration of 60 minutes. Next, sections were shortly rinsed with deionised water followed by three successive exchanges in 30,60 and $90 \%$ acetone in deionised water, respectively. SDH-stained sections were air-dried for $15 \mathrm{~min}$. Thereafter, also these sections were incubated for $30 \mathrm{~min}$ with the laminin-antibody and a FITC-conjugated secondary antibody (Southem Biotechnology Associates, ITK, Uithoom, The Netherlands), respectively, to visualise the cell membranes. Stained sections were embedded in Mowiol. Following this procedure sites of high SDH activity are coloured greyblue whereas low SDH activity results in a pale colour (29). 


\section{Image capturing, processing, and analysis}

All sections were examined using a Nikon E800 fluorescence microscope (Nikon Instruments Europe B.V., Badhoevedorp, The Netherlands) coupled to a Basler A101C progressive scan colour charge-coupled device camera. Multiple random images were captured for every single colour (red and blue) in case of the Oil red $O$ and in bright field for the SDH activity staining. The fluorescent signal representing the cellular membrane in de $\mathrm{SDH}$ stained sections was grabbed in the appropriate channel (green) and SDH activity was imaged using bright field. Both images, as well as the merged overlay were saved. All sections were processed and analysed using Lucia GF 4.80 software (Nikon, Düsseldorf, Germany). Special care was taken to use the same camera settings (gain and exposure time, and woltage and diaphragm in case of bright field) while grabbing all images. For both SDH and IMTG $>120$ cells per muscle were analysed.

IMTG

All images were analysed for the lipid droplet over myocyte area fraction. To this end, a semiautomatic macro was written that allowed 1) autodetection of the cellular membrane (identified in the blue channel); 2) measurement of the area covered by the measured myocytes; and 3) measurement of the area covered by lipid droplets (identified in the red channel). The area fraction was computed by dividing the area covered by lipid droplets (in $\mu \mathrm{m}^{2}$ ) by the cell surface of the measured myocytes (in $\mu \mathrm{m}^{2}$ ). The mean area fraction thus reflects the percentage of the total measured cell surface covered by lipid droplets.

SDH activity

Like in the IMTG analyses, a semiautomatic macro was used to identify the cellular membrane. The bright-field image of SDH activity was converted to 8-bits greyscale after which integral optical density of every pixel in individual muscle cells was measured. The mean optical density of every individual cell was computed and used as a semi-quantitative read-out for $\mathrm{SDH}$ activity. Similar methods have previously been shown to correlate well with whole muscle homogenate spectrophotometrical analysis of SDH activity $(30,31)$.

\section{Western blot analysis of $\mathrm{FAT} / \mathrm{CD} 36$}

Muscle homogenates were analysed for the muscle fatty acid transporter FAT/CD36 by Western blotting according to the procedure described by Keizer et 
al. (32). After clectrophoresis and blotting, nitrocellulose membranes were blocked for 20 min with $5 \%$ non-fat dry milk in $0.05 \%$ Tween $20 / \mathrm{PBS}$ and incubated with a mouse IgA monoclonal antibody raised against mouse FAT/CD36 (MAB1258Chemicon, Invitrogen, Breda, The Netherlands) 1:10,000 in blocking buffer. After the primary ancibody incubation, the membranes were incubated for 60 min with a horseradish peroxidase-conjugated rabbit anti-mouse IgA (Southern Biotechnology Associates, ITK, Uithoorn, The Netherlands) at a dilution of 1:5,000 in blocking buffer, The membranes were then washed for $1.5 \mathrm{~h}$ in $0.05 \%$ Tween $20 / \mathrm{PBS}$ and again for $10 \mathrm{~min}$ in PBS. Subsequently, they were treated for $1 \mathrm{~min}$ with enhanced chemiluminescence substrate (Super Signal West Dura Extended Duration Substrate; Pierce/Perbio Science, Etten-Leur, The Netherlands). Finally, nitrocellulose membranes were exposed to X-ray film (CL-Xposure Film; Pierce/Perbio Science) for $1 \mathrm{~min}$ and analysed by densitometry using Imagemaster (Pharmacia Biotech).

\section{Statistical analysis}

Results are presented as mean $上 S E M$. Differences within animals were analysed by the Wilcoxon signed-rank test for paired samples. Differences between genotypes were evaluated by the Mann-Whitney test for independent samples. Outcomes were regarded as statistically significant if $p<0.05$.

\section{Results}

\section{Body mass and food intake}

Initial body mass in the chow gtoup was not statistically different between genotypes $\left(20.6 \pm 1.0 \mathrm{vs} .24 .6 \pm 1.9 \mathrm{~g}\right.$ in UCP3 $\%$ and $\mathrm{UCP}^{+\gamma+}$ mice, respectively, $p=0.14$ ). Four weeks of chow feeding did not change body mass, neither in UCP $3 \%$ nor in UCP3 $3^{+/ *}$ animals (by $0.3 \pm 0.6 \mathrm{vs} .-0.5 \pm 1.1 \mathrm{~g}$ in UCP $\%$ and UCP $3^{*+*}$ animals respectively, NS). Gross energy intake during four weeks of chow feeding was significantly lower in UCP3 $\%$ animals, compared to their wildtype littermates $(1693 \pm 63$ vs. $1874 \pm 47 \mathrm{~kJ} / 4$ weeks, $p=0.043)$. The gross energy intake positively correlated with initial body mass $(\mathrm{r}=0.53 ; p=0.052)$ and when expressed per gram of initial body mass, gross energy intake was not significantly different between the groups (UCP3 $/: 82.9 \pm 3.5 ; \mathrm{UCP}^{+/+}: 78.6 \pm$ $6.2 \mathrm{~kJ} / \mathrm{g} / 4$ weeks, $p=0.49$, NS). 


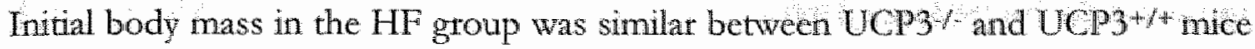
$(21.4 \pm 1.4 \mathrm{vs} .24 .4 \pm 1.8 \mathrm{~g}$, respectively, $p=0.18$ ). Four weeks of $\mathrm{HF}$ feeding significantly increased body mass in both genotypes (by $1.6 \pm 0.4 \mathrm{~g}[p=0.012] \mathrm{in}$ UCP3 $1 \%$ and by $2.4 \pm 1.0 \mathrm{~g}[p=0.046]$ in $\left.\mathrm{UCP}^{+/+}\right)$. The increase in body mass upon HF feeding, was not different between the two genotypes $(p=0.76)$. Gross enetgy intake upon HF diet was comparable in UCP3/- and UCP3 $3^{+/+}$mice $(1929 \pm 82 \mathrm{vs}$. $2189 \pm 107 \mathrm{~kJ} / 4$ weeks, respectively, $p=0.11$ ), and correlated with initial body mass $(r=0.74 ; p=0.002)$. Gross energy intake per gram of initial body mass was similar between genotypes (UCP3 $\% 91.7 \pm 4.0 ; \mathrm{UCP}^{+/ 4}: 91.6 \pm 6.1 \mathrm{~kJ} / \mathrm{g} / 4$ weeks, $p=0.85, \mathrm{NS}$ ).

\section{Intramuscular lipid bydroperaxides (LPO)}

UCP3 $\%$ animals $(n=8)$ showed significantly higher levels of intramuscular LPO upon chow feeding, as compared to UCP3 $3^{++}(n=6)$ mice $(38.2 \pm 11.2$ vs. $12.5 \pm$ $0.9 \mathrm{nmol} / \mathrm{g}$ wet weight, $p=0.001)$. Surprisingly, 4 weeks of high-fat feeding resulted in similar $\mathrm{LPO}$ levels in UCP3- vs. UCP3+/+ mice $(13.6 \pm 3.2[\mathrm{n}=8]$ vs. $16.2 \pm 5.1$ $\mathrm{nmol} / \mathrm{g}$ wet weight $[\mathrm{n}=0]$, respectively, $p=0.85$, NS; fig. 6.1).

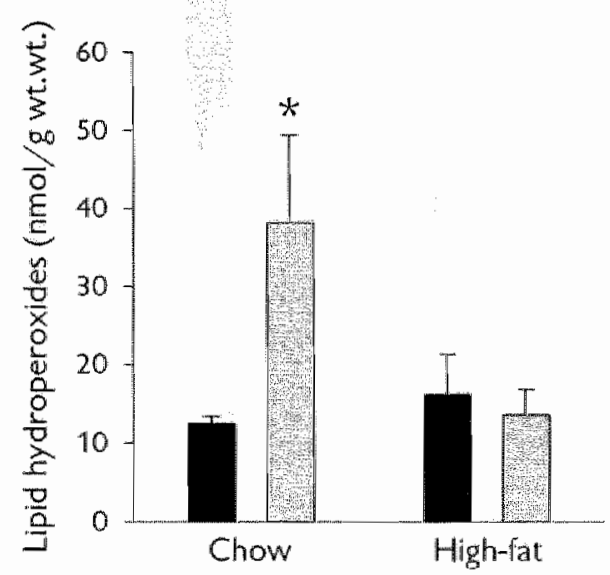

Figure 6.1 Intramuscular lipid hydroperoxide levels in $m$. tibialis anterior upon chow and high-fat feeding. Black bars, UCP3 $3^{+*}$ mice; grey bars UCP3 mice. Values are mean \pm SEM." $p<0.05$ compared to UCP3 $3^{* / 4}$ upon chow reeding. 


\section{Intramuscular triagylgherol levels}

Upon chow feeding, no differences in IMTG levels (fig. 6.2) were found between UCP3 $\%(n=8)$ and UCP $3+1+(n=6)$ animals $(0.68 \pm 0.44$ vs. $0.72 \pm 0.32 \%$ of the cell surface covered by lipid droplets, tespectively, $p=0.70$, NS). After four weeks of $\mathrm{HF}$ diet, IMTG levels were significantly lower in the UCP3 $\%(\mathrm{n}=8)$ animals compared to their wildtype $(n=5)$ littermates $(1.39 \pm 0.44 \%$ vs. $3.01 \pm 0.35 \%$, respectively, $p=0.019$ ).

\section{Oxidative capacity}

Oxidative capacity, measured as SDH activity, was similar in UCP $3^{-/}$and $\mathrm{UCP} 3^{+/+}$ mice, after chow (UCP3 $\% 0.32 \pm 0.05[\mathrm{n}=7]$ vs: $\mathrm{UCP} 3^{+/+}: 0.31 \pm 0.06 \mathrm{AU}[\mathrm{n}=4]$ ) as well as after $\mathrm{HF}$ feeding (UCP3- $-0.36 \pm 0.08[\mathrm{n}=7]$ vs. UCP3 $3^{+/+}: 0.39 \pm 0.06$ $\mathrm{AU}[\mathrm{n}=5])$.

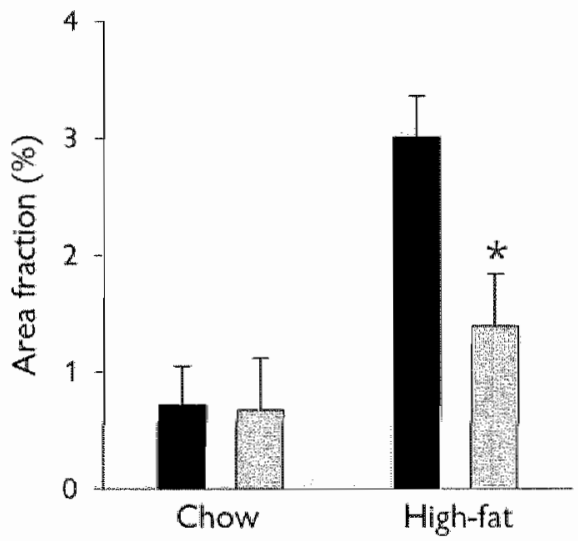

Figure 6.2 Intramuscular triacylglycerol (MTG) levels in $\mathrm{m}$. tibialis anterior after 4 weeks of chow or hightat feeding. Black bars, UCP3 ${ }^{\text {th }}$ mice, grey bars, UCP $3^{*}$ mice. Vallues are mean $\pm 5 E M$. $p<0.05$ compared to UCP3 $3^{\text {t/t }}$ upon high-fat feeding.

\section{Fatty acid transporter F $A T / C D 36$}

Protein levels of FAT/CD36, determined by Western blotting, were similar between $\mathrm{UCP} 3 \%(\mathrm{n}=4)$ and $\mathrm{UCP} 3^{+/+}(\mathrm{n}=5)$ mice after chow feeding and averaged $124 \pm 25$ and $101 \pm 24 \mathrm{AU}$, respectively.

Also after 4 weeks of high-fat diet, no significant differences were detected between $U C P 3 /(73 \pm 19 \mathrm{AU}, \mathrm{n}=8)$ and $\mathrm{UCP}^{+/ *}(86 \pm 13 \mathrm{AU}, \mathrm{n}=5)$ mice. 


\section{Discussion}

The physiological function of UCP3 is still under debate. However, several lines of evidence point towards a role for this mitochondrial protein in protection against lipid-induced oxidative damage to mitochondria. We have previously hypothesised that UCP3 fulfils this protective role in skeletal muscle mitochondria by exporting non-metabolisable fatty acid anions away from the side of the mitochondrial matrix, a function especially important in situations of increased lipid supply. Reactive oxygen species, regarded as inevitable by-products of normal aerobic metabolism, can peroxidise these fatty acid anions, giving rise to toxic and highly reactive lipid peroxides that would be trapped in the inner mitochondrial membrane and/or matrix. In addition to this putative role of UCP3, it has also been hypothesised that UCP3, upon activation by lipid peroxides (such as 4hydroxy-trans-2-nonenal, 4-HNE), reduces ROS production directly $(1,3,17)$. Indeed, Echtay et al. (1) showed that 4-HNE was able to uncouple skeletal muscle mitochondria in the absence, but not in the presence of GDP, indicative of UCPmediated uncoupling. Moreover, the uncoupling effect of 4-HNE was significantly less in UCP3-ablated mice compared to wildtype mitochondria (1). Furthermore, GDP did not prevent the stimulation of proton conductance in UCP3-ablated mice. Thus, the increased UCP3 activity upon lipid peroxides, such as 4-HNE, lowers protonmotive force and results in a decrease in superoxide production, thereby providing a simple feedback loop (17).

However, according to both hypotheses, UCP3 ablation would lead to increased levels of lipid peroxides, especially during lipid oversupply. Here we show that UCP3-ablated mice display significantly higher levels of intramuscular lipid hydroperoxides upon standard chow feeding. Surprisingly, however, no increase in lipid peroxidation in UCP3\% mice was observed on a high-fat diet, but under this condition, other adaptive mechanisms seem to operate preventing further augmentation of intramuscular lipid peroxides.

In addition to confirming the previous finding that levels of lipid peroxides are increased in UCP $3 /$ - mice on a chow diet (2), the present study remarkably showed that, UCP3 $\%$ mice did not differ in their levels of lipid peroxides upon a high-fat diet, as would have been expected on the basis of the present hypotheses on the physiological function of UCP3. This may indicate that UCP3 is not important in the prevention of ROS production under high-fat conditions. More likely, however, UCP3 $\%$ animals may display other protective mechanisms to cope with 
the incteased lipid supply and/or increased ROS production. To elucidate that, we examined whether UCP $3 \%$ mice on a high-fat diet were able to limit the storage of muscular fatty acids. To this end, we measured intramuscular triacylglycerol (IMTG) levels by Oil Red O staining in UCP $3 \%$ and UCP $3^{+/ *}$ mice, both after chow and high-fat feeding. Surprisingly, UCP $3 \%$ mice were indeed characterised by matkedly lower IMTG levels $(\sim 54 \%)$ compared to their wildtype littermates upon 4 weeks of high-fat diet. The difference in lipid peroxidation between UCP3 $\%$ and UCP3 $+/ \%$ mice upon chow feeding, would be maintained $(p=0.06)$ under high-fat conditions if the muscular lipid peroxidation is expressed per unit of muscular lipid. However, our data clearly illustrate that this is not directly due to the lack of protection by UCP3, but due to a rematkable lowering of the amount of intramuscular lipids. In fact, IMTG levels in UCP3- mice fed a high-fat diet were only marginally higher compared to chow-fed UCP3\% mice, whereas in wildtype animals, 4 weeks of HF diet caused a $\sim 4$.4-fold increase in IMTG levels. These differences could not be accounted for by differences in muscle fibre type distribution (data not shown). A reduction in IMTG levels can, based on the putative functions of UCP3, not be directly deduced from the lack of UCP3 and it is therefore tempting to speculate that the reduction in IMTG represents an adaptive mechanism to limit peroxidation of muscular fatty acids by the increased ROS production that has been observed in muscle of UCP3 $\%$ mice on a regular diet $(2,4)$.

To address the question how UCP3\% mice are capable of limiting intramuscular fat accumulation upon a high-fat diet, we examined oxidative capacity in these mice. However, we could not detect any differences in oxidative capacity between $\mathrm{UCP} 3 \%$ and $\mathrm{UCP} 3^{+/+}$mice, neither on a chow not on a high-fat diet. These results are compatible with the finding that UCP3 ablation on a chow diet had no effect on markers of fatty acid oxidation (33), as well as with the results of Vidal-Puig et al. (4) who were unable to show a difference in fatty acid oxidation between UCP3 $\%$ and UCP3 $3^{+/+}$mice, neither in sedentary nor in exercised animals. Moteover, in the fasted state an impaired, in contrast to improved, fat oxidation in UCP3 $\%$ mice was observed (34).

Vidal-Puig et al. (4) reported earlier that UCP3 $/$ mice display increased plasma free fatty acid levels, when challenged with a high-fat diet. This finding indicates that the lower IMTG levels that we observed in UCP3 $\%$ mice upon high-fat feeding, cannot be explained by a diminished supply of fatty acids to the muscle, but is suggestive for a decreased fat uptake in muscle. To this end, we determined protein levels of the muscle fatty acid transporter, FAT/CD36, which has been 
shown to be involved in the uptake of plasma free fatty acids into skeletal muscle. Nevertheless, we could not detect any differences in the protein levels of FAT/CD36 between UCP3 $\%$ and UCP3 $+1+$ mice. However, controlled measurements with labelled fatty acids may be required to exclude the possibility of diminished fatty acid uptake in skeletal muscle from UCP3 mice upon high-fat feeding.

In summary, UCP $3 \%$ mice show significantly higher levels of intramuscular lipid peroxides upon standard chow feeding, as compared to their wildtype littermates. Remarkably however, no differences were observed in the levels of lipid peroxides after 4 weeks of a HF diet. The latter observation was accompanied by the finding that, upon HF feeding, IMTG levels were markedly lower in UCP3\% mice, in comparison to the UCP3 $3^{+/+}$animals. Differences in oxidative capacity, as assessed by SDH activity, or the protein levels of FAT/CD36 could not account for the lower IMTG levels, observed in UCP3-ablated mice on a $\mathrm{HF}^{-}$diet. Therefore, the exact underlying (molecular) mechanism for the reduced IMTG levels in UCP $3 \%$ mice remains to be established.

These data also indicate that the UCP $\%$ mouse may not be the best model to answer the question whether low UCP3 levels will lead to lipid-induced mitochondrial damage and contribute to the pathogenesis of type 2 diabetes, as we have previously suggested (25). Such information, however, is eagerly awaited since insulin resistant subjects and/or type 2 diabetic patients are characterised by a $50 \%$ reduction of UCP3 protein content (18) and are also characterised by increased levels of lipid peroxidation (19) and mitochondrial damage (20), but may require novel methodologies such as siRNA to acurely suppress UCP3. The adaptive capacity to reduce IMTG levels in UCP3 - mice may also explain why these mice have no apparent phenotype (such as obesity and diabetes).

\section{Acknowledgements}

M. Sc. J. Hoeks was supported by a grant from the Netherlands Organisation for Scientific Research (NWO) and the research of Dr. P. Schrauwen has been made possible by a fellowship of the Royal Netherlands Academy of Arts and Sciences. 


\section{References}

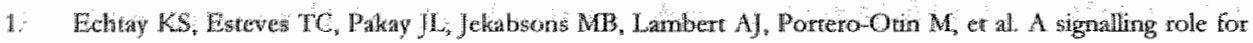

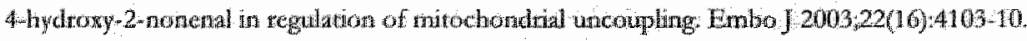

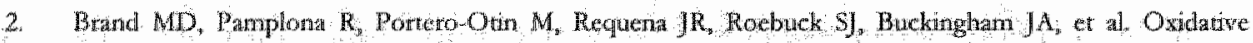
damage and phospholud faty aryl composition in sketctal muscle mitodhondria from mice

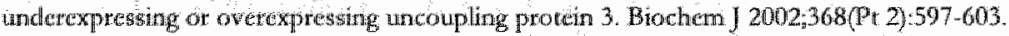

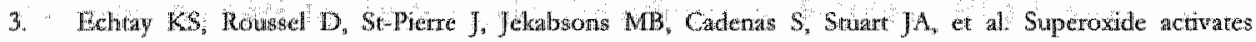

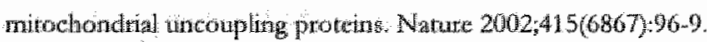

4. Vidal Pug $\mathrm{A}$. Grutic $\mathrm{D}$, Zhang $C Y$, Hagen $T$, Boss $O$, Ido $Y$, et al. Energy nuetabolism in uncoupling protein 3 gene knockot mice. I Biol Chem 2000;275(21),16258-66.

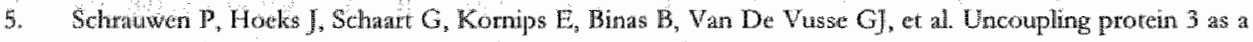

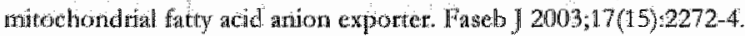

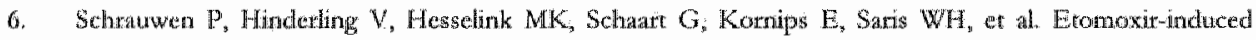
increase in UCP3 supports a role of uncoupling protein 3 as a mitochondrial farry acid anion expotter. Pask J 2002;16(12):1688-90.

7. Schrawen P, Hoppeler H, Billeter R, Bakker AH, Fendergast DR. Fber type dependere upregulation of huma sketetal muscle UCP2 and UCP3 mRNA expression by high-far elliet. Int of Obes Reat Metab Disotd $2001 ; 25(4): 449-56$.

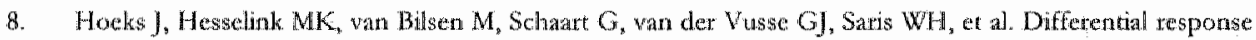
of UCP3 to medium wers as long chain friacylgycerols; manifestation of a functional adaptation. FEBS Let: $2003,555,3): 6311-7$.

9. Hesselink MK, Keizer HA, Borghouts LB, Schart G, Kornips CF, Sliether LJ, et al. Protein expression of UCP3 differs between human type 1, type 2a, and type 2b fibres. Faseb ] 2001;15(6):1071-3.

10. Russell AP, Somm E, Pra M, Crettenand A, Hartley O, Meloti A, et al. UCP3 protein regulation in human

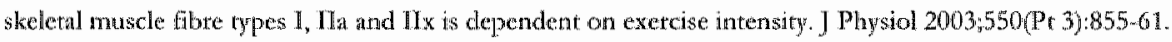

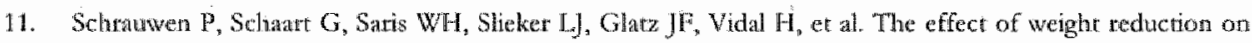
skeleral muscle UCP2 and UCP3 mRNA expession and UCP3 protein content in Type II diabetic subjects. Disberologia $2000 \% 43(11): 1408-10$.

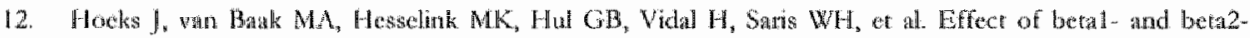

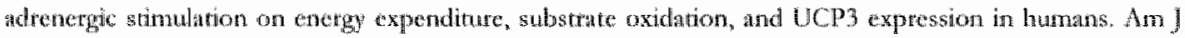
Physalol lindocrinol Matab 2003;285(4):E775-82.

13. Schawwen P, Saxis WH, Hesselnk MK. An altermative functon for humen uncoupling protein 3:

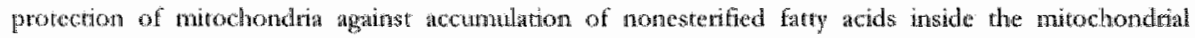
matrix. Giseb J $2001,15(13), 2407-502$.

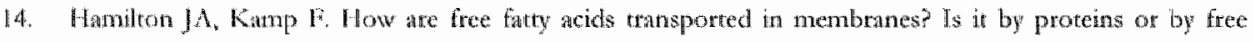
diffusion through the lipids: Diaberes $1099,48(12): 2255-69$.

15. Jexk P, Otose DI, Modiansky M, Garlid KD. Temsport of anions and protons by the mitochondral ancotylng protein and its regulation by nucleocides and fatry acids. A new look at old hypotheses. J Biol Chen $1994269(42) \times 26184-20$.

16. Goglia D, Skulacher VP. A tuncton for novel uncoupling proteins: antioxiclane detense of mitochondrial matrix by thuslocating tatry acid peroxides from the inner to the ouren nembrante leaflet. Jaseb J $2003,17(12): 1585-91$.

17. Brand MD, Buckingham JA, Esteves TC, Gren K, Lambert Al, Miwa S, it al Mirochondrial superoxide and aging tuncoupling protein activity and superoxide production. Biochem Soc Symp 200471):203-13. 


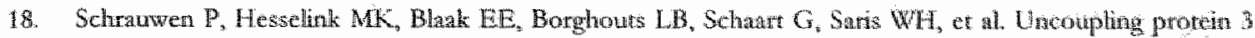
content is decreased in sheletul muscle of patients with rype 2 diabetes. Diaberes 200150012 y 3879

19. Wusell AP, Gastaldi G, Bobbioni-Harsch E, Arboir P, Gobelet C, Deriaz O, at Lipid peroxidnan in

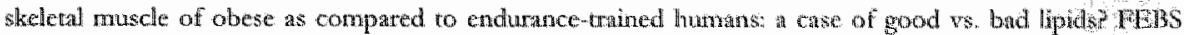
Lett $2003,551(1-3): 1046$.

20. Kelley $D E$, He J, Menshitowa EV, Ritov VB. Dysfucton of mitochondria un buman skeletal muscle in Dpe 2 diabietes. Diabetes 2002;51(10):29:44-50.

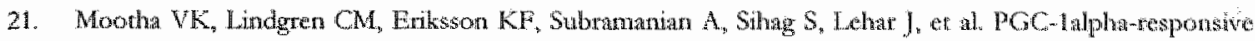
genes inwolved in oxidative phosphorylation are coordinately downreguated in loman dinberes. Nat Genet $2003 ; 34(3): 267-73$.

22. Patti ME, Bute A, Crumhom $S$, Cusi $K$, Berra $R$, Kashysap $S$, er al Coordinated reducton of gemes of oxidative metabolism in humans with insulin resistance and diabetes: Potental role of PGC1 and NRJ Proc Nad Acad Sci U S A 2003;100(14):8466-71

23. Petersen KF, Befroy D, Dufour $S$, Dxiura J, Aryan C, Rothman DL, et al. Mitochondrial dystunction in the elderly: possible role in insulin resistance Science $2003,300(5622): 1140-2$

24. Petersen KF, Dufour $S$, Befroy $D$, Gatcia $R$, Shulman GI. Impaired mitochondrial acrivity ith the insulin uesistant offspring of patients with type 2 diabeces. N Engl I Med 2004:350(7):664-71

25. Schrauwen P. Hesselink MK. Oxidative capacity, lporoxicity, and mitochondrial damage in type 2 diabetes. Diabetes $2004 ; 53(6) ; 1412-7$.

26. Cademas S, Echay $\mathrm{KS}_{3}$ Harper JA, Jekabsons MB, Buckingham JA, Grat lit et al The basal proton conductance of skeletal muscle mitochondria from transgenic mice oxerexpressing or lacking uncoupling protein 3. J Biol Chem 2002;277(4):2773-8.

27. Nourooz-Zadeh ], Tajaddini-Samadi J, Wolft SP. Measurenuent of plasma hydroperoxide concentrations by the fetous oxidation xylenol orange assay in conjunction with triphenylphosphine Anal Biochem $1994,220(2) ; 403 \% 9$

28. Koopmat. $\mathrm{R}$, Schart $\mathrm{G}$, Hesselink MK. Optimisation of oil red $\mathrm{O}$ staining permits combination with immunofuctescence and automated quantificarion of lipids. Histochem Cell Biol 2001:1 16(1):63-8.

29. Sheehan DC, Hrapchak BB. "Theory and Practice of Histotechnology, 2nd ed. Ohio: Batelle Press; 1987.

30. Skorjane $D$, Heine $G$, Pette $D$. lime-dependent increase of succinate delydrogenase acriviry in low trequency sismulated rabbir masclo: a comparison between microphotometric and biochemical methods. Histochern Cell Biol 1997;107(1):47.55.

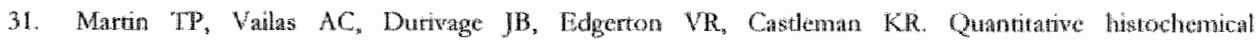

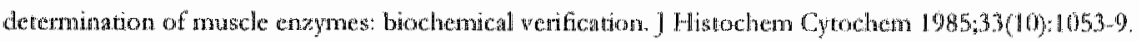

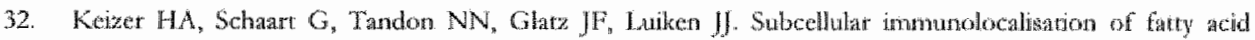

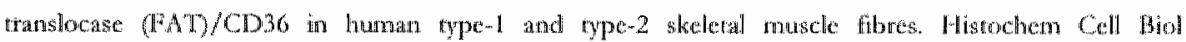
$2004: 121(2): 101 \% 7$.

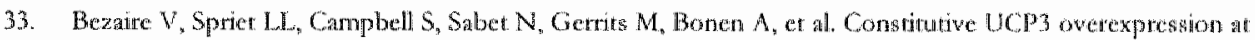
physiological levels increases mouse sheletal muscle capacity for faty acid transport and oxidation. Faseb 2005.

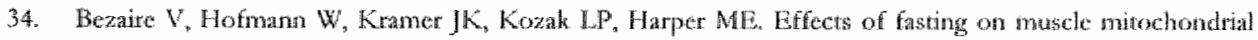
energetics and fatty acid metabolism in Ucp3(-/-) and with-rype mice. An J Physiol Endocrinol Menab $2001 \div 281:(5): 8975-82$. 


\section{7}

\section{Down-regulation of PGC- $1 \alpha$ and PPAR $\alpha$ upon lipid-induced insulin}

resistance in human skeletal muscle depends on muscular fat accumulation

Joris Hoeks, Matthijs K.C. Hesselink, Aaron P. Russell, Marco Mensink, Wim H.M. Saris, Ronald P. Mensink and Patrick Schrauwen

Departments of Human Biology and Movement Sciences, Nutrition and Toxicology Reseanch Institute Maastricht (NUTRIM). Maastricht University. Maastricht, The Netherlands

Wageningen Centre for Food Sciences (WCFS), Wageningen. The Netherlands Clinique Romande de Readaptation SUVA Care, Sion. Switzerland 


\section{Abstract}

In the present study, we examined whether lipid-induced insulin resistance was associated with a down-regulation in the expression of skeletal muscle genes inwolved in oxidative metabolism and mitochondrial biogenesis in humans. To test if intramuscular fat accumulation affects gene expression profiles, a lipid emulsion with readily oxidisable medium chain fatty acids (MCT/LCT) was tested against a lipogenic emulsion with long chain fatty acids (LCT).

A $6 \mathrm{~h}$ infusion of long chain triacylglycerols, leading to insulin resistance and accompanied by a $\sim 1.7$-fold increase in intramuscular lipids decreased PGC-1 $\alpha$ and PPARa expression down to $\sim 61 \%$ and $\sim 52 \%$ of baseline, respectively. Infusion of a mixture of medium and long chain triacylglycerols (50/50\%) up to similar plasma free farty acid levels caused a similar reduction in insulin sensitivity, but did not result in increased muscular fat content and did not reduce PGC-1 $\alpha$ and PPAR $\alpha$ expression. UCP3 gene expression was more pronouncedly upregulated upon LCT in comparison to MCT/LCT.

In conclusion, our results indicate that lipid-induced insulin resistance is accompanted by down-regulation of PGC-1 $\alpha$ and PPAR $\alpha$ and that accumulation of fat inside muscle tather than high circulatory free fatty acid concentrations per se, is of importance for the reduced gene expression levels. The up-regulation of UCP3 upon LCT infusion is in support of the putative role of uncoupling protein 3 (UCP3) in the protection of mitochondria against lipotoxicity. 


\section{Introduction}

There is compelling evidence that disturbances in fatty acid metabolism play a pivotal role in causing insulin resistance, a predictive factor in the pathogenesis of type 2 diabetes mellitus. For example, accumulation of triacylglycerols in skelletal muscle has been shown to be highly associated with insulin resistance (1-3) and the insulin resistant state can even be induced in healthy individuals by the infusion of lipids, most likely due to accumulation of lipid derivatives and subsequent insulinsignalling disturbing effects (4-7).

Recently, an impaired mitochondrial functioning has also been identified as a key determinant in the aetiology of type 2 diabetes. Hence, it was shown that skeletal muscle mitochondria from type 2 diabetic patients were smaller, showed more damage and displayed a reduced functional capacity (8). In addition, Petersen et al. (9) showed that elder, insulin resistant, subjects were characterised by higher levels of intramuscular lipids in comparison with young controls matched for body composition. This finding was accompanied by a $40 \%$ reduction in mitochondrial oxidative and phosphorylation activity in these subjects (9). A molecular explanation for these findings was provided by two independent studies, showing that the expression of a cluster of genes involved in oxidative phosphorylation and under transcriptional control of peroxisome proliferator-activated receptor (PPAR)- $\gamma$ co-activator $1 \alpha$ (PGC-1 $\alpha)$, was reduced in human type 2 diabetes (10, 11).

These findings may suggest that a reduced mitochondrial function is responsible for the accumulation of muscular fat, ultimately leading to insulin resistance. However, it is equally well possible that frequent consumption of high-fat diabetogenic diets, associated high plasma free farty acid levels and/or muscular fat accumulation, lead to impaired mitochondrial function, possibly via negative effects on the expression of genes involved in mitochondrial biogenesis in combination with deleterious effects of fatty acids on mitochondrial structure. Therefore, the first aim of the present study was to test whether the acute elevation of plasma free fatty acids during a hyperinsulinemic-euglycemic clamp, leading to muscular insulin resistance, was associated with a down-regulation in the expression of skeletal muscle genes involved in oxidative metabolism and mitochondrial biogenesis. 
Long chain triacylglycerol infusion during a hyperinsulinemic euglycemic clamp leads to the accumulation of intramuscular lipids because the supply of fatry acids to the mitochondria exceeds their oxidative capacity. To unravel whether a potential down-regulation of genes, involved in oxidative metabolism and mitochondrial biogenesis was related to the accumulation of fat inside the muscle, we made use of lipid emulsions containing different amounts of long and medium chain fatty acids. The rate-limiting step in the oxidation of long chain fatty acids is the mitochondrial entrance of these fatty acids via the carnitine shuttle system (12). However, because of their shotter chain length, medium chain fatty acids bypass this rate-limiting step and access the mitochondria by simple diffusion. As a result, medium chain farty acicls can be readily oxidised (13) and are unlikely to result in profound increases in intramuscular triacylglycerols.

Hence, as a second aim of the study, we compared the effects of long chain triacylglycerol (LCT) and medium chain triacylglycerol (MCT/LCT) infusion to determine whether intramuscular fat accumulation is a pretequisite for the effects of lipid infusion on muscular gene expression.

\section{Methods}

\section{Subjects}

Nine healthy lean male volunteers participated in the present study (Age: $20.1 \pm 0.5$ $y$; Body Mass Index: $21.7 \pm 0.6 \mathrm{~kg} / \mathrm{m}^{2}$, Body fat: $\left.16.0 \pm 1.3 \%\right)$. None of the subjects were involved in endurance training or engaged in sports activities for more than $2 \mathrm{~h}$ a week. In addition, none of the subjects had a family history of diabetes mellitus or any other endocrine disorder (as assessed by a questionnaire on medical history). The study protocol was reviewed and approved by the Medical Ethical Committee of Maastricht University and all subjects gave their written informed consent before participating in the study.

\section{Experimental design}

All subjects underwent three euglycemic-hyperinsulinemic clamps with simultaneous infusion of glycerol, LCT or MCT/LCT in randomised order. All test days were separated by at least one week. On all experimental days, subjects arrived at the laboratory at 8:00 am after an overnight fast. Subjects were asked to avoid strenuous physical activity at least 24 hours prior to each test and came to the 
laboratory by cat or by public transportation. Upon arrival at the laboratory subjects underwent a percutaneous muscle biopsy from the vastus lateralis muscle, according to the technique by Bergstrom et al. (14). The muscle biopsy was frozen immediately in melting isopentane cooled with liquid nitrogen and stored at $-80^{\circ} \mathrm{C}$ until assayed.

Subsequently, a Teflon cannula was inserted into an antecubital vein of one arm for the infusion of lipid emulsion or glycerol. A second cannula was inserted into an antecubital vein of the contralateral arm for the simultaneous infusion of insulin and glucose. A third cannula was placed retrogradely into a superficial dorsal hand vein for blood sampling. This venous blood was arterialised by placing the hand in a hot-box $\left(\sim 65^{\circ} \mathrm{C}\right)$.

Subsequently, subjects were rested on a bed and baseline blood samples were taken. Next, a $6 \mathrm{~h}$ lipid or glycerol infusion period, combined with a euglycemichyperinsulinemic clamp was started and blood samples were taken at regular time points for determination of circulating FFA. After 6 hours of lipid or glycerol infusion, a second muscle biopsy was taken.

\section{Lipid infusions}

In the LCT condition, subjects were infused with a $20 \%$ triacylglycerol emulsion (Intralipid, Ftesenius Kabi) at a rate of $81 \mathrm{ml} / \mathrm{h}$ for 6 hours. The fat source used in this emulsion was soybean oil and the present fatty acids all contained 16 carbon atoms or more (long chain fatty acids). Heparin was co-infused with the lipid emulsion $(0.2 \mathrm{IU} / \mathrm{kg} / \mathrm{min})$ to stimulate hydrolysis of the infused triacylglycerols. In addition, subjects received an intravenous bolus injection of heparin (200 IU) before starting the infusion.

In the MCT/LCT condition, a $20 \%$ triacylglycerol emulsion (Lipofundin, Braun Medical) was infused at a rate of $53 \mathrm{ml} / \mathrm{h}$ for 6 hours, an infusion rate that, after pilot studies, proved to result in plasma FFA levels similat to LCT infusion. However, $50 \%$ of the fatty acids present in this emulsion were of medium chain length ( $\leq 12$ carbon atoms) while $50 \%$ consisted of long chain fatty acids $(\geq 16$ carbon atoms), again derived from soybean oill. Infusion was also accompanied by a prime (200 IU)-continuous $(0.2 \mathrm{IU} / \mathrm{kg} / \mathrm{min})$ infusion of heparin.

As a control condition, subjects were infused with glycerol $(4.15 \mathrm{~g} / 100 \mathrm{ml})$ at at rate of $73 \mathrm{ml} / \mathrm{h}$ to match the infused amounts of glycerol in the lipid conditions. 


\section{Euglyemi-byperinudinemic damp}

At $t=0$, intravenous insulin infusion (Actrapides Novo Nordisk, Copenhagen, Denmark) was started at $40 \mathrm{mUU} / \mathrm{m}^{2} / \mathrm{min}$ for the duration of 6 hours and blood glucose levels were clamped at $-5 \mathrm{mmol} / \mathrm{L}$ by variable co-infusion of a $20 \%$ glucose solution. At regular time points (every 5 or 10 minutes), a small volume of blood $(\sim \mathbb{1} \mathrm{ml})$ was sampled for immediate determination of whole-blood glucose concentration. When necessary, ghucose infusion rate (GIR) was adjusted to obtain blood glucose levels of $\sim 5 \mathrm{mmol} / \mathrm{L}$ (euglycemia).

\section{Body compasition}

On a separate day, body density was determined by hydrostatic weighing. Body weight was measured with a digital balance with an accuracy of $0.01 \mathrm{~kg}$ (Sauter, type E1200). Lung volume was measured simultaneously with the helium dilution technique using a spirometer (Volugtaph 2000, Mijnhardt). Body composition was calculated according to the equation of Siri (15). Fat free mass (FFM) was calculated by subtracting fat mass from total body weight.

\section{Blood analysis}

Blood for determination of plasma free fatty acids (FFA) was collected in tubes containing $30 \mu \mathrm{l} 0.2 \mathrm{M}$ EGTA per $5 \mathrm{ml}$ of blood, in order to prevent in witro lipolysis due to the co-infused heparin. Blood was immediately centrifuged at high speed and plasma was transferted to plastic vials. Plasma was rapidly frozen in liquid nitrogen and stored at $-80^{\circ} \mathrm{C}$ until further analysis. Plasma FFA concentrations were measured using the Wako NEFA C kit (Wako chemicals, Neuss, Germany), with adjustments made to allow valid measurement of free fatty acids levels exceeding $1,000 \mu \mathrm{mol} / \mathrm{L}$.

\section{Intramuscular triaglghycerols (IMTG)}

Cryosections $(5 \mu \mathrm{m})$ were thaw-mounted on uncoated pre-cleaned ( $96 \%$ ethanol) glass slides. Immediately after mounting, air-dried, fresh cryosections were stained for intramuscular triacylglycerols (IMTG) by Oil Red O staining (16) combined with immunolabelling of the basal membrane marker laminin, to allow quantification of IMTG.

Briefly, cryosections were fixed in 3.7\% formaldehyde for $1 \mathrm{~h}$. Then the sections were treated with $0.5 \%$ Triton $\mathrm{X}-100$ in PBS for $5 \mathrm{~min}$, and washed three times 
with PBS. Thereafter, sections were incubated for 30 min with a polyclonal ralbit antibody against the basement membrane protein laminin (Sigma-Aldrich, St. Louis, MO, USA, 1:50 dilution in PBS) to visualise individual cell membatanes followed by a $30 \mathrm{~min}$ incubation with a Alexa350-conjugated goat anti-rabbit (Invitrogen Molecular Probes, Leiden, The Netherlands; 1:80 dilution in PBS). After washing with PBS, glass slides were immersed in the ORO working solution for 30 min for the detection of lipid droplets and rinsed three times with deionised water for $30 \mathrm{~s}$ followed by $10 \mathrm{~min}$ of washing with running tap water. Stained sections were embedded in Mowiol.

All sections were examined using a Nikon E800 fluorescence mictoscope (Nikon Instruments Europe B.V., Badhoevedorp, The Netherlands) coupled to a Basler A101C progressive scan colour charge-coupled device camera. Multiple random images were captured for every single colour (red and blue) and both images, as well as the merged overlay, were saved. All sections were processed and analysed using Lucia GF 4.80 software (Nikon, Düsseldorf, Germany). Special care was taken to use the same camera settings (gain and exposure time) while grabbing all images.

All images wete analysed for the lipid droplet over myocyte area fraction. 'To this end, a semiautomatic macro was written that allowed 1) autodetection of the cellular membrane (identified in the blue channel); 2) measurement of the area covered by the measuted myocytes; and 3) measurement of the area covered by lipid droplets (identified in the red channel). The area fraction was computed by dividing the area covered by lipid droplets (in $\mu \mathrm{m}^{2}$ ) by the cell surface of the measured myocytes (in $\mu \mathrm{m}^{2}$ ). The mean area fraction thus reflects the percentage of the total measured cell surface covered by lipid droplets.

\section{Reverse transcription and quantitative PCR ( $9 P C R$ ).}

Total RNA was extracted from skeletal muscle biopsies using Trizol reagent (Invitrogen, Breda, The Netherlands). One $\mu \mathrm{g}$ of RNA was reverse transcribed to cDNA using Random Hexomer primers and a Stratascript enzyme (Stratagene, The Netherlands). qPCR was performed using an MX3000p thermal cycler system and Brilliant ${ }^{(B)}$ SYBER Green QPCR Master Mix (Stratagene, The Netherlands). The PCR conditions for all genes consisted of one denaturing cycle at $90^{\circ} \mathrm{C}$ for 10 min followed by 40 cycles, consisting of denaturing at $90^{\circ} \mathrm{C}$ for $30 \mathrm{sec}$, anncaling at the pre-determined temperature (see table 7.1) for $60 \mathrm{sec}$ and elongation at $72^{\circ} \mathrm{C}$ for $60 \mathrm{sec}$. At the end of the PCR the samples were subjected to a melting curve 
andusis. To control for any wationis due to efficiencies of the reverse trancription and PCR, acidic ribosomal phosphoprotein $\mathrm{PO}(36 \mathrm{~B} 4$ ) was used as internal control mRNA expression was calculated as follows. The number of cycles at which the best fit line through the log linear portion of each amplified curve intersects the noise band is inversely proportional to the log copy number (17). This walue is referred to as the critical threshold (CT) value. The $\triangle C T$ was calculated by subtracting the CT for $36 \mathrm{~B} 4$ from the CT for the gene of interest. The relative expression of the gene of interest is calculated using the expression 2$\triangle C T$ and reported as arbitrary units. All PCR nuns were performed in triplicate. PCR primer sequences are provided in table 7.1 .

Table 7. Primen sequences and annealing temperatures

\begin{tabular}{|c|c|c|c|}
\hline Gene & Forward $5^{\prime}-3^{\prime}$ & Reverse $5^{*}-3^{*}$ & $T$ \\
\hline PGC-1a & GGTCTCTCCTTGCAGCACAAG & CTGGGATGACCGAAGTGCTIT & 60 \\
\hline PPARQ & AGCTITGGCTTIACGGAATACCA & CCACAGGATAAGTCACCGAGGA & 60 \\
\hline PPARB- & ATGGAGCAGCCACAGGAGGAAGCC & GCATGAGGCCCCGTCACAGC & 58 \\
\hline CPTI & GAGGCCTCAATGACCAGAATG & GIGGACTCGCTGGTACAGGAA & 60 \\
\hline $\operatorname{ACC}$ & CTGACC ACAGGTGAAGCTGA & GACAAACTCAGCGGGAGAAG & 60 \\
\hline UCP3 & CGTGGTGATGTTCGTAACCTATG & CGGTGATTCCCGTAACATCTG & 60 \\
\hline MrSOD & CTTCAGCCTGCACTGAAGTTCAAT & CTGAAGGTAGTAAGCGTGCTCCC & 56 \\
\hline $36 B 4$ & GTGATGTGCAGCTGATCAAGACT & GATGACCAGCCCAAAGGAGA & 60 \\
\hline
\end{tabular}

\section{Statistical analysis}

All values are expressed as mean \pm SEM. Changes in plasma free fatry acids were calculated as total area under the curwe (AUC) minus baseline values. Differences between conditions were evaluated by analysis of variance (One-way ANOVA). When significant differences were found, a Bonferroni adjusted post hoc test was used to determine the exact location of the difference. Pre- and post-experimental differences within conditions were analysed pair-wise by Student's t-tests. Outcomes were regarded as statistically significant if $p<0.05$.

\section{Results}

Plasma free fotty acids and insulin sensituity

Baseline plasma free fatty acids (FFA) were similar in all experimental conditions $(545 \pm 25 ; 555 \pm 25$ and $467 \pm 48 \mu \mathrm{mol} / \mathrm{L}$ in LCT, MCT/LCT and glycerol, 
respectively, NS). LCT and MCT/LCT infusion both increased plasma FTA Levels by -2.7 -fold $(t<0.001)$, up to $1475 \pm 88$ and $1494 \pm 89 \mu$ mol/L, respectively (fig. 7.1a).

In concordance with previous studies, the rise in plasma free fatty acids was accompanied by a decrease in whole body insulin sensitivity, as manifested by a drop in glucose infusion tate (GIR) 2 to 3 hours after the start of the infusion. The reduction of insulin sensitivity, calculated as the difference in GIR between 120 150 min and $330-360 \mathrm{~min}$, was similar upon $\operatorname{LCT}(\sim 31 \%)$ and MCT/LCT $(-24 \%)$ (fig. $7.1 \mathrm{~b})$.
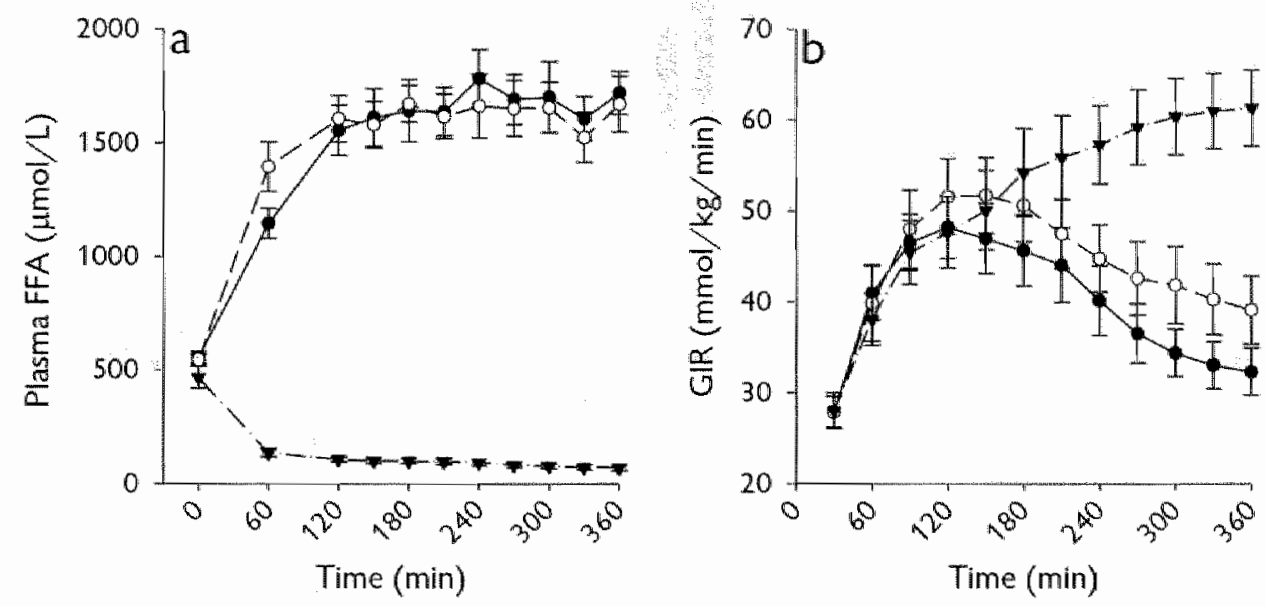

Figure 7.1 a) Plasma free fatty axid levels and b) glucose infusion rate (GIR) during hyperinsulinemiceuglycemic clamp with simultaneous glycerol (triangles), LCT (closed circles) and MCT/LCT (open circles) infusion. Values are mean \pm SEM..

The euglycemic-hyperinsulinemic clamp per se (with glycerol as control) decreased plasma FFA levels to $\sim 30 \%$ of baseline to $129 \pm 14 \mu \mathrm{mol} / \mathrm{L}(p<0.001)$ which was significantly lower than the FFA levels observed upon both lipid emulsions $(p<0.001)$.

\section{IMTG}

The infusion of long chain triacylglycerols resulted in a significant increase in IMTG from $2.84 \pm 0.68 \%$ to $4.42 \pm 0.85 \%$ (fig. $7.2, p=0.02$ ). As predicted, preand post IMTG values were similar upon MCT/LCT infusion ( $2.87 \pm 0.80$ vs. 3.13 
$\pm 0.90 \%$, respectively; $p=0.541$ ). During the hyperinsulinemic-uglycemic clamp plus glycerol infusion, IMTG tended to decrease ( $2.97 \pm 0.77$ vs. $1.56 \pm 0.57 \%$; $p=0.065$ ).

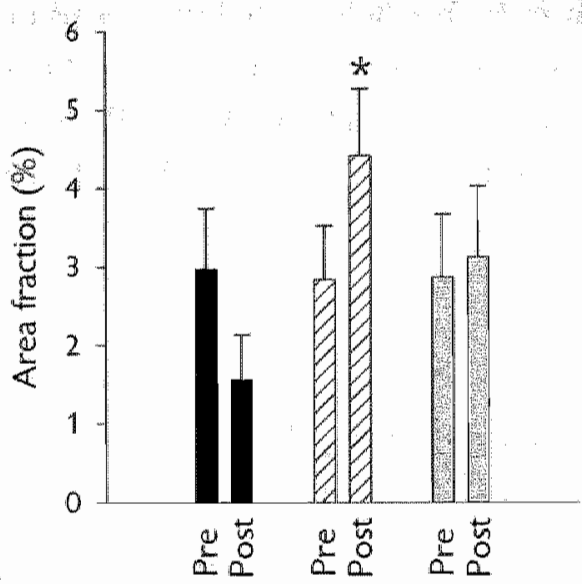

Figure 7.2 Intramuscular triacyglycerol levels before (pre) and after (post) the hyperinsulinemiceuglycenic clamp with simultaneous infusion of glycerol (black bars). LCT (hatched bars) and MCT/LCT (grey bars). Values are mean \pm SEM. ${ }^{*} p<0.05$ compared to pre-infusion.

\section{Skeletal muscle gene expression}

The changes in expression level of all measured skeletal muscle genes are depicted in table 7.2 and figures 7.3 and 7.4. There wete no significant differences in baseline gene expression levels among experimental conditions.

Infusion of long chain triacylglycerols (LCT), during a glucose clamp, significantly down-regulated the expression of PGC-1 $\alpha$ (fig. 7.3a) by approximately $40 \%$ $(p=0.034)$. Strikingly, this down-regulation was absent upon the infusion of mainly medium chain triacylglycerols (MCT/LCT), whereas there was a tendency for an up-regulation of PGC-1 $\alpha$ in the glycerol condition $(p=0.098)$.

PPAR $\alpha$ mRNA levels significantly decreased by $\sim 48 \%(p=0.025)$ upon the infusion of the LCT emulsion but remained unaltered upon MCT/LCT and glycerol infusion (fig. 7.3b). PPAR $\beta-\delta$ was unaffected by infusion of either LCT, MCT'/LCT or glycerol (fig. 7.3c).

The expression of camitine palmitoyl transferase 1 (CPT1), the rate-limiting enzyme in mitochondrial fatty acid uptake and subsequent oxidation (fig. 7.4a), and the expression of acetyl-CoA carboxylase-2 (ACC2), which is involved in 
controlling fatty acid oxidation by inhibiting CPT1 (fig. $7.4 \mathrm{~b}$ ), was not affected by either LCT or MCT/LCT infusion, although CPT1 rended to be down-regulated in the glycerol condition $(p=0.082)$.

Table 7.2 Skeletal muscle gene expression

\begin{tabular}{|c|c|c|c|c|c|c|}
\hline & Glycerol & & $\mathrm{LCT}$ & & MCT/LCT & \\
\hline Gene & Pre & Post & Pre & Post & Pre & Post \\
\hline PGC-1a & $0.42 \pm 0.05$ & $0.71 \pm 0.13$ & $0.44 \pm 0.07$ & $0.27 \pm 0.06$ & $0.41 \pm 0.05$ & $035 \pm 0.03$ \\
\hline PPARa & $0.44 \pm 0.07$ & $0.40 \pm 0.05$ & $0.54 \pm 0.08$ & $0.28 \pm 0.06^{\star}$ & $0.51 \pm 0.07$ & $0.46 \pm 0.10$ \\
\hline PPAR $\beta-\delta$ & $0.44 \pm 0.08$ & $0.57 \pm 0.13$ & $0.50 \pm 0.10$ & $0.46 \pm 0.08$ & $0.46 \pm 0.09$ & $0.43 \pm 0.08$ \\
\hline CPTI & $0.62 \pm 0,07$ & $0.51 \pm 0.08$ & $0.69 \pm 0.09$ & $0.59 \uplus 0.07$ & $0.72 \pm 0.09$ & $0.62 \pm 0.14$ \\
\hline $\mathrm{ACC}$ & $0.30 \pm 0.03$ & $0.31 \pm 0.04$ & $0.35 \pm 0.04$ & $0.40 \pm 0.07$ & $0.34 \pm 0.04$ & $0.34 \pm 0.06$ \\
\hline UCP3 & $1.14 \pm 0.17$ & $1.08 \pm 0.16$ & $1.11 \pm 0.18$ & $1.95 \pm 0.29^{*}$ & $1.18 \pm 0.17$ & $1.30 \pm 0.12$ \\
\hline masoD & $0.43 \pm 0,09$ & $0.55 \pm 0.06$ & $0.40 \pm 0.09$ & $0.49 \pm 0.06$ & $0.39 \pm 0.08$ & $0.44 \pm 0.07$ \\
\hline
\end{tabular}

Values are mean \pm SEM and expressed as a ratio ower the control gene 36B4, before (pre) and after (post) a hyperinsulinemic-euglycemic elamp with simultaneous infusion of glycerol LCT or MCT/LCT. $*$ PCOOS companed to pre-infusion.

The expression of uncoupling protein 3 (UCP3), a protein involved in the mitochondrial handling of fatty acids, significantly increased by $\sim 80 \%$ (fig. $7.4 \mathrm{c}$; $p=0.011)$ upon LCT and by $\sim 10 \%(p=0.048)$ upon MCT/LCT infusion, and tended to be down-regulated in the glycerol condition $(p=0.066)$. The upregulation of UCP3 expression caused by LCT infusion was more pronounced than the increase seen on MCT/LCT infusion $(p=0.007)$.

There was no effect of glycerol, LCT or MCT/LCT infusion on the gene expression of MnSOD (fig. 7.4d), the mitochondrial isoform of the endogenous anti-oxidant superoxide dismutase.

\section{Discussion}

The consecutive observations that 1) elder, insulin-resistant subjects displayed decreases in mitochondrial oxidative activity and ATP synthesis (9);2) similat decreases were observed in young insulin-resistant offspring of type 2 diabetics (18); 3) genes involved in mitochondrial oxidative phosphorylation, and under the transcriptional control of PGC-1, were coordinately down-regulated in type 2 diabetes $(10,11)$ and 4) PGC-1 itself was also down-regulated in human type 2 diabetics and even more striking, in family history-positive non-diabetic subjects 
(11); have led to the attractive hypothesis that subjects at risk for developing type 2 diabetes hawe a susceptibility towards an impaired mitochondrial biogenesis and functioning, thereby diminishing fat oxidative capacity.

As a result; nutrient excess, especially increased supply of fatty acids to skeletal muscle might further contribute to the detetionation of mitochondrial functioning and may promote intramuscular fat accumulation and muscle insulin resistance. However, whether the disturbed mitochondral functioning that was observed in the atiology of type 2 diabetes is cause or effect with respect to intramuscular lipid accumulation remains uncertain.

Hete, we show that an acute increase in long chain fatty acid supply, leading to insulin resistance, decreases skeletal muscle PGC-1 and PPAR $\alpha$ mRN expression, indicating that acute elevation of FFA levels, or resultant downstream effects, can interfere with the expression of these major activators of mitochondrial biogenesis and oxidative metabolism.

To examine whether the down-regulation of PGC-1 $\alpha$ and PPAR $\alpha$ was due to high plasma fatry acid levels or due to intramuscular lipid accumulation, we compared the effect of a $100 \%$ ICCT lipid infusion with the infusion of a mixture of MCT and LCT $(50 / 50 \%)$, on gene expression. We anticipated the latter to result in less accumulation of muscular fat. We indeed found that, in contrast to LCT infusion which increases IMTG by $\sim 1.7$-fold, MCT/LCT infusion did not lead to the accumulation of IMTG, whereas in the control condition, IMTG tended to decrease during the clamp. This suggests that MCT/LCT infusion, despite similar plasma FFA concentrations, had an intermediate effect on IMTG content, probably due to the fact that $50 \%$ of the MCT/LCT emulsion was comprised of long chain fatty acids. Although out of the scope of the present study, a similar degree of insulin resistance was observed in MCT/LCT versus LCT despite differences in IMTG, suggesting that other factors such as accumulation of fatryacyl CoA and/or diacylglycerol contribute to the decrease in insulin sensitivity upon MCT/LCT.

Interestingly, $\mathrm{PGC}-1 \alpha$ and PPAR $\alpha$ gene expression remain unaltered upon MCT/LCT infusion. This suggest that the down-regulation of these genes is associated with muscular fat accumulation and may suggest that in diabetes, muscular fat accumulation precedes the down-regulation of oxidative genes and potentially even mitochondrial dysfunction, although the latter was not determined in the present study. 

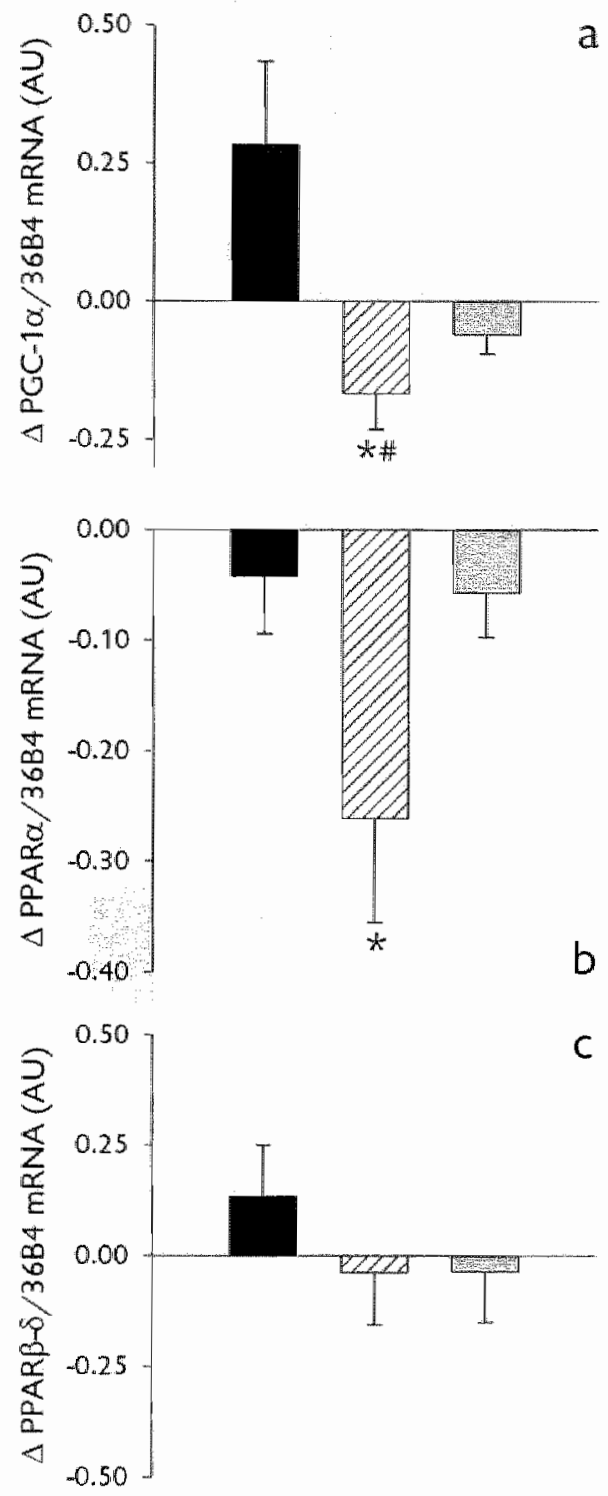

Figure 7.3 Changes in gene expression of skeletal muscle transcription factors upon hyperinsulinemiceuglycemic damp with simultaneous infusion of glycerol (black bars). LCT (hatched bars) and MCT/LCT (grey bars). Values are mean \pm SEM. * $p<0.05$ compared to baseline, "p<0.05 compared to glycerol a) PGC- $1 \alpha$ b) PPAR $\alpha$ c) PPAR $\beta-\delta$ 

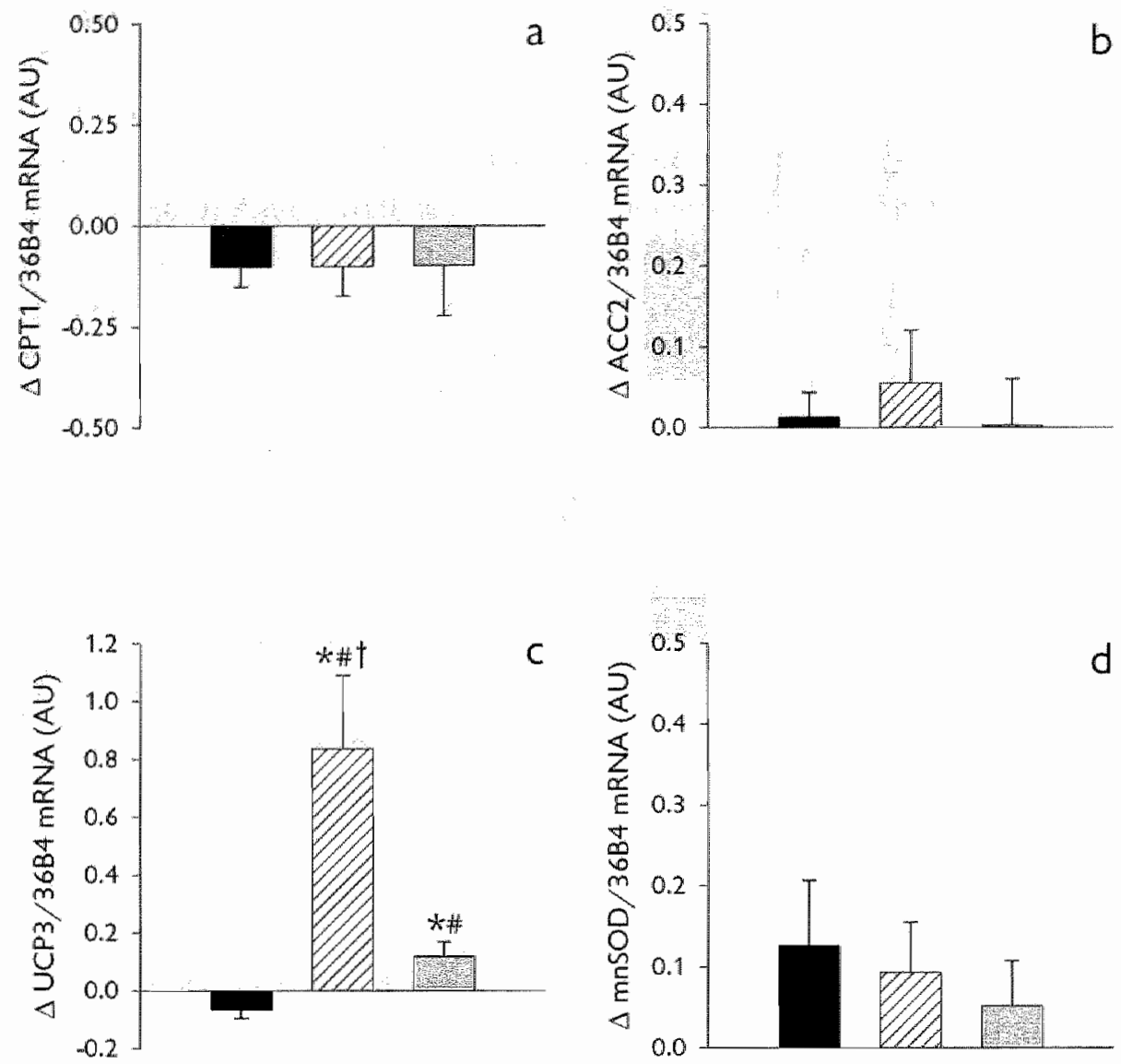

Figure 7.4 Changes in skeletal muscle gene expression upon hyperinsulinemic-euglycernic clamp with sirnultaneous infusion of glycerol (black bars). LCT (hatched bars) and MCT/LCT (grey bars). Values are mean \pm SEM. * p<0.05 compared to baseline; $p<0.05$ compared to glycerol; $p<0.05$ compared to MCT/LCT. a) CPTI b) ACC2 c) UCP3 d) MnSOD

The down-regulation of PGC-1 $1 \alpha$ upon LCT infusion is further stressed by the findling that the control condition revealed an increase in PGC-1 $\alpha$, although not significant, implying that the down-regulation of PGC-1 $\alpha$ might represent an undetestimation of the LCT effect on PGC-1 $\alpha$. In light of this, studies in cultured primary human skeletal myotubes revealed that insulin is indeed capable of inducing PGC-1 expression (19). It should be noted that the lack of change in PGC-1 $\alpha$ expression upon MCT/LCT infusion can be interpreted as an intermediate effect whereby MCT/LCT infusion prevented the insulin-induced induction of PGC-1 $\alpha$. This again would parallel the changes in IMTG, suggesting 
that intramuscular accumulation of fat affects the expression of PGC-1 $\alpha$ in a content-dependent manner.

Our results are in accordance with the recent finding by Richardson et al. (20), who reported a decrease in PGC-1 $а$ mRNA expression upon a prolonged, 48h lipid infusion period. Another recent paper showed a reduction in the expression of genes involved in oxidative phosphorylation, as well as PGC-1 $\alpha$, after three days of high-fat diet in human subjects (21).

To examine whether lipid-induced insulin resistance also affected key genes directly involved in oxidative metabolism, we measured the expression of CPT1 and $A C C 2$, key regulators of fat oxidation. In previous studies it was shown that a cluster of oxidative genes is down-regulated in type 2 diabetes mellitus $(10,11)$. Here we find that lipid infusion dic not affect CPT1 and ACC2 expression within the time frame of the present study, suggesting that first their transcription factors must be affected

Next to a reduction of oxidative genes, possibly explained by the accumulation of fat in skeletal muscle, type 2 diabetic patients are also characterised by increased mitochondrial damage (8). Our laboratory has previously hypothesised that the accumulation of fat in the vicinity of muscle mitochondria may lead to ROSinduced lipid peroxidation and the subsequent lipid peroxides may be responsible for the damage to mitochondrial proteins and structure (22). Indeed, it was recently shown that insulin resistant subjects display increased levels of lipid peroxides (23). In addition, we and others have hypothesised a role for uncoupling protein 3 (UCP3) in the protection of mitochondria against this lipid-induced damage either by directly diminishing $\operatorname{ROS}$ production $(24,25)$, or by exporting lipid peroxides (26) or fatty acid anions (27) away from the mitochondria. In accordance with the increased level of lipid peroxides and mitochondrial damage, type 2 diabetic patients were indeed shown to have a $50 \%$ reduction in UCP3 protein levels (28). The increased expression of UCP3 upon LCT infusion (which increases IMTG), and a markedly less pronounced increase upon MCT/LCT infusion (which does not increase IMTG), supports the idea that UCP3 protects against accumulation of detrimental lipids, irrespective of the exact mechanism via which UCP3 can do so. This is also in accordance with our previous finding that long term high-fat LCT feeding up-regulated UCP3 at the protein levels, whereas long term MCT feeding did not affect UCP3 protein content (29). Interestingly, Vidal et al. (30) showed that the fatty acid-induced induction of UCP3 mRNA expression was impaired in type 2 diabetics, suggesting an impaired defence mechanism to protect mitochondria against lipid-induced damage. 
Anothier way to reduce lipid-induced oxidative damage is by increasing mitochondrial anti-oxidant capacity. Therefore, we measured gene expression of MnSOD but found no effect of LCT or MCT/LCT infusion on the expression levels of this gene. This suggests that UCP3 may be specifically involved in the defence of lipid-induced mitochondrial damage, although gene expression of MnSOD and UCP3 does not necessarily reflect protein levels, let alone biological activity of the proteins.

In summary, we showed in the present study that skeletal muscle PGC-1 $\alpha$ and PPAR $\alpha$ expression was decteased upon $6 \mathrm{~h}$ infusion of long chain triacylglycerols that led to muscular fat accumulation and insulin resistance. Infusion of a mixed long and medium chain triacylglycerol emulsion showed intermediate effects, both on the expression of PGC-1 $\alpha$ and PPAR $\alpha$ and on the levels of intramuscular triacylglycerols, despite similar plasma free fatty acid levels and a similar reduction in insulin sensitivity. This indicates that the accumulation of fat inside the muscle is related to the observed changes in gene expression. In addition, UCP3 expression was up-regulated upon LCT in comparison to MCT/LCT infusion in accordance with the putative role for UCP3 in the protection of mitochondria against lipotoxicity. The down-regulation of PPARa expression upon LCT, next to the down-regulation of PGC- $1 \alpha$, could have a detrimental effect on mitochondrial biogenesis and functioning upon chronic exposure to elevated plasma FFA and may explain the down-regulation of oxidative genes in type 2 diabetes mellitus.

\section{Acknowledgements}

This study was funded by the Wageningen Centre for Food Sciences, an alliance of major Dutch food industries, TNO Nutrition and Food Research, and Wageningen University and Research Centre, with financial support from the Dutch government.

M. Sc. J. Hoeks was supported by a grant from The Nethetlands Organisation for Scientific Research (NWO) and the research of Dr. P. Schrauwen has been made possible by a fellowship of the Royal Netherlands Academy of Atts and Sciences.

\section{References}

1. Boten $G_{*}$ Lebed B, Schar M, Homko $C$, Lemieux S. Effects of acute changes of plasma frec fatty acids on intrumyocdlulat fat content and insulin resiscunce in healthy subjects. Diabetes $2001,50(7): 1612-7$. 


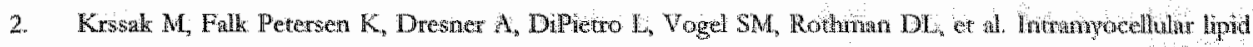

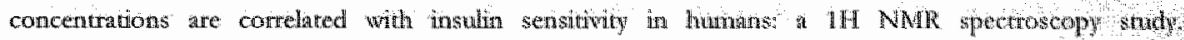
Dïsbetologia $1999 ; 42(1): 113-6$.

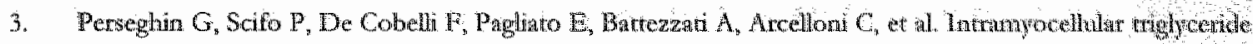

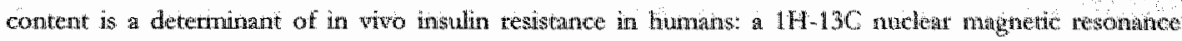
spectroscopy assessment in offpring of type 2 diabetic parents Disbetes $1999 ; 8(8): 1600$-6.

4. Dresner $A$, Laturent $D$, Marcucci $M$, Griffin MF, Dufour $S$, Cline $G W$, et al Effects of frete faty acids on glucose ramport and IRS-1-associated phosphatidylinositol 3-kanase activity. I Clin Irivest 1999:103(2):253. 9.

5. Griffin ME, Marcuce M], Cline GW, Bell $K$, Barcect $N$, Lee $D$, et all Free fatty acid induced insulit resistance is associated with activation of protein kinase $C$ theta and stcerations in the insulin signaling cascade. Diabetes $1999,48(6): 1270-4$.

6. Itani SI, Rudeman NB, Schmieder $F$, Boden $G$. Lipid-induced insuhn resistance in buman muscle is associated with changes in diacylgherol, protein kinase $C_{\text {, and }} 1 \mathrm{kappaB}$-alpha. Dabetes 2002;510)200511.

7. Roden M, Price TB, Perseghin G, Petersen KF, Rothman DI, Cline GW, at al. Mechanisn of titex farty acid-induced insulirn tresistance in humans. ] Clita Invest 1996:97(12):2859-65.

8. Kelley DE, He J. Menshikova EV, Ritov VB. Dysfunction of mitochondtia in human skeletal muscle in type 2 diabetes. Disabetes 2002;51(10):2944-50.

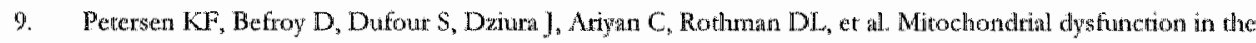
elderly: possible role in insulin resistance. Science $2003,300(5622): 1140-2$

10. Patti ME, Butte Al, Crunkhom S, Cusi K, Berria R, Kashyap S, et al. Coordinated retinction of genes of oxidative metabolism in heunans with insulin tesistance and diabetes: Potential role of PGCI and NREI. Proc Natl Acad Sci U S A 2003; 1000(14):8466-71.

11. Mootha VK, Lindgren CM, Eriksson KF, Subramaninn A, Sihag S, Lehar J, et al. PGC-1alpha-responsive genes involwed in oxidative phosphotylation are coordinately dowyregulated in hunzan diabetes. Nat Genet $2003 ; 344(3): 267-73$.

12. Tol WA. Aspects of long-chair acyl-COA metabolism. Mol Cell Brochem 1975;7(1):19-31.

13. Hasmussen BB, Holmback UC, Volpi E, Morio-Liondore B, Paddon-Jones D, Wolfe RR. Malonyl coenzyme $A$ and the regulacion of functional canitinc patmitopltransfetase-1 activity and fat oxidation in human skctetal muscie. I Clin Invest 2002;110(11):1687-93.

14. Bergstrom J, Hemansen L, Hulman E, Saltin B. Diet, muscle glycogen and physical pertomance. Acta Physiol Scand $1967,71(2): 140-50$.

15. Sir W. The gross composition of the body. Adw Biol Med Physiol 1956,4239-80.

16. Koopman $\mathrm{R}$, Schart $\mathrm{G}$. Hesselink MK. Optumisatom of ol red $\mathrm{O}$ stanng permits combination with immunofluorescence and automated quantification of lipids. His tochem Cell Biol 2001:116(1):63-8.

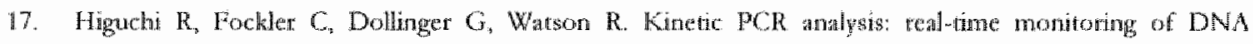
amplification reactions. Bickechnology (N Y) 1993; $119 \% 1026-30$.

18. Petersen KF, Dufour $\mathrm{S}$, Befroy D, Gurcis $\mathrm{K}$, Shulman GI. Imprated mitochondral achivity in the insurim resistant of spring of patients with rype 2 diabetes. N Engl I Med 2004;350(7);664-71.

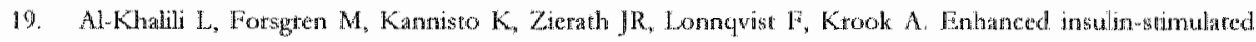

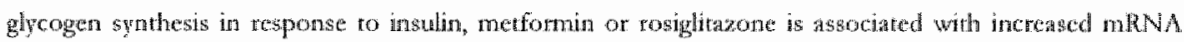

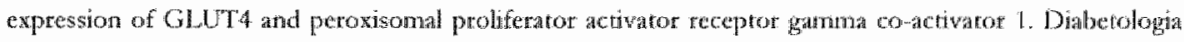
2005 . 


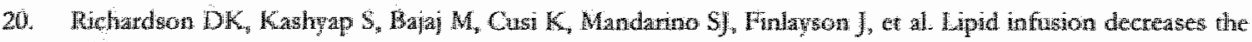

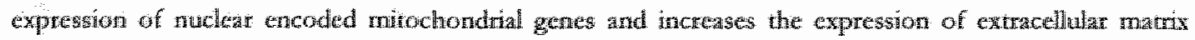

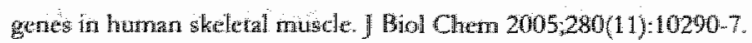

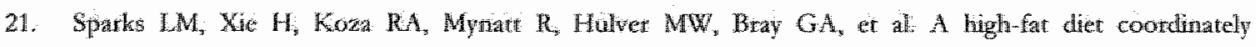

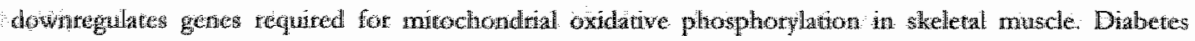
$2005,54(7): 1926-33$.

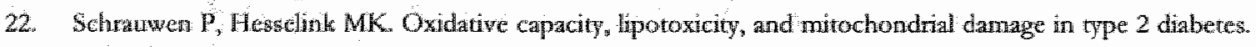
Diaberes $200453(6): 1412 \%$.

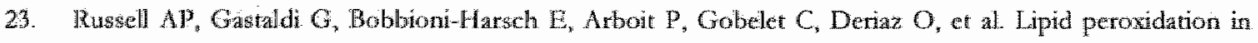
skeletal muwe of obeste as compared to endurance-tranied humans a case of good ws. bad lipids? HEBS Letr $2003,551(1-3): 104-1 \%$.

24. Echray $\mathrm{KS}$, Estrewes " $\mathrm{CC}$, Pakay $\mathrm{JL}$, Jekabsons MB, Lambert Al, Portero-Ouin M, et al A signalling role for 4-Jydroxy-2-nonenal in regulation of mitochondral uncoupling Embo J 2003,22(16):4103-10.

25. Brand MO, Buchingham JA, Estwes TC, Green $K_{\text {; }}$ lambert $\mathrm{AJ}$, Miwa $S$, et al. Mitochondrial sepetoxide and aging: uncoupling-protein activity and superoxide production Biochem Soc Symp 2004(71):203*13.

26. Goglia ${ }^{2}$, Skulachev VP. A function for noved uncouphing proteins: antioxidant defense of mitochondnal matrix by tramslocating fatty acid peroxides from the inner to the outer membrane leafer. Faseb I $2003 ; 17(12): 1585-91$.

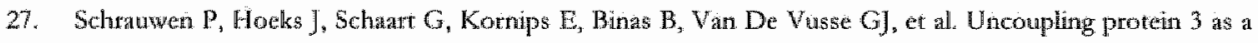
mitochondrial fatty acid anton expontet. Frab ] 2003;17(15):2272 4

28. Schrauwen P, Hesadink MK, Bhalk EE, Borghonts I.B, Schart G, Saris WH, et al. Uncoupling proten 3 content is decreased in skeletal muscle of patients with type 2 diabetes. Diabetes $2001 ; 50(12): 287043$.

29. Hoeks ], Hesselink MK, wan Bilsen M, Schaat $G$, wan der Vusse $G$ ], Saris WH, et ail, Differentiall response of UCP3 to medium versus long chain triacyglycerols; nanifestation of a functional adaptation. FEBS Iett $2003 ; 555(3): 631-7$.

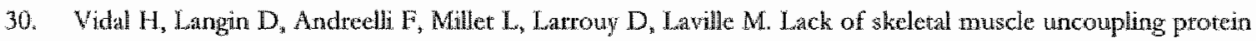
2 and $3 \mathrm{mRNA}$ induction during fasting in type-2 diabetic subjects. Am I Physiol 1099277(5 Pt 1).E830-7. 
General Discussion 


\section{UCP3 in the defence against mitochondrial lipotoxicity}

Mitochondrial uncoupling, dissipating the proton gradient present across the inner mitochondrial membrane, causes heat production and requires more substrate oxidation in order to maintain the proton gradient and to produce sufficient amounts of ATP to meet the cellular energy demands. In other words, inducing inefficiency in the ptocess of mitochondrial ATP synthesis would cause excess substrate to be burnt off rather than stored in the body and would create a powerful therapy against obesity. Indeed, dinitrophenol, a chemical uncoupler was introduced for the treatment of obesity in 1933 and proved to be highly effective in terms of weight loss (1). However, numerous reports of severe intoxications and deaths led to the discontinuation of its urilisation (2).

The discovery of an endogenous, potentially energy-wasting protein in an organ highly contributing to human energy expenditure raised great expectations in the battle against the worldwide epidemic of obesity. Hence, uncoupling protein 3 (UCP3) showing $\sim 57 \%$ homology to UCP1 (3), the only bana fide uncoupling protein identified so far, was initially regarded as an anti-obesity target gene. Eight years later we know, however, that although several lines of evidence show that UCP3 is indeed associated with energy metabolism (reviewed in chapter 2), the primary physiological role of this protein does not seem to be the regulation of energy expendinure. The observed relation between UCP3 and energy metabolism could be due to a secondary effect of UCP3 function. It is very likely that this physiological function resides within fatty acid metabolism, given the numerous associations between UCP3 and fat metabolism observed in literature (also reviewed in chapter 2 ).

In chapter 3 we studied the possible involvement of UCP3 in regulating energy expenditure in humans by exploring whether $\beta$-adrenergic stimulation, known to increase energy expenditure, is accompanied by changes in UCP3 gene expression. In this study, we found no evidence for a regulatory role for either $\beta_{1^{-}}$or $\beta_{2^{-}}$ adrenetgic activity on skeletal muscle UCP3 expression. However, infusion of a $\beta_{2^{-}}$ adrenergic agonist with simultaneous blocking of lipolysis, resulting in significantly lowered levels of plasma free fatty acids, down-tegulated skeletal muscle UCP3 mRNA levels, despite an increase in energy expenditure. Therefore the changes in UCP3 gene expression directed our attention to its possible role in fatty acid 
metabolism, rather than in the regulation of energy expenditure. The effect of vatiations in plasma free fatty acids on UCP3 gene expression had been observed previously and is suggested to explain the effect of many physiological stimuli on UCP3 expression (4-7). This may raise the question why in our study, despite increased plasma free fatty acids upon $\beta_{1}$ - and $\beta_{2}$-adrenergic stimulation, UCP3 mRNA levels were unaffected. However, the absolute levels of plasma free fatty acids that were reached upon $\beta$-adrenergic stimulation were only $-50 \%$ of the levels reached in other studies $(5,6)$, suggesting that the regulation of UCP3 expression by plasma free fatry acids is concentration-dependent. Furthemore, according to our hypothesis, the balance between fat supply and fat oxidative capacity is the determining factor in regulating UCP3 action and/or expression. So even when plasma free fatty acids levels are similar between subjects, individual differences in muscular fat oxidative capacity coud influence UCP3 expression.

Although the dissociation between energy expenditure and UCP3 gene expression in this study does not point towards a regulatory tole for UCP3 in the $\beta$ adrenergic-induced rise in energy expenditure, it must be noted that UCP3 mRNA levels do not necessarily reflect UCP3 protein levels, let alone the biological activity of UCP3. Although unlikely given the decreased UCP3 gene expression, it cannot be ruled out that $\beta$-adrenergic stimulation increases mitochondral uncoupling through an increase in the activity of the existing UCP3 protein pool. However, testing this possibility is complex and would require the measurement of UCP3mediated proton leak in isolated mitochondria incubated in medium containing activators or inhibitors of UCP3 but so far the endogenous activators/inhibitors of UCP3 are fairly unknown and only deduced from UCP1 research. Moreover, it is unlikely that acute regulatory matabolic changes that occur during $\beta$-adrenergic stimulation would survive the procedure to isolate mitochondria and will thus not be detected during in nitw assessment of proton leak. However, incubating permeabilised muscle fibres with specific $\beta$-adrenetgic agonists in wito and subsequently measuring oligomycin-insensitive respiration (tespiration due to proton leak) should give information about $\beta$ adrenergic-induced uncoupling. UCP3/ mice could then be valuable to determine whether of not this uncoupling is mediated by UCP3. Novel techniques such as nuclear magnetic resonance (NMR) spectroscopy can, and are currently used to assess in wivo uncoupling, but this technique does not allow, at least in humans and genetically non-manipulated animals, discriminating between UCP3-mediated uncoupling and uncoupling caused by other factors, such as via the adenine nucleotide translocase (ANT). 
Naturally, it would be possible to use this technique in UCP3\% mice to determine a possible role fot UCP3 in the $\beta$ adrenergic-induced rise in energy expenditure. The results in chapter 3 as well as mumerous other observations in literature show a strong association between UCP3 and fatty acid metabolism. Based on these data we proposed the hypothesis (8) that UCP3 acts as an exporter of nonmetabolisable fatry acid anions, a feature that is especially relevant when the supply of fatty acids to the muscle exceeds its capacity to oxidise them. Under such conditions, fatty acids would accumulate in the cytosol and this could drive neutral fatty acids into the mitochondrial matrix by so-called flip-flop diffusion (9). Upon entering the mitochondrial matrix or the inner leaflet of the inner mitochondrial membrane, these fatty acids will be deprotonated because of the existence of a proton gtadient present across the inner mitochondrial membrane, giving rise to fatty acid anions. It should be noted that these fatty acid anions cannot be metabolised, since only fatty acyl-CoA can undergo $\beta$-oxidation and the enzyme necessary for this conformation is not (at least for long chain fatty acids) present in the mitochondrial matrix (10). Since fatty acid anions cannot diffuse back into the intermembrane space either (11), they would accumulate inside the matrix, with potentially toxic side-effects. It is not evident that these fatry acid anions leave the phospholipid bilayer and could therefore equally well accumulate at the inner leaflet of the inner mitochondrial membrane. Nevertheless, reactive oxygen species (ROS) that are produced in the mitochondrial matrix as an inevitable by-product of respiratory chain activity could directly peroxidise these fatty acids, leading to highly reactive and toxic lipid radicals. To protect mitochondria from these deleterious radicals, we hypothesised that UCP3 facilitates an ourward ransport of non-metabolisable fatty acid anions, which would be especially important in situations of fatty acid oversupply, such as upon high-fat feeding, an acute bout of exercise or fasting.

At the site of the intermembrane space the exported fatty acid anions will capture a proton again and may either diffuse back into the matrix, leading to mitochondrial uncoupling via fatty acid cycling (11-13), or leave the inner mitochondrial membrane once the cytosolic fatty acid levels decrease. This function of UCP3, protecting mitochondria against the lipotoxic effects of intramitochondrial fat accumulation, could explain the associations seen between UCP3 and both energy - and fat metabolism.

In summary, the results obtained in chapter 3 pointed towards a role for UCP3 in fatty acid metabolism and is in support of our hypothesis that the primary physiological role of UCP3 is to protect mitochondria against the potentially 
detrimental effects of intra-mitochondrial fat accumulation. "To elucidate this proposed UCP3 function we interfered at distinct steps in muscular farty acid metabolism through pharmacological, genetic and physiological interventions: Thus, we created conditions in which the entry of neutral fatty acids into the mitochondria is enhanced (chapters 4 and 5) in order to test whether such conditions would lead to increased UCP3 levels.

We utilised mice lacking the cytosolic fatty acid binding protein (H-FABP or FABPC) that is important in controlling the intracellular unbound farty acid concentration in order to maintain a fatty acid gradient between plasma/interstitium and cytoplasm to facilitate fatty acid uptake (14, 15). $\mathrm{H}-\mathrm{FABP} \%$ mice show elevated plasma free fatty acids and a diminished fat oxidation as H-FABP is suggested to be essential for activation (esterification) of fatty acids to allow oxidation by interacting with long chain acyl-CoA synthetase (ACS) (16-18). Therefore, we have used mice lacking H-FABP to increase the intracellular concentration of unbound (non-esterified) fatty acids and measured the levels of UCP3 protein levels in these mice. Indeed, we observed a 5.3-fold increase in UCP3 protein levels, fitting our hypothesis that UCP3 is needed to facilitate outward transport of fatty acid anions, although the actual intracellular concentration of fatty acids was not determined in this study. A collaborating group has also found that rats made diabetic by a 4 week streptozotocin treatment displayed a decreased fat oxidative capacity of the heart and showed a concomitant -16-fold up-regulation of heart UCP3 protein levels compared to control rats (19). Interestingly, this increase in UCP3 was closely associated with increased levels of fatty acids in the sarcoplasm, linking the change in UCP3 mote directly to the presence of non-esterified intracellular fatty acids. In the (animal) heart lipotoxicity, the accumulation of fat in cardiomyocytes is associated with contractile dysfunction (20-22) and the rapid and pronounced up-regulation of UCP3 in hearts of streptozotocin-treated rats, with increased intracellular fatty acid levels, might indicate that UCP3 also plays an important role in the protection against cardiac lipotoxicity. In this context, subjecting UCP3 $\%$ mice to a chronic high-fat load and monitoring cardiac performance would be an interesting experiment.

Carnitine palmitoyl transferase 1 (CPT 1 ) is the rate-limiting enzyme for the uptake and subsequent oxidation of (long chain) fatty acids in mitochondria. In a successive study (chapter 4), we used etomoxir, an inhibitor of CPT1, to obstruct the main route for mitochondrial transport of long chain fatty acyl-Co $A$ esters and 
we anticipated that this would increase the levels of cellular non-esterified fatty acids. Under these conditions, these neutral fatty acids have a high probability to enter and accumulate in the mitochondrial matrix requiring increased UCP3 amounts or activity. Two weeks of etomoxir treatment in rats, decreased CPT1 activity down to $\sim 38 \%$ of control values, while UCP3 protein levels were indeed increased, by 1.9-fold. This up-regulation of UCP3 by approximately 2-fold upon etomoxir treatment was also seen in a human trial, accompanied by a decrease in fat oxidation (23).

In another set of experiments (chapter 5), we made use of the metabolic characteristics of medium chain triacylglycerols (MCT) to specifically test our hypothesis. Medium chain fatty acids have a shorter carbon chain length (C8-C12), are more water-soluble and because of this physical property, they can freely diffuse over membranes and do not rely on the carnitine shuttle system for their transport into mitochondria (24). Moreover, the mitochondrial matrix contains enzymes that are able to activate short-and medium- but not long chain fatty acids for subsequent $\beta$-oxidation (25-28). So even if medium chain fatty acids would accumulate in the sarcoplasm and reach the mitochondrial matrix, they can still be activated to acyl-COA and subsequently be oxidised and would therefore not accumulate in the matrix. Since UCP3 action is not necessary in this situation, we tested whether a high-fat diet, based on medium chain triacylglycerols, affected skeletal muscle UCP3 mRNA and protein levels. Indeed, we observed no effect of the high-fat MCT diet on mRNA and UCP3 protein levels while a high-fat long chain triacylglycerol diet up-regulated UCP3 $\mathrm{mRNA}$ and protein levels by $\sim 2$-fold. This expression pattern was present in glycolytic, oxidative and cardiac muscle tissue, although basal levels of UCP3 were much lower in cardiac and oxidative muscle, compared to glycolytic muscle. The latter observation also confiums that muscles with a low fat oxidative capacity (glycolytic muscle), require more UCP3 compared to oxidative muscles (oxidative skeletal and cardiac muscle), again supporting our hypothesis. In contrast to UCP3 gene expression, the expression of two PPAR-responsive genes was not differentially affected by high-fat LCT or MCT feeding, indicating that the observed changes in UCP3 are of physiological relevance and do not merely reflect a PPAR-response. With our in tivo model we can however, not exclude that differential use of the two types of fatty acids by other tissues, especially the liver, influenced the outcomes of this study. In other words, it remains possible that, due to oxidation in other tissues, the absolute amount of fatty acids supplied to the muscle was different upon the high-fat LCT 
and high-fat MCT diet, thereby affecting UCP3 expression in a concentrationdependent way. The significantly lower body weight gain upon high-fat MCT compared to high-fat LCT, despite a similar net energy intake underscores the potential themogenic effect of MCT feeding, but we cannot conclude which tissue is responsible for the oxidation. If however, the lack of effect on UCP3 by high-fat MCT would be acconnted for purely by a diminished supply of fatty acids to the muscle compared to high-fat LCT, intermediate UCP3 levels would be expected since it seems highly unlikely that all medium chain fatty acids upon a high-fat diet are metabolised in the liver or other non-muscle tissues. Furthermore, if the observed effect on UCP3 is merely caused by differences in fat supply to the muscle the other PPAR-responsive genes should reveal a differential expression partern, which is not the case. In addition, plasma free fatty acid levels were not significantly different between the two types of high-fat feeding.

Given the induction of UCP3 upon etomoxir treatment, it would be interesting to study whether combining a high-fat MCT diet with etomoxir would leave skeletal muscle UCP3 levels unaffected, which is predicted based on our hypothesis. Combining etomoxir treatment with a high-fat LCT diet would increase fat supply and decrease fat oxidative capacity which should result in an even more pronounced up-regulation of UCP3.

Given the proposed role of UCP3 in the defence against lipotoxicity, ablation of the UCP3 protein would result in intramitochondrial fat accumulation. As stated before, the mitochondrial matrix is also the site where ROS are produced, and the accumulated fatty acids are highly susceptible to direct oxidation by the oxygen radicals. The resulting lipid peroxides are highly reactive molecules and can induce damage to the mitochondrial membranes, proteins and DNA, ultimately leading to mitochondrial dysfunction. "Therefore, we hypothesised that UCP3 ablation in mice would result in increased intramuscular lipid peroxide levels, and that subjecting these UCP3 $\%$ mice to a high-fat diet would result in even more pronounced increases in lipid peroxidation.

We indeed showed (chapter 6 ) that UCP3 $\%$ mice displayed $\sim 3$-fold higher levels of intramuscular lipid peroxides upon standard chow feeding, compared to theit: wildtype littermates.

The increase in muscular lipid peroxides upon chow is in line with previous studies that reported an increased production of ROS and increased levels of oxidative damage in UCP3 $\%$ mice $(29,30)$, suggesting that UCP3 indeed acts as part of the antioxidant defences of the muscle cells. However, it should be noted that (muscle) 
cells are equipped with several other, well-estalilished defence mechanisms against oxidative stress. An important patt of the cellular antioxidant defence system consists of the antioxidative enzymes such as superoxide dismutase, catalase and glutathione peroxidase. These enzymes scavenge teactive oxygen species and convert them into less reactive compounds. This implies that the potentiall oxidative damage due to high fat supply in mitochondria equipped with low levels of UCP3 could be counteracted by other antioxidative defence systems.

Remarkably, the difference in lipid peroxidation levels between the two genotypes was no longer apparent on the high-fat diet. An increased antioxidative activity in the UCP3\% upon high-fat feeding could therefore be involved in the lack of difference in lipid peroxide levels upon the high-fat diet and measuring protein levels of the antioxidative enzymes, or preferably, the activity of the various enzymes would be a valuable additional experiment.

However, we also found that upon high-fat feeding, intramuscular triacylglycerol (IMTG) levels wete down to $\sim 50 \%$ of the levels observed in UCP3 $3^{+/ *}$ animals. In an attempt to pinpoint the molecular mechanism behind the decreased IMTG levels in UCP3- mice upon high-fat feeding we used a succinate dehydrogenase (SDH) activity staining as a matker for oxidative capacity. The lack of differences between the genotypes with respect to this parameter indicates that no major changes in oxidative capacity occurred. However, more detailed measurements such as in witro experiments with labelled palmitate in fresh muscle, dissected after 4 weeks of high-fat feeding, could give a more accurate insight in the possible, more subtle, changes in fat oxidative capacity. Following this approach, earlier studies detected no differences in muscle fatty acid oxidation between UCP3 $\%$ and wildtype mice (30). However, in witro determination of fatty acid oxidation in muscle from UCP3\% mice has never been performed after a high-fat diet intervention,

In addition, a similar in titso approach could be employed to determine whether the actual tat uptake in skeletal muscle is altered in UCP3 $\%$ mice upon high-fat feeding. Although we did not detect any differences in total protein levels of FAT/CD36, this protein has been suggested to translocate from intracellular depots towards the plasma membrane in response to insulin and contractions (31), analogous to the translocation of the glucose transporter GLUT4. Therefore, it remains possible that an altered subcellular distribution of this fatty acid transporter in UCP3 $\%$ mice upon high-fat feeding diminished muscular fatty acid uptake. 
Irrespective of the exact underlying molecular mechanism, a reduction in IMTO levels can not directly be explained by any of the proposed UCP3 functions and our data therefore suggest that the lower IMTG levels in UCP3\% mice upon highfat feeding is a compensation for the lack of UCP3. Although it is tempting to speculate that this compensation is an active adaptive mechanism to limit the peroxidation of muscular fatty acids by the increased ROS production due to lack of UCP3 $(29,30)$, we do not have data to support this speculation.

Next to our hypothesis concerning the physiological tole of UCP3 in skeletal muscle, two other mechanistic models exist in literature that inplicate a role for UCP3 in the protection against reactive oxygen species or ROS-related compounds.

The first model states that UCP3 limits the production of ROS by mediating a mechanism of mild uncoupling resulting in a decrease in protonmotive force, thereby diminishing ROS production $(32,33)$. Although this model does not clearly explain the numerous physiological observations relating the expression of UCP3 to fatty acid metabolism, a direct decrease of mitochondrial ROS production would obviously reduce the peroxidation of lipids and their downstream detrimental effects.

Closely associated to our hypothesis, the second model postulates that UCP3 acts to prevent potentially damaging accumulation of fatty acid petoxides in the inner leaflet of the inner mitochondrial membrane (34). The chemical nature of fatty acid peroxides (which are, in contrast to neutral fatty acids, unable to flip-flop) makes that the peroxides, transported to the outer leaflet by UCP3, will remain in this leaflet while the inner leaflet is purfied from these compounds. In this way, potentially hazardous fatty acid peroxides are transpotted away from the most vital part of the mitochondria. The probability of fatty acid peroxidation will increase with fatty acid concentration and therefore this hypothesis is supported by the recognised relation between UCP3 and fat metabolism.

The experiments described above support our hypothesis that UCP3 acts as a fatty acid anion exporter in order to prevent lipid-induced mitochondrial damage. However, the results obtained in our experiments also fit with the hypothesis that UCP3 protects mitochondria by transporting fatty acid peroxides to the outer leaflet of the inner mitochondrial membrane, away from the matrix (34). In other words, our data does not allow us to discriminate between these two mechanistic models. The idea that UCP3 directly lowers ROS production by a mechanism of mild uncoupling (33) however, seems only plausible for $R O S$ production related to fat metabolism. 


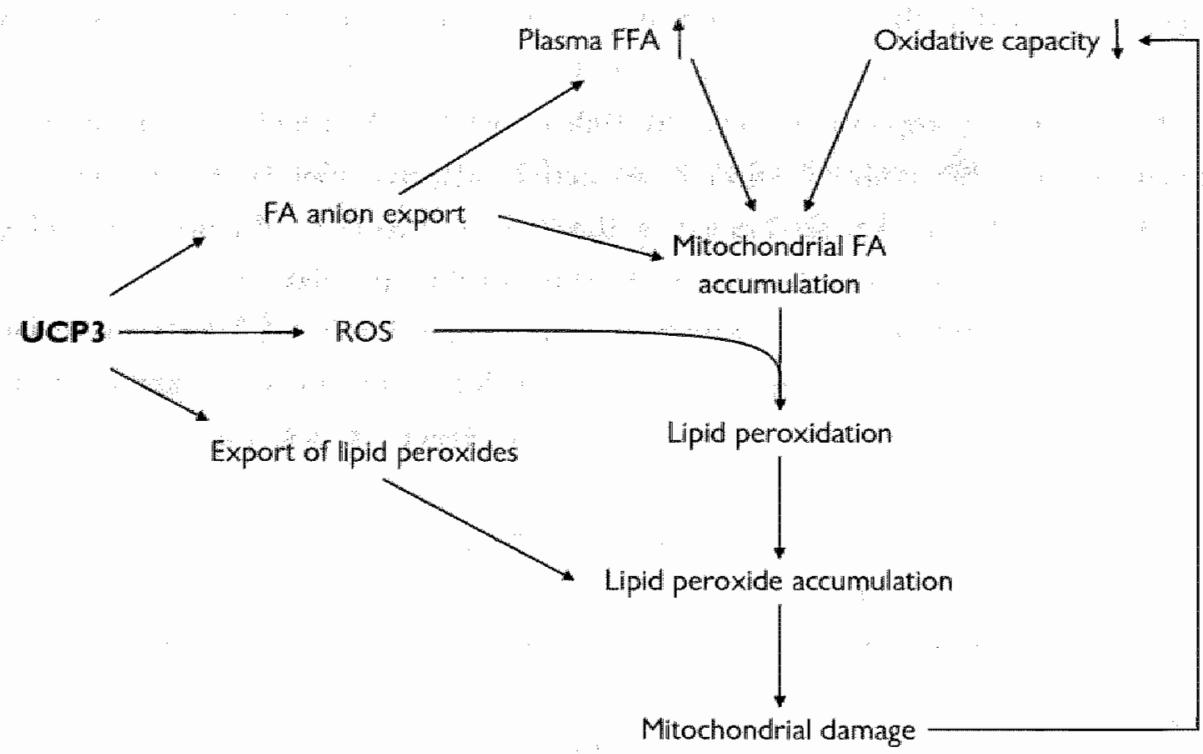

Figure 8.1 Schematic representation of the putative involvement of UCP3 in the pathogenesis of type 2 diabetes mellitus (43). Irrespective of the exact mechanism. UCP3 limits the intramitochondrial accumulation of harmful lipid peroxides thereby protecting the functional capacity of mitochondria. FA. fatty acid; FFA, free fatty acids; ROS, reactive oxygen species.

If UCP3 indeed functions as a protective mechanism against mitochondrial lipotoxicity, diminished UCP3 function in combination with high fat availability would eventually lead to mitochondrial damage and dysfunction. Interestingly, there is an increasing amount of evidence that points towards an important role of mitochondrial damage and dysfunction in the development of type 2 diabetes. In this context it was shown that skeletal muscle mitochondria from type 2 diabetic patients are smaller, show more damage and display a reduced functional capacity (35-37). Naturally, a reduced oxidative capacity would also diminish the capacity to oxidise fatty acids which in tum would enhance the accumulation of fat inside the muscle cells and it has been shown previously that the accumulation of fat inside the muscle contributes highly to insulin resistance $(38-40)$, a predictive factor in the pathogenesis of type 2 diabetes mellitus.

Hence, if UCP3 protects against mitochondrial lipotoxicity then aberrations in UCP3 function in combination with a condition of high fat supply would lead to intra-mitochondrial accumulation of fatty acids that are vulnerable to oxidative 
damage by ROS. This could result in increased lipid peroxidation levels and induce mitochondrial damage and dysfunction, which in turn could contribute to intramuscular fat accumulation and the development of type 2 diabetes. As such, UCP3 might directly contribute to the pathogenesis of type 2 diabetes mellitus. Interestingly, increased levels of muscular lipid peroxides were found in the insulin-resistant state (41) and type 2 diabetic subjects are characterised by a $50 \%$ reduction in UCP3 protein levels (42). This led to the attractive hypothesis (43) that the reduction of UCP3 in diabetic patients is a pathological condition, in which low levels of UCP3 fail to adequately protect mitochondria against oxidative damage induced by fatty acids, ultimately leading to lipid-induced mitochondrial damage (fig. 8.1).

To address these issues, we examined in chapter 7 whether the acute induction of insulin resistance through infusion of a lipid emulsion in healthy individuals was associated with a down-regulation in the expression of skeletal muscle genes and transcription factors involved in oxidative metabolism and mitochondrial biogenesis in humans. In addition, we measured UCP3 expression to determine whether this gene was up-regulated in response to the lipid-induced insulin resistance. To test if intramuscular fat accumulation affected the gene expression profiles, a lipid emulsion with readily oxidisable medium chain fatty acids (MCT/LCT) was tested against a lipogenic emulsion with long chain fatty acids (LCT). We observed that lipid-induced insulin resistance was accompanied by a significant down-regulation of both peroxisome proliferator-activated receptor (PPAR)- $\gamma$ co-activator $1 \alpha$ (PGC-1 $\alpha$ ) and PPAR $\alpha$, two transcription factors with a major role in regulating mitochondrial biogenesis and fat oxidative capacity, while UCP3 expression significantly increased. Interestingly, infusion of the readily oxidisable mixed MCT/LCT emulsion resulted in intermediate (between LCT and control) effects, both on the expression of PGC-1 $\alpha$, PPAR $\alpha$, UCP3 and on the levels of intramuscular triacylglycerols, despite similar plasma free fatry acid levels and a similar reduction in insulin sensitivity. This suggests that the accumulation of fat inside muscle is of importance for the reduced gene expression levels. Thus, chronic exposure to high fat loads and subsequent increases in intramuscular fat could both negatively affect mitochondrial biogenesis and result in intramitochondrial accumulation of fatty acids. These fatty acids can become directly oxidised by ROS which in turn can lead to damage to mitochondrial DNA, RNA and proteins in the mitochondrial matrix, further contriburing to mitochondrial damage and dysfunction. Furthermore, the acute up-regulation of UCP3 upon 
LCT infusion (which increased IMTG), and a markedly less pronounced increase upon MCT/LCT infusion (which did not increase IMTG), supports the idea that UCP3 protects against detrimental accumulation of lipids. Interestingly, it was shown that the farty acid-induced induction of UCP3 mRNA expression was impaired in type 2 diabetics, suggesting an impaired defence mechanism to protect mitochondria against lipid-induced damage (44). It should be stressed though, that UCP3 mRNA levels do not necessary reflect functional UCP3 protein or protein activity and that the up-regulation seen upon lipid lipid-induced insulin resistance might rather reveal the PPAR-tesponsiveness of the UCP3 gene. However, the finding that CPT1, also a known PPAR-responsive gene is not yet affected by a $6 \mathrm{~h}$ lipid infusion, suggests that the up-regulation of UCP3 is more specific than a mere PPAR-mediated effect. Nevertheless, more detailed experiments are needed to establish whether UCP3 is causally related to mitochondrial dysfunction and to examine whether UCP3 is essential in the prevention and treatment of lipidinduced muscular insulin sensitivity.

As shortly described above, one hypothesis concerning the physiological function of UCP3 states that UCP3 limits the production of ROS by a mechanism of mild uncoupling. According to this mechanism; UCP3 (and the other uncoupling proteins) are activated by 4-hydroxy-2-nonenal (4-HNE) that originates from a cascade of lipid peroxidation reactions initiated by superoxide. Since there is much debate whether UCP3 possesses uncoupling activity at all we have studied the proposed interaction between 4-hydroxy-2-nonenal and the originally identified uncoupling protein UCP1 in brown adipose tissue, because it is uncontroversial that UCP1 functions as an uncoupling protein. This work was carried out at the Wenner Gren Institute, Stockholm University, Sweden (see list of publications).

Based on these results in brown adipose tissue, it seemed that knocking out a bona fide uncoupling protein did not affect the level of oxidative stress, questioning the suggested beneficial effects of the limited uncoupling activity (compared to UCP1) that UCP3 might possess. Although UCP3 (and UCP2, another UCP1 homologue) has been shown to protect against ROS, it was pointed out that the antioxidant activity of these novel UCPs is too large to be explained solely by contribution of UCP2 and 3 to the mild uncoupling (34). However, exporting fatty acid anions, as we suggested, or fatty acid peroxides (34) from the matrix or the matrix side of the inner mitochondrial matrix would contribute further to the antioxidative capacity of UCP3, especially when fat supply to the muscle exceeds the capacity to oxidise them. Thus, although the results from this study are not easily extrapolated to the 
function of UCP3 in skeletal muscle, the techniques applied in this study could be valuable to look into the potential protective effect of skeletal muscle UCP3 in situations of fat oversupply.

\section{Conchding remarks and future directions}

In this thesis we studied the putative physiological function of uncoupling protein 3 (UCP3) in skeletal muscle metabolism. Based on the results we conclude that the proposed physiological function of UCP3 in the protection against mitochondrial lipotoxicity is feasible but we have no conclusive evidence that UCP3 fulfils this function by exporting fatty acid anions out of the mitochondrial matrix. More detailed in vitro experiments in isolated mitochondria are required to test that LCP3 can indeed function as a fatty acid anion exporter. Collaboration with experts from the field of the fatty acid transporters, applying the techniques that have been used to characterise the fatty acid transport capacity of the fatty acid transporters, could be extremely valuable for these experiments. Furthermore, given the proposed central role for mitochondrial damage and dysfuncrion in type 2 diabetes mellitus, the hypothesis that the reduction of UCP3 observed in diabetic patients is a pathological condition, in which low levels of UCP3 fail to adequately protect mitochondria against oxidative damage induced by fatty acids, should be addressed. To that purpose, in vitro experiments with isolated mitochondria from UCP3 - mice can be performed to test whether the lack of skeletal muscle UCP3 impairs mitochondrial function under conditions of high farty acid availability. In addition, in vivo human and animals experiments should investigate the obligatory need of UCP3 in the development and the restoration of muscular mitochondrial function and insulin resistance under conditions of high fatty acid availability. 


\section{References}

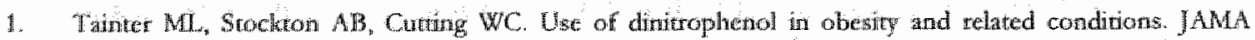
$1933,101: 1472-1475$

2. Councill on Phamacy ard Chemigury, Dinimophenol not acceptable for N. N. R JAMA 1935, 105(31-33).

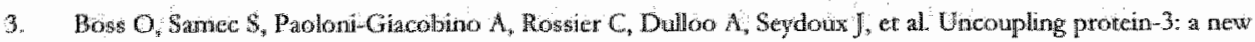

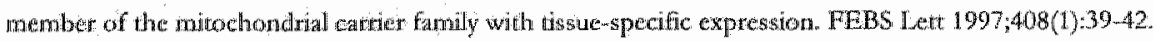

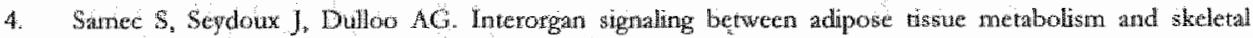
musele uncoupling proten homologs: is there a role for circulating free fatty acids? Diabetes $1908,47(11): 1693-8$

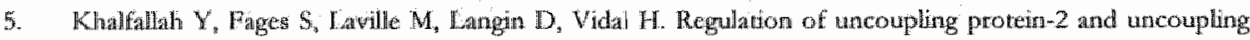
protein-3 mkNA expression during lipid infusion in human skeletal muscle and subcuraneous adipose tisistic. Dirbeter $2000 ; 49(1) \div 25-31$.

6. Schrmwen P, Hegelink MK Vartics I, Kontos E, Saris WH, Giacobino JP, et al. Effect of acute exercise on uncoupling protein 3 is a fat metabolismmediated effect. Am I Physiol Endocrinol Metab $2002282(1) \div 11-7$.

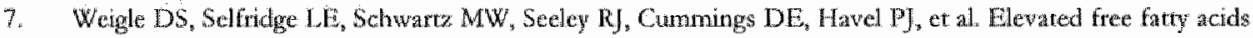
induce uncoupling protein 3 expression in muscle a potential explanation for the effect of fasting. Diabetes $1908,47(2): 298.302$

8. Schrawen P, Satis WH, Hesselink MK. An alternatud function for human unconpling protein 3: protection of mitochondria against accumalation of nonesterified farty acids inside the mitochondrial mattix. I a seb ) $2001 ; 15(1.3) 2497-502$.

9. Hamilon JA, Kamp F. How are free fatry acids tratusported in membranes? Is it by proteins of by free diftusion through the Hipids? Diaberes $1999,48(12): 2255-69$.

10. Tol VA Aspects of long-chain acyl-COA metabolism. Mol Cell Biochem 1975,7(1):19-31.

11. Jezck P, Oros DE, Modransky M, Garlid KD. Tmapport of anions and protons by he mitochondrat uncoupling protein and its regulation by nuclcotides and fatry acids. A new loak at old Jypotheses. I Biol Chem $1994269(42 ; 2618490$

12. Skulache VP. Faty acid circuis a physiological mechanism of uncoupling of oxidarive phosphorylation. PEBS Let $1994294(3): 158-162$.

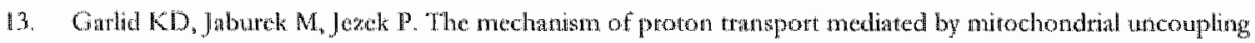
proteing DiBs Lert 1998;438(1-2):10-4

14. Van der Vusse G. Rocmen TH. Gradent of tatry acids from blood plasma to skelenal muscle in dogs. I Mppl Physiol 1995;78(5);1839-43.

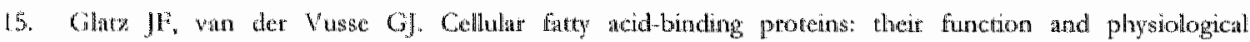
significance. Prog lipid Re: 1996;3)(3):243-82.

16. Binas B, Danneberg H, MeWhit J, Mullins L, Clatk A. Requirement for the heat-gpe atry acid binding protein in cardac fatry acid utilization. Fasb J $1990,13(8) 805-12$

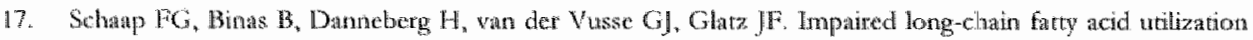
by cardiac myogtes isolated from mice lacking the heart-type faty acid binding protein gene. Circ Res $1999): 85(4) \div 329-37$.

18. Vectamp JH, van Moerkerk HT. Faty acid-binding protein and its relacion to farcy axid oxidation. Mol Cell Biochem 1993;123(1-2):101-6. 
19. Hesselink MK, Mensin M. Mchratwen P. Human uncoupling proteh-3 and obesity an update Obes kes $2003 ; 11(12): 1429-43$.

20. Zhou XT, Grayburn P, Karan A, Shimabukno M. Higa M, Bactens D, at al diporoxic hetut disease in obese rate: implications for human obesity. Proc Nad Acad Sci U S A 2000,97(4):1784-9.

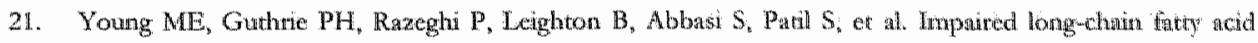
oxidation and contractile dysfuncrion in the obese Zueker mat heart. Diabetes 2002;51(8)2587,95.

22. Unger RH. The physiology of eellutat liporegulation. Annu Rew Physiol $2003 ; 6533347$.

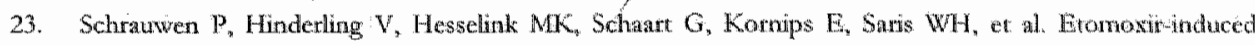
increase in UCP3 supports a rolle of uncoupling protein 3 as a mitochondnal fatry acid anion expouter. [Faseb] 2002:16(12):1688 90

24. Rasmussen BB, Holmback UC, Volpi E, Moriomiondore B, Paddon jones D, Wolte RR Matonyl coenzyme $A$ and the regulation of functional caunione palmitoyltransferasc 1 activer and far oxidation in human sketteral muscle. J Clin Inxest 2002;110(11):1687-93.

25. Aas M, Bremer ]. Shortchain fatry acid acrivarion in wat liwer. A new assay procedure for the entymes and studies on their intracellular: localization. Biochim Btophys Acta 1968,164(2):157-66.

26. Aas M. Organ and subcelular distribution of fatry acid actiating enzynes in the rat. Biochim Biophys Actu $1971,231(1) 32-47$.

27. Eaton S, Bartlet K, Pourfarzan M. Mammalian mitochondrial betamoxidarion. Biochem J 19963,320 (Pt 2):345-57.

28. Webster LT, Jr., Gerowin I.D, Rakita L. Purifacation and Chatacteristics of a Butyry. Coenzyme a Synthetase from Bowine Heart Mitochondria. J Biol Chem 1965;240:20-33.

29. Brand MD, Pamplona R, Portero-Oan M, Requena JR, Roebuck SI, Buckingham JA, et al. Oxidative damage and phospholipid fatty acyl composition in skeletal muscle mitochondrat from mice underexpressing or onerexpressing uncoupling protein 3. Biochem J 2002: $\mathrm{Pr}$.

30. Vidal-Puig AJ, Grujic D, Zhang $C Y$, Hagen $\mathbb{T}$, Boss $O$, INo $Y$, et al Enetyg wnetabolism in unconpling protein 3 gene knockout mice. J Biol Chem 2000;275(21) 16258-66.

31. Bonen A, Campbell SE, Benton CR, Chabowski A, Coort SL, Han XX, et all. Regulation of fraty acid transport by fatty acid translocase/CD36. Proc Nut Soc 2004;63(2):245-9.

32. Buand MD, Buckingtham JA. Esteves TC, Green $\mathrm{K}$, Lambert $\mathrm{AJ}$, Miwa $\mathrm{S}$, et al. Mitochondrial superoxide and aging: uncoupling protein activity and supetoride production. Biochem Soc Symp 2004(7/)203-13.

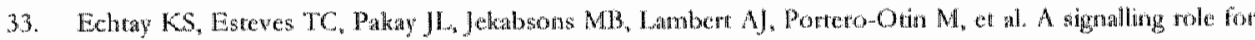
4-hydroxy-2-nonenal in regulation of mitochondral uncoupling. Embo) $2040,22(16) 4103 \cdots 10$.

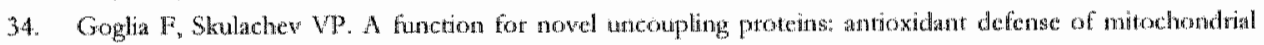
matrix by translowang faty acid peroxides from the inner to the outer membrane lathet. Fas I $2003 ; 17(12): 1585-9)$

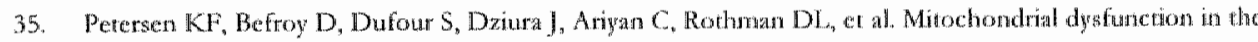
eldety: possible role in insulin resistance. Saience $2003 ; 300(5622): 1140-2$

36. Peteren KF. Dufour S, Befroy D, Garcia R, Shuman GI. Innlared mitodyondrial activity in the insulin resistant offspring of pratients wirh type 2 diabetes. N Engl I Med 2004:350(7):664-71.

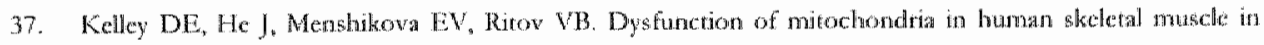
type 2 diabetes. Diabetes $2002,51(10): 2044-50$.

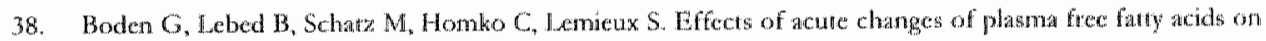
intramyocellular fat conent and insulin tesistance in healthy subjects. Diabetes $2001,50(7): 1612 \%$.

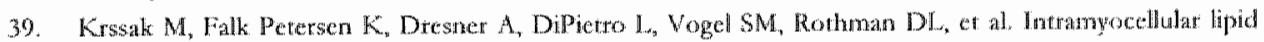
concentrations are correlated witlin insulin sensitivity in humatns: a $H$ MMR specroscopy stady. Duaberologia 1990,42(1):113-6. 


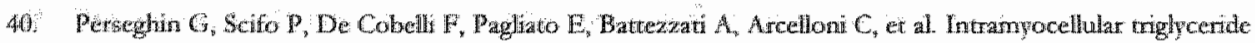

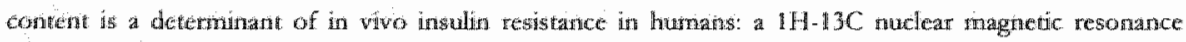

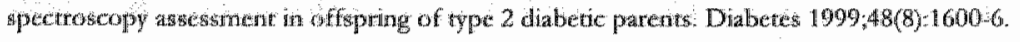

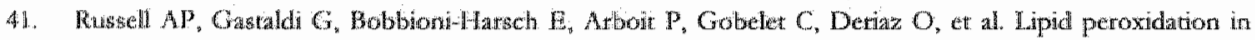

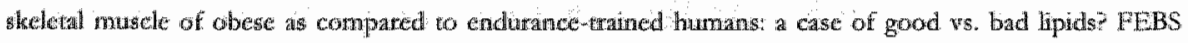
Lete $2003 ; 5511-3): 104-0$.

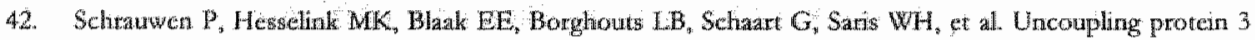
content is decreased in sketetal iruscle of patients with type 2 diabetex. Diabetes $2001 ; 50(12): 2870-3$.

43. Sehraw en 1, Hesselik MK Oxintative capacity, hipotoxicity, and mitochondrial damage in type 2 diabetes. Dialbetes $200453(6): 1412 \%$

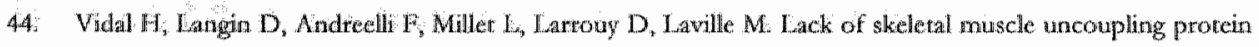

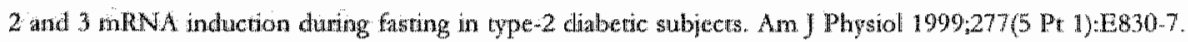


Summary - Samenvatting 


\section{Summary}

Due to its homology to uncoupling protein 1 (UCP1), the bona fide uncoupler present in brown adipose tissue, and due to its almost exclusive location in skeletal muscle which highly contributes to human energy expenditure, it was initially suggested that uncoupling protein 3 (UCP3) might play a role in energy metabolism. Although several associations between energy expenditure and UCP3 exist, newer reports also indicate that UCP3 is involved in fatty acid metabolism (reviewed in chapter 2).

In chapter 3 , it was shown that $\beta_{1}$ and $\beta_{2}$-adrenergic stimulation in humans, inducing significant increases in energy expenditure, was not accompanied by changes in UCP3 gene expression. $\beta_{2}$-adrenergic stimulation in combination with simultaneous blocking of adipose tissue lipolysis, tesulting in significantly lowered plasma free fatty acid levels but increased energy expenditure, down-regulated UCP3 mRNA levels. These results indicate that the expression of UCP3 is related to circulating fatty acids, rather than to changes in energy expenditure.

In addition to these findings, numerous other findings support a role for UCP3 in fat metabolism. In general, it seems that skeletal muscle UCP3 is up-regulated or high when the supply of fat to the muscle exceeds the oxidative capacity to oxidise these fatty acids (e.g. fasting, high fat intake, acute exercise and in type $2 \mathrm{~b}$ muscle fibres). On the other hand when fat oxidative capacity improves or matches the fat delivery to the muscle, UCP3 is down-regulated or low (endurance training, weight reduction, type 1 muscle fibres, acipimox trearment?).

Based on these observations, we postullated the hypothesis (explained in chapter 2) that UCP3 acts as a fatty acid anion exporter to protect mitochondria against the detrimental effects of fat accumulation and this thesis describes a series of experiments in support of this hypothesis.

In chapter 4, we interfered at distinct steps in muscle fatty acid metabolism to create conditions in which the entry of (non-esterified) fatty acids into the mitochondrial matrix is enhanced and the need for UCP3 would, according to our hypothesis, increase. First, teducing the cellular fatty acid binding capacity, known to increase cytosolic concentrations of non-esterified fatty acids, up-regulated UCP3 by 5.3-fold. Second, inhibition of carnitine palmitoyl transferase 1 (CPT1) thereby diminishing the mitochondrial entry of esterified long chain fatty acids and the subsequent oxidation, up-regulared UCP3 by 1.9-fold. Thirdly, a high-fat diet 
based on long chain triacylglycerols (LCT), increasing the supply of (long chain) fatty acids to the muscle, up-regulated UCP3 by 2 - fold in m. gastrocmersisus mediadis. However, feeding isoenergetic amounts of medium chain triacylglycerols (MCT), which can be activated and subsequently oxidised inside the mitochondrial matrix and therefore do not need to be exported from the matrix, failed to affect UCP3 protein levels.

These latter findings were extended to other muscles in chapter 5 where we confirmed the up-regulation of UCP3 upon high-fat LCT, but not high-fat MCT, feeding in multiple skeletal muscles as well as in cardiac muscle, with distinct fat oxidative capacity. In the basal, low-fat fed, state however, we observed an inversed relation between muscular fat oxidative capacity and UCP3 protein levels indicating that muscles with a low fat oxidative capacity require more UCP3.

Given the proposed role of UCP3 in the defence against mitochondrial lipotoxicity, it was anticipated in chapter 6 that UCP3\% mice would show increased levels of muscular lipid peroxides, especially upon a high-fat diet. Indeed, we found significantly higher levels of muscular lipid peroxides in UCP $3 \%$ mice but, rather remarkably, this difference was not apparent upon the high-fat diet. However, upon HF feeding, UCP $3 \%$ mice showed $\sim 50 \%$ lower levels of intramuscular triacylglycerol (TMTG) in compartison to the control animals, suggesting that these mice developed an alternative mechanism to limit lipotoxicity. So far, the exact molecular mechanism responsible for this phenomenon remains to be established.

Based on the above described results we concluded that the proposed physiological function of UCP3 in the protection against mitochondrial fat accumulation is plausible, although our physiological data do not prove that the suggested mechanistic model of fatry acid anion export is correct.

If UCP3 indeed provides a protection against mitochondrial lipotoxiciry, one condition in which this may have physiological relevance is within the pathogenesis of type 2 diabetes mellitus. It was shown that skeletal muscle mitochondria from type 2 diabetic patients are smaller, show more damage and clisplay a reduced functional capacity. Interestingly, increased levels of muscular lipid peroxides were found in the insulin-resistant state and type 2 diabetic subjects are characterised by a $50 \%$ reduction in UCP3 protein levels. This led to the attractive idea that the reduction of $\mathrm{UCP} 3$ in diabetic patients is a pathological condition, in which low levels of UCP3 fail to adequately protect mitochondria against oxidative damage induced by fatty acids, ultimately leading to lipid-induced mitochondrial damage, 
decreased (fat) oxidative capacity, intramusculat fat accumulation and insulin tesistance.

Intramuscular fat accumulation and insulin resistance can acutely be induced through infusion of lipid emulsions in healthy individuals. In chapter 7 we showed that the gene expression of skeletal muscle peroxisome proliferator-activated teceptor (PPAR)- $\gamma$ co-activator $1 \alpha$ (PGC-1 $\alpha$ ) and PPAR $\alpha$, important transcription factors in mitochondrial biogenesis, were decreased upon infusion of a lipogenic long chain triacylglycerol (LCT) emulsion that led to muscular fat accumulation and insulin resistance. Infusion of a readily oxidisable combined medium and long chain triacylglycerol emulsion (MCT/LCT), resulting in intermediate effects on intramuscular fat accumulation, also showed intermediate effects on the expression of PGC $1 \alpha$ and PPAR $\alpha$. In addition, UCP3 expression was up-regulated upon LCT infusion and significantly less pronounced upon MCT/LCT infusion, in accordance with the putative role for UCP3. These results indicate that the accumulation of fat inside the muscle is related to the observed changes in gene expression, suggesting that UCP3 tries to counteract the free fatty acid-induced reduction of transcription factors involved in mitochondrial biogenesis.

In conclusion, the proposed physiological function of UCP3 in the protection against mitochondrial lipotoxicity is feasible and all physiological interventions performed are compatible with a rolle of UCP3 in the modulation of lipotoxicity. Conclusive evidence for our mechanistic model postulating UCP3 as a fatty acid anion exporter, however, requires in-depth mechanistic studies also in cellular model systems. Furthermore, the hypothesis that the reduction of UCP3 observed in diabetic patients is a pathological condition, in which low levels of UCP3 fail to adequately protect mitochondria against lipid-induced oxidative damage, is an interesting and potentially important target for future research.

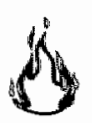




\section{Samenvatting}

Ontkoppelingseiwit 1 (uncoupling protein 1, UCP1), aanwezig in mitochondria van bruin vetweefsel, verlaagt de efficiëntie waarmee energierijke moleculen geproduceetd worden. Als gevolg hiervan gaat een groot deel van de energie, verkregen uit de verbranding van substraten afkomstig uit o.a. de voeding, verloren als watmte.

Dit proefschrift richt zich op de mogelijke functie wan een homoloog van UCP1, te weten ontkoppelingseiwit 3 (uncoupling protein 3, UCP3), welke tot op heden nog onbekend was. UCP3 bevindt zich met name in mitochondria van de (skelet)spier en vertoont een ongeveer $55 \%$ gelijkenis met UCP1. Aangezien de volwassen mens geen bruin vetweefsel (en dus geen UCP1) bezit, was de ontdekking van een ander, mogelijk energieverspillend eiwit interessant in de strijd tegen overgewicht, mede omdat de spier een orgaan is dat een zeer groot aandeel heeft in het energiegebruik bij de mens. Hoewel er in de literatuur wel degelijk associaries tussen UCP3 en energiegebruik zijn gerapporteerd, zijn er sterke anwijzingen dat de werkelijke functie van UCP3 meer gekoppeld is aan de vetstofwisseling (zie hoofdstuk 2 voor een overzicht).

Zo wordt in hoofdstuk 3 van dit proefschrift aangetoond dat $\beta_{1}$ - en $\beta_{2}$-adrenerge stimulatie bij proefpersonen, wat tot een significante toename in het energiegebruik leidt, niet gepaard gaat met veranderingen in de genexpressie van UCP3. Wanneer echter tijdens $\beta_{2}$-adrenerge stimulatie de vetzuurspiegels in het bloed worden verlangd door gelijktijdig de lipolyse van het vetweefsel te remmen, neemt de genexpressie van UCP3 significant af. Deze resultaten laten zien dat de genexpressie van UCP3 niet zozeer verband houdt met veranderingen in energiegebruik, maar cerder geassocieerd is met circuletende vetzuren.

Naast deze tesultaten, duiden talloze andere bevindingen in de literatuur op een rol voor UCP3 in het vetmetabolisme. Deze literatuur suggereert enerzijds dat het UCP3 niveau in de spier toeneemt of hoog is wanneer het aanbod van vetzuren aan de spier groter is dan de capaciteit om deze vetzuren te verbranden. Anderzijds neemt het UCP3 niveau af, of is het laag, wanneer de ververbrandingscapaciteit hoger is dan het aanbod van vetten. Op basis van deze gegevens hebben we gehypothetiseerd dat UCP3 mogelijk belangrijk is in situaties waarin vetzuren zich ophopen in de spiercel en in de zich daarin bevindende mitochondria. Om vetzuuraccumulatie in de mitochondria te voorkomen zou UCP3, volgens de door 
ons geformuleerde hypothese, vetzuren uit de mitochondria transporteren en zo het functioneren van de mitochondria beschermen. Om deze hypothese te toetsen is een serie experimenten uitgevoerd, in zowel dier als mens, waarin op verschillende niveaus is geinterfereerd met het vetzuurmetabolisme.

Hoofdstuk 4 beschrijft een serie experimenten in verschillende diermodellen waarin wordt aangetoond dat: 1) een werhoging van de intracellulaire vetzuurconcentratie, door afwezigheid wan het zogenaamde "fatty acid binding protein" (FABP), zorgt voor een 5,3-voudige toename in UCP3 eiwitniveau; 2) remming van het bij de vetoxidatie betrokken enzym carnitine palmitoyl transferase 1 (CPT1), resulterend in een afname van de vetzuuroxidatie, leidt tot een verdubbeling in UCP3 eiwitgehalte; 3) ook een hoog-vet voeding, bestaande uit lange-keten vetzuren, resulteert in een verdubbeling van de hoeveelheid UCP3 eiwit in de spiet. Een hoog-vet voeding bestaande uit middellange-keten vetzuren heeft echter geen effect op de UCP3 eiwitniveaus in de spier. Middellange-keten vetzuren worden vanwege hun kortere ketenlengte sneller verbrand, accumuleren verwolgens niet in de spiercel en een toename van UCP3 is volgens onze hypothese dan ook nier noodzakelijk.

Deze laatstgenoemde bevindingen worden in hoofdstuk 5 uitgediept: de verhoging van het UCP3 eiwitniveau in reactie op een voeding rijk aan lange-keten - maar niet op een voeding rijk aan middellange-keten - vetzuren wordt bevestigd. in verschillende spiertypen, variërend in vetverbrandingscapaciteit. Bovendien wordt in ratten op een normale, laag-vet voeding een omgekeerd eventedige relatie gevonden tussen de vetverbrandingscapaciteit van de spier en de UCP3 eiwitniveaus, wat aangeeft dat spieren met een lage vetverbrandingscapaciteit meer UCP3 nodig hebben.

Als UCP3 inderdaad een beschermende functie tegen vetzuren heeft, dan zou het ontbreken van UCP3 moeten leiden tot meer schade an de mitochondria, vootal in situaties waarin een overmat aan vet aan de spier wordt aangeboden, zoals het geval is bij een vetrijke voeding. Moleculen die deze schade zou kunnen veroorzaken zijn de zogenaamde vetzuurradicalen, sterk reactieve verbindingen die ontstaan wanneer vetzuren worden angetast door zuurstofradicalen, een bijproduct van de normale verbranding. Uit hoofdstuk 6 blijkt inderdaad dat de spieten van muizen zonder UCP3 meer van deze reactieve vetzuurradicalen bevatten in vergelijking met normale muizen. Opvallend is echter dat dit verschil wegvalt wanneer deze muizen worden blootgesteld aan een vetrijke voeding. Nadere analyse wijst uit dat de hoeveelheid opgeslagen vet in de spier met $50 \%$ is verminderd in UCP3-deficiënte muizen op een vetrijke voeding, wat aangeeft dat 
deze muizen wellicht altematieve mechanismen hebben ontwilkkeld on de schadelijke effecten van vetaccumulatie in de spier te beperken.

Al met al onderschrijwen bovenstaande resultaten de gesuggeteerde beschermende functie van UCP3 hoewel het exacte werkingsmechanisme nadere studie vereist. De klinische relevantie van deze bevindingen ligt mogelijk in het ontstaan van type 2 diabetes mellitus. Het (dis) functioneren van mitochondria is de laatste jaren namelijk sterk in verband gebracht met het ontstaan van type 2 diabetes mellitus. Door de verminderde functie van de mitochondria zou de capaciteit van de spier om vetten te verbranden afnemen, waardoor vetten zich kunnen ophopen in de spiercellen. De stapeling van vet in de spier is op zijn beurt sterk negatief gecorreleerd met insulinegevoeligheid.

Waarom mitochondria bij type 2 diabeten minder functioneren is nog niet geheel opgehelderd, maar vetzuur-geinduceerde schade aan mitochondria lijkt een belangrijke rol te kunnen spelen. Een interessant gegeven is dat de hoeveelheid UCP3 eiwit in type 2 diabeten met $50 \%$ verlaged is. Men kan speculeren dat deze lagere UCP3 niveaus de mitochondria onvoldoende beschermen tegen de hoge concentraties vetzuren, met mitochondriële dysfunctie, vetstapeling en insulineresistentie tot gevolg.

Hoofdstuk 7 laat zien dat in jonge, gezonde proefpersonen het acuut (en reversibel) induceren van insulineresistentie middels het geven van een vetemulsie per infuus gepaard gaat met een sterke stijging van de genexpressie van UCP3. Dit zou kunnen duiden op een reactie met als doel het beschermen van de mitochondria tegen deze vetzuren. De infusie van vetzuren leidt ook tot een reductie van genen die betrokken zijn bij de aanmak van nieuwe mitochondria. Deze effecten ontstaan parallel aan de stapeling van de vetzuren in de skeletspier. Uit recente literatuur is bekend dat type 2 diabeten, gekenmerkt door hoge vetzuurspiegels in het bloed, ook een verlaagde expressie vertonen van genen betrokken bij de aanmaak van nieuwe mitochondria in de spier. Het resultaat van onze studie in gezonde proefpersonen suggereet dat de verlaagde expressie van deze genen in type 2 diabeten het gevolg zou kunnen zijn van de vetstapeling in de spier die bij deze patiënten wordt gevonden. Samen met een verlaagd UCP3 niveau, zoals gevonden in type 2 diabeten, zou dit de basis kunnen zijn voor het ontstaan van mitochondriële dys functie. 
Dankwoord 


\section{Dankwoord}

Hoewel de kaft van dit boekje anders doet vermoeden, vertegenwoordigt dit proefschrift het werk van vele mensen die ik bij deze graag wil bedanken.

Patrick, Matthijs, met jullie als co-promotoren en directe begeleiders mag duidelijk zijn dat ik de afgelopen jaren lekker dicht bij het vaur heb gezeten en me daar goed aan heb kunnen warmen. Ik noem jullie met opzet in één zin omdat met name jullie samenwerking in mijn ogen van grote waarde is. Ik heb mogen profiteren van deze succesformule en ben trots dat ik ook de komende jaren onderdeel mag zijn van dit geheel! In dit kader wil ik meteen de hele (SHOCk-)groep noemen die (hoewel niet meer helemaal in deze samenstelling) onder supervisie van de twee heren de afgelopen jaren is ontstaan en zich soms het vuur uit de sloffen heeft gelopen: Marco, Esther, Marie-Jeanne, Berber, Wendy, Alie, Johan, Esther P., Jodil bedankt Wim, als promotor wist je me op de juiste momenten te prikkelen om af en toe een stapje extra te doen ("schrijven doe je toch in de avonduurtjes?") en hield je vanuit de achtergrond alles goed in de gaten.

Marten Hofker, Coen Stehouwer, Aalt Bast, Michaela Diamant and Mary-Ellen Harper, thank you very much for critically evaluating this thesis. Marleen van Baak, Gabby Hul, Hubert Vidal, Bert Binas, Ger van der Vusse, Marc van Bilsen, Joost Luiken, Susan Coort, Jan Glatz, Wim Sluiter, Alastair Morrisson, John Clapham, Aaron Russell and Ronald Mensink, thank you for your contributions to the different chapters of this thesis.

Gert, als mijn paranimf ben jij de verpersoonlijking van de goede werksfeer en samenwerking binnen onze groep die in mijn ogen de basis vormen voor vele mooie resultaten. Maar bovenal ben je gewoon een geweldige kerel! Joost, als mijn andere paranimf en beste vriend vertegenwoordig jij het belang van een goede vriendenkring voor de nodige ontspanning buiten werktijd. Ik heb veel geleerd van jouw sociale valardigheden en ik ben ervan overtuigd dat jouw naam vanwege die eigenschap nog lang zal rondwaren op de universiteit. Heren, ik ben blij dat ik jullie achter me heb staan op de dag van de verdediging!

Dat vrienden en collega's belangrijk zijn geweest bij het bereiken van deze mijlpaal behoeft waarschijnlijk weinig verdere uitleg. Allereerst Gijs en René, het is dat er maat twee paranimfen zijn toegestaan anders had ik jullie er graag bij gehad. Succes met jullie eigen afronding! Jos, Joan en Wendy, bedankt voor de ondersteuning bij de diverse plasmabepalingen. Dank ook aan de overige (oud-)collega's van 
Humane Biologie en Bewegingswetenschappen die het werken de afgelopen jaren aangenaam hebben gemaakt: Mirjam, Hasibe, Ellen, Hanneke, Niels, Freek, Marjolein, Kirsten, Mandy, Eefje, Kristel, Stefan, Annemie, Petra, Anneke, Larisa, Pascal, Marja, Johan J., Ariënne, Annemiek, Ilona, Lydia, Manuela, Kaatje, Tanja H., Luc, Natalie, Ralph, Edwin, Wouter, Ronald, Ronny, Claudia, Margtiet, Jogchum, Julian, Johan R., Cheryl, Paul, Astrid, Egbert, Elke, Kristof, Neelije, Julia, Ping, Klaas, Sander, Loek, Antoine, Cyriel, Reinout, Ronnie, Freddy, Tanja A, Guy, Annemarie, Renate en Klien.

Bart-Jan, we zien elkaar veel te weinig maar nooit nemen we elkaar dat eigenlijk kwalijk, bedankt voor het vormgeven van de omslag en de tips voor de layout. Bryan, waar zou ik zijn zonder mijn privé-chauffeur, bedankt!

Dear Barbara and Jan, thank you very much for giving me the opportunity to work in your lab for some time. Besides the fact that I learned a lot, it was a great experience and I'm looking forward to the continuation of our collaboration. Irina, thank you for your supervision and your patience to teach a movement scientist in the physiology of mitochondria. Also many thanks to the other members of Zoofysiologi for a great and, in many ways, interesting period. Tore, Anders, Annelie, Olle, Therése, Birgitta, Dana, Lotta, Tomas, Daniel, Victor, Bihu and Damir: tack så jättemycket!

$\mathrm{Pa}$ en ma, ontzettend bedankt voor jullie onvootwaardelijke steun. Jullie hebben me de mogelijkheden geboden om te komen waar ik nu ben. Verder kan ik voor van alles en nog wat bij jullie terecht en zelfs als je bijna gepromoveerd bent, is dat een heel geruststellend idee!

Remko en Charlotte, ook wij zien elkaar veel te weinig maar nu jullie je intrek hebben genomen in het nieuwe huis moesten we daar maar eens verandering in brengen! Veel geluk daar!

Johanna, thank you for being you... I expected a lot from my visit to Stockholm but never that it would result in ending the acknowledgements of my thesis in English. I am confident, however, that it can be both Dutch and Swedish soon! Scientific results can always be doubted but of you I'm very sure... 


\section{Curriculum vitae}

Joris Hoeks was born on December 29th 1978 in Eindhoven, The Netherlands. In 1997, he completed his pre-university education at the "Scholengemeenschap Were Di" in Valkenswaard. In the same year, he started his study Health Sciences with specialisation Movement Sciences at Maastricht University where he graduated in 2001. His master thesis entitled "Cytoskeletal disruption and glucose disposal in rat skeletal muscle" was awarded with the Student Prize for best master thesis by the Faculty of Health Sciences of Maastricht University.

In September. 2001, he started his $\mathrm{PhD}$ at the department of Human Biology, Maastricht University. In 2003, he was awarded by the Dutch Scientific Organisation (NWO) with the "Foppe ten Hoor" Young Investigator Award for his work on UCP3 as a mitochondrial fatty acid exporter. In 2005 he was awarded with a Young Investigator Award for his presentation "The effect of high-fat feeding on intramuscular lipid and lipid peroxidation levels in UCP3-ablated mice" at the 4th international conference of mitochondrial physiology (MiP2005) in Schröcken, Austria.

From October 2004 until April 2005, he was a visiting volunteer in the department of Zoophysiology of the Wenner-Gren Institute in Stockholm, Sweden, to study the measurement of oxygen consumption in isolated skeletal muscle mitochondria under supervision of prof. dr. Barbara Cannon.

In October 2005, he was granted a "Talent" scholarship of the Faculty of Health Sciences of Maastricht University, to continue his work on the role of mitochondrial uncoupling per se and UCP3 in particular.

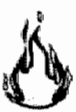




\section{List of publications}

1. Hoeks, J., van Baak, M.A., Hesselink, M.K.C., Hu, G.B., Vidal, H., Saris, W.H.M., Schrauwen, P. The effect of $\beta_{1}$ and $\beta_{2}$-adrenetgic stimulation on energy expenditure, substrate oxidation and UCP3 expression in human skeletal muscle. Am J Physiol, 285(4), E775-E782, 2003.

2. Hoeks, J., Hesselink, M.K.C., van Bilsen, M., Schaart, G., van der Vusse, G.J., Saris, W.H.M., Schrauwen P. Differential response of UCP3 to medium versus long chain triacylglycerols; manifestation of a functional adaptation. FEBS letters, 555 (3), 631-637, 2003.

3. Schrauwen, P., Hoeks, J., Schaart, G., Komips, E., Binas, B., Vusse, G. J. van der., Bilsen, M. van., Luiken, J.J.F.P., Coort, S.L.M., Glatz, J.F.C., Saris, W.H.M., Hesselink, M.K.C. Uncoupling protein 3 is a mitochondrial fatty acid anion exporter. FASEB J, 17 (15), 2272-2274, 2003.

4. Gilde, A.J., Willemsen, P.H.M., Lindhout, M., Hoeks, J., Schtauwen, P., Benton, C., Bonen, A., Vusse, G. J wan der., Bilsen, M. van. PPAR-dependent and PPAR-independent changes in cardiac gene expression. Submitted for publication.

5. Hoeks, J., Hesselink, M.K.C., Russel, A.P., Mensink, M., Saris, W.H.M., Mensink, R.P. Schrauwen, P. Down-regulation of PGC $1 \alpha$ and PPAR $\alpha$ upon lipid-induced insulin resistance in human skeletal muscle depends on muscular fat accumulation. Submitted for publication.

6. Hoeks, J., Hesselink, M.K.C., Sluiter, W., Schart G., Willems, J., Mortisson, A., Clapham, J.C., Saris, W.H.M., Schtawwen, P. The effect of high-fat feeding on intramuscular lipid and lipid peroxidation levels in UCP3-ablated mice. FEBS Lett. 2006 (in press).

7. Schrauwen, P., Hoeks, J., Hesselink, M.K.C. Putative function and physiological relevance of the mitochondrial uncoupling-3: involvement in fatty acid metabolism? Prog. Lipid. Res. 2006. (in press). 
8. Hoeks, J., Hesselink, M.KC., Schrauwen, P. Involvement of UCP3 in mild uncoupling and lipotoxicity. Proceedings Issue of MIP2005 meeting in Exp. Geront. Submitted for publication.

9. Shabalina, I.G., Petrovic, N., Kramarova, T., Hoeks, J., Cannon, B., Nedergaard, J. UCP1 and defence against oxidative stress: 4-hydroxy-2nonenal effects on brown-fat mitochondria are uncoupling protein-1 independent. Submitted for publication.

10. Shabalina, I.G., Hoeks, J., Kramarova, T., Schrauwen, P., Larsson, N-G, Cannon, B., Nedergaard, J., Cold-induced increase in UCP3 protein in skeletal muscle mitochondria of UCP1-knockout mice does not mediate increased uncoupling. In preparation. 